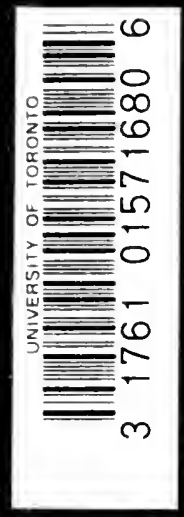

Univ. of Tonourto 




\title{
EFFECT OF ALCOHOL ON PSYCHO-PHYSIOLOGICAL FUNCTIONS
}

\author{
$\mathrm{Br}$
}

WALTER R. MILES

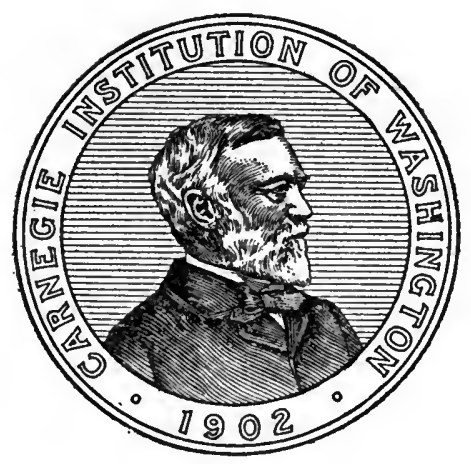

$$
\frac{149172}{20 / 3 / 19}
$$

Published by the Carnegie Institution of Washington Washington, 1918 


\section{QP 915 \\ A3ms}

CARNEGIE INSTITUTION OF WASHINGTON

Publication No. 266 


\section{PREFACE.}

The experimental results presented in this monograph supplement and amplify the published work of Dodge and Benedict on the Psychological Effects of Alcohol, and form another contribution on the psychological side under the tentative plan for alcohol investigation at the Nutrition Laboratory. It is a pleasure to acknowledge my obligation to the above investigators, both of whom generously spent much time counseling with me on various phases of the work.

The report has had the further advantage of the competent editorial supervision of Miss A. N. Darling. I was assisted in the experiments by Mr. E. S. Mills and in the preparation of the alcohol and control doses by Miss E. B. Babcock.

NUTRITION LABORATORY OF THE

Walter R. Miles.

Carnegie Institution of Washington, Boston, Massachusetts, March 28, 1918. 


\section{CONTENTS.}

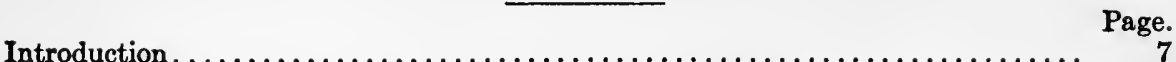

Subject selected for the repetition of the measurements...................... 10

Experience of Subject VI................................ 12

General experimental conditions............................ 15

Amount of alcohol employed................................. 19

General effects of the alcohol......................................... 20

Measurements employed and their sequence....................... 23

Statistical method of presentation of results...................... 29

Data obtained in the repetition measurements....................... 36

Patellar reflex............................................. 37

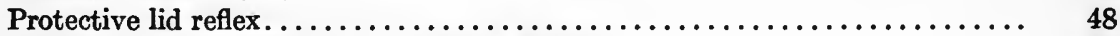

Eye reaction to peripherally appearing stimuli................... 59

Reaction time in reading isolated words......................... 62

Memory.............................................. 67

Sensory threshold for faradic stimulation....................... 74

Eye movements....................................... 79

Finger movements..................................... 84

Pulse and respiration......................................... 92

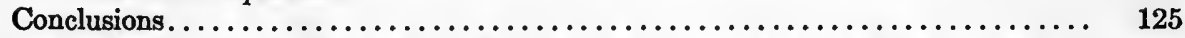

Appendix I.-Data concerning the use of alcoholic beverages outside of the psychological laboratory by the subjects of Dodge and Benedict................ Appendix II.-The general effects of alcohol, doses A and B, experienced by the

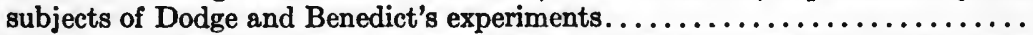

Appendix III.- Observations on the averages of data for normal and alcohol days presented by Dodge and Benedict.

Appendix IV. - Observations on the association pulse data of Dodge and Benedict...

\section{ILLUSTRATIONS.}

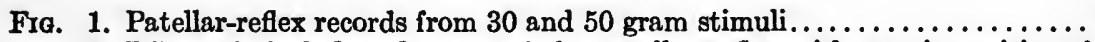

2. Effect of alcohol on latency of the patellar reflex with two intensities of

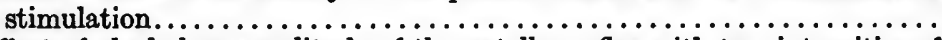

3. Effect of alcohol on amplitude of the patellar reflex with two intensities of

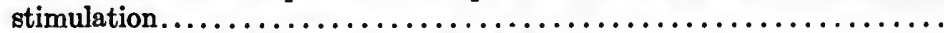

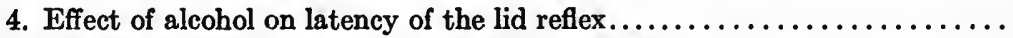

5. Effect of alcohol on amplitude of the lid reflex...................

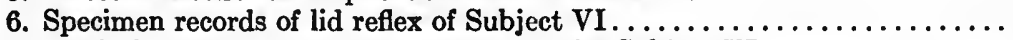

7. Typical record of memory measurement for Subject VI...............

8. Typical eye-movement records of Subject VI reproduced unretouched from

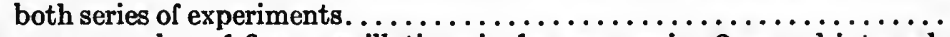

9. Average number of finger oscillations in four successive 2 -second intervals

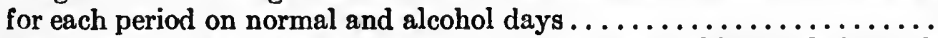

10. Differences for finger oscillations in $2,4,6$, and 8 second intervals for each period after the control and alcohol doses.....................

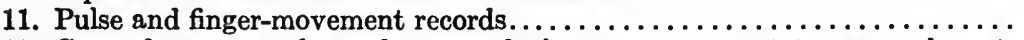

12. General averages for pulse rate during pre-tetanus, tetanus, and posttetanus periods on three normal and three alcohol days, after the control

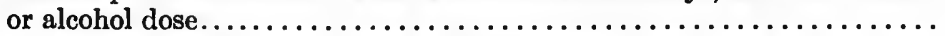

13. Average duration of pulse cycles on three normal and three alcohol days during pre-tetanus, tetanus, and post-tetanus periods after the control or

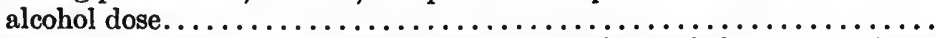

14. Duration of pulse cycles in first, second, and third periods on normal and alcohol days in pre-tetanus, tetanus, and post-tetanus periods. ........

15. Average duration of pulse cycles under experimental conditions 1 to 7 on normal and alcohol days, as compared with pulse duration during word

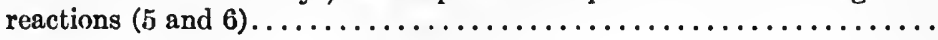




\section{EFFECT OF ALCOHOL ON PSYCH0-PHYSIOLOGICAL FUNCTIONS}

$$
\mathrm{By}
$$

WALTER R. MILES 


\section{Digitized by the Internet Archive in 2008 with funding from Microsoft Corporation}




\section{INTRODUCTION.}

The experiments reported in detail in the following pages give information regarding the effect of moderate amounts of ethyl alcohol upon the human organism. Since numerous workers have concerned themselves with this problem, it may seem to many readers that nothing remains to be said. However, the fact is that no solution seems to have been sufficiently substantiated to have gained general recognition. The results of the many experiments show numerous disagreements and there seems no way of harmonizing many of the contradictions. It is unsafe to discredit totally certain experiments that do not harmonize with others, for each experiment must be regarded as a sincere attempt to answer scientific inquiry, and it must be remembered that the problem is by no means a simple one. There are many known variables which exercise an influence on the results and there are doubtless as many unknown and unrecognized factors. If all the conditions of performed experiments in this field were known, doubtless unexplained contradictions would still exist.

In previous alcohol experimentation, particularly with human subjects, there has been much variation in the experimental conditions. The dose employed has ranged in amount from 10 to $100+$ c.c. of absolute alcohol, and in concentration from pure alcohol through all the degrees of dilution with numerous liquids. The time of taking the dose and its relation to previous ingestion of food have varied, as well as the physical and mental condition of the subject. The processes measured, and the indicators of the alcohol effect used by the several investigators, have likewise differed. Furthermore, the subjects varied as to the previous taking of alcohol; some of them were habitual drinkers (a very few), others were more or less irregular in their use of alcohol, and still others were total abstainers previous to the experiments. Since control doses have rarely been used, the subjects of the experiments have, in many cases, known when the alcohol has been administered; even with control doses alcohol in any considerable quantity can generally be recognized by certain characteristic subjective sensations. Finally, the interpretation of the results is complicated by the fact that the effect of a so-called "moderate" amount of alcohol is not conspicuously large as measured by the usual methods. Taking into consideration all these variations in the experimental conditions, it would seem that sufficient complexity existed to warrant one in expecting a considerable conflict in results.

The tendency has been for each experimenter in this field to try new methods of attack; the variety of results has thus continually increased. More refined methods are constantly available and should by all means 
be employed. Many techniques must be discarded because of faults in operation, or because later work shows them to be defective. But a certain amount of well-chosen repetition of experiments would be of great benefit to this problem. The path of repeated experiment, while in many ways unattractive, offers the only way to the harmonizing of the contradictions and to the final establishment of the solution of this problem. Certainly any one contemplating experimentation on the psychological effects of alcohol should fairly consider the possibility of making his experiments in such a way as to repeat the work of some previous investigator in this field. In the work done by Kraepelin and his pupils there was a limited amount of repetition of experiments, with the result that progress has been made. Probably criticism would have been less had there been more repetition and verification of the experimental findings. Of course, strictly speaking, no experiment can ever be repeated. This is perhaps as literally true when working with the nervous system of human subjects as in any other domain. Thus the complexity of the experimental material is an argument for the best possible standardization of the experimental conditions if it is hoped to isolate the effect of certain consciously varied factors. If different investigators would independently employ the same dosage, apparatus, methods, and procedure, their combined results would be of unique importance. It would then be more nearly possible to discover whether the different results actually represent (1) individual differences in susceptibility to the action of the alcohol (a general conclusion which is now used to explain all sorts of contradictions in experimental results) or (2) varied experimental conditions.

No very well recognized psychological measurements or procedures in taking such measurements have been advocated for use in testing for the effect of a drug on human organisms. In much of the work special apparatus has been employed; the duplication of this special apparatus is expensive and is frequently regarded as unnecessary. It has seldom, if ever, happened in this field that an investigator has had the opportunity which came to the writer of stepping into a laboratory equipped and used by others and attempting independently to repeat a part of the work of his predecessor. The possible value of repetition of experiments for the thorough establishment of experimental results in this field was not so apparent to the author at the time of experimentation as at the present writing. In the spring of 1914, at the close of Professor Dodge's experimental work at the Nutrition Laboratory, the least promising of the normal group employed by Dodge and Benedict (Subject VI) ${ }^{1}$ was chosen for repetition work. It is now regretted that diligent effort was not made to secure repeat experiments with the other subjects. While not all of the subjects would have been available, it is possible that some of them could have been secured for further experi-

${ }^{1}$ Dodge and Benedict, Carnegie Inst. Wash. Pub. No. 232, 1915. 
menting. This should not be construed as signifying in any way or manner a doubt concerning the experiments and findings of Dodge and Benedict. That these deserve the confidence of the reader has been proved by a rechecking of the experiments from original protocols and in many cases a recalculation of the results with very minor corrections, as indicated in the following pages. The new set of experiments on Subject VI has shown so many agreements with the previous findings for this subject as to convince us of the worth of this method of attacking the problem. Furthermore, the comparison experiments have established certain individual differences as to the effect of alcohol upon this subject which could not otherwise well have been proved.

There is ample precedent for the publication of experimental results obtained on only one subject; in fact, most alcohol researches have employed a very limited number of subjects. Ach, ${ }^{1}$ Frankfurther, ${ }^{2}$ Fürer ${ }^{3}$ Hellsten, ${ }^{4}$ Lombard, ${ }^{5}$ Mayer ${ }^{6}$ Scheffer,${ }^{7}$ Totterman, ${ }^{8}$ and Vogt, ${ }^{9}$ as well as others, report experiments performed on one individual. The studies mentioned are among those in which the author has in each instance experimented on himself. This method of experimental selfobservation, while having certain advantages, can not usually be depended upon to produce the objective results which are so much to be desired in this field.

Ideally, alcohol research should be conducted in such a way that adequate data would be recorded and reported on each one of a large number of subjects who are chosen in accordance with certain classifications. The results, then, for the individual and for the group would be adapted to statistical treatment. The obstacles which confront the single investigator who would complete such a research on human subjects, while not insurmountable, are nevertheless such as to make it a labor of years. In the meantime other investigators, who are working on the same or related problems, should have some of the data made available for their use and criticism. Logically one of the first steps toward the broader solution of the problem is to discover how large a variety and how many measurements of each process must be taken on the individual in order to obtain a satisfactory sample of his performance under alcohol. The data for the individual must be subjected to statistical treatment in so far as practicable and the experiments repeated to discover agreements or disagreements between successive sets of results. Accordingly, while reports on single subjects may be con-

1 Ach, Kraepelin's Psychol. Arbeit., 1901. 3, p. 203.

2 Frankfurther, Kraepelin's Psychol. Arbeit., 1914, 6, p. 419.

${ }^{3}$ Fürer, Ber. üb. d. V. intern. Kongr. z. Bekämpf. d. Missbr. geist. Getränkes zu Basel, 1896, p. 355 .

${ }^{4}$ Hellsten, Skand. Arch. f. Physiol., 1904, 16, p. 139.

${ }^{5}$ Lombard, Journ. Physiol., 1893, 13, p. 1.

- Mayer, Kraepelin's Psychol. Arbeit., 1901, 3, 535.

${ }^{7}$ Scheffer, Arch. f. exp. Pathol. u. Pharmakol., 1900, 44, p. 24.

8 Totterman, Finska Läkaresällskapets Handlingar, 1916, 58, p. 1527.

Vogt, Norsk Magazin for Leagevidenskaber, 1910, 8, p. 605. 
sidered uneconomical or even of minor value from some standpoints, they have a specific usefulness. There are, moreover, certain advantages in the individual experiment; the experiments are apt to be more carefully made, the details and special experimental incidents are more faithfully reported, and the results may be more thoroughly analyzed.

The single subject of the alcohol experiments treated of in this monograph was an adult male, 26 years old, who had been found ${ }^{1}$ to show the smallest general effect of the alcohol. This second series of experiments employed the same alcohol dose as was used for the first series, $i$. e., 30 c.c. of absolute alcohol, the smaller dose used by Dodge and Benedict, and it was compounded in the same way. Measurements of the various processes studied by them were repeated, with only minor changes in technique and procedure, in the same laboratory with the same apparatus and thus under almost identical conditions. Longer experimental days ( 5 hours in contrast to 3 hours) were used in the second series; since these days were successive, the apparatus was continually in adjustment for the subject, with the result that a minimum of experimental time was lost. The data are thus more extensive than any that have heretofore been gathered on a single subject over a similar period of time; ${ }^{2}$ but still there is much to be desired. There are as many normal as alcohol data.

The comparison of the results from the two sets of experiments has necessitated a large expenditure of time in working over the Dodge and Benedict material. Certain minor corrections and notes concerning their publication are embodied here which seem of significance either to the former or to the later experiments. No attempt has been made to review other recent literature in connection with these findings, and this omission here must be pardoned. The unique feature of this study is the comparison of two series of alcohol experiments, one more intensive than the other, performed by different investigators under otherwise identical laboratory conditions and on the same subject. The comparison has been made as simple and as uninvolved as possible.

\section{SUBJECT SELECTED FOR THE REPETITION OF THE MEASUREMENTS.}

The experimental measurements employed by Dodge and Benedict in their study on the psychological effects of alcohol were chosen with the definite purpose of bringing together coordinated data concerning the most fundamental aspects of neuro-muscular action. It was their conviction that the attempt to secure accurate measurements of as

\footnotetext{
1 Dodge and Benedict, Carnegie Inst. Wash. Pub. No. 232, 1915, p. 55.

2 Other individual studies on the influence of alcohol have continued over a longer period and have in this sense been more extensive, as, for example, the work of Frankfurther concerning the effect of alcohol on the complicated process of learning typewriting, and that of Vogt on memory and alcohol. But none of these studies employed such a variety of measurements which at the same time concern closely related processes. Dodge and Benedict did not use all their measurements on the same day, except in their 12-hour experiments. They divided the experimental processes into two convenient series (Dodge and Benedict, Carnegie Inst. Wash. Pub. No. 232, 1915, p. 15) and gave these series on different days.
} 
complete a group as possible of systematically related phenomena is a sound procedure which is better adapted to revealing the effects of alcohol, particularly with human subjects, than is the measurement of special, isolated processes. The individual subjects frequently showed considerable variation which, in the case of an isolated process like reaction time, may cause confusion in the interpretation of the results. When experimenting with a group of related phenomena, the various measurements supplement each other; accordingly, while the subjective variations may be as large, they do not exercise proportionately as marked an effect on the general results. Thus, a group of processes selected because of their (1) inter-relation, (2) elementary nature, and (3) theoretically practiced condition, provided the techniques and controls are adequate, should yield results of such definiteness that a repetition of the experiments with the same subject or subjects would not change the findings essentially.

In choosing a subject for a repetition of the Dodge and Benedict series of experiments, we were fortunate in securing the services of the one who had shown the most irregular effects of the alcohol, and, on the average, an effect which was less than that for the other normal subjects. ${ }^{1}$ This seemed the crucial subject with whom to test the general proposition of a repeat experiment, in which the technique employed in the earlier investigations should be used. On several pages in their publication ${ }^{2}$ Dodge and Benedict call special attention to this subject, who showed rather wide variation from the average for the normal group of subjects, as will be considered later in the discussion of the results obtained with the various measurements. Dodge and Benedict make this general statement concerning him:

"This tendency of Subject VI to differ from the group was a troublesome matter to handle. It was possible that he actually presented a physiological exception to the average effects of alcohol as represented by the rest of the group. As far as our controls went, however, it was not impossible that he was taking food or drugs that masked the effect of the alcohol. It was further possible that his was one of the cases of chance variation. In any event it appeared advisable to repeat the experiments on him after his work in the medical school had closed in June."3

On the suggestion of Professor Dodge, who knew these conditions but had not fully revealed them to the writer, Subject VI was chosen for the second series of observations. It was our desire that the two series be elaborated entirely independently, that they might the better serve for a critical comparison.

${ }^{1}$ As is found, Dodge and Benedict (Carnegie Inst. Wash. Pub. No. 232, 1915, p. 263, table 50, Subject VI) demonstrated an alcohol effect less than the average in patellar reflex, lid reflex, eye reactions, and word reactions, $i$. e., all of the more simple processes; see statements at bottom of page 245 of the same monograph that "the lowest centers are depressed most and the highest least." The effect was larger than the average in memory, faradic threshold, and finger movements. Eye movements would have been included here also, but the data for movements to the left were insufficient.

${ }^{2}$ Dodge and Benedict, Carnegie Inst. Wash. Pub. No. 232, 1915, pp. 55, 71, 72, 133, and 209.

Dodge and Benedict, ibid., p. 55. 


\section{EXPERIENCE OF SUBJECT VI.}

Prior to June 29, 1914, the date on which the second series of experiments began, Subject VI had served parts of 21 days, a total of approximately 70 hours, as a subject for Professor Dodge. The dates for these days, with information concerning the time of day for the particular session, the approximate number of hours' work, the number of experimental periods of repetitions of the series of tests used on the particular day, the doses of alcohol given, together with an indication of the measurements used, are presented in table 1, sections I, II, and III. ${ }^{1}$ This table has been compiled solely with the intention of presenting a statement showing the experience which the subject had had with these experiments under the general laboratory conditions which obtained. It is not a tabulation of comparable data, for not all of the measurements taken on the several dates and classified under one head are comparable. As an example, normal eye movements according to the table would appear to have been taken on October 22, November 5, November 19, 1913, and January 1, 1914. However, those so classified for November 5 and 19 were corrective eye movements during the reading of moving words, and can not be compared with the eye movements, right and left, through an arc of $40^{\circ}$, the common measurement used under this name. It was merely a matter of convenience to classify these data for November 5 and 19 in this way, as it represented practice in the eye-movement measurements with the Dodge technique. As outlined in the tentative psychological program, ${ }^{2}$ Professor Dodge proposed several measurements, data for which are not presented in the published report of Dodge and Benedict. Some of these measurements were tested, as has been instanced in this case of eye movements, but the amount of data secured with the whole group of subjects was insufficient to warrant its publication. In section II the data which have already been published in Dodge and Benedict's report are indicated by the letter P. The unpublished material represented in section I of the table, December 22 to 24, 1912, was obtained in connection with a series of measurements on the effect of acidosis. These observations

\footnotetext{
1 There are certain errors concerning subject and date of experiment in the Dodge and Benedict publication. Those which are most likely to confuse the careful reader should be corrected as follows: The 12-hour experiments with Subject VI came on January 1 and 2, 1914, while those for Subject IX came on December 22 and 23, 1913. At places these dates have become confused, giving the false impression that both subjects were used on the same day in these long experiments; page 65, Subject VI, December 22, 1913, should be changed to read January 1, 1914; page 65, Subject VI, December 23, 1913, should be changed to read January 2, 1914; page 66, Subject VI, Con., December 23, 1913, should be changed to read January 2, 1914; page 67, Subject IX, January 1, 1914, should be changed to read December 22. 1913; page 68, Subject IX, Con., January 1, 1914, should be changed to read December 22, 1913; page 68, Subject IX, January 2, 1914, should be changed to read December 23, 1913; page 157, Subject IV, February 18, should be changed to read February 13; page 158, Subject IV, Con., 12-hour experiment, should be changed to read Subject VI, Con., 12-hour experiment; page 218, Subject VII, the second October 8 should be changed to read October 28 (Dose A); page 260, fourth line from top of page, Subject VII should be changed to read Subject IX.

${ }^{2}$ Dodge and Benedict, Carnegie Inst. Wash. Pub. No. 232, p. 272.
} 
TABLE 1.-The experience of Subject VI in the measurements used. ${ }^{1}$

\begin{tabular}{|c|c|c|c|c|c|c|c|c|c|c|c|c|c|}
\hline $\begin{array}{l}\text { Section, date, } \\
\text { and time of } \\
\text { day. }\end{array}$ & 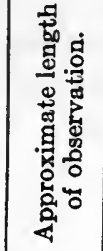 & 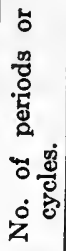 & 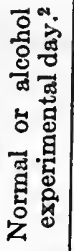 & 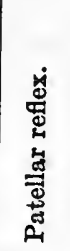 & 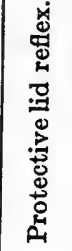 & 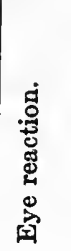 & 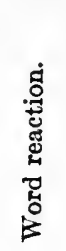 & 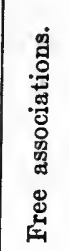 & 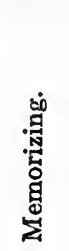 & 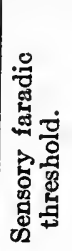 & 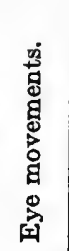 & 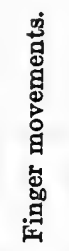 & 离 \\
\hline $\begin{array}{l}\text { Section } I . \\
1912 .\end{array}$ & hours. & & & & & & & & & & & & \\
\hline Dec. 22 , a. $\mathrm{m}$. & 1.5 & 1 & $\mathrm{~N}$ & N.P. & N.P. & N.P. & $\ldots$ & ... & N.P. & $\ldots$ & N.P. & N.P. & \\
\hline Dec. 22, p. m. & 1.0 & 1 & $\mathbf{N}$ & N.P. & N.P. & N.P. & $\cdots$ & .... & N.P. & $\ldots$ & N.P. & N.P. & \\
\hline Dec. 23 , a. m. & 1.5 & 1 & $\ldots$ & N.P. & N.P. & N.P. & ... & $\ldots$ & N.P. & $\cdots$ & N.P. & N.P. & $\cdots$ \\
\hline $\begin{array}{l}\text { Dec. 24, a. m. } \\
\text { Section II. } \\
1913 .\end{array}$ & 1.0 & 1 & $\ldots$ & N.P. & N.P. & N.P. & $\ldots$ & ... & N.P. & $\ldots$ & N.P. & N.P. & $\cdots$ \\
\hline Oct. 7, p. m. & 3.0 & 4 & $\mathrm{~N}$ & $\mathbf{P}$ & & & & $\ldots$ & & $\mathbf{P}$ & $\ldots$ & $\mathbf{P}$ & $\mathbf{P}$ \\
\hline Oct. 14, p. m. & 3.0 & 8 & A & $\mathbf{P}$ & & $\cdots$ & & $\ldots$ & & $\mathbf{P}$ & $\cdots$ & $\mathrm{P}$ & $\mathbf{P}$ \\
\hline Oet. 22, p. m. & 3.0 & 6 & $\mathbf{N}$ & $\ldots$ & $\mathbf{P}$ & $\mathrm{P}$ & $\ldots$ & .... & $\mathrm{P}$ & $\ldots$ & $\mathbf{P}$ & N.P. & $\mathbf{P}$ \\
\hline Oct. 29, p. m. & 3.0 & 6 & A & $\ldots$. & $\mathbf{P}$ & $\mathbf{P}$ & & $\ldots$ & $\mathbf{P}$ & $\ldots$ & $\mathbf{P}$ & $\ldots$ & $\mathbf{P}$ \\
\hline Nov. 5, p. m. & 3.0 & 4 & $\mathbf{N}$ & $\ldots$ & $\mathbf{P}$ & $\ldots$ & N.P. & $\ldots$ & $\mathbf{P}$ & $\ldots$ & N.P. & $\ldots$ & $\mathbf{P}$ \\
\hline Nov. 12, p. m. & 3.0 & 6 & A & $\ldots$ & $\mathbf{P}$ & $\ldots$ & N.P. & $\ldots$ & $\mathbf{P}$ & $\ldots$ & N.P. & & $\mathbf{P}$ \\
\hline Nov. 19, p. m. & 2.0 & 4 & $\mathbf{N}$ & $\ldots$ & $\ldots$ & $\ldots$. & $\mathbf{P}$ & $\ldots$ & $\ldots$ & $\ldots$ & N.P. & N.P. & $\mathbf{P}$ \\
\hline Dec. 2, p. m. & 2.5 & 6 & A & $\ldots$ & $\ldots$ & $\ldots$ & $\mathbf{P}$ & $\ldots$ & $\ldots$ & $\ldots$ & N.P. & $\ldots$ & $\mathbf{P}$ \\
\hline Dec. 8, p. m. & 1.0 & 1 & $\mathbf{N}$ & $\ldots$ & $\ldots$ & $\ldots$ & $\ldots$ & $\mathbf{P}$ & $\ldots$ & .... & $\ldots$ & $\ldots$ & $\ldots$ \\
\hline Dec. 9, p. m. & 2.0 & 6 & $N$ & $\cdots$ & $\cdots$ & $\cdots$ & $\cdots$ & $\mathbf{P}$ & $\cdots$ & N.P. & $\cdots$ & $\cdots$ & ... \\
\hline $\begin{array}{c}\text { Dec. 16, p. m. } \\
1914 .\end{array}$ & 3.0 & 2 & A & $\cdots$ & $\ldots$ & $\ldots$ & $\ldots$ & $\mathbf{P}$ & $\ldots$ & N.P. & $\cdots$ & $\cdots$ & ... \\
\hline Jan. 1 , day.. & ${ }^{3} 12.0$ & 10 & $\mathbf{N}$ & $\mathbf{P}$ & $\mathbf{P}$ & $\mathbf{P}$ & $\mathbf{P}$ & $\cdots$ & $\ldots$ & $\mathbf{P}$ & $\mathbf{P}$ & $\mathbf{P}$ & $\ldots$ \\
\hline Jan. 2, day.. & 3.12 .0 & 10 & C & $\mathbf{P}$ & $\mathbf{P}$ & $\mathbf{P}$ & $P$ & $\ldots$ & .... & $\mathbf{P}$ & $\mathbf{P}$ & $\mathbf{P}$ & $\ddot{p}$ \\
\hline Jan. 22, p. m. & $\begin{array}{l}2.0+ \\
3.0\end{array}$ & $\begin{array}{l}6 \\
8\end{array}$ & $\begin{array}{l}\text { B } \\
\text { B }\end{array}$ & $\dddot{p}$ & $\mathbf{P}$ & $\mathbf{P}$ & $\mathbf{P}$ & $\cdots$ & $\cdots$ & $\ddot{N} . \ddot{P}$. & $\mathbf{P}$ & $\dddot{p}$ & $\begin{array}{l}\mathbf{P} \\
\mathbf{P}\end{array}$ \\
\hline Feb. 4, p. m. & $2.0+$ & 6 & B & & & & $\cdots$ & N.̈.P. & $\cdots$ & $\mathbf{P}$ & $\ldots$ & $\ldots$ & $\ldots$ \\
\hline Feb. 12, p. m. & 3.0 & 3 & A & N.P. & N.P. & N.P. & N.P. & & $\ldots$ & N.P. & N.P. & $\ldots$ & $\mathbf{P}$ \\
\hline $\begin{array}{l}\text { Mar. 2, p. m. } \\
\text { Section III. } \\
\text { 1914. }\end{array}$ & 3.0 & 6 & $\mathbf{N}$ & $\cdots$ & $\ldots$ & $\cdots$ & $\ldots$ & N.P. & $\ldots$ & $\mathbf{P}$ & $\cdots$ & $\cdots$ & $\cdots$ \\
\hline June 29 , a. m. & 5.0 & 4 & $\mathbf{N}$ & $\mathbf{P}$ & $\mathbf{P}$ & $\mathbf{P}$ & $\mathbf{P}$ & .. & $\mathbf{P}$ & $\mathbf{P}$ & $\mathbf{P}$ & $\mathbf{P}$ & $\mathbf{P}$ \\
\hline June 30 , a. $\mathrm{m}$. & 5.0 & 5 & $A$ & $P$ & $P$ & $\mathbf{P}$ & $P$ & & $\mathbf{P}$ & $\mathbf{P}$ & $\mathbf{P}$ & $\mathbf{P}$ & $\mathbf{P}$ \\
\hline July 1, a. m. & 5.0 & 5 & $N$ & $\mathbf{P}$ & $\mathbf{P}$ & $\mathbf{P}$ & $\mathbf{P}$ & $\ldots$ & $\mathbf{P}$ & $\mathbf{P}$ & $\mathbf{P}$ & $\mathbf{P}$ & $\mathbf{P}$ \\
\hline July 2, a. $\mathrm{m}$. & 5.0 & $\begin{array}{l}6 \\
6\end{array}$ & $\stackrel{A}{N}$ & $\mathbf{P}$ & $\begin{array}{l}\mathbf{P} \\
\mathbf{P}\end{array}$ & $\mathbf{P}$ & $\begin{array}{l}\mathbf{P} \\
\mathbf{P}\end{array}$ & $\cdots$ & $\begin{array}{l}\mathbf{P} \\
\mathbf{P}\end{array}$ & $\mathbf{P}$ & $\mathbf{P}$ & $\begin{array}{l}\mathbf{P} \\
\mathbf{P}\end{array}$ & $\begin{array}{l}\mathbf{P} \\
\mathbf{P}\end{array}$ \\
\hline $\begin{array}{l}\text { July } 3 \text {, a. m. } \\
\text { July } 4 \text {, a. }\end{array}$ & $\begin{array}{l}5.0 \\
5.0\end{array}$ & $\begin{array}{l}6 \\
6\end{array}$ & A & 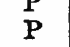 & $\mathbf{P}$ & $\mathbf{P}$ & $\begin{array}{l}\mathbf{P} \\
\mathbf{P}\end{array}$ & $\ldots$ & P & $P$ & $\mathbf{P}$ & $\mathbf{P}$ & $\mathrm{P}$ \\
\hline
\end{tabular}

1 The use of the letter $P$ in the table means in section II that the data were published by Dodge and Benedict; in section III that the data were taken in the second series and published in this monograph. The designation N.P. means throughout the table that the data were taken but not published, apparently because the techniques were not strictly comparable; see p. 12.

2 The designations in this column have meanings as follows: $\mathrm{N}$, normal day; $\mathbf{A}$, alcohol day with dose of 30 c.c., $i$. e., absolute alcohol diluted to a total volume of 150 c.c. given after the first period; B, alcohol day with a dose of 45 c.c., $i$. e., absolute alcohol diluted to 225 c.c. given after the first period; C, alcohol day on which 9 separate doses, each containing 12 c.c. of absolute alcohol diluted to 60 c.c., were taken.

3 The 12-hour experiment began at $8 \mathrm{a} . \mathrm{m}$. with the first period normal. Alcohol (dose C) was taken at $9^{\mathrm{h}} 15^{\mathrm{m}}, 10^{\mathrm{h}} 15^{\mathrm{m}}$, and $11^{\mathrm{h}} 15^{\mathrm{m}}$ a.m. (no alcohol with dinner at $12^{\mathrm{h}} 20^{\mathrm{m}} \mathrm{p} . \mathrm{m}$.), then again at $1^{\mathrm{h}} 25^{\mathrm{m}}$, $2^{\mathrm{b}} 20^{\mathrm{m}}, 3^{\mathrm{h}} 20^{\mathrm{m}}, 4^{\mathrm{h}} 25^{\mathrm{m}}, 5^{\mathrm{b}} 20^{\mathrm{m}}$, and $6^{\mathrm{h}} 20^{\mathrm{m}} \mathrm{p}$. m. The experiment continued until $8 \mathrm{p}$. $\mathrm{m}$. The statements made by Dodge and Benedict (their p. 21) are misleading here concerning the number of doses taken in the 12-hour experiments. Subject VI took 9 doses (see note 2) and Subject IX took 8 (see Dodge and Benedict's report, p. 30). These doses were diluted with water, cereal coffee, or other flavoring liquid, to a total volume of $60 \mathrm{c.c}$. 
served primarily as a test of the technique to be subsequently employed in the alcohol investigation. ${ }^{1}$

The material given in section III of the table was obtained in the repetition series of experiments and is published in the present report. These data are comparable with each other. At the commencement of this second series of experiments it may be supposed that the subject was thoroughly familiar with the conditions of the various techniques employed, having had a rather extensive experience scattered over a period of months. Any interest due to the novelty of the measurements must have been lost by this time. As the disposition of the apparatus had not been altered and the general laboratory conditions ${ }^{2}$ were the same in both series, the subject understood from the beginning the adjustments to be made on his part. None of the measurements were entirely new to him, and every effort was made to have the instructions identical in the two series. Whereas in the first series only three or four of the tests were given on any one experimental day, according to the grouping described by Dodge and Benedict on pages 14 and 15 of their report, in the second set all the measurements were used daily, thus providing a greater variety but necessitating longer experimental periods.

While Subject VI served willingly ${ }^{3}$ and seemed to cooperate in the measurements, one constantly had the impression that he was not trying hard in the tests in which voluntary functions were involved, such as finger movements, word reactions, memory, and general tetanus for producing rapid changes in pulse rate. He of course had little, if any, personal interest in the experiments as such. The only records he ever saw were those on the kymograph, and these, to mere inspection, showed no indication of the effect of alcohol. This tendency to take things easy was natural with this subject and was favored, no doubt, by the previous experience, with its many repetitions of instructions and measurements. The use of consecutive experimental days intensified this difficulty. While familiarity with the conditions, by producing greater relaxation, theoretically might favor such measurements as patellar reflex and pulse, frequent repetition, as, forillustration, of the list of 24 words used in the word reactions at the rather slow rate of one word every 10 seconds, with the considerable demand made upon the subject's attention, no doubt grew tedious. With practice there developed some habits of reaction to the experimental situations which are not the most favorable to the comparison of these results with the former series, in spite of our every effort to make the conditions identical. It is not possible to equate the results for these factors, and

\footnotetext{
${ }^{1}$ Dodge and Benedict, Carnegie Inst. Wash. Pub. No. 232, 1915, p. 17.

Ibid., p. $30 \mathrm{ff}$. Also consult fig. I for the general plan of the psychological laboratory and apparatus.

' He was paid by the hour for his services, as were all the subjects used by Dodge and Benedict, excepting No. $X$.
} 
aside from some mention of them in the succeeding pages under the discussion of particular measurements, it must be assumed that they tend in general to compensate each other.

\section{GENERAL EXPERIMENTAL CONDITIONS.}

At the time of the second series of observations, June 29 to July 4 , 1914, the subject, having completed the year's work at the medical school, was serying as intern in a neighboring hospital. His hours on duty were from late afternoon until $1 \mathrm{a} . \mathrm{m}$., and as he had considerable freedom from work he regarded the period as vacation. His health was excellent. On no day did he mention feeling the effects of a cold or a headache. His habits were regular with respect to food and daily routine. The last food before each experimental session was a hearty meal taken 7 hours previously, from which coffee and tobacco were excluded. This meal was taken between $12^{\mathrm{h}} 30^{\mathrm{m}}$ and 1 o'clock a. $\mathrm{m}$., that is, when the subject went off duty at the hospital. While the food was varied as to kind, the amount was fairly constant.

No alcohol was taken during the week, other than that given at the Laboratory. The subject slept approximately 2 hours in the afternoon, before taking up his work at the hospital, and again from 1 until 8 a. m. Immediately after dressing in the morning and without breakfast he came to the Laboratory, and our experiment began at $8^{\mathrm{h}} 30^{\mathrm{m}}$ a. m. and continued until $1^{\mathrm{h}} 30^{\mathrm{m}}$ p. m., a total period of 5 hours, as contrasted with the 3-hour periods employed formerly. The longer periods were used designedly, that the effect of alcohol might be followed further than in the previous investigation.

According to the statements of the subject, the longer periods were not unsatisfactory. The variety and nature of the measurements were such as to minimize the development of fatigue, and the periods were not long enough to cause serious difficulty from excessive hunger. The subject preferred to serve one long period rather than two short ones. From the experimental standpoint longer sessions are more economical, in that much less time is taken up in the preliminary adjustments, such as weighing the subject and gathering and recording data relevant to food and general conditions. The longer periods have the further advantage of calling forth a more steady, even performance on the part of the subject.

In the former series the subject was working hard in regular course in a medical school; it was not feasible for him or the other student subjects to serve in the experiments on successive days, and an effort was made to guard against any prominent weekly rhythm that might exist by having all the experiments come on the same day of the week. In the later experiments the need of extending the sessions over a period of weeks to avoid any influence of a weekly rhythm seemed less urgent than at the time of the previous experimenting, as the regular 
work of the subject was lighter during the second series. It was, however, more from the practical standpoints of availability of the subject and laboratory convenience that the measurements were made on consecutive days.

The alcohol was given on the second, fourth, and sixth days. This frequency in administering the alcohol presents the well-known possibility of an additive effect. ${ }^{1}$ On the other hand, in experiments in which the additive effect has been demonstrated, the alcohol dose has always been greater than 30 c.c. On close analysis it must be clear that such an effect, provided it exists in a measurable degree with doses of 30 c.c., would, so far as these experiments are concerned, theoretically cause a smaller resulting difference to be shown between alternate alcohol and normal days, as such an effect from an alcohol day would apply more to the succeeding normal day than to the following alcohol day, from which it is separated by 48 hours. ${ }^{2}$ The indicated alcohol effect is possibly somewhat reduced by the use of successive days.

It might be supposed ${ }^{3}$ that in this second series of experiments every effort would be made to exercise a rigid regulation and control of the life of the subject during the period of experimentation, especially in consideration of the fact that Dodge and Benedict felt that it was not impossible that Subject VI was taking food or drugs that masked the effect of the alcohol. ${ }^{4}$ This matter in reference to the later experiments was carefully considered in conference with Dodge and Benedict, and it was decided not to require the subject to live at the Laboratory during the experimental days, under conditions of constant observation. Moreover, it did not seem desirable ${ }^{5}$ to rigidly predetermine the kind, amount, and time for taking food and fluids antecedent to the experiment, or other conditions, such as the amount and kind of mental and physical work. As a matter of fact, these conditions were as well reg-

${ }^{1}$ A. Smith, Beitr. u. d. V. intern. Kongr. z. Bekämpf. d. Missbr. geist. Getränke, Basel, 1896; Fürer, ibid.; Kurz and Kraepelin, Kraepelin's Psychol. Arbeit, 1901, 3, p. 417.

${ }^{2}$ Kurz and Kraepelin, Kraepelin's Psychol. Arbeit, 1901, 3, p. 454.

Rivers, in a review of the Dodge and Benedict report (Science, 1916, n. s., 44, p. 102) says: "In such survey work, in which a number of subjects were employed, it was perhaps impossible to regulate their lives more completely and thus bring the research nearer to the ideal of the method of difference, but this regulation should not be neglected in more intensive work."

4 The original protocols for February 4, 1914 (see table 1, section II) are pertinent to this discussion. The subject came to the Laboratory at $4^{\mathrm{h}} 10^{\mathrm{m}} \mathrm{p}$. m.; his last food was at $12^{\mathrm{h}} 30^{\mathrm{m}}$ p. m., and consisted of chicken soup, potatoes, and plum pudding. He had drunk one bottle of beer the previous evening. During the preliminary adjustments the subject remarked: "I came prepared for the test to-day." When pressed to explain what he meant, he said, "I am not as tired as last time, and I drank all the water I needed before I came." On this day use was made of dose B, that is, 45 c.c. of absolute alcohol diluted to a total volume of 225 c.c. The subject asked permission to urinate at $5^{\mathrm{b}} 25^{\mathrm{m}}$ p. m. The remarks made by the subject on this occasion, together with the fact that the influence of alcohol on Subject VI seemed to be different from the average of the normal group, aroused some suspicion. Nothing has been discovered, however, since that time to substantiate this suspicion in any way, and it seems probable that the subject's "preparedness" consisted solely in his having taken an extra drink of water. Although the alcohol was given in a 20 per cent solution, it is evident that under these conditions of the food taken only three hours before the experiment and water immediately before, the dilution was considerable after the alcohol had reached the stomach.

${ }^{6}$ Dodge and Benedict, Carnegie Inst. Wash. Pub. No. 232, 1915, pp. 19 and 27. 
ulated during this experimental period as they would normally be in the life of any business or professional man, unless he lived under military training conditions. From the time the subject entered the Laboratory until the experimental session for the day was complete, he was continuously under observation. Following the set of experiments a careful physical examination was made. Information obtained from this, together with information obtained from those who knew the subject best, confirmed our belief that he was sincere in his attitude toward the experiments and in his desire to cooperate in them. It is believed that the previous suspicion that the subject might be tampering with the experimental results was not well founded, or at least does not apply to the present series, and that the affidavit made by the subject is to be taken at face value. This affidavit was as follows:

1. The data given by me concerning the last ingestion of food and the use of alcohol were correct according to the best of my knowledge and belief.

2. There has been no conscious effort or intention to modify the results of the experiments.

3 . There has been no discussion of the experiments and of probable results with any person outside the Psychological Laboratory.

4. There has been no habitual use of drugs during the experimental week, no use of alcoholic beverages outside the Laboratory, and no occasional use of any drug that might modify the effect of the alcohol, as far as I know.

In order that the conditions for the comparison of the results of the two series of experiments may be more fully before the reader, the following section of personal history given by Dodge and Benedict ${ }^{1}$ is here reprinted.

\section{SUBJECT VI.}

Date-October 7, 1913.

Family history.-Both father and mother American, Scotch descent; married 28 years. One brother, not living, 21 years.

None of the family take alcohol or drugs. There is no insanity in the family, and no alcoholism in the collateral branches.

Personal data.-Age, 25 years; height, $164 \mathrm{~cm}$.; weight, 68 kilos. Occupation, student, second year medical school. Sport, walking 2 miles a day.

Education.-Oklahoma Agricultural College. Average scholarship; best in biology, worst in English grammar.

Memory.-Poor, verbal. Not quick, accurate, long, or responsive.

Non-abstainer.-Drinks beer, etc., at banquets; 1 or 2 glasses at a time; effect, stupefying. Largest amount ever taken, 10 or 12 glasses, mixed drinks, in the evening, one year previous; "attempted to get drunk"; stupefying effect; only time ever intoxicated. Last used, October 3, 1913, one glass of beer. Two glasses of beer can be taken on a full stomach without noticeable effect.

First noticeable effects are drowsiness and unsteadiness. Produces no excitement, though subject is normally nervous; causes talkativeness, normally moderate in speech; produces a feeling of elation, normally cheerful. No peculiar sensations. Seems to increase the flow of ideas. No effect on the

${ }^{1}$ Dodge and Benedict, Carnegie Inst. Wash. Pub. No. 232, 1915, p. 277. 
affections, but sweetens the temper. Effect on routine work not known, as he never takes it when working. No effect on morals. One glass aids digestion; two glasses retard it; no effect upon the urine.

Tea and coffee.-One cup strong coffee every morning.

Life insurance.-Examined for life insurance a year previous. Northwestern Mutual Life Insurance Company. Accepted.

This personal history must be supplemented, particularly with regard to the frequency with which alcohol was commonly taken by this subject, since during the later experiments no alcohol was used outside the Laboratory or for four days previous to beginning the work. It is stated that alcohol is used "at banquets," and in the same paragraph "last used, October 3, 1913, one glass of beer." This last quotation, which really refers only to the pre-experimental condition for October 7, 1913 (see table 1, section II), might be taken as meaning a period of abstinence during the following months in which the experiments were interspersed. From the original protocols the following facts are discovered:1

October 22, 1913 (normal experiment), 3 bottles of beer taken within previous week, one-half bottle two days previous to experiment. October 29, 1913 (alcohol experiment), 3 bottles of beer and 1 bottle of wine taken within the previous week; one-half bottle of beer taken two days previous to experiment. November 12, 1913 (alcohol experiment), 1 glass of beer four days before. November 19, 1913 (normal experiment), 2 bottles of beer taken within preceding week, one of them three days previous to experiment. December 2, 1913 (alcohol experiment), 3 bottles of beer taken during the previous week, two of these on the evening of November 29. December 9, 1913 (normal experiment), 2 glasses of beer on the evening of December 6. December 16, 1913 (alcohol experiment), 2 ounces of port wine taken previous evening, a total of 1 pint of port wine taken during the week previous to the experiment. January 1, 1914 (normal experiment), 2 bottles of beer in the previous week. January 22, 1914 (alcohol experiment), 2 glasses of beer taken during the week previous. January 28, 1914 (alcohol experiment), 1 glass of beer and 1 glass of wine taken January 27. February 4, 1914 (alcohol experiment), 2 glasses of beer during previous week, one of these taken the evening of February 3. February 12, 1914 (alcohol experiment), "1 glass of ale last night." March 2, 1914 (normal experiment), " 1 glass of beer last Saturday night." The notes in the protocols do not cover all the dates on which experiments occurred. The subject ordinarily drank from 1 to 6 glasses of beer and wine during Saturday and Sunday. The experiments were usually made on Tuesday and Wednesday. Those on December 8, 1913, and March 2, 1914, occurred on Monday.

A personal communication from Subject VII adds the information that he and Subject VI roomed together during the school year in which these experiments were made. Their custom was to buy a case of beer and several bottles of wine at a time. Subject VI drank beer and wine only (see above). Subject VII drank these and stronger beverages which were frequently on hand. His usual consumption was, he thinks, greater than that of Subject VI. Subject IX roomed near and the three frequently spent the evenings together.

${ }^{1}$ See p. 13 , table 1 , section II, for other data concerning the dates which follow. 
Although the data given in the preceding paragraph regarding the quantities of alcoholic beverages taken are admittedly not exact, ${ }^{1}$ it still seems fair to assume on the basis of the usual alcoholic content of these beverages that two or three times per week during the months covered by experimentation, Subject VI had from 15 to 40 c.c. of absolute alcohol. The common amount taken in an evening may have been a near approximation to dose $\mathrm{A}$ of these experiments, that is, 30 c.c. of absolute alcohol diluted to a total volume of 150 c.c. The possibility of an additive or prolonged effect serving to reduce the contrast between normal and alcohol experimental days by alcoholic doses following within 48 hours of each other may be assumed as approximately equal in both series. In the Dodge and Benedict series the doses were close together because of the amounts taken outside the Laboratory, and also in the repetition series because the experimental days were consecutive. ${ }^{2}$

During the week of the repetition series of experiments (June 29 to July 4,1914 ) the nude weight of the subject varied slightly. The values for the experimental days were in order as follows: 66.9, 67.8, 67.0, $66.6,66.6,66.4$ kilograms. The cup of strong coffee in the morning, mentioned in the personal history, was, as previously stated, omitted from the last meal preceding the experiment. The subject took milk with this meal.

The outdoor noon temperatures for the six days beginning with June 29 were $15.0,22.8,15.6,14.4,13.9$, and $21.7^{\circ} \mathrm{C}$. The barometer readings at the Nutrition Laboratory were 757.4, 760.0, 766.6, 758.2, 766.1, and $765.3 \mathrm{~mm}$. The Laboratory was not heated and forced draft ventilation was employed.

\section{AMOUNT OF ALCOHOL EMPLOYED.}

The alcohol for each day was given in a single portion. The dose used was that designated by Dodge and Benedict as "dose A," which contained 30 c.c. of absolute alcohol, 7 c.c. of orange infusion, ${ }^{3} 1$ c.c. of strong infusion of quassia, a slight amount of saccharine for sweetening, and water to bring the volume to 150 c.c. A mixture of the same composition and volume, but without the alcohol, served as the control dose for each of the three normal days. This regular use of the control mixture constitutes a difference between the two series of measurements. Dodge and Benedict (page 24 of their report) finally abandoned the use of the control mixture, as it proved a failure in completely masking the alcohol. From the standpoint of uniformity it is, however, desirable to give a control dose of some kind, particularly if the actual alcohol dose is not pleasant to take.

\footnotetext{
1 The quantities are probably not smaller than reported.

2 The extra-laboratory use of alcoholic beverages by other Dodge and Benedict subjects is of significance in the interpretation of their individual alcohol results. These data from the original protocols, with certain observations, are embodied in Appendix I of this monograph. (See p. 135.)

${ }^{3}$ Rivers, The influence of alcohol and other drugs on fatigue, London, 1908.
} 
Every effort was made to prevent the subject from distinguishing between the alcohol and the control doses. Before giving the nonalcohol mixture, the rim of the glass was swabbed with strong alcohol that the odor might help to hide the identity during the early part of the experiment. But as the alcohol frequently produced sensations of warmth in the stomach and flatulency, the subject never failed to identify the mixture by the time the experimental session was over; that is, his final impression was always correct as to its identity. He had no way of knowing before the session what he would be given, and of course he received no confirmatory information regarding his impressions. As may be seen from the latter part of table 1, section Ir, his more recent experience would not lead him to expect that normal and alcohol days would regularly alternate. Unfortunately only the 30 c.c. dose could be used in the second series. This was in accordance with the expressed desire of the subject, who insisted that the 45 c.c. dose which he had taken three times before (see table 1, section II) made him feel uncomfortable for the rest of the day. The larger dose was more than he was in the habit of taking, according to the data given on page 18.

\section{GENERAL EFFECTS OF THE ALCOHOL.}

It is of course recognized that the alcohol dose in these investigations was a 20 per cent solution by volume of raw alcohol and water mixture, strongly bitter, which was decidedly unpleasant to take. ${ }^{1}$ Moreover, the total amount was swallowed within one minute, the subject preferring to drink rapidly. The experiments of Dodge and Benedict usually began about $4 \mathrm{p}$. m., the previous food having been taken (except in the case of Subject X) nearly $3 \frac{1}{2}$ hours before, i. e., at $12^{\mathrm{h}} 30^{\mathrm{m}}$ p. $\mathrm{m}$. Under these conditions it is a fair question, and one that has been asked since the publication of the earlier report, whether or not the subjects experienced or showed any general effects which would be interpreted as evidence of incipient intoxication, other than the results given in the experimental measurements. As this matter has a bearing upon the interpretation of both sets of results, the available material for Subject VI is included here, while that for the other subjects is given in Appendix II (see p. 138).

Dodge and Benedict, in their original protocols, record the following notes regarding the general effects of the alcohol upon Subject VI:

October 7, 1913. No alcohol; no comments.

October 14, 1913, dose A taken $5^{\mathrm{h}} 12^{\mathrm{m}}$ p. m. At $5^{\mathrm{h}} 33^{\mathrm{m}}$ p. m., subject sleepy; $6^{\mathrm{h}} 10^{\mathrm{m}}$ p. m., during faradic threshold measurement, subject falls asleep.

\footnotetext{
${ }^{1}$ Rivers, The influence of alcohol and other drugs on fatigue, London, 1908, p. 81. The use of some common high-percentage alcoholic beverage would have been appreciated by the subject. This would, however, have greatly reduced the possibility of a control dose resembling it closely enough to cause any confusion to taste. Lange and Specht, Zeitschr. f. Pathopsychol., 1915, 3, p. 155, report that some of their subjects preferred to take the 40 c.c. of absolute alcohol as a drink of 99 per cent alcohol rather than to dilute it with 100 c.c. of water and fruit juice.
} 
October 22, 1913. Cereal coffee control dose after fourth period. No comments.

October 29, 1913, dose A taken $5^{\mathrm{h}} 06^{\mathrm{m}}$ p. m. At $5^{\mathrm{h}} 30^{\mathrm{m}}$ p. m., subject stated "feel half intoxicated." He made very vigorous taps in one of the tests and realized he was making a louder noise than usual, but did not think he was putting forth more energy.

November 5, 1913. No control dose mentioned and no recorded impressions.

November 12, 1913, dose A taken 5 p. m. No notes are given to indicate that the subject was sleepy or felt the effects of the alcohol. Protocol otherwise very complete.

November 19, 1913. Control session; no dose specified or comments given.

December 2, 1913, dose A taken 5 p. m. At $5^{\mathrm{h}} 25^{\mathrm{m}}$ p. m., subject felt perfectly comfortable and sleepy, "as always after alcohol." "Relaxes between reaction tests and comes up more easily after alcohol; time goes faster between tests; gets confused and bothered less."

December 9, 1913. Control session; no dose specified or comments recorded:

December 16, 1913, dose A taken about $4^{\mathrm{h}} 30^{\mathrm{m}}$ p. m. No comments concerning effects.

January 1, 1914. Control session for 12-hour experiment; no dose specified or comments recorded.

January 2, 1914, dose C taken in the method previously described. (See table 1 , footnotes 2 and 3, p. 13.) No comments concerning effects, other than that the appetite was not the same for lunch as the day previous, when he had had no alcohol. It is not stated whether the appetite was better or poorer, but understood to mean the latter.

January 22,1914 , dose B taken 5 p. m. No comments made concerning any effect.

January 28,1914 , dose B taken 5 p. m. Subject subsequently went to sleep twice during the evening, once during the finger-movement test, and movements stopped.

February 4, 1914, dose B given 5 p. m. No statement concerning effect other than that subject urinated at $5^{\mathrm{h}} 25^{\mathrm{m}} \mathrm{p} . \mathrm{m}$.

February 12, 1914, dose A taken 6 p. m. No effects of alcohol noted.

March 2, 1914, control session. No dose specified or comments recorded.

In the repetition series, Subject VI was not encouraged to comment upon his feelings or impressions during the experimentation. At.the close of the session he was asked if he had any remarks to make. These statements were brief and confined themselves usually to the nature of the dose given on that particular day. They are as follows:

June 29, 1914, control dose taken $10^{\mathrm{h}} 10^{\mathrm{m}}$ a. m. Subject stated: "Very little alcohol."

June 30,1914 , dose A taken $9^{\mathrm{h}} 40^{\mathrm{m}}$ a. m. At $10^{\mathrm{h}} 37^{\mathrm{m}}$ a. m., subject complained of being very thirsty; was given one-half glass of water. Session finished $1^{\mathrm{h}} 25^{\mathrm{m}}$ p. m. Subject stated, "dose to-day contained alcohol, smelled it, tasted it, and belched it."

July 1,1914 , control dose taken at $9^{\mathrm{b}} 50^{\mathrm{m}}$ a. m. "No alcohol to-day."

July 2 , 1914, dose A taken $9^{\mathrm{h}} 30^{\mathrm{m}}$ a. m. $10^{\mathrm{h}} 15^{\mathrm{m}}$ a. m., urination. At close of session, subject said dose was alcohol.

July 3, 1914, control dose taken at $9^{\mathrm{h}} 25^{\mathrm{m}}$ a. m. "Drink was water and flavoring."

July 4,1914 , dose A taken at $9^{\mathrm{h}} 30^{\mathrm{m}}$ a. m. $10^{\mathrm{h}} 10^{\mathrm{m}}$ a. m., urination. At close of session, subject said dose contained alcohol. 
The effort in all these experiments was to present objective results, free from personal bias. It is understood that the comments concerning the general effects of alcohol were only incidentally recorded, with no intention of securing complete, introspective data. It is also to be considered that, for reasons which Dodge and Benedict discuss on pages 23 and 24 of their report, they abandoned the giving of a control dose on a normal day. The almost certain knowledge of having taken alcohol may naturally enough have colored the introspection of some subjects, particularly in the cases of Subject VIII (total abstainer) and Subject II (very moderate user). Both of these subjects seem to have usually experienced in a more marked degree than the others the general effect with the 30 c.c. dose. Dose B (45 c.c. of absolute alcohol) produced general effects clearly evident to all subjects; dizziness, numbness, and nausea are usually mentioned as following the ingestion of this quantity. (See Appendix II, p. 138.)

Subject VI, in whom we are most immediately interested, curiously enough makes his most striking comment on October 29, 1913, following dose A. Considered in connection with the comments made concerning the general effect of doses on subsequent days, it appears most probable that the statement "feel half intoxicated" is an exaggeration, unless by this he means simply sleepy. Otherwise some unusual condition must have made the subject more susceptible to the alcohol on this day, as he makes almost no comment concerning any effect from dose $\mathrm{B}$ taken three times later in the Dodge and Benedict series. It will be recalled, however (see p. 20), that the subject objected to taking dose $\mathrm{B}$ in the second series on the plea that it incapacitated him for work during the remainder of the day. This subject may have been in certain respects somewhat more resistant to the effects of alcohol than some of the others. The comments of Dodge and Benedict on his experimental results give weight to this point of view, while his seeming lack of experiencing the general effects may have been due to his giving less expression to introspection, or the effects were possibly more delayed in his case.

From the data at hand concerning the amounts of alcoholic beverages used by the different subjects in the week immediately preceding the experiment (see Appendix I, p. 135), it is clear that Subjects III, VI, VII, and IX, consumed the largest amounts. These same subjects, according to their comments (see Appendix II, p. 138), experienced the milder effects as a result of the doses given in the Laboratory. It of course can not be stated whether they were actually less affected by the doses given or made fewer comments because of their familiarity with the effects. However this may be, three of the same group of subjects - that is, III, VI, and VII-show experimental results as to the effect of alcohol which are below the average. (See Dodge and Benedict's report, p. 264, fig. 32.) On the other hand, Subject IX, who 
perhaps had been in the habit of taking more alcohol than any other one of the normal group and who recorded the most mild general effects from the Laboratory doses, demonstrates according to this same summary experimental effects of the alcohol which are above the average. The case of Subject $\mathrm{X}$ was peculiar in that this subject ate a full meal immediately before the experiment began, and only dose A, 30 c.c., was given.

The basis for judging the quantity of alcohol which constitutes a moderate dose must ultimately be the experimental evidence of an effect plus the general subjective effect which the alcohol produces. Obviously for any one amount, as, for example, dose A of these experiments, the general effect will vary in degree with the subject and the particular group of conditions which are present at the time of any specific experimental session. For the abstainer 45 c.c. is perhaps immoderate, while for Subject IX (and probably for Subject VII), judged on the basis of usual habits, it certainly could not be so considered. ${ }^{1}$

\section{MEASUREMENTS EMPLOYED AND THEIR SEQUENCE.}

Since Dodge and Benedict have carefully described the apparatus employed and the technique of the various measurements which have been used, it is not necessary to duplicate these descriptions and discussions here. The purpose, as stated, was to repeat in part their observations. Therefore, the same apparatus was used and only a few minor changes were permitted in the procedure. Most of these changes were kindly suggested by Dodge on the basis of his experience with the normal group of subjects. They were not proposed as adjustments required specifically for Subject VI. It is likely that some specific changes should have been made for this particular subject, as, for example, more insistent instructions to be very careful and look exactly at the fixation marks in the eye-movement measurements. (See p. 79.)

The routine of the experimental day was as follows: Immediately upon reaching the Laboratory the subject was seated and the pulse was counted at the wrist. The assistant adjusted the electrodes to their places of contact with the body for the taking of electro-cardiograms and fastened the respiration recorder in place. Meanwhile data were secured concerning the amount of sleep in the previous 24 hours; the last food taken, time of eating, and approximate amount eaten; general condition of the subject, and any other details that seemed pertinent. ${ }^{2}$

\footnotetext{
1 The consensus of opinion as expressed in experimental studies on human beings is that any amount of alcohol between 15 and 60 c.c. may be considered as moderate. Kurz and Kraepelin (Psychologische Arbeiten, 1901, 3, p. 418) gave 100 c.c. of absolute alcohol and still claimed that it was a quantity such as is generally supposed to be moderate, that is, equaling 2 liters of beer. For information concerning the amount of absolute alcohol in usual retail measures of the ordinary alcoholic beverages, see the useful book, D'Abernon and others, Alcohol; Its action on the human organism, London, 1918, Appendix 5.

2 The nude weight of the subject was secured at the end of the day's session.
} 
Then the measurements, to be described in more detail in succeeding paragraphs, were made. The time required to complete the group of observations was approximately 50 minutes. The dose for the day contained alcohol or was simply a control mixture, as the case might be, prepared as stated on page 19. The total volume of liquid contained in either case was 150 c.c. It was given the subject at this point in the experimental program for the day. He drank it rather rapidly while he was reclining in the steamer chair. Following the taking of the dose the measurements were repeated in identical order as many times as the 5-hour limit would permit. It will be convenient to term each repetition of the group of measurements a "period." Thus, the dose is regularly given between periods 1 and 2 , and from three to five periods were completed following the dose. The measurements may be described in order as follows:

(1) Pulse.-An experimental period began with the subject seated in a steamer chair. He was instructed to relax as much as possible. After three or four minutes the first pulse record, designated as No. 1, was taken. All of the pulse records, except the count made at the beginning of the session, were electro-cardiograms from body leads. Eleven of these records were taken in each experimental hour. In the subsequent paragraphs their order and location will be indicated by numbers. The photographic paper moved $1.5 \mathrm{~cm}$. per second, and the records are long enough to permit the counting of 15 seconds of pulse. Respiration curves were incorporated directly with the photographic pulse records, to show the time relations between pulse and breathing. A large tambour, buttoned under the vest of the subject, was connected to a small tambour carrying a registration point so located as to cast a shadow on the cylindrical lens of the camera. Connections for the pulse and respiration records could be established or broken very quickly. The body electrodes and respiration tambour did not hamper the breathing or other body movements and produced no discomfort whatever.

(2) Patellar reflex.-Two similar stimuli, separated by an interval of 0.5 second, so that the latter came within the relatively refractory period of the reflex, were delivered to the tendon of the left leg by pendulum hammers. Ten records with 30 -gram stimuli were followed by 10 records with 50-gram stimuli. Appropriate levers with a magnification of 6 times wrote directly the reflex thickening of the quadriceps muscle on a kymograph rotating at a rate of $100 \mathrm{~mm}$. per second. From this record both the latency and amplitude were measured. The subject reclined in a steamer chair. He was instructed to relax and to say "Ha" immediately following each stimulus blow, that the respiration phase might be controlled. After the patellar-reflex measurements the subject remained quiet and relaxed for pulse record No. 2 .

(3) Sensory threshold for faradic stimulation. ${ }^{1}$ - The assistant placed a suitable arm-rest, bearing the non-polarizable electrodes, in a conven- 
ient position for the subject, who remained seated in his chair in the same position as for the patellar reflex. The first and second fingers of the right hand, immersed in a normal salt solution to the depth of $2 \mathrm{~cm}$., were used as receptors. The key in the primary circuit of the inductorium was of the general type used by Martin, but operated by a small motor at the regular rate of two breaks per second. Dodge had previously used a.hand or foot control for breaking the primary circuit, since the subject was in the room with the apparatus and the sound of the regular Martin key gave secondary criteria when used in such proximity. When the shocks are near threshold value, and particularly if they are separated from each other by more than a second, the subject is apt to confuse them with the sensation from pulse beat, slight finger movement, and changes of pressure. Furthermore, the attention may be very unfavorable for observing the sensation at the actual time of the shock. The regular, more rapid shocks produced by the mechanically operated key were substituted that they might supply more favorable conditions and hence more consistent threshold values than were produced by the previous method. Special photographic measurements made with the aid of the string galvanometer across the secondary coil showed that two makes and breaks per second in the primary did not cause any decrement in the strength of the shock delivered by the secondary of the inductorium. In fact, there was no appreciable decrement when the rate of make and break in the primary of this coil was changed to 10 per second. The motor which operated the key in the primary circuit was used always at the same speed, excepting for changes brought about by the slight fluctuations in line voltage. The make-shocks were not short-circuited from the fingers. They were subthreshold, however, as the method employed (see Dodge and Benedict's report, p. 135) was always to increase the stimulus strength of the break-shock until the threshold was reached. The threshold value was determined by averaging the first three ingoing threshold positions of the coil. Three such average threshold values were determined, one when the resistance in the circuit was simply that of the tissue and the secondary coil, and the others with added resistances in the secondary circuit of 20,000 and $40,000 \mathrm{ohms}$, respectively. From these three values for $Z$, two $\beta$ values were found according to the regular formula of Martin. ${ }^{1}$ The average of the two $\beta$ values is the significant measure for the period. Pulse record No. 3 followed the threshold measurements. The subject had been sitting quietly for approximately 15 minutes previous to this pulse record. This condition favored relaxation.

(4) Reaction time in reading isolated words.-The subject changed to an ordinary chair and sat upright in front of an exposure apparatus

${ }^{1}$ Martin, Bigelow, and Wilbur, Am. Journ. Physiol., 1914, 33, p. 416; Dodge and Benedict's report, p. 143. 
with the voice key in hand. ${ }^{1}$ Pulse record No. 4 was then made. An offset from the shaft of the kymograph momentarily opened a circuit and exposed a stimulus word which remained in view. The instructions were to keep the voice key pressed lightly against the lips, and to pronounce the words as quickly as possible after their appearance. One word appeared every 10 seconds. Both exposure and reaction were registered by the same signal magnet, the rate of the kymograph being $100 \mathrm{~mm}$. per second. The kymograph drum was visible to the subject. A signal was given him before the exposure of each word, and care was exercised to make sure that the correct word was pronounced. The set of 24 four-letter words previously used was employed in this series. The 24 small cards bearing the words were well shuffled before each set of reaction measurements, in order that the subject might have no tendency to anticipate the sequence of their exposure. As connections were already made with the string galvanometer and the respiration recorder, pulse records Nos. 5 and 6 were taken by the assistant during the latter third of the reaction measurements, and occasioned no interruption. After 30 seconds of quiet, following the reactions, pulse record No. 7 was made, the subject sitting upright and still holding the voice key.

(5) Finger movements.-The movements were not interrupted by mechanical limitation of their amplitude. The subject sat in a steamer chair, leaning forward. The right arm and hand were supported by a rest and in a comfortable position, suitable for the free oscillation of the middle finger in a horizontal plane. A light system of levers (total mass, 7 grams) attached to the finger operated in front of the cylindrical lens of the pulse-recording camera, and made possible the photographic registration of the oscillations reduced to one-fifth their actual amplitude at the same time that pulse and respiration curves were recorded. The uniform instruction was to make the movements as rapidly as possible; they were continued for about 9 seconds, a period too short for development of conscious fatigue. Two records were taken, with an intervening rest of 1 minute. Thus pulse records Nos. 8 and 9 are incorporated directly with the finger-movement records.

(6) Voluntary tetanus pulse.-During the finger movements the subject sat upright in the steamer chair, leaning slightly forward. After this measurement was concluded he was instructed to recline and relax until a given signal, when he was expected to tetanize voluntarily the muscles of arms, legs, and trunk (he sat up, both fists were clenched, and arms and legs were extended directly in front), and to retain this position until the second signal, a period of 5 seconds. A continuous pulse tracing was taken covering the latter part of the preliminary period of relaxation, the tetanus, and the 20 seconds following, a period during

\footnotetext{
1 For a diagram indicating the positions occupied by the subject and the general distribution of the apparatus, see Dodge and Benedict's report, p. 95. The construction and sensitivity of the voice-reaction key can be judged from their figures 16 and 17 to 20 .
} 
which the heart recovered approximately its normal relaxation rate. Two similar tracings, designated as pulse records Nos. 10 and 11, were taken as outlined. The time interval between the tetanus signal for No. 10 and that for No. 11 was 1 minute. The actual taking of these two records after the subject was in position and had relaxed required approximately 2 minutes.

In the Dodge and Benedict observations, ${ }^{1}$ the pulse records taken with the purpose of showing the change in heart rate with muscular activity were with the subject sitting in position, immediately after standing, 60 seconds after standing, immediately after two double genuflections, and 60 seconds thereafter. In our series this group of five records was, at the suggestion of Professor Dodge, shortened to the three-part continuous record described.

(7) Memory.-A series of twelve 4-letter words, carefully printed on a strip of white paper, was made to encircle the kymograph drum. ${ }^{2}$ A circular screen hid the words from view, except as they could be seen through a window $15 \mathrm{~mm}$. wide, which permitted a view corresponding to the width of two of the letters used in the words. When the word series had been placed upon the kymograph and properly covered, the subject was disconnected from the string galvanometer and the respiration recorder, and changed chairs to the position previously occupied during the reactions to isolated words (measurement No. 3). The drum rotated at a rate of $10 \mathrm{~mm}$. per second in a clock-wise direction, i. e., from left to right of the subject. Hence the last letter of a word appeared first in the window, which limited the subject's view, and not until the first letter of the word had appeared could the subject pronounce it correctly in the voice key, which recorded the reaction. The instructions were as follows:

"There are twelve words; each is composed of four letters; watch carefully and at the first exposure speak each word as soon as you are sure of its identity, also try to remember each word in its order that at the second revolution of the drum you may speak each particular word immediately before any part of it has appeared in the window. If you can not recall a word to speak it before it has partly appeared, let as little as possible of it appear before you do speak it. If you speak the wrong word correct yourself immediately by speaking the right one."

The distance on the kymograph record between the first and second reactions to a particular word was taken as the measurement of the residual memory for that word. For the twelve such values an average was found. Dodge and Benedict ${ }^{3}$ had used different sets of word series for the different experimental days, but came to the conclusion "that for purposes of determining the effect of a drug we would have done better to use only one group for all days alike." This method was employed here. The same series of twelve words was used for period 1 
of each day, another series for period 2, and so on. In the Dodge and Benedict experiments the series was exposed three times to the subject, but in the repetition experiments only two complete exposures were used, as mentioned, in order to reduce the possibility of the words presented being completely learned by the subject and remembered from day to day.

(8) Eye reaction to peripherally appearing stimuli.-A slight movement of the subject's chair brought him into position for this measurement and the two which follow. The sudden fall of a shutter carrying a fixation mark exposed another mark or letter, which was 1,2 , or 3 $\mathrm{cm}$. to the right or left of the aforesaid mark; the distance of the object from the eye was $48 \mathrm{~cm}$. The subject, who was in ignorance of the exact place where the stimulus mark would appear, was instructed to look from the fixation mark to the stimulus as soon as it should appear to him, and to pronounce the letter aloud if it were a letter that was exposed. A beam of light, interrupted by a tuning fork and of comfortable intensity, was made by reflection to fall upon the eye at the moment of appearance of the stimulus. From the cornea this light was reflected through an enlarging camera and registered itself on a falling photographic plate. The resulting string of dots with the sharp bend at the moment the eye moved to the exposed letter or mark is a record from which the reaction time can be easily and accurately counted. Five such reaction records were taken side by side on the same plate.

(9) Eye movements. - The general apparatus in this measurement was the same as that which was used for the eye reactions. At the instant that the interrupted light was turned upon the eye a dot appeared, this time in an expected position. From this the subject looked $40^{\circ}$ on his arc of vision to the left to a second dot, and then back to the first, and continued these movements as rapidly as possible throughout the period of 5 seconds during which the photographic plate was falling. In the records each dash with one interspace represents 0.01 second. Precautions were taken to guard against head movements by the use of a suitable head-rest. The left eye was covered with an opaque screen. Uniform instructions preceding each record were to make the movements as fast as possible, but to look carefully at the fixation marks. With this particular subject, these instructions should have been reversed and strong emphasis placed on the careful fixation of the marks in their turns.

(10) Protective lid reflex.-An artificial eyelash consisting of a strip of black paper 1 by $16 \mathrm{~mm}$. was attached to the left lid so that it remained in a horizontal position when the eye was open and viewing a fixation mark. This could be worn without discomfort for an indefinite period, except possibly when the subject rubbed his face with his hand. When a beam of interrupted light was reflected across the face, 
the eyelash cast a shadow upon the slit of a camera, behind which a sensitive plate could be made to move in a horizontal direction. The shadow was so placed that the usual closure of the lid would not completely withdraw it from the camera slit, causing a break in the picture. Thus the conditions for recording the amplitude of movement were standardized. The stimulus for the wink reflex was produced by the sharp snap of a spring hammer against a sounding board. This latter member has a short projection reaching to the slit of the photographic camera, and the vibration of this pointer at the moment of sound registered the instant of stimulus on the photographic record. Two stimuli were used, separated by an interval of approximately 0.5 second, which was within the relatively refractory period. The instruction was to count backward verbally, not too rapidly, from a number which was given by the operator just prior to the stimulus. Some time after the subject had commenced to count, the plate was noiselessly released and its movement opened in turn two circuits, which released the spring hammers and delivered the stimuli. The photographic curves were read for latency and amplitude. Four such records were made for each period.

The ten measurements just described completed the cycle of observations taken during an experimental period (approximately 50 minutes). ${ }^{1}$ The periods followed each other without intermission, excepting the slight break which always came between periods 1 and 2 when the dose was given. Theoretically, for purposes of comparison the same number of periods should be taken each day and the periods should be of equal length; this ideal of uniformity is hard toattain with a complicated group of measurements. Much depends upon the facility with which the subject can adjust himself to the apparatus and perform his part. During the six days there was no accidental interruption to cause the omission of any measurement or enforce a delay of more than ten minutes for the adjustment or repair of apparatus. The number of experimental periods completed on the respective days was as follows: June 29, four periods; June 30 and July 1, five periods; July 2, 3, and 4 , six periods.

\section{STATISTICAL METHOD OF PRESENTATION OF RESULTS.}

In comparing normal and alcohol experiments we are interested in any differences which may exist between the two groups of data, and in the "probable correctness" of such differences as evidence of an alcohol effect. Any group of measurements is most conveniently described in terms of (1) central tendency and (2) variability. In the following

\footnotetext{
1 Dodge and Benedict's periods were approximately 30 minutes in length, for, as stated in their report (pp. 14 and 15), in their experiments all of the different measurements (reflexes, reactions, coordinations, etc.) were not made on the same day, as was the case in this second group on Subject VI.
} 
pages, the average (arithmetical mean) is used for the statement of central tendency and the mean variation (average deviation) as a measure of variability. ${ }^{1}$ It is conceivable that alcohol may affect not only the average, which represents speed, amount, or sensitivity according to the process measured, but the mean variation, also, since in psychological data this stands for uniformity of conditions, consistency of judgment, and controlled attention of the subject. Wherever possible, differences between normal and alcohol data will be given for the mean variation as well as for the averages. The "probable correctness" will be computed only for differences between averages.

Dodge and Benedict assumed that the values obtained in measuring any process were functionally related to the particular day on which the subject and process were tested. ${ }^{2}$ Hence, in addition to providing for an equal number of normal and alcohol days, it will be seen that the first period of each alcohol day was also normal, since the dose was not given until the beginning of the second period. These first-period values serve to indicate the neural condition, disposition, or level of excitability on the different days for the different processes measured. In the presentation of results emphasis is placed upon the differences, plus or minus, between the first-period values of a particular measure and those obtained for the succeeding periods of the same day. A comparison of the differences obtained for normal days with those obtained for alcohol days provides true differences between the two groups of data and supplies a numerical statement of any effect of alcohol. This is also the method used in this monograph; it may be illustrated simply and concretely as follows:

A series of eye-reaction time averages with their mean variations, given in thousandths of a second, is shown in table 2 . The average reaction time (R. T.) for the first period of the normal day is $212 \sigma$. (See section I.) At the close of this period and just previous to the beginning of the reactions of the second period, the control mixture was taken. Following this we have the average values for succeeding

\footnotetext{
1 See Whipple, Manual of mental and physical tests; simpler processes, Baltimore, 1914, Chap. III, for a very readable account of the usual statistical methods.

2 The statement is made by Dodge and Benedict (p. 28 of their report) that their tables "are commonly accompanied by a statement of average measurements, but the latter are regarded as of relatively little importance. They are only given as details that may be of interest to some future investigators who may be measuring similar processes."

The actual average measurement values were not included in the case of the patellar reflex, but only the differences were given. While the average values would have considerably enlarged the table, their omission is already a source of regret, as it greatly hampers the comparison of other data with the material collected by Dodge and Benedict, which is the most extensive concerning this human reflex that is readily available.

Dodge and Benedict found it necessary in some cases, notably in the memory (see Dodge and Benedict's report, p. 130) and pulse sections, to make the averages the basis for comparison. Also, their tables 27 on eye movements and 30 and 32 on finger movements are entirely devoted to them.

That wide differences in nervous excitability will be found is illustrated in Dodge and Benedict's table 1 , page 46 of their report, and can be seen in many places throughout their tables where the measured values are given. The differences between days are probably larger when the experiments occur once a week and are scattered over a month or possibly several months than when consecutive days are employed.
} 
periods of 194,192 , and $189 \sigma$ in order. Similarly on the alcohol day a first period average of $190 \sigma$ is followed after the taking of the 30 c.c. of alcohol by 223,214 , and $201 \sigma$, respectively. These averages, even when so few in number, are not capable of being readily comprehended without further statistical elaboration. It is desirable to relate the two sets of averages and to secure a simplified expression for them.

TABLE 2.-Illustrative table showing statistical method employed in presenting the data of these experiments.

Eye-reaction time averages and mean variations in thousandths of a second $(\sigma)$.

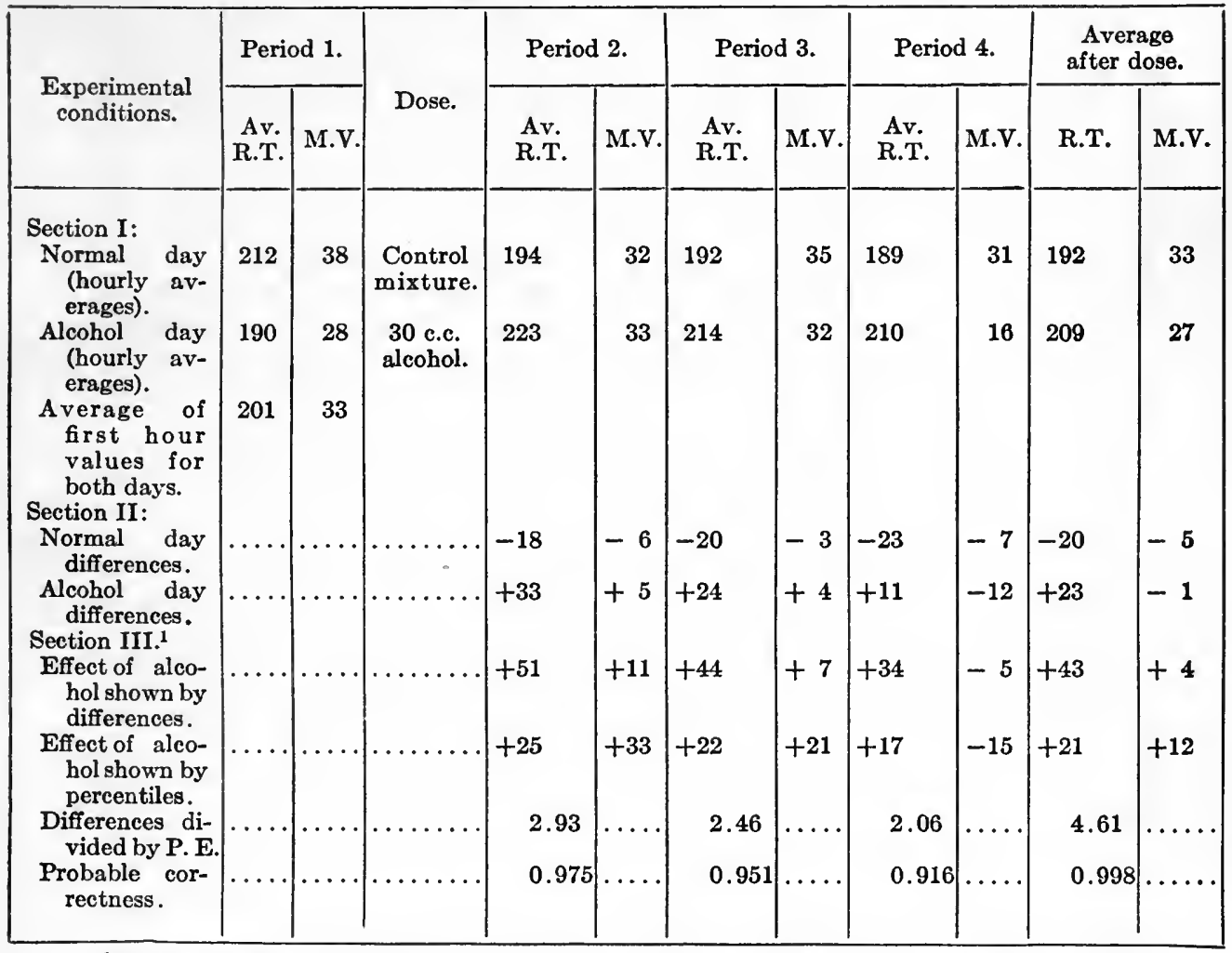

${ }^{1}$ The data in this table, taken from table 9, p. 60, give an exaggerated impression of the effect of alcohol, which must be corrected by reference to the fuller data and results in the later table.

The reaction times in table 2 following the alcohol dose are in every case longer than those which follow the taking of the control mixture. If we average the three values for each condition we should have averages of 192 and $209 \sigma$, the difference between these total averages showing $17 \sigma$ longer reaction after the alcohol. But such a statement would be only partial, as it takes no account of the fact that the so-called alcohol day began with a normal period which gave reactions considerably shorter $(190 \sigma)$ than those for the similar period $(212 \sigma)$ of the normal day. In the expression for the alcohol effect, allowance must be made 
for this initial difference in level, since the nervous organism is subject to changes from experiment to experiment. It is not uncommon ${ }^{1}$ to give preliminary averages an arbitrary value of 100 each and then on this basis to transpose the succeeding averages for the respective periods or days into percentages. These percentages are adequate for mere comparison, but they entirely obliterate the real measurement unit and hide the direct appreciation of any possible difference in neural level as expressed in the measured values of the first periods. In this monograph it is assumed that tables of data are much more generally useful if the material be stated in the original units of measurement.

To obtain a simplified statement of relation for two series of measments, it is necessary first to compute the difference between the assumed normal and each of the succeeding values of a series, and to do this separately for each series. The differences are obtained very simply and are given in section II. Starting with the normal day shown in table 2 , the preliminary value of $212 \sigma$, which we assume as the reaction-time level, or "normal of the day," is deducted from 194, 192 , and $189 \sigma$, respectively, yielding differences of $-18,-20$, and $-23 \sigma$. The minus sign indicates that the reaction-time averages following the first hour are shorter than the average obtained in the first hour, in other words, than the "normal of the day." Using the same method for the alcohol day, we obtain in this instance a series of plus differences-i.e., $190 \sigma$ deducted from 223,214 , and $201 \sigma$ yields +33 , +24 , and $+11 \sigma$, respectively-indicating lengthened reactions following the alcohol dose. The two series of differences which have thus been found are assumed to be related to each other in somewhat the same manner as the first-period value (normal of the day) is related to those values which come after the alcohol or control dose. The normal differences are hence deducted algebraically from the alcohol differences, just as the normal of the day was subtracted from the averages for periods 2,3 , and 4 of the day. For instance, from the alcohol difference $+33 \sigma$ for period 2 , one subtracts the normal difference of $-18 \sigma$; the true difference which, according to the conditions of the experiment, is assumed to be the effect of alcohol in this period, is therefore $+51 \sigma$. If the normal differences and alcohol differences were given as two curves in a diagram, the distance between the two curves on the ordinate for period 2 would obviously also be $51 \sigma$. Using the average of the relevant preliminary values as a standard (212 and $190 \sigma$, average, $201 \sigma$ ), $+51 \sigma$ may be conveniently expressed as +25 per cent increase in the length of eye-reaction time. The effect of alcohol on the reaction times for periods 3 and 4 (see table 2 , section III) was found in the same way as illustrated with period 2 , the amounts being $+44 \sigma$ and $+34 \sigma$, respectively, as "shown by differences." The average effect for all periods following the dose is $+43 \sigma$. In terms of per cent the results for periods

1 Kraepelin, Intern. Monatsschr. z. Erforschung des Alkoholismus, Oct.-Nov. 1916. 
3 and 4 are +22 and +17 , with an average of +21 for all periods following the dose.

Having obtained these differences with these particular data, we should know what degree of reliability attaches to them. Since the reaction times in table 2 form only a small series, we may reasonably expect that if eye reactions were taken on many normal and alcohol days the final resulting differences would not be exactly the same as those obtained. We may ask: "Are the differences which we have found due to chance or is it likely that a more extensive series or several series of experiments would confirm this one by yielding differences which, if not exactly equal in magnitude, would at least be the same in direction?" To answer this question it is necessary to find (1) the probable error of the difference (P. E.D); (2) to calculate the ratio between the probable error of difference and the difference $\left(\frac{D}{P . E \cdot D}\right)$; and finally (3) from a table of the probability integrals to read off for this particular ratio the probable correctness of the difference. ${ }^{1}$ Section III of the illustrative table 2 contains figures for the last two of these expressions. Obviously a difference is considered reliable and significant according to the relative size of its P. E.D. If in a particular instance $\frac{\mathrm{D}}{\mathrm{P} . \mathrm{E} \cdot \mathrm{D}}=1.0$ (i.e., the probable error of difference is just as large as the difference), the value of the probability integral for this ratio is $0.50 .^{2}$ In other words, there are 50 chances out of 100 that the difference will deviate from the observed value by an amount greater than that value. In only one-half of these 50 chances, or in 25 cases, will the change be a decrease (a difference with opposite sign). Therefore the probable correctness of this difference would be $100-25=75$, usually written 0.750 . A probable correctness of 0.500 represents pure chance, while 1.000 is certain cause. Usually values above 0.900 are considered to indicate reliable, significant differences. The probable correctness figures in table 2 , section III, are all above 0.900 , notwithstanding that only 5 reactions were taken in each experimental period,

\footnotetext{
1 The mean variation, as has been noted, expresses the degree of variability of the individual reaction times from the average. Likewise every individual average also varies somewhat from the theoretically true average which would result from several series of experiments. The expression $\pm \frac{0.8453 M . V}{\sqrt{n}}$, where $M . V$. represents the mean variation and $n$ the number of observations (reaction times) is known as the probable error of the mean (P. E.M) and is a measure of

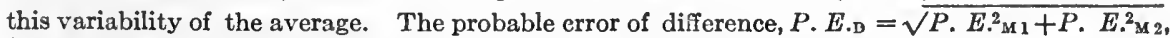
$i . e .$, the square root of the sum of the squares of the probable errors of the means.

2 Boring has recently contributed two articles which illustrate very clearly the method of obtaining and the usefulness of the "probable correctness of the difference"; see "The number of observations upon which a limen may be based," Am. Journ. Psychol., 1916, 27, p. 315, and "On the computation of the probable correctness of differences," Am. Journ. Psychol., 1917, 28, p. 454 .
} 
which would produce a much larger $P . E_{\cdot \mathrm{M}}$ than would result, other things being equal, from series of 25 reactions each. ${ }^{1}$

The "certain cause" indicated by a probable correctness of 1.000 is of course not synonymous with specifying that cause as a 30 c.c. dose of alcohol. Any difference between two averages may be produced by one cause, but more likely by several factors, the resultant of which changes the phenomena under observation. In these experiments it was naturally the aim to make the alcohol dose the critical change and cause. While the probable correctness supplies an estimate of the reliability of particular differences in results as being produced by some change or other, it is not by itself a measure of success in isolating the alcohol effect.

The mean variations (M. V.) are included in table 2 in parallel columns with the averages to which they apply. The differences are computed for these exactly as was done for the averages (see p. 32). In section III of the table, the effect of alcohol upon the M. V. is found to produce +11 and $+7 \sigma$ in periods 2 and 3 , an increase in the variability of the reaction time following the dose, while period 4 shows a decrease.

It should be borne in mind that the plus and minus signs are employed in their usual meaning throughout this monograph. For example, a plus $(+)$ difference or percentage means a longer reflex time, a larger amplitude, a larger number of finger-movements, a larger number of electrical units required for threshold stimulation, a larger variability between measurements, etc., whereas the minus (-) sign in these same connections would have the reverse meaning. The effect of alcohol must, of course, always be interpreted according to the nature of the measurement; e. g., a + reaction-time percentage (slower reactions) would not ordinarily be associated with a + percentage for finger movements (faster movements).

It will be seen by consulting Dodge and Benedict's report, page 29, that they computed the average difference (Av. D.) of the day's measurement according to the formula ${ }^{2}$

$$
\text { Av. D. }=\frac{(1-2)+(1-3)+(1-4)+(1-n)}{n}
$$

According to our method for determining the differences outlined in previous paragraphs, the formula for Av. D. would be:

$$
\text { Av. } D=\frac{(2-1)+(3-1)+(4-1)+(n-1)}{n}
$$

1 This condition of a small $n$ (5 eye reactions, 10 patellar reflexes, 4 lid reflexes, etc., taken within any one period) is operative throughout all our measurements and increases the size of the probable errors. The usual method of obtaining the P. E.M for the 3-day averages for any period has been to find the P. E.M for each of the three values which are averaged. The sum of the three P. $E_{M}$ is divided by three to obtain the typical P. E.M; then the result is divided by $\sqrt{3}$, since the $n$ for the three averages together is three times as large as for one.

${ }^{2}$ It is obvious that $n$ in their formula refers to the number of experimental periods following and excluding the first period, or normal of the day. 
It may appear of little consequence as to whether one subtracts the preliminary first-period values from those which succeed the giving of the dose (the method employed in this paper) or subtracts succeeding values from the preliminary first-period values (the method employed by Dodge and Benedict). However, by the latter method the resulting signs have, when taken in connection with the discussion in the text, exactly the reverse meaning from that which is usually associated with them. According to Dodge and Benedict (see their page 29): "If the Av. D. has a minus sign it shows that the measured values are larger as the session progresses. Conversely, if the Av. D. has a positive sign, it shows that on the average the subsequent measurements are less than the normal of the day." It is a real disadvantage for clear understanding of data to have to carry in mind continually this reversal of meaning for + and - which runs through the Dodge and Benedict publication; accordingly, at the risk of some confusion in a comparison of results, the method represented by the second formula given and illustrated in table 2 has been adopted. Of course the results themselves are not affected by either method of computation, but that method which most facilitates clear understanding and interpretation is to be desired. Wherever data from the Dodge and Benedict report are reprinted for comparison, the liberty is taken to change the signs.

Dodge and Benedict took the average of the individual differences for all periods of an experimental day as the significant result. The individual periods received no consideration. Our experimental day was 5 hours long as contrasted to the 3 hours used previously. As will be seen later in this paper, the differences produced by the ingestion of alcohol do not always with this subject retain the same sign (plus or minus) throughout the experimental day. For example, a series of plus differences during the first three periods following the dose may change to minus differences during the last two periods of the session. To average together the five differences under these conditions would mask important tendencies and give quite misleading comparisons. The 5-hour experiment was adopted in this repetition series in order that the effect of alcohol might be traced for a longer time after the ingestion of the alcohol. The results are therefore presented as illustrated by table 2 in a more analytical form and chief attention is given to a comparison by periods following the alcohol. ${ }^{1}$ The method used in this report has been to average the differences for homologous periods on normal days and subtract these from a series of such averages for alcohol days in order to obtain an expression of the effect. of alcohol for the different periods. This method does not preclude comparison of the averages for individual days, when this is desirable.

Another item of statistical nature should receive attention. A com-

1 Dodge and Benedict's report, p. 210, table 39, is the one instance in which these authors have used this form of presentation of their data. 
mon footnote accompanying all of the Dodge and Benedict tables states that "the values for the first period of the alcohol experiment were obtained before the alcohol was given, and are therefore not included in the averages," whereas on normal days the values for the first period of the day were included in the average. It is clear that the alcoholday average and the normal-day average would have been more strictly comparable if the latter had also been computed without including the first-period values. Wherever averages for the day are given in the following tables, usually in the next to the last column, these averages always include only the values which follow the giving of the alcohol dose or the control dose, that is, the above quoted footnote is applied to all of the normal days as well as to the alcohol days. . The results of recomputing some of the Dodge and Benedict material on this basis may be seen in Appendix III. (See p. 140.)

In succeeding pages, where such terms and expressions as "inferior functioning of processes," "less efficient performance," "depression," and the like, are employed, it is assumed that these terms and their opposites properly describe the changes and conditions found in these neuro-muscular measurements. In the case of the respiration rate and possibly of the reflexes this terminology may be open to question.

\section{DATA OBTAINED IN THE REPETITION MEASUREMENTS.}

In considering the effect of 30 c.c. of absolute alcohol upon some neuro-muscular processes of the subject used in this research, the various measurements used will be treated in the order in which they were presented in the earlier publication, not necessarily in the order in which they came in the experimental hour. (See p. 23.) It is not needful to discuss here the availability, apparatus, technique, and general experimental procedure for the different processes considered. This report primarily concerns results. For a more detailed treatment of the experimental methods than is given in the mere outline on pages 23 to 29, the reader must consult the full description of Dodge and Benedict. Unless definitely stated to the contrary, the experimental procedure was fundamentally the same as theirs. As this report relates to a single subject and one who was thought to vary quite widely from a supposedly normal group, certain features of the data will call for discussion in a way that was not feasible in the earlier monograph. So far as we know, this group of data, for the measurements involved, is as extensive as any which has heretofore been collected for one individual. Some attention should therefore be given to the normal values as such, aside from their comparison with the alcohol values.

Fortunately, Dodge and Benedict have usually given separate averages for the different doses in their final statement of the effect of alcohol; this facilitates comparison with the data obtained in the later 
research, in which only dose $\mathrm{A}$ was used. ${ }^{1}$ In this report an effort has been made to employ uniform tabular presentation for the different measurements, and thereby to facilitate comprehension of the data and any comparison that the reader might desire to make.

\section{PATELLAR REFLEX.}

The patellar-reflex data are given in tables 3 and 4, table 3 showing the values for the reflex caused by the first stimulus and table 4 those for the second reflex, which came within the relatively refractory period. Each table is divided into three sections, as follows: Section I, normal and alcohol measurement values for the latency (L) and amplitude (A) of the reflexes, i.e., the actual averages for the respective periods on the different days stated for 30-gram and 50-gram stimuli separately, and accompanied by average mean variations; section II, normal and alcohol differences, which are found by subtracting first-period values from those which succeed; and section III, the effects of alcohol computed from the differences and expressed in these terms and also in per cent, together with the ratio of the differences to their probable errors and the probable correctness of the differences.

The first column in table 3, headed "Experiment and stimulus," specifies the nature of the experiment (normal or alcohol), the date, and the weight in grams of the hammer falling through an arc of $90^{\circ}$, a vertical distance of $20 \mathrm{~cm}$., which produced the stimulus for the reflex. Under the caption "Period I" are the averages for L (latency) and A (amplitude) for the first set of reflexes on the different days and with the respective intensities of stimulation. ${ }^{2}$ The relative position of the dose, which was control or alcohol according to the kind of experiment, come between periods 1 and 2. Following the drinking of the dose, sets of reflexes were recorded for periods 2 to 6 as indicated. The results ior normal days and alcohol days are grouped and averaged separately in the different sections of the table. Table 4, showing the values for the second reflex, follows the form of the preceding table, the designations $\mathrm{L}^{\prime}$ and $\mathrm{A}^{\prime}$ being used for the latency and amplitude, respectively.

The patellar reflex was the first one of the group of ten different measurements which together required approximately 50 minutes for their completion. Since each measurement occupied the same position in the group, it is evident that the time elapsing from the first performance of the individual test, as, for example, the patellar reflex, until the last repetition of it during the day, would be approximately 4 hours. The averages in section $\mathrm{I}$ for June 29 , period 4 (L, 35 and $34 \sigma$, and $\mathrm{A}$,

\footnotetext{
1 The tables in the Dodge and Benedict report in which the effect of doses A and B are averaged together are as follows: Nos. $3,14,15,46$, and 50 .

'In Dodge and Benedict's report, $R^{\prime}$ and $R^{\prime \prime}$ were used to designate latency and $H^{\prime}$ and $H^{\prime \prime}$ for amplitude for the first and second reflexes, respectively.
} 


\begin{tabular}{|c|c|c|c|c|}
\hline \multirow{2}{*}{ 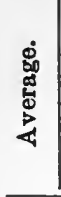 } & 4 & 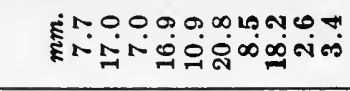 & 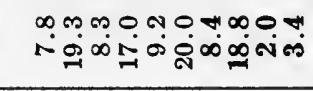 & 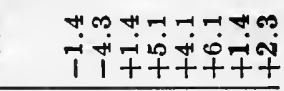 \\
\hline & 1 & 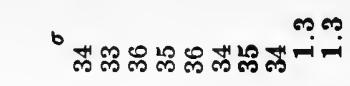 & 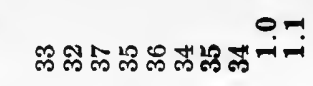 & 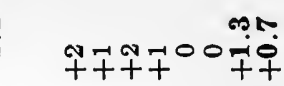 \\
\hline \multirow{2}{*}{$\begin{array}{l}\dot{0} \\
\ddot{0} \\
\dot{0} \\
\dot{0} \\
\dot{0}\end{array}$} & 4 & 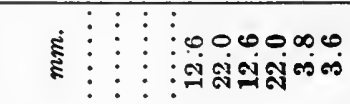 & $\begin{array}{l}\vdots \infty \\
\vdots \\
\vdots\end{array}$ & $\begin{array}{l}\vdots \infty \infty \infty n+\infty \\
\vdots \\
\vdots\end{array}$ \\
\hline & ค & 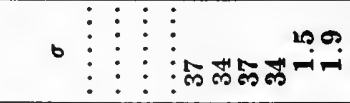 & 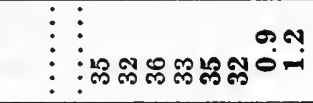 & 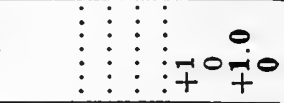 \\
\hline \multirow{2}{*}{ 官 } & 4 & $\begin{array}{l}\vdots \\
\vdots \\
\vdots\end{array}$ & 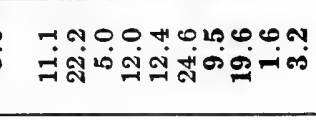 & 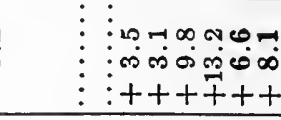 \\
\hline & ค & 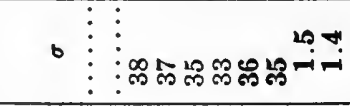 & 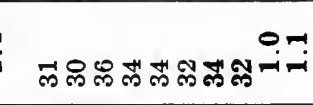 & $\begin{array}{l}\vdots \\
\vdots \\
\vdots\end{array}$ \\
\hline \multirow{2}{*}{ 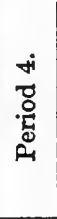 } & 4 & हैं & مُ & 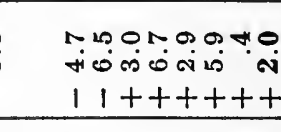 \\
\hline & $\mapsto$ & 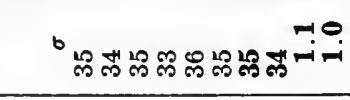 & 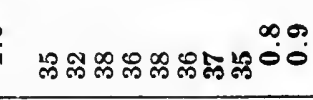 & 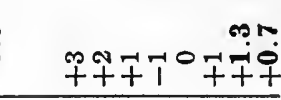 \\
\hline \multirow{2}{*}{ 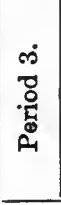 } & $<$ & हं心 & 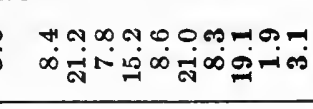 & 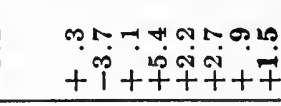 \\
\hline & $H$ & 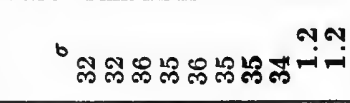 & 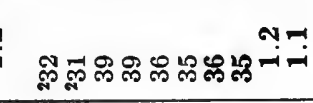 & oOnTotith \\
\hline \multirow{2}{*}{ 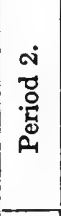 } & 4 & 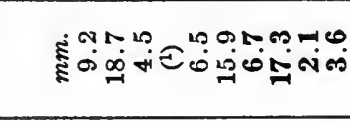 & 뭄 & 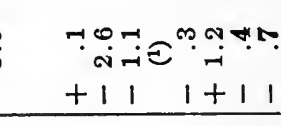 \\
\hline & Н & 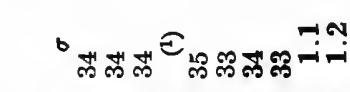 & 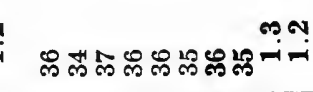 & พัพ \\
\hline \multirow{2}{*}{ - } & 4 & 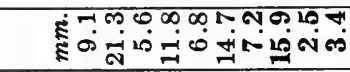 & क & \\
\hline & म & 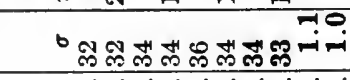 & 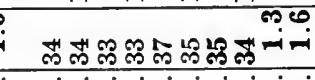 & \\
\hline \multicolumn{2}{|c|}{ 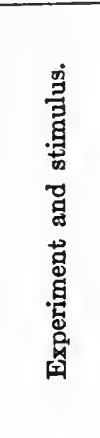 } & 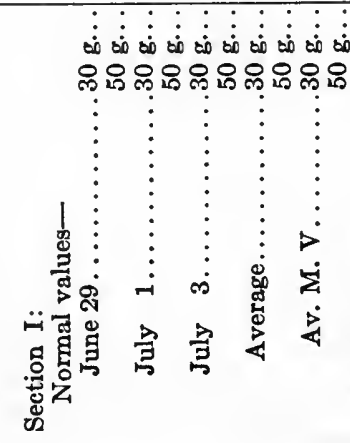 & 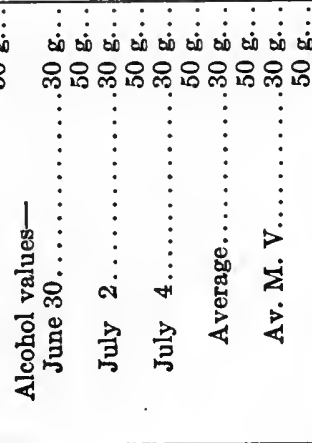 & 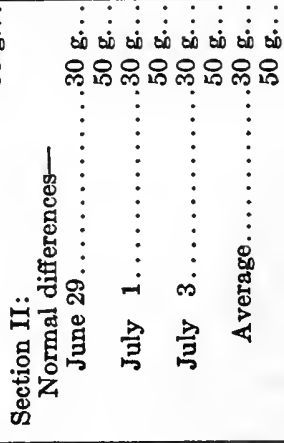 \\
\hline
\end{tabular}




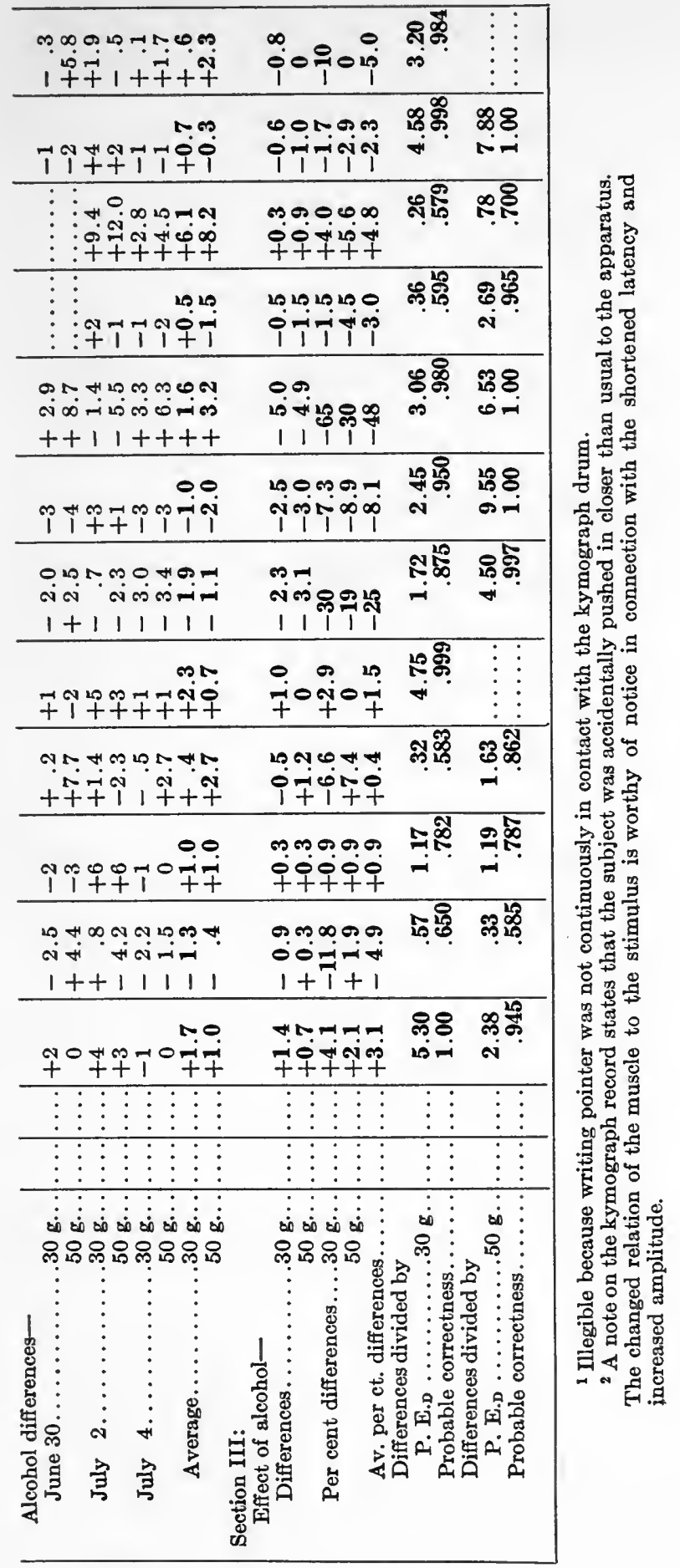




\begin{tabular}{|c|c|c|c|c|}
\hline \multirow{2}{*}{ 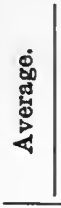 } & द & हूँ & サஸ் & 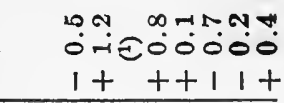 \\
\hline & 闶 & 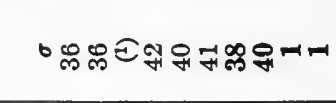 & బ & 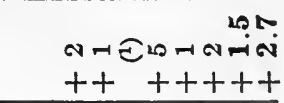 \\
\hline \multirow{2}{*}{ 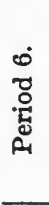 } & ¿ & 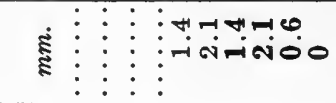 & $\begin{array}{l}\vdots \\
\vdots \\
\vdots\end{array}$ & 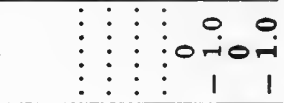 \\
\hline & 今 & 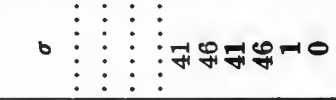 & 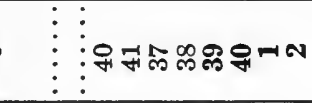 & $\begin{array}{l}\vdots \vdots \vdots \\
\vdots \vdots \\
\vdots\end{array}$ \\
\hline \multirow{2}{*}{. } & ¿ & $\begin{array}{l}\vdots \vdots \\
\vdots \\
\vdots \\
\vdots\end{array}$ & નું & 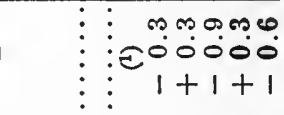 \\
\hline & मे & 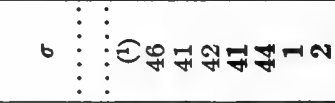 & 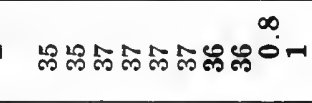 & $\begin{array}{r}\vdots \\
\vdots \\
\vdots\end{array}$ \\
\hline \multirow{2}{*}{ 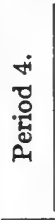 } & ¿ & हُ & - & 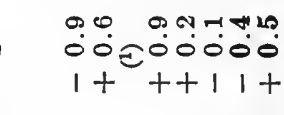 \\
\hline & 问 & 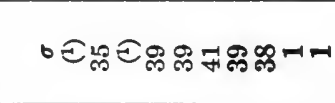 & 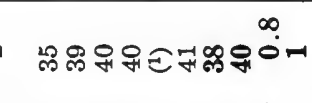 & $\begin{array}{c}\text { EOENonom } \\
+++\end{array}$ \\
\hline \multirow{2}{*}{$\begin{array}{l}\dot{m} \\
\dot{0} \\
\dot{0} \\
\dot{0}\end{array}$} & 之 & 苜 & 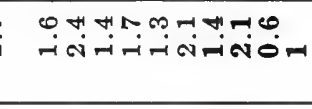 & 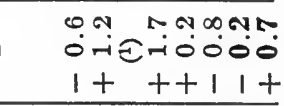 \\
\hline & 计 & 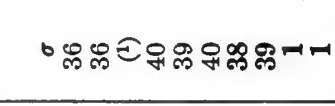 & 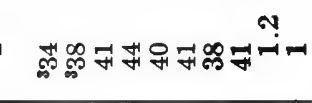 & $\begin{array}{l}\text { on } \\
\text { N-Cmon- } \\
++++++\end{array}$ \\
\hline \multirow{2}{*}{ 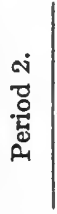 } & 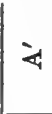 & हُ & 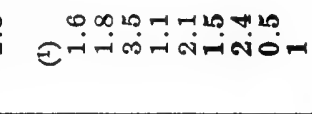 & 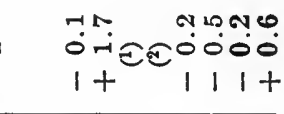 \\
\hline & 句 & 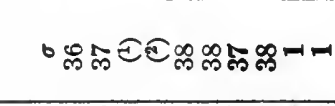 & 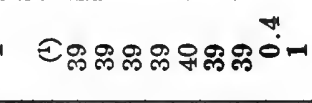 & 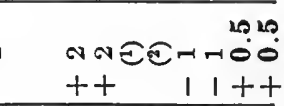 \\
\hline \multirow{2}{*}{ 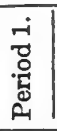 } & द & 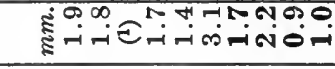 & 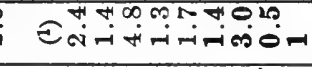 & 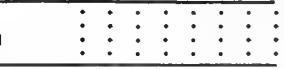 \\
\hline & i & 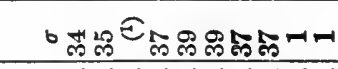 & - ¿ $_{\infty}$ & $\vdots \vdots \vdots \vdots \vdots \vdots \vdots \vdots$ \\
\hline & 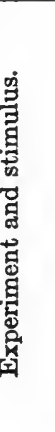 & 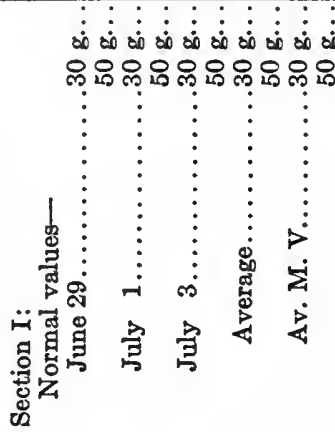 & 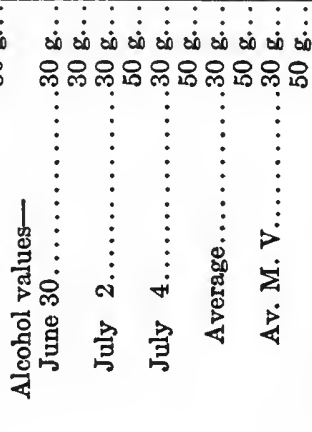 & 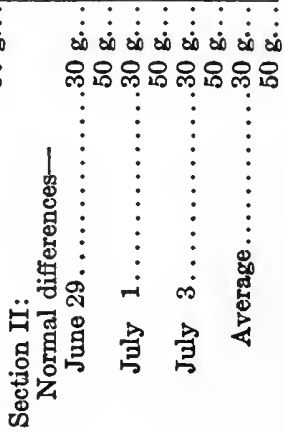 \\
\hline
\end{tabular}


Patellar Reflex.

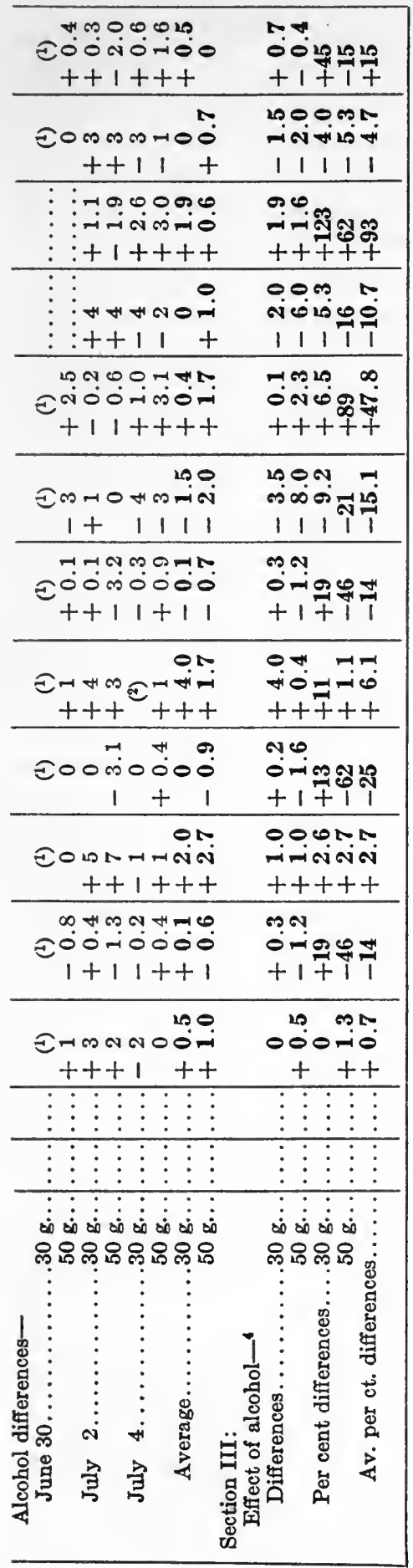

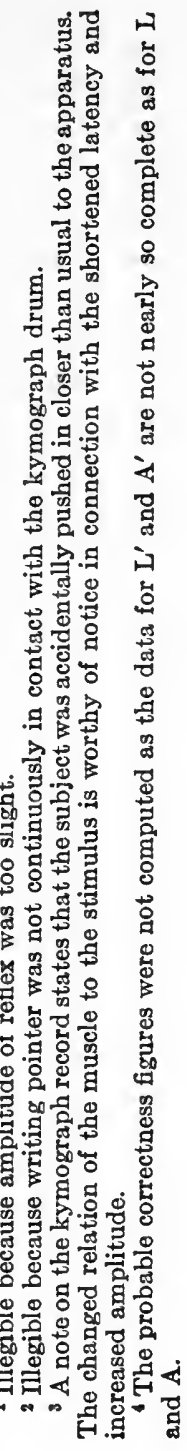


4.4 and $14.8 \mathrm{~mm}$.), in strict accuracy should be placed under periods 5 or 6 , or in an intermediate position between these two. On June 29 only four repetitions of all the measurements could be accomplished in the 5-hour session, as compared to the six periods on three of the other days. It did not seem feasible, however, to distribute the fewer measurements for June 29 and 30 and July 1 so that they would correspond in point of time with the averages for the periods on the other days. The values have therefore been entered under columns by periods rather than an attempt made to specify more exactly the number of minutes which elapsed between the measurements and the dose. The averages of the values for $\mathrm{L}$ and $\mathrm{A}$ obtained after the dose $(i . e$. , in periods 2 to 6) are given in the last two columns of the table. Thus, L, $34 \sigma$, June 29 , is an average for 34,32 , and $35 \sigma$. The averages in black type represent the group averages for the period values in each column, the 30 -gram and 50-gram reflexes being averaged separately. If the reader will consult the general averages in the last two columns of the table in section $\mathrm{I}$, these values will be found:

Normal days, L, 30 grams, $35 \sigma, 50$ grams, $34 \sigma$; alcohol days, L, 30 grams, $35 \sigma, 50$ grams, $34 \sigma$.

Normal days, A, 30 grams, $8.5 \mathrm{~mm}$., 50 grams, $18.2 \mathrm{~mm}$.; alcohol days, A, 30 grams, $8.4 \mathrm{~mm}$., 50 grams, $18.8 \mathrm{~mm}$.

That is, these average values, which do not include the measurements taken on the first periods on any of the days, show for the groups as a whole almost identical latencies and amplitudes for the respective intensities of stimulation. It is inconceivable that with normal experiments the average values could have been more nearly identical, but this is not true of the data when studied and compared by periods.

Section II naturally shows no differences under period 1 , for, as will be recalled from the explanation of the illustrative table 2 , the value for this period is used as the normal of the day and is subtracted from those obtained in the other periods. Thus, $32 \sigma$ (the normal value for $\mathrm{L}$ in period 1 , June 29 ) is deducted from $34 \sigma$ for $L$ in period 2 on the same day, yielding a difference of $+2 \sigma$ (see first normal difference for June 29). The average difference in amplitude for this same group of reflexes is obtained by deducting A, $9.1 \mathrm{~mm}$. (period 1, June 29) from A, $9.2 \mathrm{~mm}$. (period 2, June 29), giving a difference for the second period of $+0.1 \mathrm{~mm}$. The differences for the other periods and for all the days are found in like fashion. These differences are averaged for each day and for each stimulus intensity; the results are shown in the last two columns of the table. The average differences in the heavy-faced type are in every case for the differences in the vertical columns above them. In finding these averages the signs have been taken into account. The series of averages for normal differences in section II, i.e., 30 grams, $+0.3,+0.7$, $+1.3,+1.5,+1.0 \sigma$, indicate that with this stimulus the latent time of the patellar reflex for a normal day tends to increase gradually, on the average, for three or four hours after the beginning of the measure- 
ments. The comparison series of values for the alcohol days, +1.7 , $+1.0,+2.3,-1.0$, and $+0.5 \sigma$, show in the first three periods an increase in the latency with a 30 -gram stimulus which is greater than in the similar periods under normal conditions. To secure a statement for this difference in degree of increase of latency, which we assume to be the effect of alcohol, the normal differences are subtracted from the alcohol differences. The results thus obtained, shown in section III, for the 30-gram stimulus, are $+1.4,+0.3,+1.0,-2.5,-0.5 \sigma$ for periods 2 to 6 , respectively. These differences averaged, according to the method of Dodge and Benedict, equal $-0.6 \sigma$ (see next to last column, section III). The average latency for all of the first-period measurements, both normal and alcohol days (see section $\mathrm{r}, \frac{34+35}{2}$ $=34.5 \sigma$ ), forms the basis for computing the percentile effect of alcohol. For example, the computation for period 2 will be: $\frac{+1.4}{34.5}=+4.1$ per cent for the 30-gram stimulus (see section III, period 2). The percentile values for the other periods and for the amplitudes are computed in a similar fashion. Finally, the percentage effects on the reflexes produced by the two intensities of stimulation are averaged.

Before discussing the results certain features of the data should be noted. The strength of stimulus changes the latency and amplitude of the reflex. This has been shown by Exner, ${ }^{1}$ Rosenthal, ${ }^{2}$ Dodge ${ }^{3}$ and others, and can be seen clearly in figure 1, comparing reflexes with 30 gram and 50-gram stimuli, and from table 3 , section $\mathrm{I}$, in which the averages for 30 -gram and 50-gram stimuli are given separately. The difference in the relation of the two intensities of stimulation to the second reflex, which came within the refractory phase, can not be demonstrated in figure 1, but may be seen in table 4, section I. From these values it is apparent that the average latency, $\mathrm{L}^{\prime}$, is increased with the 50-gram stimulus in contrast to the condition for $\mathrm{L}$, while $\mathrm{A}^{\prime}$ is also usually larger with the 50 -gram stimulation. The variability of the patellar reflex is a feature to which Dodge and Benedict call special attention, illustrating normal variations by the case of their Subject II (see page 46 of the Dodge and Benedict report), whose values for September 23, 1913, first period, were L, $35 \sigma, \mathrm{A}, 21.4 \mathrm{~mm}$; $\mathrm{L}^{\prime}, 42 \sigma ; \mathrm{A}^{\prime}, 7 \mathrm{~mm}$.; while for October 8, 1913, the similar values were $\mathrm{L}, 51 \sigma ; \mathrm{A}, 2.4 \mathrm{~mm}$.; $\mathrm{L}^{\prime}, 50 \sigma ; \mathrm{A}^{\prime}, 2.2 \mathrm{~mm}$. The data which have been presented in tables 3 and 4 show no such large variation. Probably this was because the experimental days were successive and the conditions more homogeneous and constant throughout the week. In working with one subject it is possible, moreover, to maintain a better

\footnotetext{
1 Exner, Archiv f. d. ges. Physiol, 1874, 8, p. 526; and Vörtrag auf dem allg. fort. Internat. Kongress für Elektromedizin u. Radialogie, Amsterdam, 1908.

${ }^{2}$ Rosenthal, Arch. f. Psychiatrie u. Nervenheilkunde, 1885, 15, p. 184.

${ }^{3}$ Dodge, Zeitschr. f. allg. Physiol., 1910, 12, p. 28.
} 
adjustment of the apparatus to the particular individual and thus to favor the production of comparable results.

The mean variation within any one series of consecutive reflexes is usually for the latent time not larger than $1.5 \sigma$, which is from 3 to 5 per cent of the average latency. The mean variation for the amplitude is from 1.5 to $4.0 \mathrm{~mm}$. for first reflexes. Here the two intensities of stimulation must be considered. Figure 1 is composed of parts of three records. The amplitude of the reflexes from 30-gram blows is, in general, about one-half that resulting from 50-gram stimuli. The amplitude with the 50-gram hammer is very large at the beginning, then gradually decreases, although the curves commonly cross and recross each other. They show greater variation among themselves than is found with reflexes from 30 -gram stimuli. Referring to tables 3 and 4, section $\mathrm{I}$, we find that the usual mean variation in millimeters for amplitude of reflexes with 50-gram stimuli is approximately 50 per cent larger than that with 30 -gram stimuli. However, if the mean variation is expressed in per cent, it is found to be larger for the 30-gram stimuli, the average with the first reflexes being about 30 per cent and for 50 grams nearer 20 per cent. The amplitude of the patellar reflex is therefore a much more variable and, it may be, unreliable quantity than the latency is. The mean variations for latency are practically identical with both intensities of stimulation, notwithstanding that the more intense stimulus produces reflexes with larger variations in amplitude, which variations should, according to Hoffman, ${ }^{1}$ react on the latency to some extent. From figure 1 it can be shown that the error in reading the curve for latent time will be larger in the case of those reflexes produced by the 30 -gram stimulus. In the first place, the depression at the extreme left of the curve, the beginning of which fixes the moment of stimulation according to the technique employed, is less well marked for the 30-gram stimulus, and the curve at the moment of muscle thickening leaves the base-line more gradually. The errors in reading these curves will tend to cancel each other, as far as the average latency is concerned, but will, on the other hand, increase somewhat the mean variation. As both points are more definitely fixed for measuring the curves produced by 50-gram stimuli, the errors of observation should be smaller, and as the mean variation for latency in the case of both reflexes produced by both intensities is almost identical, it seems that the actual variations in latency for the reflexes from the 50gram stimulus must theoretically be somewhat larger. Probably a 50gram stimulation was too strong for the best condition of normal relaxation with this subject, as the large contraction of the quadriceps muscle of the left leg must almost necessarily have tended to produce a preparatory stiffening of the whole body, even though the subject said "Ha" after each blow, and the excessive contraction of the muscle is

${ }^{1}$ Hoffman, Arch. f. Physiol., 1910, p. 223. 


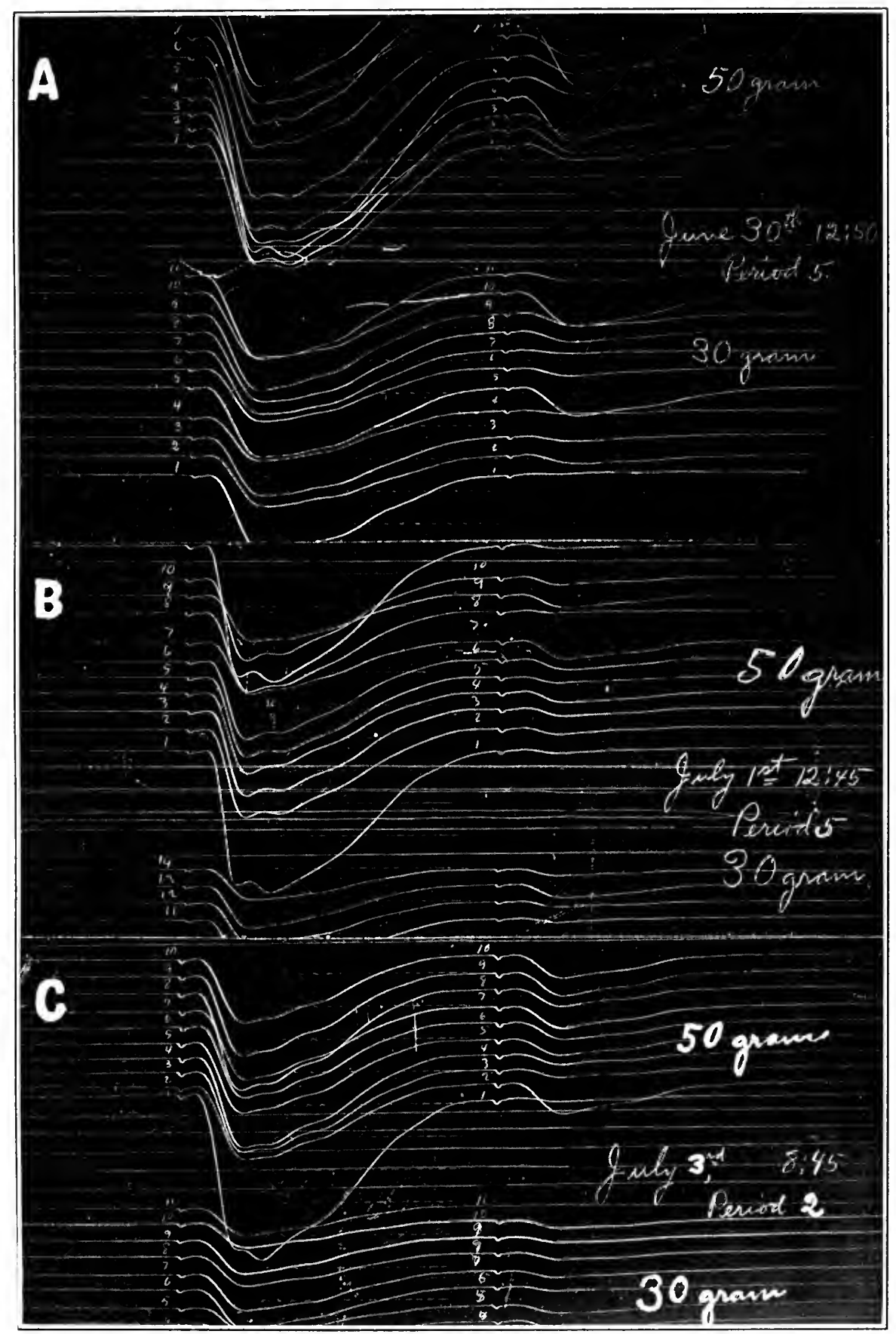

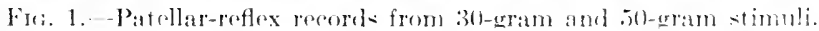




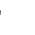


certain to produce changes in the position of the leg in relation to the stimulus apparatus.

Since $L$ and $L^{\prime}$, and $A$ and $A^{\prime}$ were measured with two stimulus intensities, there are eight products for each period of experimentation. The effect of 30 c.c. of alcohol upon these various factors and their relationship may be more clearly seen if they are given in diagrammatic form. Figures 2 and 3 are plotted from the percentage effects of alcohol on the latency and amplitude as given in section InI of tables 3 and 4, the plus percentages being above and the minus percentages below the base lines. The light and heavy lines in both figures represent the first reflex produced by the 30-gram and 50-gram stimuli, respectively, ( $\mathrm{L}$ in figure 2 and $\mathrm{A}$ in figure 3 ) and the light and heavy broken lines the second reflex within the refractory phase ( $\mathrm{L}^{\prime}$ in figure 2 and $\mathrm{A}^{\prime}$ in figure 3 ).

The latency curves in figure 2 follow, in general, the same course. During periods 2,3 , and 4 (for $2 \frac{1}{4}$ hours after the alcohol) the patellarreflex latencies are above the base line, showing a very slight lengthening, except for $\mathrm{L}^{\prime}, 30$ grams, period 4 . In two cases there was no change, and in no instance was there a decrease in latency. With this subject alcohol produced a more prominent lengthening in the latencies for the reflexes from 30 -gram than from 50 -gram stimuli. In period 2 both $\mathrm{L}^{\prime}$ are less affected than L, but subsequently they seem to be more sensitive to the effects of alcohol with both stimulus intensities. But the data for the second reflex, particularly with 30-gram stimuli, are much more fragmentary, since many times the $\mathrm{A}^{\prime}$ was so small that the $\mathrm{L}^{\prime}$ could not be measured. This being the case, the probable correctness figures were not computed.

In periods 5 and 6 , figure 2 , all of the latencies exhibit a decrease, this being less with the 30-gram stimulus than with the 50 -gram stimulus; here again $L^{\prime}$ with both stimulus weights shows the change in a more marked degree than does L. Since, for reasons previously mentioned, the normal data in tables 3 and 4 are incomplete for periods 5 and 6 , no great stress should be laid upon the striking changes indicated in figure 2 for these periods.

The effect of alcohol upon the four patellar-reflex amplitudes (see fig. 3) is not so uniform as with the latencies. Although the scale distance for the ordinates in figure 3 has been reduced to one-eighth instead of one-fourth, still the curves do not lie close to each other. A, 30 grams, and A, 50 grams, are fairly parallel, but at somewhat different levels. The former shows a decreased amplitude in periods 2, 3, and 4 , and the greatest decrease at 5 , where the latency (fig. 2) was the shortest, with a change to slightly plus at period 6 . For A, 50 grams, we find an increased amplitude in periods 2 and 3, changing to a decrease more marked in degree in 4 and 5 , and again to an increase in period 6 . The increased amplitude with the 50-gram stimulus in periods 2 and 3 might easily result if the alcohol produced a greater 
Experimental periods after alcohol

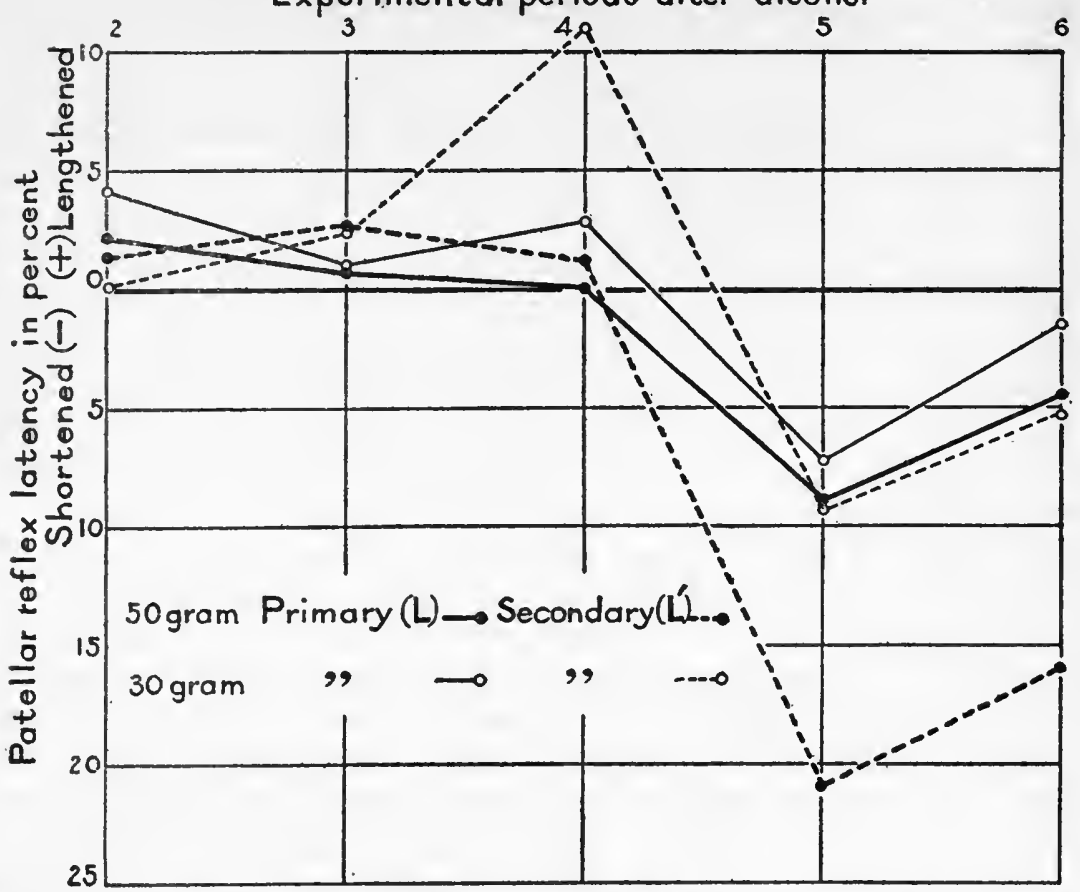

Fig. 2.-Effect of alcohol on latency of the patellar reflex with two intensities of stimulation.

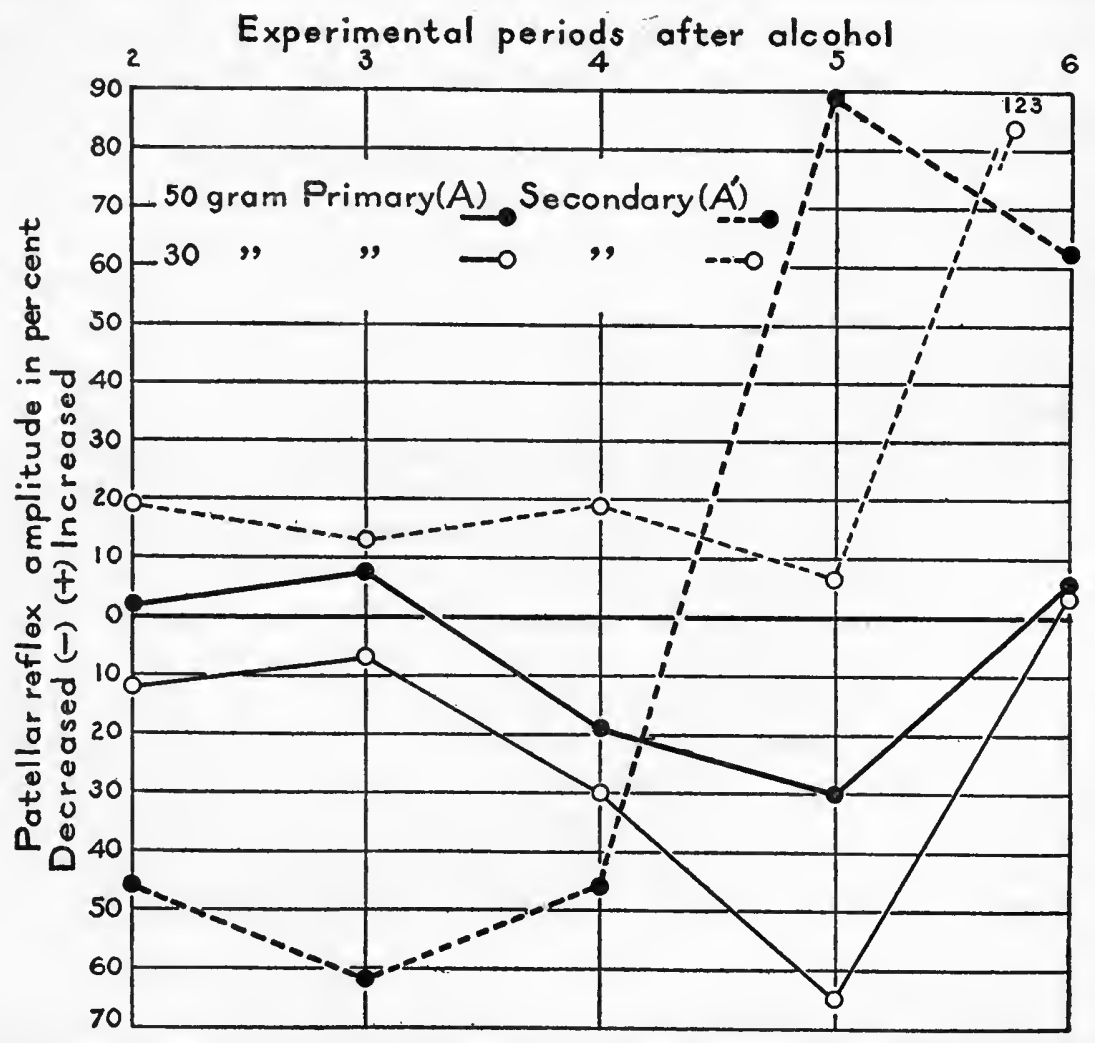

Fro. 3.-Effect of alcohol on amplitude of the patellar reflex with two intensities of stimulation. 
relaxation on the part of the subject, who previously may have stiffened the body somewhat preparatory to receiving the heavier blow on the tendon, which usually caused in his case a violent reflex.

$\mathrm{A}^{\prime}, 30$ grams and 50 grams, tend to show results which are opposed to those for the amplitudes of the first reflex. The opposition is most clearly marked in periods 2,3 , and 4 , with the reflexes from 30-rram stımuli. Whether this tendency is an alcohol effect, an individual peculiarity, or a normal phenomenon can not be determined with certainty, as there are insufficient normal data for refractory-phase phenomena on this and other subjects with which the alcohol data may be compared. The original records for the second series of patellar reflexes with Subject VI show frequent instances in which an extraordinarily large A was followed by a diminished $\mathrm{A}^{\prime}$, or vice versa, within any one set of records. The effect of alcohol as shown in percentile difference by Dodge and Benedict ${ }^{1}$ for Subject VI is $\mathrm{L},+0.3$; A, +13; $\mathrm{L}^{\prime}$ (illegible); $A^{\prime},+173$. Since the former investigators used experimental sessions 3 hours in length, while those here described were approximately 5 hours in length, an average for periods 2,3 , and 4 will most nearly compare with the previous results in point of time following the alcohol dose. The effect of alcohol as shown by an average of the percentile differences for these periods is therefore as follows:
30 grams, $\mathrm{L},+2.6$
50 grams, $\mathrm{L},+1.0$
A, -16.1
$\mathrm{A},-3.2$
$\mathrm{L}^{\prime},+4.5$
$L^{\prime},+1.7$
$\mathrm{A}^{\prime},+17.0$
$\mathrm{A}^{\prime},-37.5$

It might be supposed that the earlier results for $\mathrm{L}$ were influenced in part by the use of two intensities of stimulation, i. e., 30 grams on the normal day and 50 grams on the alcohol day. ${ }^{2}$ However, the statement that the 50-gram hammer was used for Subject VI on October 14, 1913, is incorrect, as the original records show that 30-gram hammers were employed on this day. All of the Dodge and Benedict records for this subject are therefore entirely comparable as to stimulus intensity. The two series of experiments yield results which for the 30 -gram stimulus are partially in agreement; the $\mathrm{L}$ values have the same sign $(+)$ and are both small, the $\mathrm{A}^{\prime}$ values have the same sign and are both large; those for $\mathrm{A}$ are of about equal size and opposed in sign, and those for $\mathrm{L}^{\prime}$ in the former series were illegible because the contraction was too slight. The 30 c.c. of alcohol affects but little the patellar reflex latencies of Subject VI. The percentage effects reported by Dodge and Benedict in their summary table for all their subjects are usually very much higher, partly because they include the effects of dose B (45 c.c. of alcohol); but Subject VI showed a smaller effect of alcohol on the latency than any of the others in the normal group; the two series of experiments confirm this as an individual tendency. The results for the two series on $\mathrm{A}^{\prime}$ are again peculiar, but confirm each other. 
The patellar-reflex data obtained in the second series are believed to be very homogeneous. There were no large fluctuations in the latencies, such as are mentioned by Dodge and Benedict, and the differences were usually small, as will be seen by a comparison of tables 3 and 4 with Dodge and Benedict's table 2. In only one instance (July 1, period 2, 50-gram stimulus, table 3) were the records for L and A illegible for any cause; table 4 shows relatively few cases in which it was wholly impossible to read any of the $\mathrm{L}^{\prime}$ and $\mathrm{A}^{\prime}$ values in a period on account of insufficient amplitude of reflex. So far as the data taken are concerned, there is little to be desired. It is therefore significant that the effect of alcohol is so small and that the two sets of results so nearly check each other, thus indicating the difference between Subject VI and the others in the normal group. That a slightly increased latency should be shown by the average as a final effect of alcohol can not be regarded as of great importance. Approximately the same number of plus $\mathrm{L}$ differences occur on the three normal days as on the three alcohol days; those in the alcohol days are somewhat larger and are particularly influenced by the results for July 2. The probable correctness figures are of very uneven value, and are, in general, larger for $\mathrm{L}$ than for A, but not always of such size as to warrant much confidence in the differences. All that may be said, therefore, is that 30 c.c. of alcohol had but small effect on the patellar reflex of Subject VI; in the data secured within 2 hours after the dose, it tended to depress the patellar reflex, very slightly increased the latency on the average, and more noticeably decreased the amplitude (excepting $A^{\prime}, 30$ grams). Both of the last two results are more prominent with the second reflex, in the refractory phase, than with the first reflex. The depression was more prominent on the 30 -gram reflexes.

\section{PROTECTIVE LID REFLEX.}

The patellar reflex was the first measurement in every period, and the lid reflex was always the last measurement made. The two reflexes measured, the one representative of the lowest spinal level, the other a cephalic reflex, were therefore separated by about 40 minutes. Only one intensity of sound stimulation was employed, but the same plan was followed as in the observations of the patellar reflex in that the stimuli were arranged to follow each other with an interval of approximately 0.5 second; data were thus secured concerning a group of reflexes which occurred in the refractory phase. Tables 5 and 6 give the data for the protective lid-reflex measurements, the former showing those for the first reflex, and the latter those for the reflex which came in the refractory period. The tables are compiled in like form and under the same captions as the patellar-reflex tables and need no special description. 
Lid Reflex.

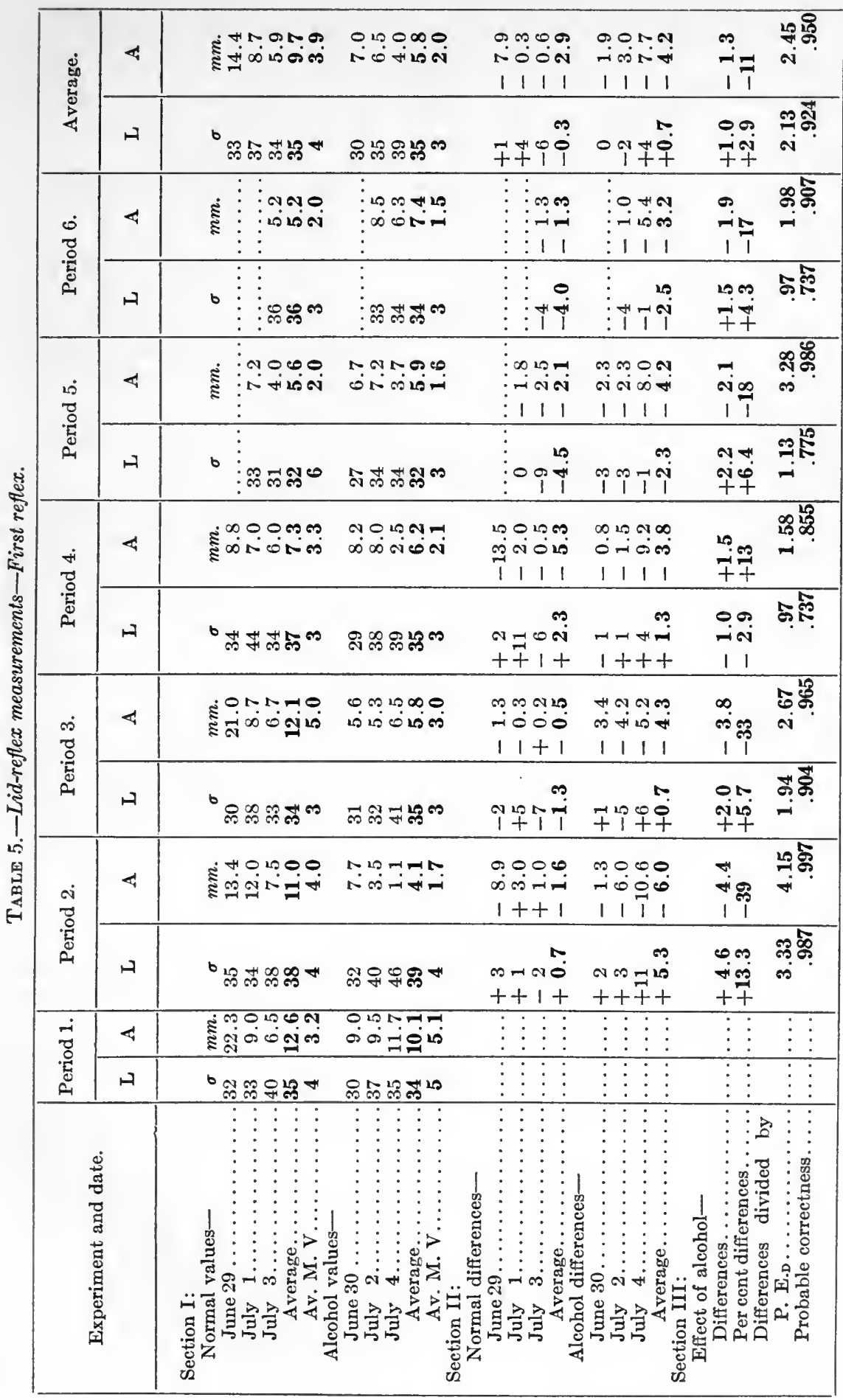




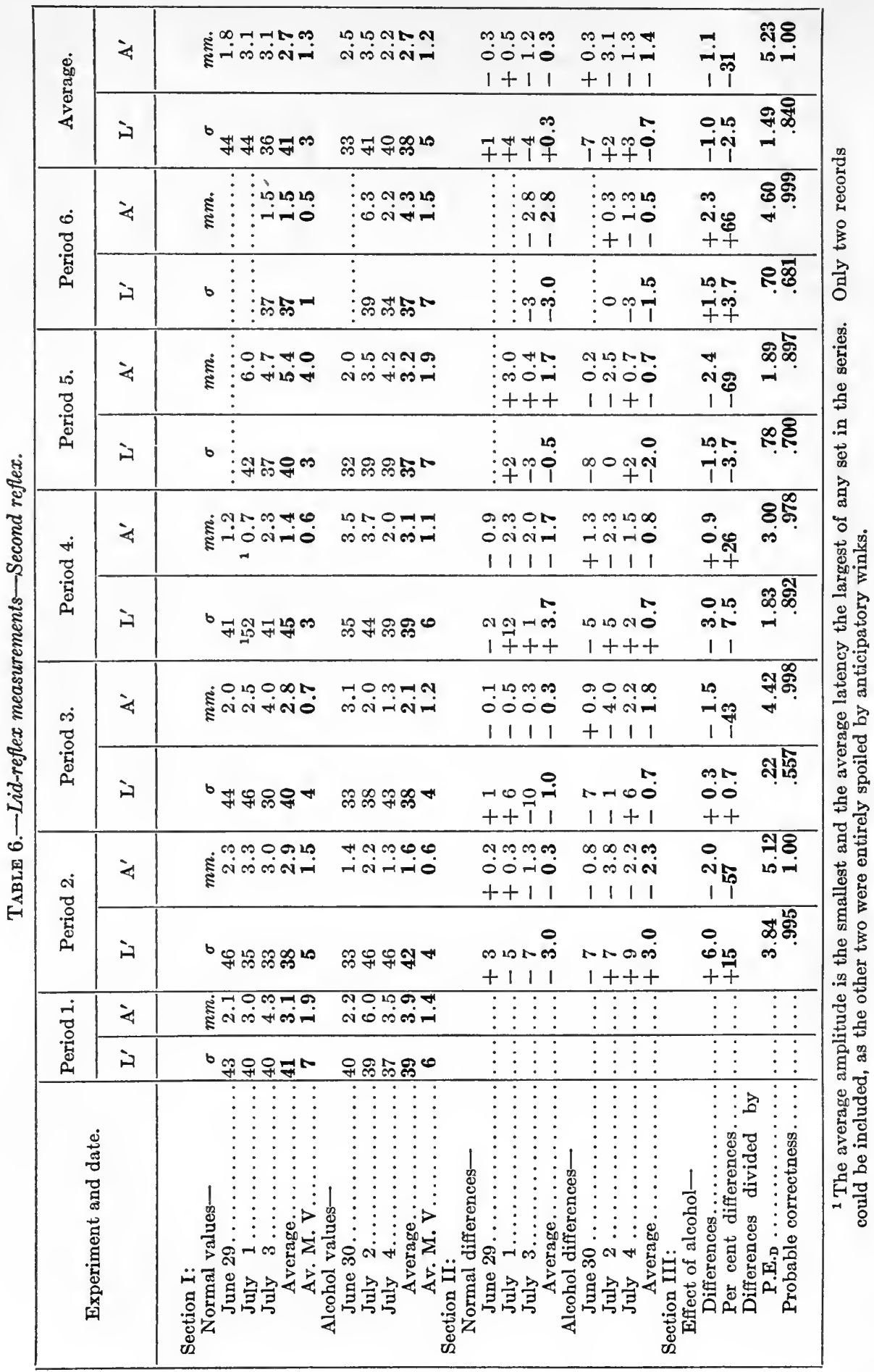


The latent time of the lid reflex is the same as that for the patellar reflex, with the technique used and for this subject. The average for $\mathrm{L}$ is $35 \sigma$. The stimulus interval was the same $(0.5$ second) for both reflex arcs, and in both instances the $\mathrm{L}^{\prime}$ was longer than its respective $L$. The average $L^{\prime}$ for the lid reflex is $41 \sigma$, as compared with $L^{\prime}$, patellar reflex, 30-gram, $38 \sigma$. The identity in the latent time of the two reflexes for this subject may not be considered as entirely accidental, since Dodge ${ }^{1}$ showed that in his own case, in which the wink reflexes were quite uninhibited, the latent time of the wink reflex and of the knee jerk were practically identical. No comparison is made on the basis of refractory phase values. That the average amplitude with the two reflexes in the data under consideration happened to be so nearly the same has, of course, no significance and is purely an accidental matter.

There is a fairly regular decrease in the amplitude of the first reflex (A). The first record taken in a period usually showed the largest amplitude, and the other three more regularly the smaller amplitudes. Reference to table 5 shows that the average amplitude for the first period is likewise usually greater than that for succeeding periods on the same experimental day, and finally, that the average A decreases from day to day. Beginning with $22.3 \mathrm{~mm}$. for the first period on the first normal day, which is the largest amplitude during the series, there is a decrease to $6.5 \mathrm{~mm}$. in the first period for July 3, the fifth experimental day. The columns of average amplitudes for the normal days regularly show a decrease. With the alcohol days there is an exception in the case of period 1, but in general the amplitude decreased as shown by the averages $7.0,6.5$, and $4.0 \mathrm{~mm}$. for periods 2 to 6 of the three days.

There is a tendency for a compensating rise in the amplitude of the second reflex; for example, the normal day values for $\mathrm{A}^{\prime}$, period 1 (see table 6 , section $\mathrm{I})$, show amplitudes increasing in size $(2.1,3.0$, and 4.3 $\mathrm{mm}$.), while those for A decrease as previously noted. The amplitude of the two lid reflexes, therefore, seem normally to approximate reciprocal relations with one another. The reduction in the amplitude of the reflex contraction, due to the possibility that the subject became accustomed to the stimulus, is of course favored by the use of consecutive experimental days. In the case of Dodge and Benedict's psychopathic subjects, ${ }^{2}$ all of whom served on consecutive days, the reduction in the amplitude of contraction is conspicuous in every case for $A$, while $\mathrm{A}^{\prime}$ shows a consistent increase. These $\mathrm{A}^{\prime}$ values are, however, very slight.

The average mean variation for the latency in the case of the protective lid reflex is larger than with the knee jerk. The patellar reflex gave an average mean variation of $\mathrm{L} 1.3$, and $\mathrm{L}^{\prime} 1.0 \mathrm{\sigma}$, without a

${ }^{1}$ Dodge, Zeitschr. f. allg. Physiol., 1910, 12, p. 44.

2 Dodge and Benedict's report, p. 69. 
noticeable difference between the two intensities of stimulation, that is, 30 -gram and 50-gram hammers. The lid reflexes, on the other hand, show an average mean variation of about $3 \sigma$, with a somewhat larger average for $\mathrm{L}^{\prime}$ (see particularly period 1 for both normal and alcohol days). This difference is all the more significant when it is considered that the protective lid-reflex records permitted more accurate measurements than the kymograph records for the patellar reflex. On the other hand, only four lid reflexes were measured in each period, and these could not follow each other so closely, because for each record a separate strip of photographic paper held in a plate-holder had to be exposed and in turn covered and withdrawn before the next reflex could be taken. This interruption between lid reflexes with the necessary manipulation of the camera and the plate-holders provided time and occasion for more extraneous agencies to act upon the subject, influencing the process considered. With the knee-jerk measurement the reflexes followed each other with great regularity. There was little to attract the attention of the subject save the stimulation blows, and relaxation was favored by the general bodily position, since he reclined in a steamer chair. During the measurement of the lid reflex the subject sat upright, held his head steadily in a rest, looked at a fixation mark, and counted backwards from a number which was given previous to the release of the camera. All of this demanded more attention and cooperation on the part of the subject than was needful in the measurement of the patellar reflex.

Associated with the attitude of attention necessary on the part of the subject for these measurements there was, in the case of Subject VI, a large amount of anticipatory voluntary lid movement. If, as will be shown later, these voluntary movements have an influence upon the latency of the reflex, we have a group of conditions which offer ample explanation for the larger mean variation in the latency of the lid reflex. There is no such large discrepancy in the average mean variation for the amplitude of the two reflexes, although here again the larger variations are found in the case of the lid reflex. It is further to be noted that the mean variations for the latency and amplitude of the lid reflex are not so large in those periods which follow the ingestion of alcohol.

The effect of alcohol upon the protective lid reflex may be seen in section III in both tables 5 and 6 . For convenience of comparison the percentile effects are also given in diagrammatic form in figures 4 and 5 , which show the latency and amplitude, respectively. The solid line represents the percentile effect on the primary reflex, the broken line the reflex in the refractory phase. From figure 4 it is evident that the latency of the reflex is considerably lengthened in those measurements which follow immediately the taking of alcohol (lid reflexes were never measured earlier than 40 minutes after the dose). In period 3 the latency is still lengthened, but not in such a marked degree. There is 


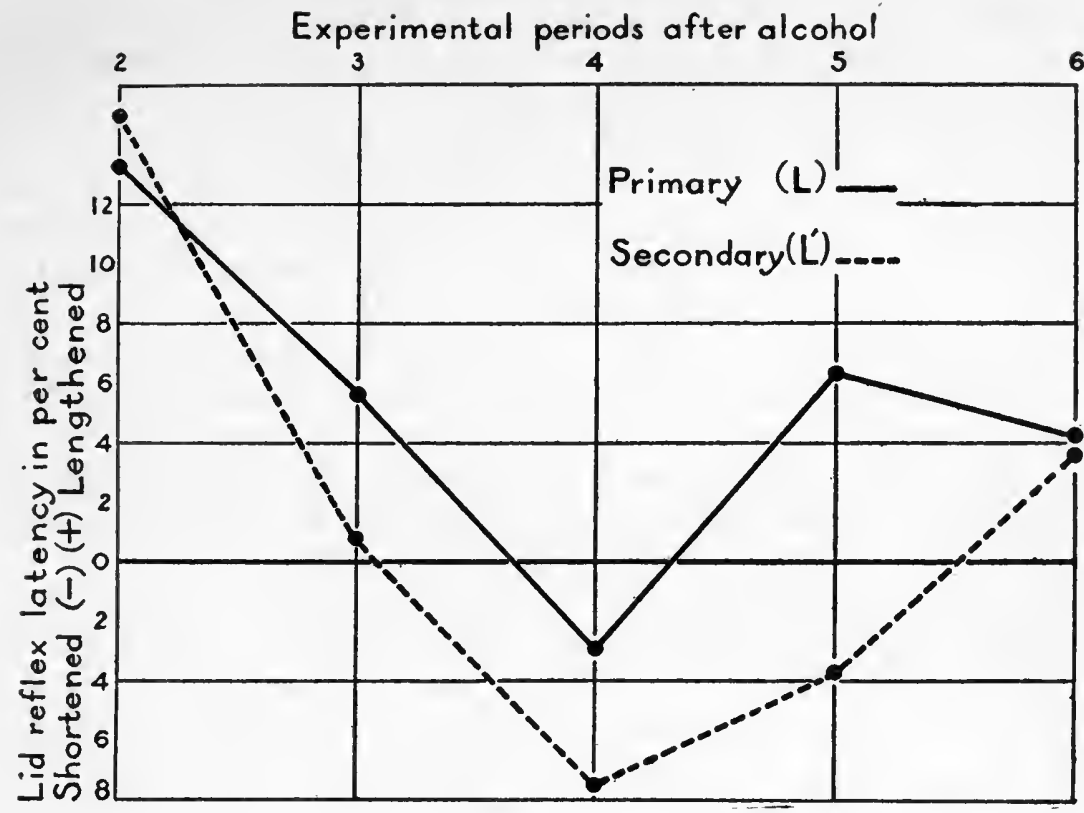

Fig. 4.-Effect of alcohol on latency of the lid reflex.

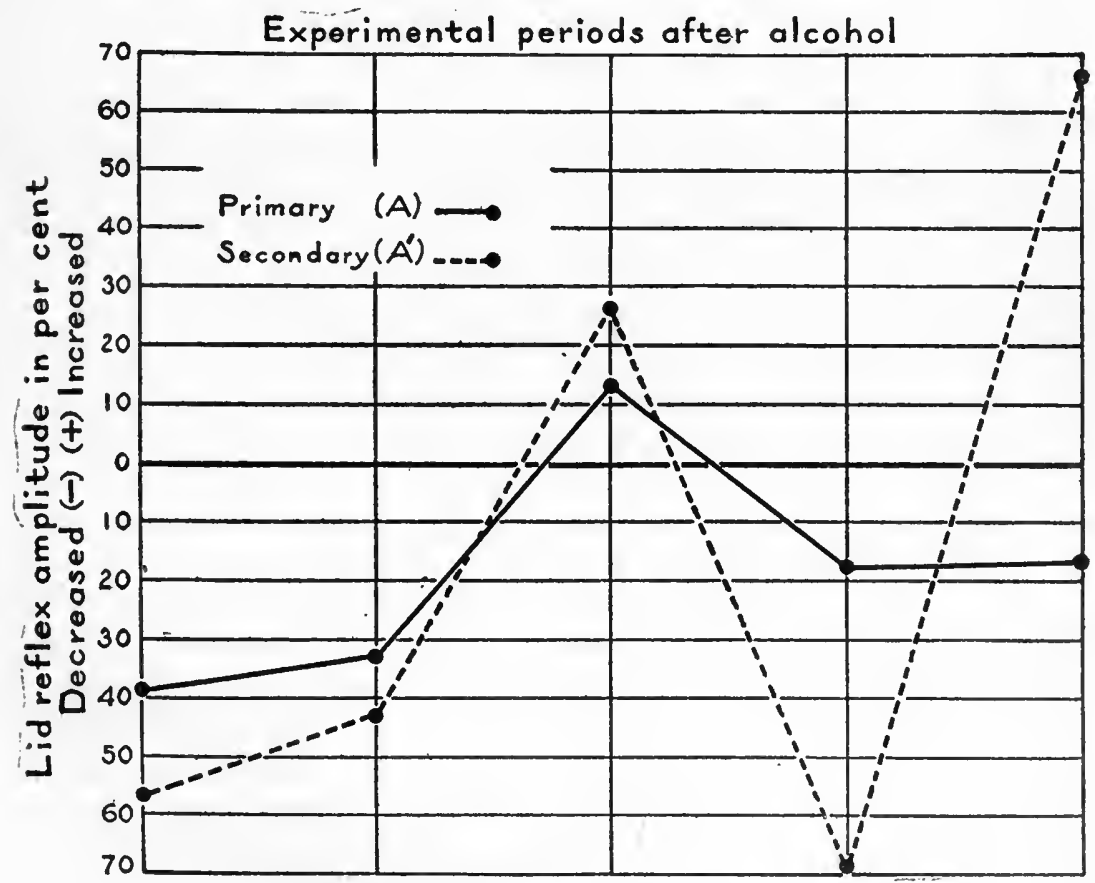

FIG. 5.-Effect of alcohol on amplitude of the lid reflex. 
a decrease in the latency in period 4 , changing again to an increase in periods 5 and 6 . The curve for the secondary reflex latency follows fairly close to that of the primary reflex.

The course of the alcohol effect upon the reflex amplitude, as represented in figure 5 , shows the greatest decrease in the amplitude in period 2 , a somewhat less decrease in period 3 , a rise to an absolute increase in period 4 , with a return below the base line for periods 5 and 6 , that is, in the case of the primary reflex. In period 5 the secondary reflex shows its greatest depression. In every period except 6 the two groups of curves, figures 4 and 5, are reciprocal, the one rising above the base line as the other falls below, and vice versa. In periods 2 and 3 taken together, which represent an interval of 80 to 90 minutes following the ingestion of alcohol, there is an average increase in latency L, 9.5 per cent, $\mathrm{L}^{\prime}, 7.8$ per cent, and in amplitude $\mathrm{A},-36$ per cent, and $\mathrm{A}^{\prime},-50$ per cent.

In figure 6 nine of the lid-reflex records for our subject are reproduced full size. These records have been trimmed down so as to permit of a larger number being presented for comparison. They are read from left to right, the time distance between the ordinates being 0.01 second. The curves which show the large depressions are direct shadows of the artificial eyelash; the stimulus line is given below each reaction curve. The first little peak in this line at the extreme left indicates the moment of the sound stimulus. In records $A$ to $E$,inclusive, it will immediately be recognized that the primary reflexes are all complicated by previous voluntary lid movements. The records were so selected as to show the voluntary lid movements approaching nearer and nearer the actual time of the reflex. In record $F$ the voluntary wink and the reflex wink fall together. The sharp, characteristic drop of the reflex is, however, clearly to be seen in all of the curves. The presence of these anticipatory voluntary lid movements is an individual peculiarity for Subject VI, not exhibited in marked degree by any of the other subjects previously employed. When the lid-reflex records of the repetition series were spread out for careful inspection, it was noted that in the period following the ingestion of alcohol the voluntary lid movement preceding the primary stimulus did not occur. In other words, all of the records were such as are shown in figure 6 , Nos. $G, H$, and $I$, each one of which is the first record following the dose on an alcohol day.

It seemed worth while to make a careful count of the records on the following points: $(A)$ the number of records showing voluntary lid movements in the $0.15^{\prime \prime}$ preceding the first stimulus, or combined with the first reflex; $(B)$ number of records showing voluntary lid movements in the $0.15^{\prime \prime}$ preceding the second stimulus, or combined with the second reflex; $(C)$ number of records showing voluntary lid movements following the second reflex. The results are given in table 7 . Only 


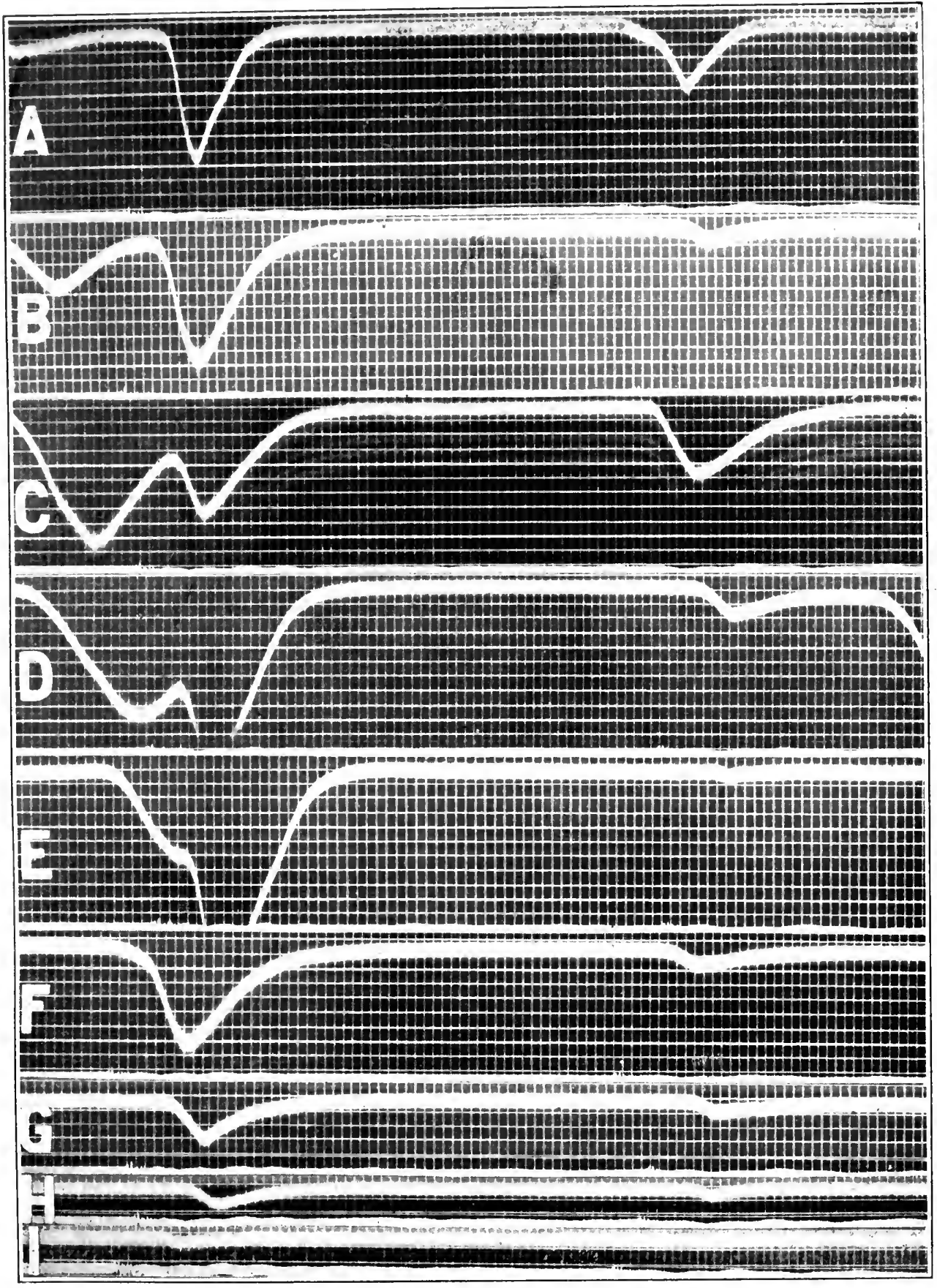

Fie. 6.-Sinerimen reeords of lid reflex of Subjecet VI

I normal recorel for subject iI commonly slows voluntary winking before or after the

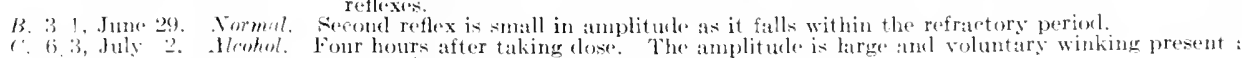

1). 1,3, July 1. Nermal. A roluntary wink followed the second reflex

F 1 i, June 20. Normal. The amplitude of the broken curve signififes that lideclosure in usuatly only partial.

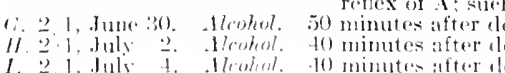


the records for the first four periods of the experimental day were counted in the Dodge and Benedict series. Normal days and alcohol days are grouped separately, and the two series of experiments are treated separately. For convenience the letters $A, B$, and $C$, representing the points under consideration, are used in the tabular form. It is clear that in more than half of the primary lid reflexes on normal

TABLE 7.-Frequency of the voluntary lid movement with the lid reflex, as shown by Subject VI on normal days and after dose A.'

A. Voluntary lid movement shown in $\mathbf{0 . 1 5}$ " preceding the first stimulus, or combined with the first reflex.

B. The same for second stimulus.

C. Voluntary lid movement following the second reflex.

\begin{tabular}{|c|c|c|c|c|c|c|c|c|c|c|c|c|}
\hline \multirow{2}{*}{$\begin{array}{l}\text { Experiment and } \\
\text { date. }\end{array}$} & \multicolumn{3}{|c|}{ Period 1.} & \multicolumn{3}{|c|}{ Period 2.} & \multicolumn{3}{|c|}{ Period 3.} & \multicolumn{3}{|c|}{ Period 4.} \\
\hline & A & B & $\mathrm{C}$ & A & B & $\mathrm{C}$ & A & B & $\mathrm{C}$ & $\mathbf{A}$ & B & $\mathrm{C}$ \\
\hline $\begin{array}{l}\text { Dodge and Benedict } \\
\text { Series. } \\
\text { Normal days: }\end{array}$ & & & & & & & & & & & & \\
\hline $\begin{array}{l}\text { Oct. } \quad 22,1913 \ldots \ldots \\
\text { Nov. } \quad 5,1913 \ldots \ldots\end{array}$ & $\begin{array}{l}3 \\
1\end{array}$ & $\begin{array}{l}3 \\
1\end{array}$ & $\begin{array}{l}1 \\
4\end{array}$ & $\begin{array}{l}3 \\
3\end{array}$ & $\begin{array}{l}1 \\
3\end{array}$ & $\begin{array}{l}4 \\
4\end{array}$ & $\begin{array}{l}4 \\
3\end{array}$ & $\begin{array}{l}2 \\
3\end{array}$ & $\begin{array}{l}3 \\
3\end{array}$ & $\begin{array}{l}3 \\
3\end{array}$ & $\begin{array}{l}1 \\
3\end{array}$ & $\begin{array}{l}3 \\
4\end{array}$ \\
\hline Jan. $\quad 1,1914 \ldots \ldots$ & 3 & 2 & 2 & 4 & 2 & 4 & 3 & 0 & 2 & 3 & 3 & 4 \\
\hline Total ${ }^{1}$. & 7 & 6 & 7 & 10 & 6 & 12 & 10 & 5 & 8 & 9 & 7 & 11 \\
\hline Alcohol days: & & & & & & & & & & & & \\
\hline Oct. $29,1913$. & 2 & 2 & 4 & 0 & 1 & 4 & 2 & 2 & 3 & 0 & 1 & 4 \\
\hline Nov. $12,1913 . \ldots$ & 1 & 1 & 4 & 2 & 0 & 23 & 3 & 2 & 4 & 2 & 2 & ${ }^{32}$ \\
\hline Jan. $22,1914, \ldots \ldots$ & 42 & ${ }^{41}$ & ${ }^{44}$ & ${ }^{4} 0$ & 4 & ${ }^{4} 4$ & ${ }^{4} 1$ & ${ }^{4} 1$ & & ${ }^{4} 1$ & ${ }^{4} 0$ & \\
\hline Total $^{1}$. & 5 & 4 & 12 & 2 & 5 & 11 & 6 & 5 & 10 & 3 & 3 & 10 \\
\hline $\begin{array}{l}\text { Repetition Series. } \\
\text { Normal days: }\end{array}$ & & & & & & & & & & & & \\
\hline June $29,1914 \ldots$ & 3 & 1 & 1 & 1 & 0 & 3 & 3 & 2 & 2 & 1 & 0 & 2 \\
\hline July $1,1914 \ldots$ & 2 & 0 & 2 & 3 & 0 & 3 & 0 & 0 & 4 & 2 & 2 & 4 \\
\hline July $\quad 3,1914 \ldots$ & 1 & 1 & 4 & 1 & 1 & 2 & 3 & 0 & 3 & 2 & 2 & 4 \\
\hline Total $^{1} \ldots$ & 6 & 2 & 7 & 4 & 1 & 8 & 6 & 2 & 9 & 5 & 4 & 10 \\
\hline Alcohol days: & & & & & & & & & & & & \\
\hline June $30,1914 \ldots$ & 2 & 0 & 2 & $\mathbf{0}$ & 0 & 1 & 0 & 0 & 1 & 1 & 0 & 3 \\
\hline July $\quad 2,1914 .$. & 1 & 0 & 1 & 0 & 0 & 3 & 3 & 2 & 3 & 2 & 2 & 3 \\
\hline July $\quad 4,1914 \ldots \ldots$ & 1 & 2 & 2 & $\mathbf{0}$ & 0 & 2 & $\mathbf{0}$ & 2 & 3 & 0 & 0 & 2 \\
\hline Total $^{1} \ldots \ldots$ & 4 & 2 & 5 & 0 & 0 & 6 & 3 & 4 & 7 & 3 & 2 & 8 \\
\hline
\end{tabular}

${ }^{1}$ The maximum number that can stand in any total is 12 .

2 Only 3 records available.

${ }^{3}$ Only 2 records available.

4 Dose B was given in the experiment on January 22, 1914.

days Subject VI preceded these by voluntary lid movements. The second reflex was not complicated by the voluntary lid movements to such a degree. It was the usual thing for the subject to wink voluntarily some time after the two reflexes. The voluntary lid movements are less conspicuous in the second series of experiments than in those of 
Dodge and Benedict. The only explanation for this is that the experimenter noted on the first day the tendency of the subject to engage in a series of rapidly following voluntary winks immediately after he began counting backwards at the signal which was given. In taking the records, therefore, it was made a rule to watch the subject closely and to release the plate in the camera at a time when he seemed relatively free from winking. As table 7 shows, this was only partly successful. In period 2 on alcohol days the anticipatory lid movements were entirely lacking in the second series of experiments and nearly so in the Dodge and Benedict series. In the latter, only 2 records out of a possible 12 showed the voluntary lid movement previous to or with the primary reflex as compared to the second period for the normal days when only 2 records out of the 12 did not show the lid movements. The records in figure 6 are, therefore, absolutely typical for lid reflexes under normal conditions and for lid reflexes 40 minutes after the ingestion of 30 c.c. of absolute alcohol.

The question is pertinent and naturally suggests itself whether the voluntary lid movements have any influence upon the latency and amplitude of the reflexes which follow them. Doubtless much more material must be brought together before this question can be adequately answered. However, from the data at hand some indication may be obtained for this relationship. It is of course evident that in many of the records, as for example $F$ in figure 6 , the combination of the voluntary wink and of the reflex is such as to make it impossible to measure the latter with any degree of certitude. Records $A$ to $E$, inclusive, figure 6, may, however, be measured satisfactorily. The first point to be fixed upon is not the beginning of descent by the reflex curve, but the place where the voluntary curve begins to change its direction under the influence of the reflex. Determinations were made as follows (see table 8):

In the normal records taken by Dodge and Benedict on Subject VI, 22 primary reflexes preceded or accompanied by voluntary lid movements gave an average latency of $34.7 \sigma$ and an amplitude of $16.2 \mathrm{~mm}{ }^{1}$ Eleven normal primary reflexes unaccompanied by voluntary lid movement yielded an average latency of $42 \sigma$, with an amplitude of $12.4 \mathrm{~mm}$. In the second series of experiments 26 normal primary lid reflexes, preceded or accompanied by voluntary lid movements, yielded an average latency of $31.7 \sigma$, with an amplitude of $11.5 \mathrm{~mm}$. Fortyfour normal primary reflexes, not accompanied by voluntary lid movements, yielded an average latency of $36.6 \sigma$, with an amplitude of $8.2 \mathrm{~mm}$.

It so happened that the available records for our subject were about equally divided between the two conditions, and as a result of this classification of the records, it appears that voluntary lid movements

1 The position of the eyelid at the moment reflex closure begins is taken as the base line from which to measure the amplitude in such records. 
preceding or accompanying the reflex decrease the latent time by about $6 \sigma$, and increase the amplitude 3 to $4 \mathrm{~mm}$. Whether or not this is a characteristic phenomenon for the optic lid reflex must be settled in the light of more extensive records. Those available show consistently this difference. In making the comparison the lid-reflex curves were of course not reread, but the original measurements were placed in the appropriate columns and averaged. No average was attempted for the second reflex. As the amplitude of this reflex is usually quite small and the departure of the curve from the base line consequently more gradual, there is admittedly a larger degree of error in determining the latency for these reflexes. ${ }^{1}$

TABLE 8.-Effect of voluntary lid movement upon latency and amplitude of the lid reflex.

\begin{tabular}{|c|c|c|c|c|c|c|}
\hline \multirow{2}{*}{ Series of experiments. } & \multicolumn{3}{|c|}{$\begin{array}{l}\text { Preceded by lid } \\
\text { movement. }\end{array}$} & \multicolumn{3}{|c|}{$\begin{array}{l}\text { Not preceded by lid } \\
\text { movement. }\end{array}$} \\
\hline & $\begin{array}{c}\text { No. } \\
\text { counted. }\end{array}$ & $\mathbf{L}$ & $\mathbf{A}$ & $\begin{array}{c}\text { No. } \\
\text { counted. }\end{array}$ & $\mathrm{L}$ & A \\
\hline $\begin{array}{l}\text { Dodge and Benedict series. } \\
\text { Repetition series........ }\end{array}$ & $\begin{array}{l}22 \\
26\end{array}$ & $\begin{array}{c}\sigma \\
34.7 \\
31.7\end{array}$ & $\begin{array}{l}\mathrm{mm} . \\
16.2 \\
11.5\end{array}$ & $\begin{array}{l}11 \\
44\end{array}$ & $\begin{array}{c}\sigma \\
42.0 \\
36.6\end{array}$ & $\begin{array}{r}m m . \\
12.4 \\
8.2\end{array}$ \\
\hline Average........... & .. & 33.2 & 13.9 & .. & 39.3 & 10.3 \\
\hline
\end{tabular}

Since the alcohol during the first hour following ingestion causes a marked decrease in the anticipatory voluntary lid movement in the case of Subject VI, and since the lid reflexes which are not preceded by such voluntary lid movements are, on the average, 5 to $7 \sigma$ longer in latency with a somewhat decreased amplitude, that is, 3 to $4 \mathrm{~mm}$., it is quite apparent from a study of section III in table 5 that the effect of alcohol in periods 2 and 3 on the latency and the amplitude of at least the primary reflex might be ascribed wholly to this cause.

Dodge and Benedict found that their Subjects IV and X were exceptional, as in both cases the reflex latency was decreased and the amplitude of response increased following the alcohol. (See table 6, p. 71, of their report.) Subject VI, dose A, is in line with the normal group and with these later findings in showing a decreased amplitude for $\mathrm{A}$ and $\mathrm{A}^{\prime}$ following the alcohol. He, however, formerly showed also a decreased latency for $\mathrm{L}$ and $\mathrm{L}^{\prime}$. This is opposed to our later results, but must be considered as more or less of an accident dependent upon the distribution of the voluntary winking and its effect upon the determination of the latency. It so happened that the first-period values for October 22 and 29 , November 5 and 12, 1913, were quite unequally affected by this factor of anticipatory voluntary winking. On October 22 three of the first four records were preccded by a voluntary wink. One of them

1 Dodge, Am. Journ. Psychol., 1913, 26, p. 5. 
yielded the shortest latency found by Dodge and Benedict for this subject, $24 \sigma$. The total average result is a small latency for the first period on normal days. On November 5, a normal day, the first two records, both of which are unaccompanied by voluntary wink, were discarded because there appeared some doubt in the minds of the authors concerning the identification of these records. The latencies, 66 and $58 \sigma$, for $\mathrm{L}$, and $49 \sigma$ for $\mathrm{L}^{\prime}$, are admittedly long, but other than this the curves give no evidence of belonging elsewhere. Of the two remaining records, one, uncomplicated by voluntary wink, yields a latency of $40 \sigma$, the other, preceded by a voluntary wink, $34 \sigma$ for the period. On October 29 , an alcohol day, two of the records without voluntary winking yield latencies of 43 and $50 \sigma$, respectively, one accompanied by a voluntary wink with a latency of $46 \sigma$, and a fourth occurred on the reflex, and so this record could not be measured. The total average for the period is $+6 \sigma$, a value which appears to be not much influenced by the voluntary wink, but on November 12, an alcohol day, with dose A, when all of the records were legible and one of them was accompanied by a voluntary wink, the average was $41 \sigma$.

It is therefore clear that the voluntary winking happened so to distribute itself as chiefly to decrease the latency of the first-period values on normal days, and to increase it on alcohol days. The final result of this would naturally be a comparative decrease in the latency of the reflex following the ingestion of alcohol. Under these conditions the disagreement between the two series of results as concerns the action of alcohol upon the latency of the lid reflex seems most likely to be accidental, due to the relatively large variability in the reflex time, the few records which were taken at each period, and the method of statististical elaboration. The two series are absolutely in agreement, first, that with this subject voluntary winking, which was very frequently preliminary to the reflex, produced a condition favorable to a shortened latency and an increased amplitude; second, that under the influence of alcohol voluntary winking is at first almost entirely eliminated as a factor and remains decreased in at least periods 3 and $4 .^{1}$ These conditions must be held in the case of Subject VI as chiefly responsible for the increased latency and decreased amplitude of the lid reflex following the taking of alcohol. ${ }^{2}$

\footnotetext{
1 The data beyond the fourth period would have been so scattered as to yield results of but littlo significance.

${ }^{2}$ A careful inspection was made of all the records of all the subjects used by Dodge and Benedict in their alcohol experiments with a view to ascertaining whether or not voluntary winking could be regarded as a factor of any considerable importance in the interpretation of the results. It was found that in the records of only Subject IX are voluntary lid movements at all frequent. The absence of voluntary lid movements was conspicuous and particularly surprising in the case of the records of four psychopathic subjects. These and some of the normal subjects showed not infrequently records with a voluntary wink following the second reflex, but very seldom was a voluntary wink preceding or complicated with the primary reflex. To consider in more detail the case of Subject IX this man had been in army service and was supposedly used to shooting. However, in approximately 70 per cent of his records he voluntarily winked following the first reflex and before the second stimulus. He showed many instances of a voluntary lid movement
} 


\section{EYE REACTION TO PERIPHERALLY APPEARING STIMULI.}

Of the total 155 individual eye reactions which constitute this series, only 12 were for any reason irregular and had to be omitted from the averages. These reaction records were lost, not through technical difficulties but because the subject voluntarily winked at the moment of the exposure of the stimulus mark, or was inattentive to the task. This is proved by the fact that his photographic records show that he was not looking at the prefixation mark at the moment of stimulation. Four of these irregular reactions occurred within 2 hours after alcohol on July 4. The recording light was interrupted 100 times per second. The individual reactions were read to the nearest half-hundredth of a second. The data obtained in the measurements of the eye reaction are given in table 9 , according to the general form used in preceding tables.

The mean variations range from 4 per cent (R. T., 229, M. V., 9) to 19 per cent (R. T., 204, M. V., 39), with an average value which equals about 14 per cent of the average reaction time. The reaction time averages from day to day show relatively small variations, the normal averages shown in the next to the last column being 192, 219, and $213 \sigma$. The same may be said for the first-period values for these normal days, that is, 212, 204, and $217 \sigma$. The second alcohol day, July 2, shows a first-period value of $237 \sigma$, which is unusually long for this series of reactions. It is noteworthy that this particularly long normal occurring on an alcohol day exercises a diminishing effect on the apparent influence of alcohol on the reaction time. Consistency is further shown by the fact that the general average for the first period for the three normal days is $211 \sigma$, while that for the three alcohol days is $208 \sigma$. Both these figures compare favorably with the general average of $208 \sigma$ for the three normal days, from which the first-period values are excluded. The respective mean variations for these three compared values are 33 and $30 \sigma$ for the normal and alcohol first periods and $29 \sigma$ or the general average for the normal days.

There is no conspicuous practice effect shown in these data. While undoubtedly practice may result in a shorter eye-reaction time for a subject with no experience in this measurement, ${ }^{1}$ Subject VI had possibly had enough experience so that later experiments would not be

following very quickly on the first reflex, so as to make it appear that the reflex involved a double movement. The first stimulus was the signal to start a series of winks lasting for about 1 second. As the interval between stimuli usually employed by Dodge and Benedict in this series was from 0.7 to 0.8 second, some of these voluntary winks were sure to precede the second reflex. The voluntary lid movements are nearly all of what may be judged extreme amplitude. There is no apparent change produced by alcohol in the frequency of the voluntary wink ing, nor does it seem to decrease at all as the result of practice in the experiment. From 15 records in which voluntary winking preceded the primary reflex the average latency and amplitude are $35.5 \sigma$ and $16.3 \mathrm{~mm}$. as compared with averages of $36.3 \sigma$ and $16.0 \mathrm{~mm}$. from 20 other normal records in which this complication did not exist.

1 See Dodge and Benedict's report, p. 89 et seq. Unpublished data on eye-reaction measurements taken in 1916 and 1917 unmistakably bear out this finding of practice effect in eye reactions. 


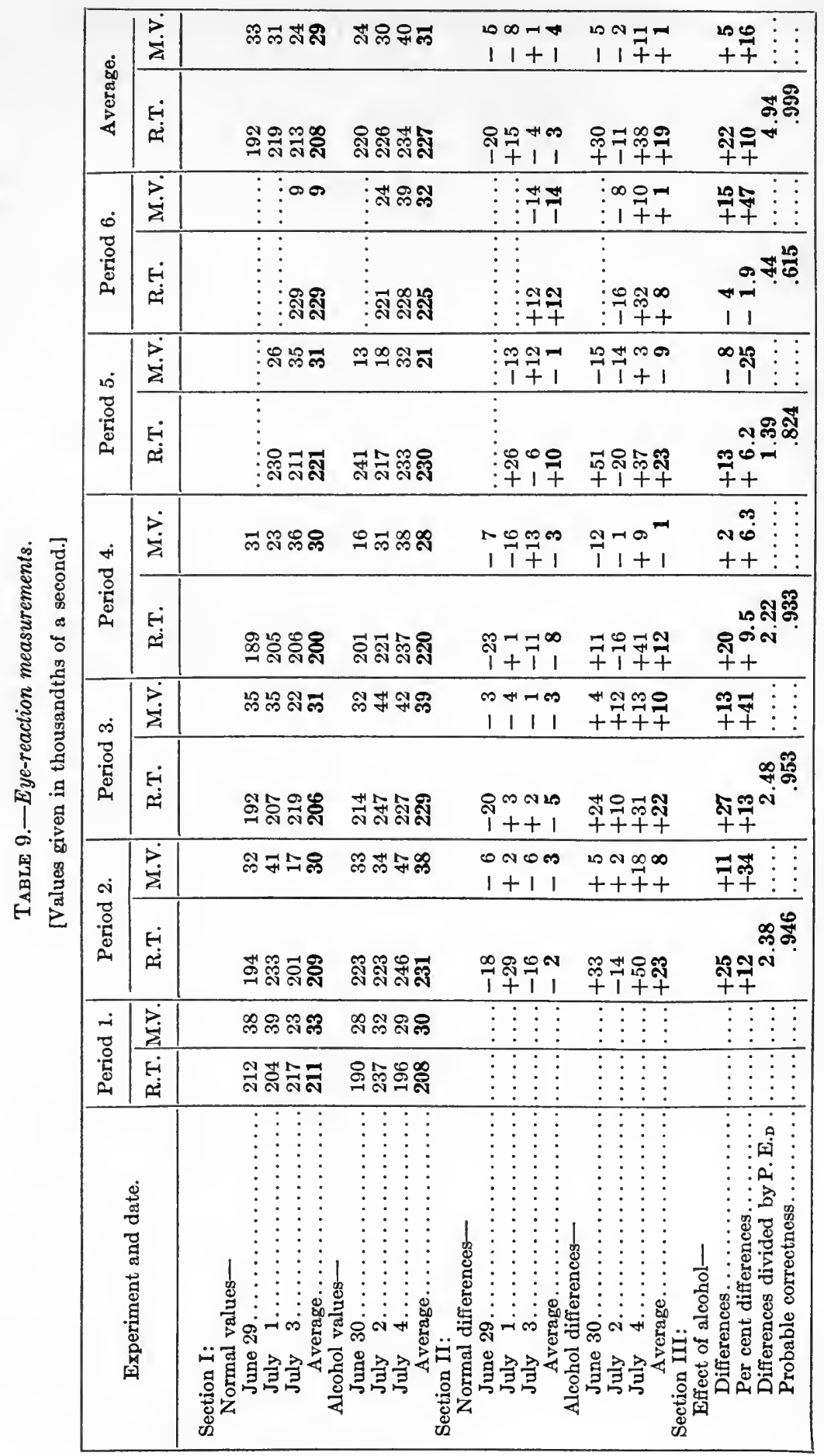


expected to produce a noticeable decrease. Particularly would this be the case when so relatively few reactions were taken, that is, only 5 every period. The general decrease in reaction time, attributed to practice for the Dodge and Benedict normal group, unfortunately rests on fragmentary normal data for Subject VI. There was but one normal day and it so happened that the records for the first period of this day were illegible. There was also only one alcohol day with dose A and the values obtained on this day were peculiar. Subject VI showed a marked variation in his average eye-reaction time between the normal day (October 22, 1913) with an average reaction time of $209 \sigma$ and a mean variation of $22 \sigma$, and that recorded on the alcohol day with dose A one week later (October 29), with an average reaction time of $159 \sigma$ and a mean variation of $24 \sigma$, there being a difference of $50 \sigma$ between the average reaction time on the two days. ${ }^{1}$ The shortness of the reaction time on the second day is astonishing, as averages such as those for periods 2 and 3 (145 $\sigma$ and $147 \sigma$, respectively) are extremely short and unusual in data thus far collected. ${ }^{2}$ No similar averages are found among those obtained for the other four days of the Dodge and Benedict series or in those obtained for the six days of the repetition series on this same subject. Considering these peculiarities of the eyereaction data for the first series, it is not surprising that the later experiments fail to agree with them.

Careful investigation and criticism have failed to reveal any factors which would seem to modify the effect of alcohol on the eye reaction as shown in table 9. The average reaction time in all of the periods after the alcohol dose, with the exception of period 6 , is larger than the comparison values for the normal days, the differences between them ranging from 9 to $23 \sigma$. The total average reaction times for the two groups of data (see next to last column) are $208 \sigma$ for normal days and $227 \sigma$ for alcohol days. The effect of alcohol in terms of differences (see section III) was to lengthen the reaction time $25 \sigma$ in period $2,27 \sigma$ in period 3, $20 \sigma$ in period 4 , and $13 \sigma$ in period 5 . In period 6 the sign is reversed, with a decrease in the reaction time amounting to $4 \sigma$. The general average shows an increase in reaction time of $22 \sigma$ as the effect of the alcohol. The differences just referred to for periods 2,3 , and 4 and for the average of all periods have, as shown in section III of table 9, in each case a probable correctness above 0.900 . The differences for periods 5 and 6 can not be regarded as especially significant, since the probable correctness figures are smaller. ${ }^{3}$ In terms of per cent, periods 2 to 5 show increases of $12,13,9.5$, and 6.2 per cent, respectively, while

\footnotetext{
1 See Dodge and Benedict's report, p. 85 , table 7, and p. 88 , table 8 .

2 See Dodge and Benedict's report, p. 84, table 7, Subject III, January 26, 1914 . The average latency of eye reactions is given as $103 \sigma$. This is a misprint; the figure should be $183 \sigma$. The total average and the differences are figured on the basis of the latter value.

${ }^{3}$ This is due partly, at least, to the smaller differences in the last two periods and also to the fact that here fewer reactions enter into the computations of the probable errors.
} 
period 6 shows a decrease of 1.9 per cent. The total average effect is an increase of 10 per cent in the time of the eye reaction to peripherally appearing stimuli as the result of 30 c.c. of absolute alcohol.

There is, furthermore, a change in the mean variation as the result of the ingestion of alcohol. This is shown by an increased variabilitythat is, a larger fluctuation between successive reactions-which is greatest in periods 2 and $3,{ }^{1}$ in which the values are respectively +34 and +41 per cent. The paucity of data for period 6 makes the results for that period of slight value. With this subject, therefore, the eyereaction time shows a lengthening of from 12 to 13 per cent and an increase in variability from 34 to 41 per cent in the first hour and onehalf following the ingestion of 30 c.c. of alcohol. ${ }^{2}$

\section{REACTION TIME IN READING ISOLATED WORDS.}

In the word-reaction measurements the peripheral velocity of the kymograph drum on which the moments of exposure of the word and the reaction were registered was $100 \mathrm{~mm}$. per second; the individual reaction was therefore read by estimation to $0.1 \mathrm{~mm}$., that is, $1 \sigma .^{3}$ In table 10, which shows the data and summary of the effect of alcohol for this measurement, the unit used is therefore 0.001 second. This table presents the material by periods and, like the preceding tables, is divided into three sections, these giving the actual reaction averages, the differences, and the effect of alcohol by differences and percentiles, with the probable correctness of these true differences. The table contains no statement of false reactions-that is, the pronunciation of the wrong word-as it rarely occurred. This may be supposed from the usual reaction-time averages shown, as the mean variation within the 24 reactions of a single period fluctuates from 19 to $44 \sigma$ for normal periods, $i$. e., from 4 to 9 per cent of the reaction time. The average mean variation is practically 6.5 per cent of the average normal reaction time.

In striking contrast to the result found for the effect of alcohol on the eye reaction to peripheral stimuli, the word reactions following alcohol were undoubtedly faster on the average for all days than those for the same periods on normal days. According to the figures in the next to the last column, the average reaction time for the three normal days

\footnotetext{
1 The eye-reaction measurement was the seventh measurement in the eyele and came approximately 30 minutes after the beginning of the period; therefore, in period 2 the measurement was made 30 minutes after the taking of the alcohol.

${ }_{2}$ The particularly low average reaction-time of $159 \sigma$ for Subject VI on the second day in the first series of experiments (see Dodge and Benedict's report, p. 85, table 7) is deeidedly the smallest average in the first series of experiments with Subjeet VI. It is to be noted that if the average values for dose $A$ given in their table 8 (p. 88 of their report) were averaged, omitting this one, the result would be $216 \sigma$, which is the same value as that given for the first normal day. (See same table.)

${ }^{3} \mathrm{~A}$ typical record of a word-reaction experiment is shown in Dodge and Benediet's report, opposite page 101, in figure 22.
} 
Word Reaction.

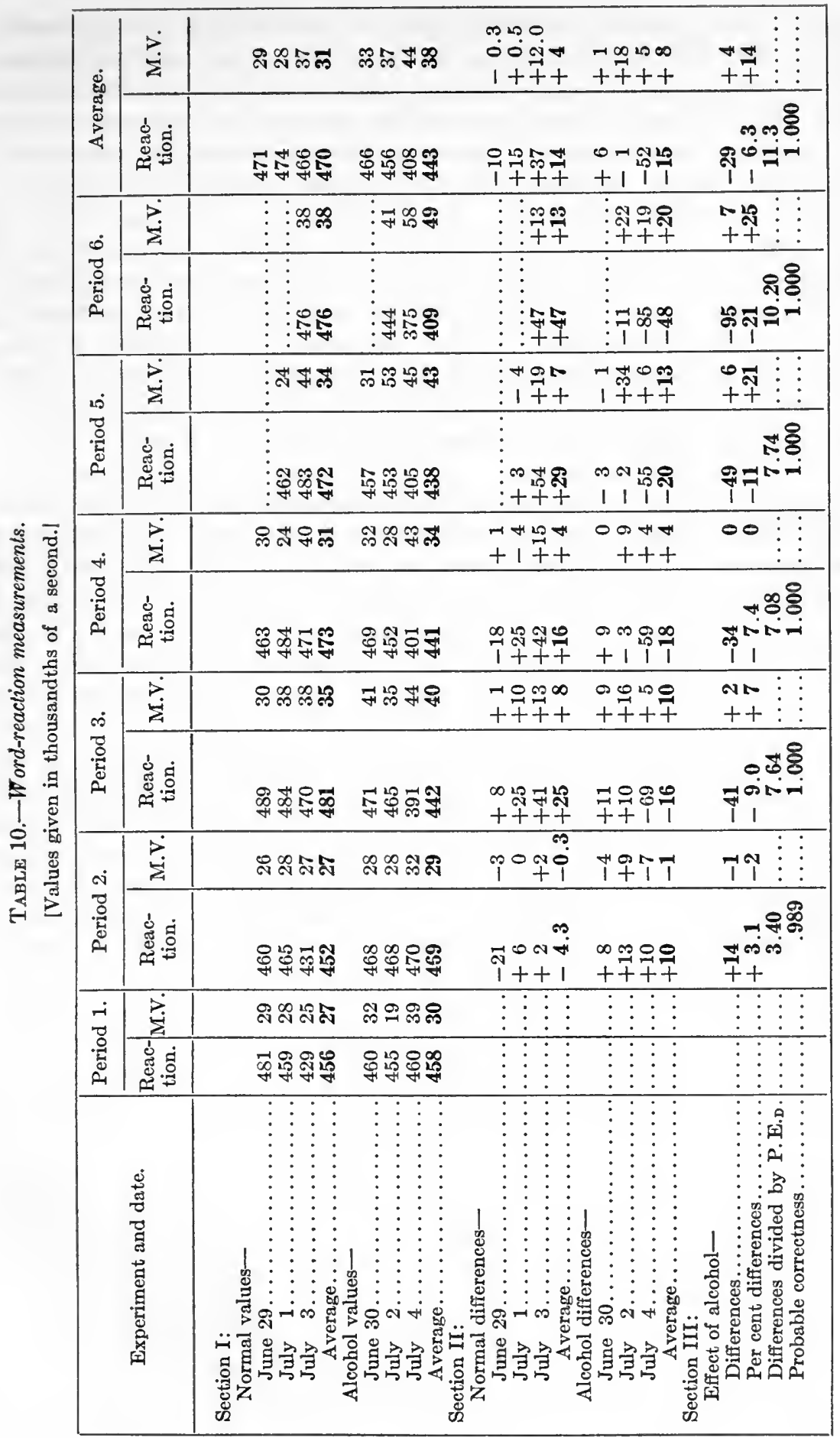


is found to be 471,474 , and $466 \sigma$, respectively, with a total average of $470 \sigma$. For the alcohol days the comparable averages are 466,456 , and $408 \sigma$, respectively, with a total average of $443 \sigma$. On the average, therefore, the word reaction following the taking of the control mixture is $27 \sigma$ longer than that after the alcohol dose. The mean variation following the alcohol is slightly larger, being $38 \sigma$ as compared with $31 \sigma$.

In terms of differences (see section II of the table) we have in the right-hand columnaverage differences for word reactions for the normal days of $-10,+15$, and $+37 \sigma$, with an average of $+14 \sigma$, and for the alcohol days $+6,+1$, and $-52 \sigma$, with an average of $-15 \sigma$. In other words, on two of the normal days (July 1 and 3), there was an average tendency in the periods which followed the taking of the control mixture for the reaction time to be longer than in the first period of the day, while on the first normal day, June 29, the reaction time at the beginning was rather long, $481 \sigma$, in comparison with the other first-period values in the series. The tendency shown on the last two normal days for the reaction time to be longer after the taking of the dose is also evident on the alcohol days June 30 and July 2, but not to so great an extent. On July 4 the average reaction for the first period, $460 \sigma$, is somewhat longer than would be expected, considering those for the previous two days. This was followed by other reaction averages for periods 3 to 6 , which are remarkably low, these being 391, 401, 405, and $375 \sigma$. The effect of these unusually rapid reactions following the rather long ones of period 1 is to give us an average difference between the first period and the succeeding periods of $-52 \sigma$. The average alcohol difference for all alcohol days, $-15 \sigma$, is thus greatly influenced by the result of July 4 . If we calculate the average effect of alcohol by the usual method, i.e., by subtracting the average normal difference from the average alcohol difference, we have, as a result, $-29 \sigma$, which, in percentiles, shows an average decrease in the word reaction of 6.3 per cent. It is further clear that the result would be in the same direction and almost of equal magnitude if we omitted the first normal day and the last alcohol day. The mean variation between the individual reactions is, on the average, increased after the alcohol to the extent of 14 per cent.

The results considered by periods show that there is a definite lengthening in the reaction time following alcohol in period 2 as contrasted with the same period on the normal days following the control mixture, the average reaction time in period 2 for the alcohol days being $469 \sigma$, and for the normal days $452 \sigma$. The differences on the three alcohol days are $+8,+13$, and $+10 \sigma$, respectively, with an average of $+10 \sigma$, as contrasted to $-21,+6$, and $+2 \sigma$, with an average of $-4.3 \sigma$ for the three normal days. The effect of alcohol is therefore $(+10)-(-4.3)$ or $+14 \sigma$, which in percentiles is +3.1 per cent. If we should omit the 
difference $-21 \sigma$ for the first normal day, June 29 , this difference being the only minus value in the group, the effect of alcohol would still be in the same direction, that is, a lengthened reaction for this period. The probable correctness, 0.989 , which applies to the difference +14 is so large as to indicate its trustworthiness. For periods 3, 4, 5, and 6 the normal differences are commonly plus and are generally very large, while those for alcohol are usually minus, exhibiting clearly the tendency for the reaction to be faster in the later periods following alcohol. The effect of alcohol in per cent for periods 3 to 6 , inclusive, is shown respectively as $-9,-7.4,-11$, and -21 per cent. The probable correctness values for periods $3,4,5$, and 6 indicate that behind these differences there is certain cause rather than chance cause. The differences are significant; the question for the following paragraphs to elucidate is what produces them. The mean variations do not show a consistent change in all periods.

Our subject is not mentioned by Dodge and Benedict as being different from the other members of the normal group in the word-reaction results, ${ }^{1}$ their results showing him to be in line with the majority in so far as the effect of alcohol is indicated by averages. On the other hand, the average differences and percentiles for both Subjects VI and IX show a shorter reaction time after alcohol, with the result that the average percentile effect of alcohol for the whole group with dose A is $0 .{ }^{2}$

The Dodge and Benedict minus differences for both doses A and B, indicating an increased reaction time after alcohol, are with all but Subject II quite small. There was a distinct tendency in the data of Dodge and Benedict for the reaction time for isolated words to increase gradually from period to period on normal days. If all the data for these normal days are averaged by periods we obtain, beginning with period 1 , the following series of values: $445,455,465,469,474$, and $507 \sigma$. A similar group of averages for the alcohol data for their normal subjects (dose A) produce the averages for periods 1 to 6 of 437, 445, $451,456,447$, and $435 \sigma$. The period averages given in our table 10 for word reactions compare favorably with those obtained from the previous series of measurements. Subject VI is, therefore, not peculiar;

\footnotetext{
1 Dodge and Benedict's report, p. 107, table 12.

2 The following correction should be made for Subject VI in Dodge and Benedict's report, page 103, table 10: February 12, 1914, which was an alcohol day (dose A) has through error been printed under the normal data. Furthermore, there were actually three periods on that day instead of two, these having the following average reaction-time values: 454,472 , and $458 \sigma$. In the pulse section of Dodge and Benedict's book (p. 218, table 40) and in our table 1 (see p. 13 of this monograph), February 12,1914, is shown as an alcohol day, dose A. Our table 1 was of course compiled from the original records. To place the data where they belong produces minor changes in results for Subject VI, as shown in tables 11 and 12, pp. 106 and 107 of the Dodge and Benedict report, with the final result for the group that the average effect of alcohol as shown by percentiles in the extreme right-hand column of table 12 is -5.8 per cent instead of -6.2 per cent. The average value for dose A, normal group, remains 0 . A complete checking of the entire Dodge and Benedict report reveals no other place where alcohol and normal data have been confused.
} 
he is consistent in the two series in showing in general a decrease in reaction time following the 30 c.c. of alcohol.

The word reactions, 24 in number, separated from each other by intervals of 10 seconds, required a much longer period with the same attention and cooperation on the part of the subject than the eye reactions did. The continuous repetition of the list of 24 words was tiresome. No doubt the test would have been much improved from the standpoint of the subject if the interval between reactions had been made 5 instead of 10 seconds. The subject indicated by his general attitude and remarks that he was always glad when this measurement was over. The first-period values show a regular tendency to diminish slightly from the first to the fifth day, the values being $481,460,459,455$, and $429 \sigma$ for the first five days in order, with $460 \sigma$ for the sixth day. This tendency is not as well borne out in the other periods of the same days in the general averages for periods $2,3,4,5$, and 6 . The three alcohol days show a decrease from first to last, the values being 466,456 , and $408 \sigma$. The decrease on the normal days is not so regular, the values being 471,474 , and $466 \sigma$. These results suggest a clear practice effect in the word reactions.

It is important to note that the average reaction time for the last period of a day is always shorter than that for the next to the last period of the same day. For the normal days in order we have lastperiod values of 463,462 , and $476 \sigma$, with an average of $467 \sigma$, and next to the last period values of 489,484 , and $483 \sigma$, with an average of $485 \sigma$. The last period is therefore on the average $18 \sigma$ shorter. For the alcohol days in order we have last-period values of 457,444 , and $375 \sigma$, with an average of $425 \sigma$, and next to the last-period values of 469,453 , and $405 \sigma$, with an average of $442 \sigma$. For alcohol days the last period is therefore on the average $17 \sigma$ shorter than the next to the last period. The difference between the last period of the alcohol days and those preceding is almost identical with that for normal days, notwithstanding that the alcohol word reactions are shorter. Even on the alcohol day, July 4, when the reactions in periods 3,4 , and 5 were so surprisingly short, 391,401 , and $405 \sigma$, the last period is still $30 \sigma$ shorter, being $375 \sigma$. These conditions are proof that the word-reaction test as used was not well adapted to the alcohol research, for the subject's attitude (e. g., his desire to finish the last word-reaction test) influenced the reaction time to a very marked degree.

The results obtained for the eye reaction are in exactly the opposite direction to those for the word reaction, for in the measurements for the eye reaction the values for the last period are always longer than those of the preceding period, the average increase in the last period being for both normal and alcohol days $13 \sigma$. It is therefore perfectly clear that in the measurement of the word reaction the subject was not consistent in his attitude toward the task to be performed. 
His best effort was made at the first and the last of the experimental days. He was capable of very rapid responses. In the measurement as used he did better after alcohol, except that the alcohol served to decrease the speed of reaction in the measurements which came approximately $\mathbf{1 5}$ minutes after the taking of the dose. It is not for the writer to pronounce at present whether the alcohol produced a speeding up of the reaction process or a relief from what the subject regarded as the tedium of the experiments, which change in attitude allowed him more naturally to do his best. The results from the other measurements must help to answer this question.

\section{MEMORY.}

The memory measurement was a modified form of the common method of measuring the total number of repetitions required for a subject to learn a series of words so as to recall them in order. The difficulty in the actual use of the method was a common one; that is, that the different series of words did not offer comparable memory material. This condition existed in spite of all precautions. ${ }^{1}$ As a result of the experience of Dodge and Benedict, it seemed that more consistent results might be obtained from the use of one group of word series. Accordingly the same series of words was used in the first period of each day, and another series of words for the second period of each day, and so on. The practice of the previous authors had been to use a different series of words for each period of experimentation, without repetition in other periods of the same series. ${ }^{2}$ In the repetition experiments with Subject VI, word series No. 11 was used in the first period on each of the six experimental days, word series No. 12 in the second period on each day, and so on.

On July 2 series 14 was inadvertently omitted and hence the remaining series were moved forward one period each on that date. The word series employed and the order used on each experimental day are as follows:

Series No. 11, period 1.- -nose pest stem wool prow barb star cord hail fool hash rain.

Series No. 12, period 2.-surf debt verb fork tent kale unit case year bell wick hall.

Series No. 14, period 3.-dose ring wave grip turf bone must host crow pane lake sign.

Series No. 15, period 4. - arch gone lump quip mole gold brat rail word bill soul clot.

Series No. 16, period 5.- - wire town page feet mill inch wine neck surf road lion door.

Series No. 17, period 6.-pond knot desk blow fact alum seed loot clay gate moth rack.

Each horizontal line of 12 words was carefully printed on a strip of paper which, when used, was fastened around the kymograph drum. From the beginning of one word to the beginning of the next was a distance of $4 \mathrm{~cm}$., representing a time duration of 4 seconds when the kymograph was in motion. The individual word itself occupied a

\footnotetext{
1 Dodge and Benedict's report, p. 130.

2 Dodge and Benedict's report, p. 132. The numbers for the word series are given in table 20 (p. 131) in a separate column.
} 
space of $2.5 \mathrm{~cm}$. During the test these words were exposed through a slit $14 \mathrm{~mm}$. wide. From the position of the subject the kymograph moved in a clockwise direction (from left to right). The exposure of the word was, therefore, from right to left, that is, from end to beginning. The last letter of the particular word appeared first and so on until the first letter was finally seen; the last letter of the word was of course by this time covered from view and had to be retained in memory. The voice key was held continuously in position and the subject was instructed to speak each word as soon as possible. Two complete revolutions of the drum, that is, two exposures of the word series, were allowed. At the time of the second exposure the subject was told to try to speak each word in order just before it began to appear, or with as little of it appearing as possible. While in position, immediately after the test, the kymograph record was carefully marked so as to show just where the first word began to appear and just where it had entirely appeared. From this latter mark the record was afterwards measured off in blocks of $4 \mathrm{~cm}$. each, these respective positions indicating the time when the respective words had entirely appeared to the subject. From figure 7, which is a typical memory measurement record for this series of experiments, these points may be seen and better understood. The short vertical line at the extreme right of the record marked with the letter $a$ indicates the position where the first word in a series began to appear, that is, where the last letter of the word began to be visible to the subject through the slit at this point. The vertical lines marked $B$ are at the position where the first letter of the word was entirely visible to the subject. From here, measuring to the left in blocks of $4 \mathrm{~cm}$., we have other positions representing the completion of exposure of other words. All of these short vertical lines were put in later in elaborating the record. The reactions are indicated by the notches in the horizontal line of the record. $R_{1}$ and $R_{2}$ for reactions 1 and 2 are marked in several places. Usually $R_{1}$ is to the left of its respective vertical line $B$, while $R_{2}$ is to the right of this line, showing that at the second exposure the subject recognized and was able to pronounce the word before it was entirely seen. If $R_{2}$ is $25 \mathrm{~mm}$. to the right of its vertical line $B$, it indicates that the subject had completely memorized and pronounced the word before any part of it was visible. There is no such case shown in the part of this record which is reproduced;. The nearest to this condition is in the second word in the series at the top of the figure. ${ }^{1}$

There are two ways in which these memory records may be treated. The time distance may be measured (1) between the two reactions $R_{1}$ and $R_{2}$ for each individual word, or (2) from the second reaction to that

\footnotetext{
1 The experimenter occupied a position just opposite the subject and marked the record from his point of view, as can be seen if the figure is revcrsed. Incidentally, from the time marked under each test $(9.10)$, (10.00), etc., the length of the experimental period will be evident. This particular record is a part of the one for July 3 , a normal day.
} 


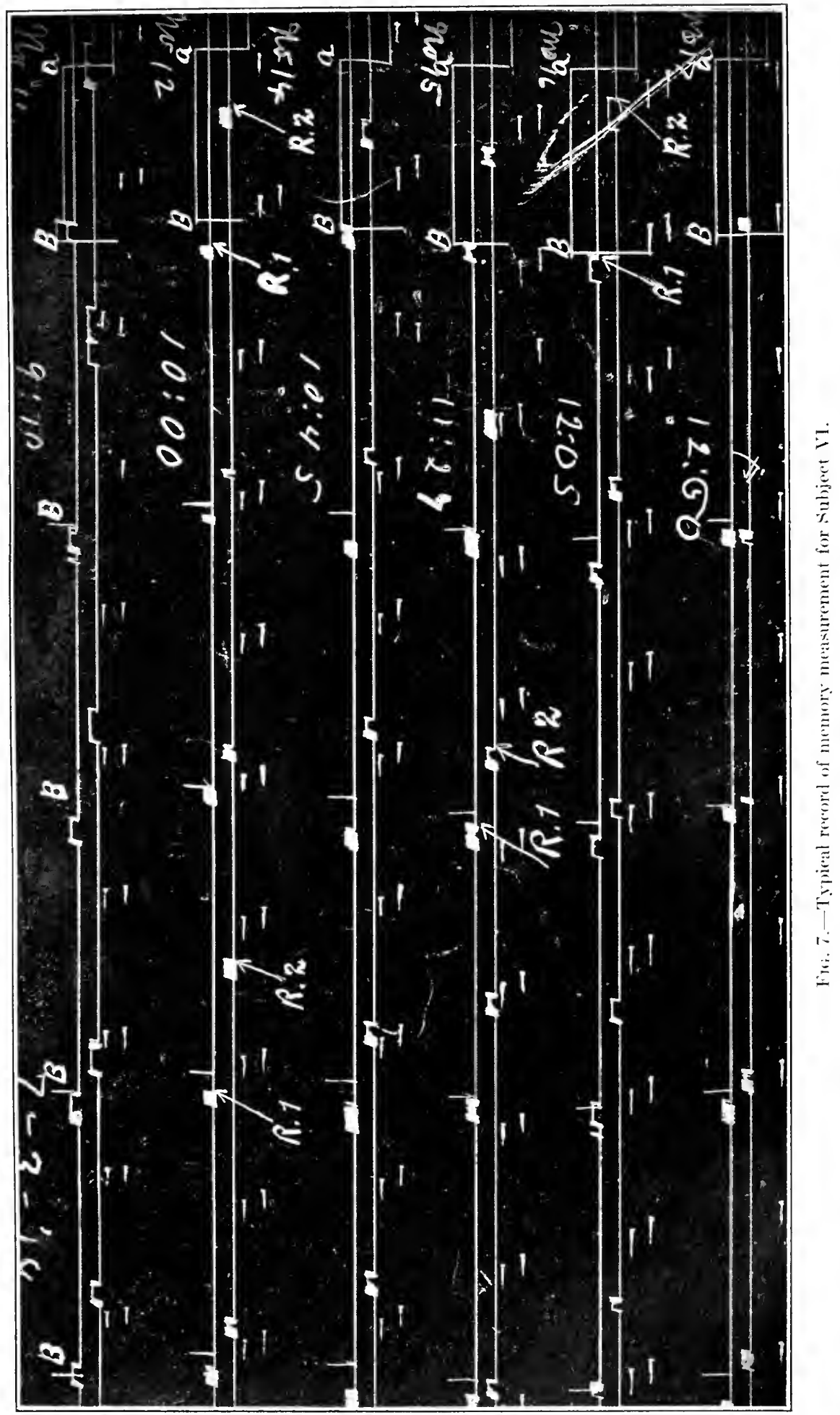



point on the record designated by $B$ where the word was entirely visible to the subject. The first treatment was the one employed by Dodge and Benedict in their series. The time distance between $R_{1}$ and $R_{2}$, provided the second reaction occurred at a point earlier than the first, was taken as the "saving" due to the influence of memory. Complete memorization would mean that the word was spoken the second time before any part of it came into view. The score would be atleast 250, and in most cases longer, depending upon the position of the first reaction.

Using the same series of words each day and on successive days enables, of course, the more or less permanent memorization of the word series; hence we have minus preliminary reaction results, $i$. e., reactions which show that the subject spoke the word during the first revolution at some time before it had been entirely exposed. This of course might happen in rare instances even with new material. The individual letters of a word vary considerably in width, the letter $m$, for example, in the type used for our lists, being $10 \mathrm{~mm}$. wide, while $b$ is $5 \mathrm{~mm}$. wide. In the exposure of the word "mill" the subject begins to see the final letter, which is the first letter of the word, sooner than he would if the word exposed was "bill." With the latter word he can not be entirely sure of its identity until the very last $2 \mathrm{~mm}$. of the movement exposing the word have been completed, for he is not sure that the word is to be "bill" or "pill," and must wait for the first clue to its identity.

This phenomenon of speaking the word the first time before the exposure has been entirely completed increases from day to day in our data, this occurring the following number of times: 1, 7, 12, 15, 9, and 31 for the six days in order, respectively. The increase is fairly regular, except on the fifth day, July 3 , when there were only 9 of these minus preliminary reactions. ${ }^{1}$ The factor of residual memory is therefore evident, even though we employed only two revolutions per test. Obviously, if the subject produces minus reactions and then at the time of the second revolution of the drum waits for a part of the word to appear before the process of recall is complete and he speaks the word, ${ }^{2}$ his "saving" as figured from reaction to reaction will be considerably reduced. The $R_{1}$ might be so early that if the subject waited for the word to appear in part before speaking it the second time, $R_{2}$ would show a very minor "saving" or even minus saving value. Cases of this sort (minus "saving"), where the $R_{1}$ occurred at a position to the right of $R_{2}$, are to be found in the series.

Since the normal day, June 29, was the first experimental day and the measurement on that day would therefore not be affected by the

\footnotetext{
1 The mental attitude of a subject not scientifically trained for such experiments will unavoidably shift from time to time in spite of instructions. On this day there was evidently less effort to speak the word as quickly as possible in the preliminary reactions.

2 This was his tendency, for in the experiments here reported only 5 reactions show that he pronounced the word before any part of it had been seen.
} 
factor of residual memory, it is to expected that the average $R_{1}$ time would be proportionately longer than that on subsequent days. The $R_{1}$ average reaction times for the six days in order of experimentation are, respectively, $21,22,9,11,15$, and 2 hundredths of a second. ${ }^{1}$ The first, third, and fifth are for normal days, with an average of 15 , while the average for the alcohol days is 12 . The advantage is therefore with the alcohol days, but it is not large. Theoretically the "saving" on the alcohol days would be somewhat diminished because of the greater opportunity for the factor of residual memory to play a rôle in shortening the reaction time of $R_{1}$ and because the treatment of the record is such as to make this position of $R_{1}$ the starting-point from which to measure the amount of "saving."

Table 11, which is arranged in the usual form by periods and sections, presents the memory data computed on the basis of the "saving" between the first and second reactions as previously discussed. The general average "saving" for the different days is given in the next to the last column in section I of table $11 .^{2}$ On every alcohol day the average "saving" is greater than that for any of the normal days. The general average for the normal days is 87 , for the alcohol days 106 , with an average mean variation for both of 34 .

Comparing the averages for the periods (see section I), we find that those for the alcohol days are consistently larger in every case, period for period. Normal and alcohol days alike show the greatest "saving" in the first period, this agreeing with the results found by Dodge and Benedict for their normal subjects, to which attention is called in Appendix III of this publication. ${ }^{3}$

Since the "saving" on the first period is quite uniformly larger than in succeeding periods of an experimental day, the differences (see section II of table 11) are almost invariably minus values. These are smaller on the alcohol days, with the result that the effect of the alcohol, as shown in section III of the table and determined by subtracting: normal differences from alcohol differences, is in per cent $+10.9,+2.5$, $-5.9,+28.0$, and +57.0 for periods 2 to 6 . The average is +9.0 . The probable correctness is small for periods 2,3 , and 4 , where the alcohol effect is usually most prominent. There is no consistent change in the mean variation.

From the data in table 11 it is evident that the "saving" is somewhat greater after the alcohol than after the control dose, notwithstanding the fact that the alcohol days were slightly handicapped by the fact that residual memory reduced the "saving" score.

The second method for the treatment of the record, as suggested on page 68 , consisted in measuring the time distance between the posi-

1 These averages do not include the reaction time during the first period of the different days, but only that in the periods which followed the giving of the control dose or the alcohol dose.

${ }^{2}$ These values are averages for their respective horizontal lines, omitting, of course, the firstperiod value.

OSee p. 140. 


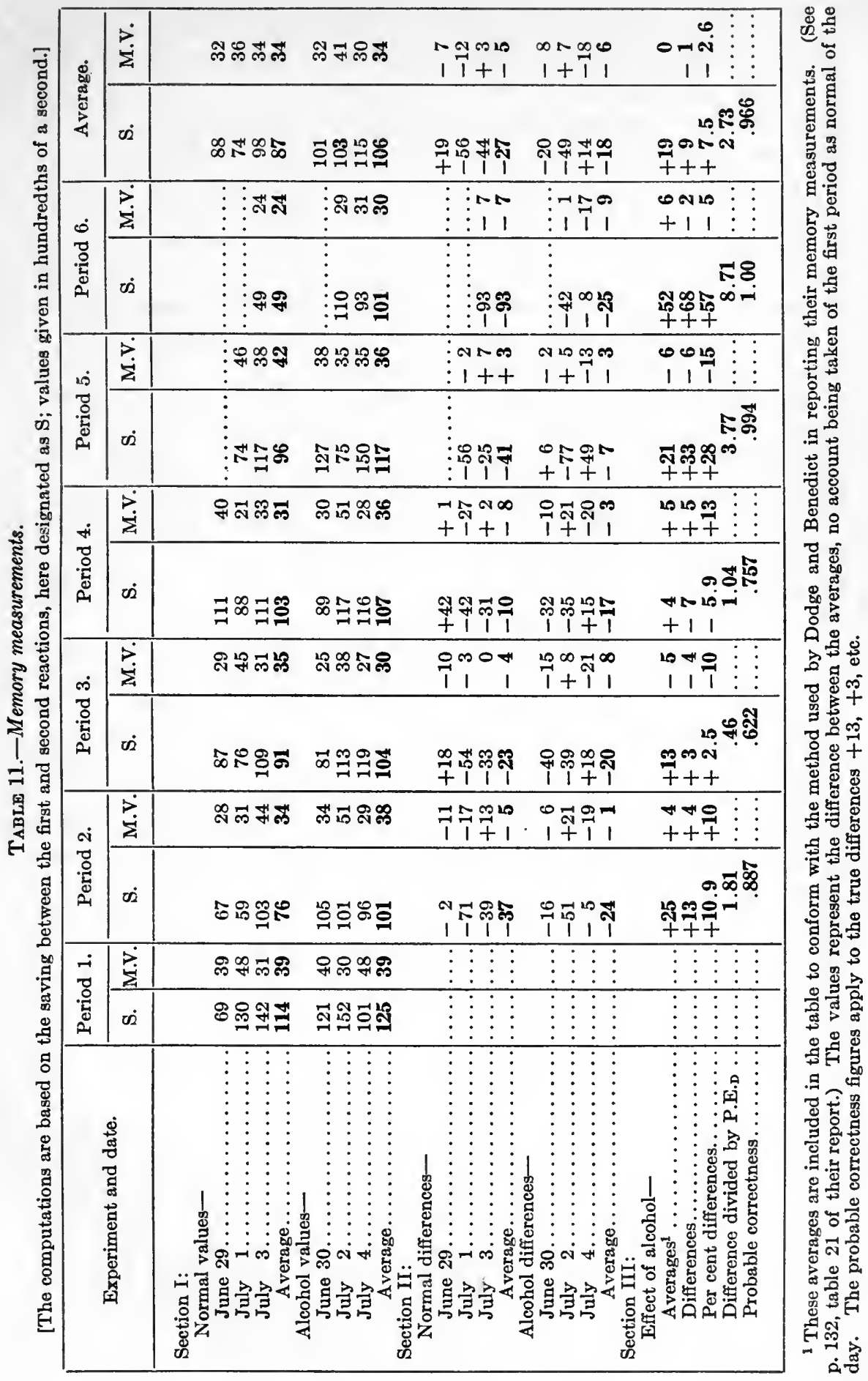


Effect of Alcohol on Psycho-Physiological Functions.

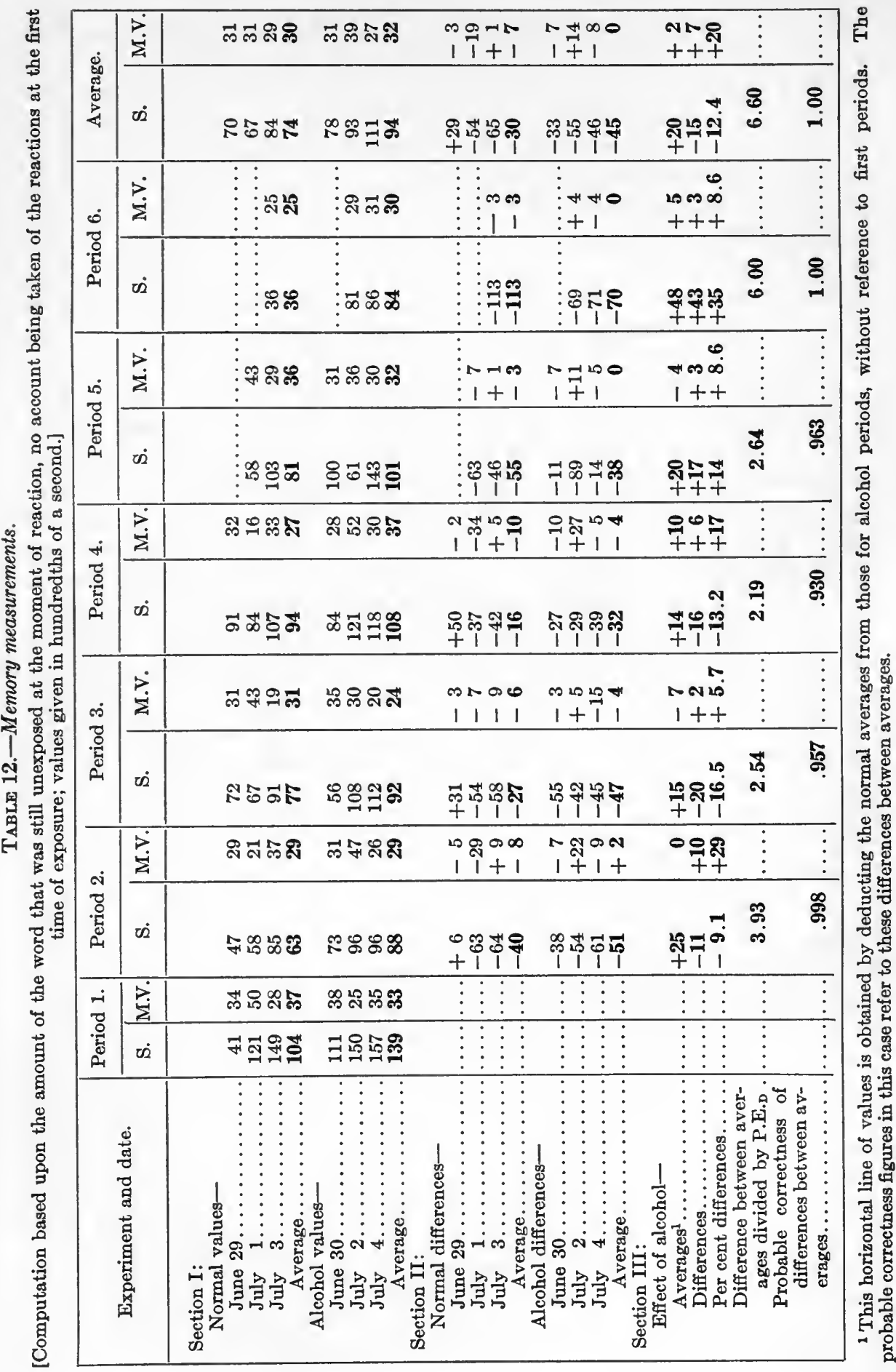


tion of the second reaction and that point which marked the complete exposure of the word. By this method no account is taken of $R_{1}$ or its position relative to the exposed words. If at the time of the second exposure the subject can speak the word before any part of it appears, he would have a score of 250 ; otherwise he would get credit for just that part of the word which is not exposed at the time of the second reaction. This does not of course eliminate the factor of residual memory, but on the other hand it does not oppose this factor to that of the "saving" which we desire to measure. If residual memory was present at the time of the first reaction so as to shorten or even to make it occur before the exposure of the word was complete, the second reaction should be still earlier than otherwise would be expected.

The data treated in this manner are presented in table 12. Referring to the column of averages at the right in section $\mathrm{I}$, we see clearly that the alcohol values are larger, particularly on July 4 . The average for normal days is 74 , for alcohol days 94 , with a difference in favor of the alcohol values of 20 . The complete exposure of a word requires 250 of our units. On normal days, therefore, the second reaction occurred on the average at a time when the word had been $\frac{176}{250}$ exposed, as against $\frac{156}{250}$ for alcohol, that is, approximately 70 and 60 per cent. The memory score, with the exception of the first normal day, June 29 , is larger for the first period; the differences are therefore nearly all preceded by the minus sign. They average -30 for the normal days and -45 for the alcohol experiments. The results for the first normal day play a particularly prominent rôle in sections II and III of the table. On the first day the score was especially low in the first period, being only 41 . . All the differences have the plus sign on this day, with the result that the average differences and per cent differences show a minus effect of alcohol for periods 2,3 , and $4,{ }^{1}$ and a total average difference of -15 , or a per cent difference of -12.4 . Since the value for period 1, June 29 , is so decidedly out of line with the first-period values for the other days, while the scores for periods 2,3 , and 4 on June 29 are practically what would be expected judging from the other normal days, July 1 and 3 , it is not thought just to trust the method of differences here, but rather to consider the simple difference between averages. The average 63 for the normal period 2 is deducted from the average of 88 for the alcohol period 2 , resulting in a difference of +25 (see section III). The differences between averages for the other periods are $+15,+14$, +20 , and +48 , with an average for all periods following the dose of +20 . The probable correctness figures apply to these differences and are in every case of such size as to give them a good degree of reliability.

The memory data, presented in whatever way we chose, shows that with this particular memory test and in the particular form used there is a better performance following the alcohol. This confirms the re-

${ }^{1}$ It should be noted that there were only 4 periods on June 29. 
sults obtained with Subject VI and with the other normal subjects in the former series. It does not, however, explain why the memory results after alcohol should be opposed to those found for most other processes. It is noteworthy that on the last day, July 4 , the subject obtained a conspicuously higher score than on any other day. His best work in this test came in periods 4 and 5 of the day, ${ }^{1} i$. e., towards the last of the session. These same features were striking in the results of the word-reaction test, which employed almost the identical apparatus used for the memory work and demanded somewhat the same attention and cooperation on the part of the subject. ${ }^{2}$

\section{SENSORY THRESHOLD FOR FARADIC STIMULATION.}

The Kronecker inductorium, which was calibrated for the Nutrition Laboratory by Professor E. G. Martin, and the accessory apparatus recommended by him for the determination of the sensory threshold for faradic stimulation, were used in the same general arrangement as described by Dodge and Benedict. ${ }^{3}$ The only change consisted in the introduction of a key for the making and breaking of the primary circuit of the inductorium which was mechanically operated by a small motor at the regular rate of two breaks per second. The adoption of such a mechanical key offered two chief advantages:

(1) The subject could be near the apparatus (of course it was not in his direct view) and at the same time be ignorant of the exact moment when to expect the stimulation. The key was placed in a sound-proof box in the dark room of the laboratory and operated continuously during the test. Its action could be judged from the operator's point of view by watching the needle of the ammeter. ${ }^{4}$ The shocks were controlled in intensity by the horizontal movement of the secondary coil and were further delivered to the fingers of the subject or not, according as the short-circuiting key in connection with the secondary coil was opened or closed. The operator constantly had his hand on this key, which could be used noiselessly.

(2) The increase in the rapidity and the regular rhythm of the shocks seemed to be more favorable for attention than an isolated shock, which may be easily confused with pulse-throb and muscle-twitches, particularly when the shocks are near to threshold value.

The most unsatisfactory point in our use of this measurement was the determination of the tissue resistance, this being necessary to

\footnotetext{
1 This does not take account of period 1, which is set off from the rest of the records as preceding the dose; furthermore, the factor of residual memory seems to have had a much greater effect on the results in the first period.

2 Subject VI did not employ regularly the method of fitting the words into a story during the time of their first exposure. If an average is made for the "saving" on the first word in every series on each day, the value 179 will be obtained; and in like manner the values for the second to the twelfth words will be in order as follows: $139,100,102,83,80,73,99,110,93,83,107$. Word series No. 11 was by far the best remembered from one day to the next.

${ }^{3}$ Dodge and Benedict's report, p. 95, fig. 14, and p. 137.

4 The current used in the primary circuit was 0.5 ampere.
} 
determine, according to Martin's formula, the number of $\beta$ units required for stimulation. As the tissue resistance is without doubt almost entirely due to the outside horny layer of skin, it is regarded as outside resistance like the resistance of the secondary coil of the inductorium, or the resistance of any unit put in the secondary circuit. The measurement of the tissue resistance is accomplished in practice by balancing on a Wheatstone bridge. In the very simple form used, the secondary of a Porter inductorium was employed as a source across a slide wire. A telephone was connected to the slide and also at a point between the known arm of the bridge, 20,000 ohms, and the arm which contained the tissue to be measured. The balance point was extremely indefinite. Practically it was necessary to endeavor to match intensities of tone on both sides of what seemed to be the indicated balance position for the slide. This method must be called in question, since the tone on one side of the balance position of the bridge has quite a different quality from that found at the other end. These quality differences play a rôle from the standpoint of intensity when the telephone is used as an indicator in the bridge, because of the characteristics of the telephone membrane. It was of course recognized that the tissue has not only resistance but capacity and that there was present a fluctuating body current. At the time of experimentation we were under the misapprehension that it was not practical to balance for capacity along with the resistance.

The tissue-resistance measure was usually about 5,000 ohms. The fingers were immersed to a depth of $2 \mathrm{~cm}$. and this condition was kept quite constant, as it was recognized that theoretically the amount of tissue immersed would change the resistance value. To balance about $5,000 \mathrm{ohms}$ tissue resistance against a known resistance of $20,000 \mathrm{ohms}$, as was done in this case and also in the measurements of the previous series, ${ }^{1}$ is theoretically not good practice. The balance position on the slide wire under these conditions is close to one end of the bridge. The observational error at the end of the slide wire of the bridge is proportionately quite large, as a change of $2 \mathrm{~cm}$. in the determined balance point would here be of much more importance on the resistance figure. The employment of a known resistance of $20,000 \mathrm{ohms}$ was an expedient, as in practice the balance point was much sharper than when using a known resistance of 5,000 ohms in its place. Probably this condition was due to a larger proportional effect of the finger capacity with a lower resistance.

Another point to be criticized in the technique is the order in which the measurements were made. As the tissue resistance is due to the outside horny layer of skin, evidently there will be a decrease in resistance when the finger tips become somewhat soaked with salt solution. It is regrettable on this account that the order of our procedure in refer-

1 See Dodge and Benedict's report, p. 137. 
ence to included secondary resistance was not reversed, since the tissue resistance decreases during the first four or five minutes after the immersion of the finger-tips in the electrodes. Our first measurement should have been with the 40,000 ohms included in the secondary circuit, and the last measurement with the tissue only in the circuit followed by the Wheatstone-bridge measurements of tissue resistance, which in the test always camelast. Thus, any change in tissue resistance would not have exercised so large an effect on the first threshold values taken. ${ }^{1}$

While the measurement of tissue resistance is thus admittedly poor and the procedure is not without fault, yet the routine from period to period and from day to day in these experiments was always the same. Hence, the value of the results for a comparison of the alcohol and nonalcohol days should not be much impaired. The data and results are incorporated in table 13, which presents them by periods, the table being divided into sections according to the usual form. In order to have data which compare directly with those presented by Dodge and Benedict for Subject VI, values for $Z$ have been included in the table. ${ }^{2}$ Since with the technique used threshold determinations were not multiplied within the period, no mean variations are given or figures for probable correctness of differences.

The averages for normal days to be found in section $\mathrm{I}$ in the last two columns of the table, and which exclude period 1 , give the impression that there was the reverse of a practice effect. The number of $\beta$ units required to stimulate increased from day to day. ${ }^{3}$ But this is not evident in the thresholds for period 1. The values for the normal days average $356 Z$ or $184 \beta$ units. This average is perhaps somewhat larger than would be expected for Subject VI from the data given by Dodge and Benedict in their table 22 for normal days October 7, 1913, and March 2, 1914. It is thus to be observed that the use of the mechanically operating key with more rapid rythmical shocks did not serve to reduce the threshold current strength. The average of 184 for $\beta$ is not, however, conspicuously large when compared to the values reported by Dodge and Benedict for some other of their normal subjects. The fact that Grabfield, ${ }^{4}$ in determining the average threshold for 135 psychopathic cases, found the average to lie at $223 \beta$ and came to the conclusion that a threshold greater than $175 \beta$ may be considered as definitely pathological, can only be interpreted as indicating a difference between the apparatus or technique employed by him and that used at the Nutrition Laboratory.

\footnotetext{
1 Grabfield (Boston Med. and Surg. Journ., 1914, 171, p. 883) assumed a tissue resistance of $2,100 \mathrm{ohms}$ and omitted the measurement entirely.

2 See Dodge and Benedict's report, p. 140, table 22, Subject VI, October 7 and 14 . It is understood that the $Z$ values given here, as in our table, are the threshold measurements, with tissue resistance only included in the secondary circuit.

3 Martin, Withington, and Putnam, Am. Journ. Physiol., 1914, 34, p. 97.

Grabfield, Boston Med. and Surg. Journ., 1914, 171, p. 883.
} 


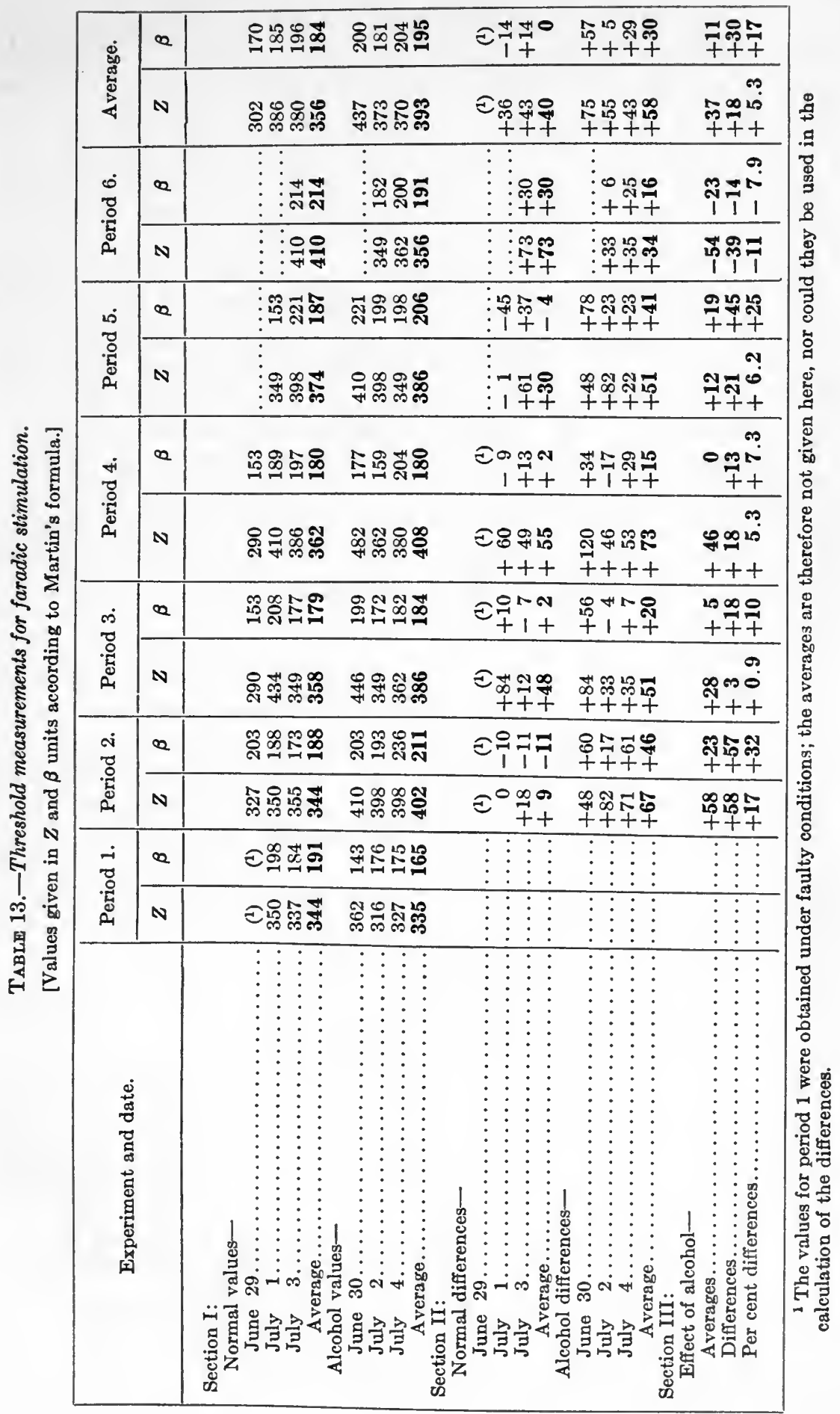


For normal days there is no prominent change from period to period. The averages for $\beta$ as given in the table are 191, 188, 179, 180, and 187 for periods 1 to 5 , respectively. Period 6 is conspicuous in showing a larger value (214), due evidently to the fact that on July 3 the threshold level was considerably higher. The alcohol days show a decided difference with a marked rise in the threshold after the ingestion of the alcohol. Beginning with period 1 , the $\beta$ values for these days are 165,211 , $184,180,206$, and 191, the average value after alcohol being 195, in contrast to the average for normal days of 184 . The rise in the threshold is most pronounced in period 2, which represents an interval of about 10 to 12 minutes after the taking of the dose of alcohol. Values for $Z$ show clearly that an increase in the strength of the current was necessary to stimulate after the alcohol. The average $Z$ value of 393 may be contrasted with the average of 356 for the non-alcohol days.

In section III of table 13 the effect of alcohol is given in averages, differences, and percentile differences. In periods $2,3,4$, and 5 , all signs are plus. There is one zero, but most of the values are comparatively large if judged on the basis of the alcohol effect on other measurements. The depressive alcohol effect is definitely prominent in period 2, the increase in the strength of the current necessary to stimulate amounting to +32 per cent for $\beta$, and 17 per cent for $Z$. In the case of $\beta$, which is of course the most trustworthy measurement, as was stated previously, the depression decreases progressively in periods 3 and 4 , the values being +10 and +7.3 per cent. The values for $Z$ are irregular. In connection with the results for periods 5 and 6 , it is significant that the first two normal days concluded with a very low threshold, $i$. e., both show $153 \beta$, while the last normal day concluded with almost the highest threshold found, 221 and $214 \beta$ for the same periods. It is impossible, of course, to say whether theresults for period 6 show, according to the statistical presentation, a large threshold due to extraneous factors or are an alcohol effect.

In conclusion, the ingestion of 30 c.c. of alcohol is found to decrease the sensitivity of the nerve endings in the finger tips to electrical stimulation by the faradic method, as was the case in the first series with this subject. The decrease in sensitivity is of such an amount that on the average an additional strength of electrical stimulation of 17 per cent $(\beta)$ is required in order to arouse sensation. This depression is most prominent in the periods immediately following the taking of the alcohol, in which it amounts to 32 per cent $\beta$, and 17 per cent $Z$. In periods 3 and 4 the decrease is not so large as in period 2 or in period 5 . In period 6 the effect is in the opposite direction, indicating greater sensitivity. 


\section{EYE MOVEMENTS.}

The general apparatus employed in this measurement was the same as that for the eye reactions, and these two tests followed each other in quick succession. There was not the slightest change in the technique from the methods used in the previous research. On a black field two white dots, separated by $40^{\circ}$ on the arc of vision, served as the fixation points. The falling of a shutter which allowed the light to fall upon the eye revealed, at the same moment, the white dot at the right. The appearance of this dot was the signal to the subject to begin the series of movements. The use of such simple fixation marks has the disadvantage that as there is no practical need for looking accurately at them, as one would do in reading, the subject after some practice may become negligent and slight the fixation of them, thus decreasing the amplitude of his eye movements. ${ }^{1}$

The tendency to disregard accuracy of fixation of the marks is clearly indicated in the photographic record, for, as Dodge has pointed out, the eye, in looking from one mark to another which is a considerable distance away, accomplishes this by one long "saccadic" movement, followed by a small readjustment, which we may term corrective movement. These corrective movements tend to become not only smaller in size but fewer in number and finally to disappear from successive records as the subject becomes more and more used to the measurement. There must be continual emphasis laid upon the necessity for the subject to look accurately at the fixation mark, and stress of this point by the operator may not always be successful in holding the subject to careful work. Unfortunately, not realizing adequately the extent of this tendency, we placed speed before accuracy in our instructions, whereas the emphasis should have been reversed. It is probable that speed should not have been mentioned with this subject, since he not only neglected careful fixation of the marks, but at times seemed to disregard them entirely, with the result that the eye-movements were of very irregular amplitude, mostly far short of the desired $40^{\circ}$.

To make clear the difficulty in dealing with these records and the impossibility of presenting the data in exactly the same form as that given by previous authors, 7 eye-movement records have been placed together in figure 8 . The records, which were taken on photographic plates, $2 \frac{1}{2}$ by 7 inches, are to be read from the bottom upward. The beginning of the first vertical line represents the moment when the light was turned on the eye by the falling shutter, which at the same

${ }^{1}$ A technique used by Diefendorf and Dodge (see Brain, 1908, p. 458) would doubtless meet this difficulty. They exposed in succession isolated numerals in two different areas of the field about $25^{\circ}$ apart. The reading of one numeral by the patient was the signal for the operator to cover it and to expose another on the opposite side of the field. This provided a good and sufficient reason for looking carefully at the marks exposed and made the eye movements between merely an incident which the subject performed without any thought of its being the important feature of the measurement.

2 Dodge, Psychol. Bull., 1916, 13, p. 422. 
time revealed the mark at the right to which the subject was to move his eye. The movement of the eye to this mark is shown in the first short horizontal line to the right connecting the first vertical line with the second vertical line. These vertical lines are of course made up of dots, the light being interrupted by the tuning fork. These dots would appear individually if the plate had been falling at a faster speed, as was the case when the record of the eye reaction was taken. Having seen the mark at the right, the subject looks to the one at the left, which was placed at a distance of $40^{\circ}$ on his arc of vision. The line of dashes connecting show the course of the movement and its speed, as each dash with one interspace represents 0.01 of a second. From the left the eye again moves to the right, and so on throughout the period of 5 seconds allotted for this series of movements.

The record at the extreme left $(A)$ in figure 8 may be taken as a typical eye-movement record. ${ }^{1}$ It was obtained in the first series of experiments for this subject on February 12, 1914, and is better than any record which the subject made in the second series and also better than 80 per cent of his earlier records. The vertical lines (periods of fixation) which separate the movements show that in almost every case there was readjustment, that is, correction for accurate fixation, following the main movement. ${ }^{2}$ The correction indicates that usually the saccadic movement was not sufficient to bring the line of regard to the mark. Such correction Dodge has designated as "plus correction," and it is a normal phenomenon. The six other records shown in figure $8(B, C$, ' $D, E, F$, and $G$ ), which are for July 4 , periods 1 to 6 in order, show clearly a general appearance which is different from record $A$. There are almost no corrective movements at the end of the long eye movements; the amplitude is irregular and nearly always short. There are very frequent breaks in the records caused by winking (for example, see $W$ on record $B$ of figure), a factor which gave considerable difficulty not only in this measurement but also in the lid-reflex records. The photographic tracing immediately preceding a wink, if part of a vertical line, is usually heavy; if it is part of a horizontal line there is a curve downward, showing a tendency for an upward movement of the eye.

The records were nearly all legible, but the irregularity exemplified in those shown, which is typical for this series, made it evident that if the records were to be used it must be on a somewhat different basis from that in the previous research, as we were dealing with many different amplitudes of movement. In the six illustrated records from this series of experiments (See $B$ to $G$ ) it is plain that the first movement to the left is usually of fairly regular amplitude. If we use record $a$ as a standard for amplitude, measurement shows that the amplitude in

1 The first of the record is slightly complicated, as it was re-exposed and shows part of a second series of movements. See also Dodge and Benedict, p. 154, fig. 27, for another typical record.

2 The corrections were mcasured in millimeters, converted into degrees, and recorded in the tables of Dodge and Benedict's report. 


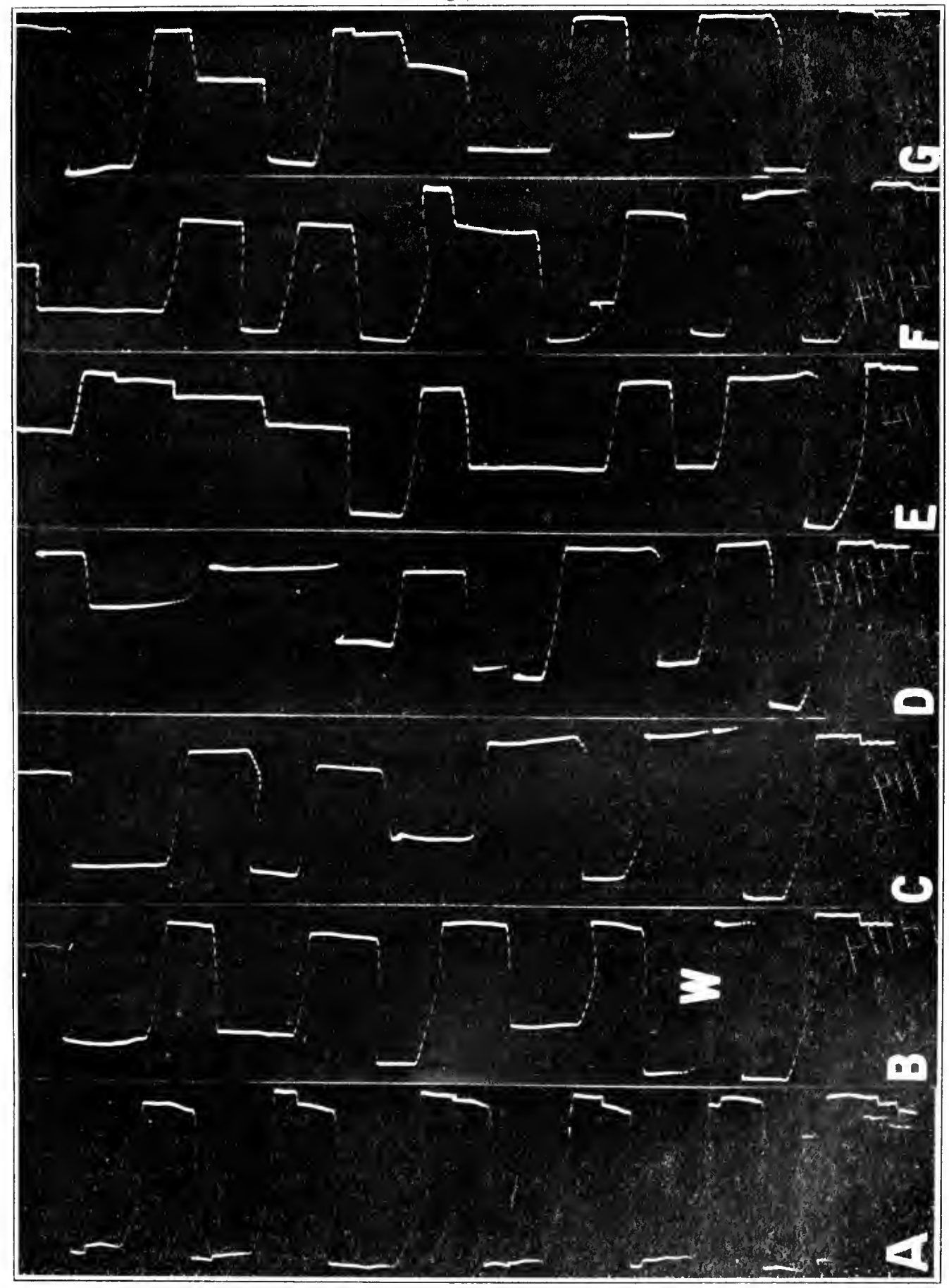


the first left movement of the others is about $40^{\circ}$ (usually a little less). The records in the figure are typical of the availability of this first left movement throughout the series. The first movement to the right which succeeded this, while often definitely less than the $40^{\circ}$ amplitude and without correction, was also in 58 per cent of the cases accompanied by a wink, ${ }^{1}$ which produces a break in the horizontal line of time dots.

Since the irregularity beyond the first movement to the left is so prominent, it appears that the only feasible use that can be made of the records, aside from this one left movement, is to measure the total amount of horizontal movement during the 5 seconds and employ this as a general measurement of the speed of eye movements. Large uncorrected movements will of course provide the maximum horizontal distance for a given time interval, as short movements require proportionately more time for their performance. ${ }^{2}$

Table 14 contains the data for the two points considered: (1) the speed of the first movement to the left $(\mathrm{L})$ for each record, ${ }^{3}$ and $(2)$ the total horizontal distance (H. D.) covered by the eye during the period of 5 seconds. The average duration of the left movement on normal days following the control dose is $142 \sigma$ (see next to the last column, section I of table 14). The durations found in the first period for both groups of days are alike, that is, $140 \sigma$. These durations are somewhat long, as will be seen if comparison is made with the table of normal data collected by Dodge and Benedict. (See their report, p. 163, table 26.) The average normal left-movement duration given by them for normal subjects is 101 and $109 \sigma$ for the first and second normal days, respectively. Records were not obtained with all of the subjects for two normal days, however. With these averages there are also errors of $2.7^{\circ}$ and $2.5^{\circ}$, respectively, which mean that the original long movements did not fully cover $40^{\circ}$, but were nearer $37^{\circ}$. This would naturally shorten somewhat their duration, but even so the results in our series on Subject VI are considerably longer than those previously obtained upon him. Dodge and Benedict give in table 26 the data for the duration of the left movement on Subject VI as an average of $92 \sigma$ without correction. ${ }^{4}$

The horizontal distance which accompanies the average duration of $142 \sigma$ in our series of normal measurements is $271 \mathrm{~mm}$., and for the average of first periods of alcohol and normal days we have 293 and $310 \mathrm{~mm}$.,

\footnotetext{
${ }^{1}$ Diefendorf and Dodge (Psychol. Bull., 1916, 13, p. 459) found a tendency to coordinate winking just at the time of saccadic eye movement.

2 See Dodge and Benedict's report, p, 151, table 24.

3 There are three instances in which the first movement to the left was complicated by a wink; these were omitted and the next movements left, which covered $40^{\circ}$, were taken in their places.

The difference between 92 and $142 \sigma$ for the first and second series of experiments is large, and since the eye movements are a good measure of neural condition, this difference must be scrutinized. The records for October 22,1913 , the one normal day on which this figure $92 \sigma$ is based, were mostly illegible. However, from them it can be clearly seen that the amplitude of movement has been reduced to about $33^{\circ}$. These shorter movements naturally require less time (see Dodge and Benedict's table 24), which would account, at least in large part, for our difference in normal values.
} 


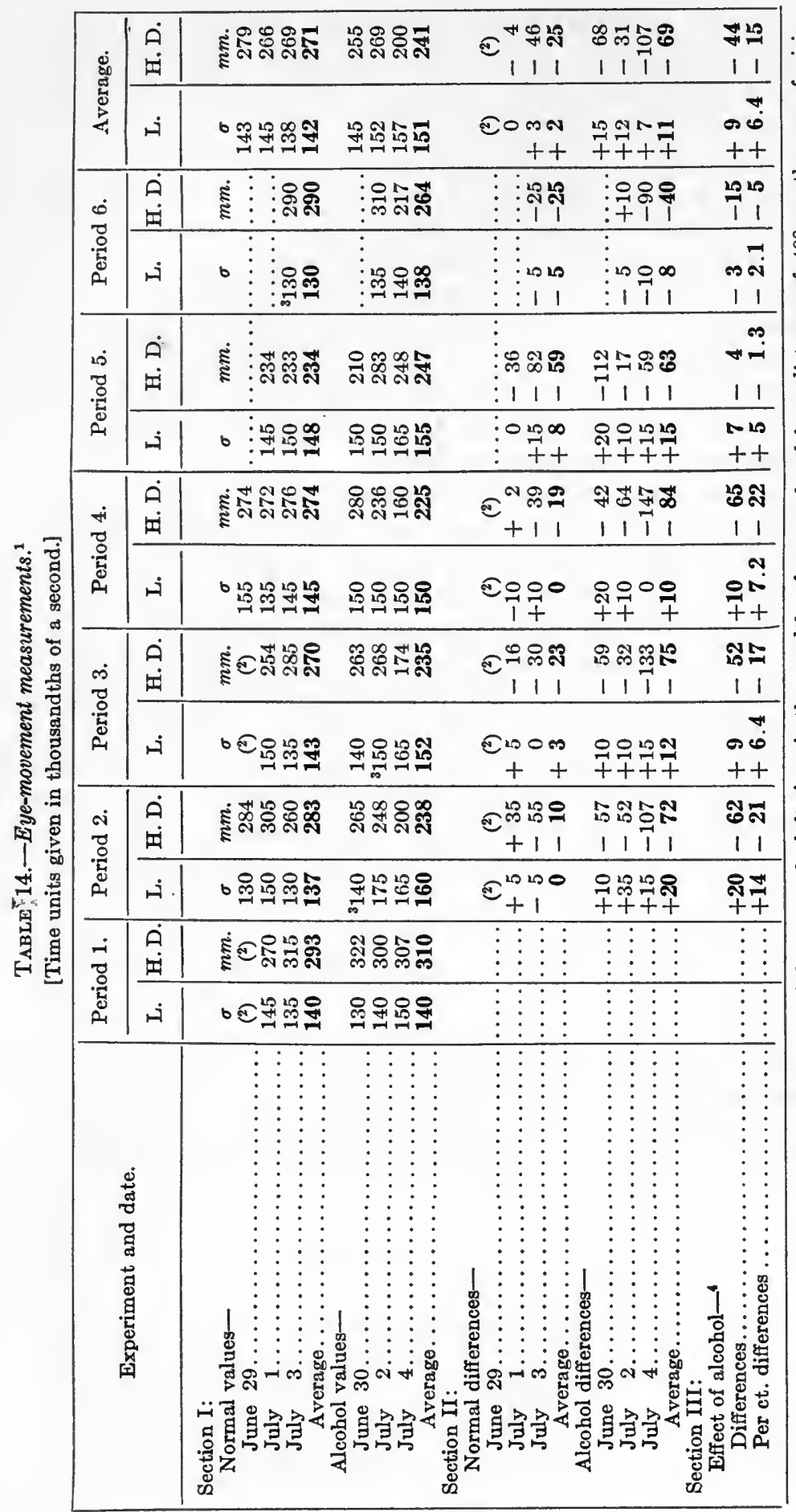


respectively. There is no standard with which we can conveniently compare these values, as in the previous series the duration of the test was not always exactly 5 seconds; hence it was inadvisable to measure the records for this factor.

The effect of alcohol upon the eye movements is strikingly evident in table 14. The average duration of the left movement on all the alcohol days and periods following the ingestion of the alcohol is $151 \sigma$, an increase of $9 \sigma$ over the average for normal days of $142 \sigma$. The total amount of horizontal movement following alcohol is $241 \mathrm{~mm}$. as compared with a normal performance of $271 \mathrm{~mm}$., that is, a reduction of 30 $\mathrm{mm}$. in the activity of the eye muscles as registered with the enlarging camera. In period 2 the duration of left movement after alcohol is $160 \sigma$, and after the dose on the normal days, $137 \sigma$; the total horizontal movement in the second period for the alcohol days is $238 \mathrm{~mm}$. and on the normal days $283 \mathrm{~mm}$. There was thus a decrease in speed of $23 \sigma$, and in distance of $45 \mathrm{~mm}$. following the ingestion of alcohol. In general the effect of the alcohol is less prominent throughout the remainder of the periods. In only one instance (horizontal distance, period 5) is the effect reversed. The signs for the differences, section II of the table, are for alcohol remarkably consistent in periods $2,3,4$, and 5 , being for $\mathrm{L}$ always plus and for H. D. always minus. Alcohol differences minus the normal differences produce results in periods $2,3,4$, and 5 which show that the duration of $\mathrm{L}$ is lengthened and the total amount of horizontal movement decreased as a result of the 30 c.c. dose. The effect of alcohol is most prominent in period 2, resulting in a decreased speed of eye movement of 14 per cent and decreased total movement of 21 per cent. For periods 3, 4, and 5, the lengthened duration of eye movements is in the neighborhood of about 6 per cent, and the decrease in movement 17, 22, and 1.3 per cent, respectively. For period 6 the data are more fragmentary. They indicate, however, that the speed of eye movement was increased, the horizontal distance still being somewhat diminished. The average effect expressed in per cent for all periods is a slowing of the left eye movement amounting to 6.4 per cent and a decrease in the amount of movement amounting to 15 per cent. These results, in so far as they are comparable, are in agreement with those previously found on this subject. ${ }^{1}$

\footnotetext{
${ }^{1}$ It is perhaps doubtful whether the records of Subject VI in the previous experiments should have been included with those of the other normal subjects (see Dodge and Benedict's report, $p$. 157 , table 25), since there was only one normal day and very scant records for that. Moreover, these values for Subject VI figured conspicuously in table 28, page 166, of Dodge and Benedict's report; see column headed "Movements to right, duration of movement." Here the subject showed a considerably slower speed than the others with dose $A$, that is, $-25 \sigma$. This value was large enough to exercise a predominating influence upon the average for the group on the movement to the right, with the result that the average is $-3 \sigma$ for dose $\mathrm{A}$.

Referring to Dodge and Benedict's table 27, p. 165, "Summary of effect of alcohol on the eyemovements as shown by changes in the average values," we find that if an attempt is made to harmonize the figures in the column "Effect on total movement," with those in the columns headed "Duration of movement" (right) and "Duration of movement" (left), which supposedly contain the data from which the total movements are computed, some difficulty will be encountered. In table 25 it will be found that the "Total duration" column contains only those values
} 


\section{FINGER MOVEMENTS.}

Although it can not be claimed that the motor activity involved in this test is a customary or practice act for every one, yet it seems a serviceable measurement. Finger movements, as in the ordinary tapping test, are used widely as a measure of motor ability. The test employed in these experiments was very simple to perform; including all adjustments it occupied scarcely 5 minutes of the experimental cycle, and 9 seconds of movement was not sufficiently long to make it at all objectionable to the subject. Neither the connection with the string galvanometer for records of the pulse nor the simple arrangement for obtaining respiration curves distracted or annoyed the subject in any way, while at the same time the simultaneous recording of these processes supplied valuable contributory data. The homogeneity and regularity of the records later presented must be the real proof of the serviceability of this measurement.

The photographic record, which included the finger movements, pulse, and respiration curves, were without exception legible. For typical records of the finger oscillation, see Dodge and Benedict's report, figure 28, opposite page 171 , and this monograph, figure $11, E$ and $F$, page 96 . In elaborating, the record was divided from the beginning of finger-movements into blocks of $2^{\prime \prime}$ each. The number of complete oscillations in the first $2^{\prime \prime}$ was recorded, then the number of complete oscillations in the first $4^{\prime \prime}$, likewise for $6^{\prime \prime}$, and finally for $8^{\prime \prime}$. There were two records in each period which were, as outlined in our experimental cycle, separated by a rest interval of 1 minute; these two records were considered individually and the count for each record is entered separately in table 15, which gives the results of the measurement. While this method of presentation has, of course, doubled the size of the table and perhaps makes it somewhat more difficult for the reader to comprehend the results, the detailed presentation proves that the first record in each period shows the better performance.

The table is arranged by periods and in two sections, section I giving the experimental data and section in the differences. As an example of the way in which the data for this particular observation are entered in the table, we will consider period 1 of the first normal day, June 29, 1914. From the first figure in the left-hand column of section $\mathrm{I}$ of table 15 it is seen that during the first 2 seconds 10.2 complete oscillations were performed. Lower in that column we find 20.0 oscillations for 4 seconds, these including, of course, the number of oscillations made in the first 2 seconds. Farther down in the column we read,

where movements both to the right and the left were legible or included, hence the values are not the sum of right and left averages. This is statistically correct if carried out consistently, but it perhaps exposes tables 26 and 27 to the unfounded criticism of containing several large errors. Apparently, it would not have been unfair to have taken the sum of the two columns referred to, for with the normal group there are ten omissions of both the duration right and the duration left values, because there were no corresponding values to include. 
for 6 seconds 29.5 and for 8 seconds 38.5 oscillations. The second record for the first period of this same day, June 29, 1914, scored 9.9, $19.3,28.5$, and 37.6 complete oscillations, respectively, for $2,4,6$, and 8 seconds. These values, if compared with those for the first record, will be seen to be somewhat smaller. This decrease in the second record is characteristic of all the data and is taken as an indication of fatigue. From the averages in the column at the right in section I, some idea of the size of this change from the first record to the second may be gained. If we examine the normal daily averages obtained for the entire 8 seconds for the periods following the control dose, we find that the decreases in the number of oscillations between the first and second records are 1.0, 0.9, and 0.7, respectively, for the three normal days, with an average of 0.9 , that is, the first record in the period showed approximately one complete oscillation more during 8 seconds than the second record. On the alcohol days, the decreases for the second records in the 8-second period are, for June 30, 1.5, and July 2, 2.7 oscillations. July 4 is the only exception to the general rule, as on that day the second record shows a slightly better score than the first, i. e., +0.1 . The average difference between the two records on the alcohol days is a decrease of 1.4; hence, after alcohol, the decrease between the first and second records of an 8-second period is apparently a little greater than on a normal day, $i$. e., approximately one-half of an oscillation in 8 seconds. ${ }^{1}$

The number of finger oscillations decreased in each succeeding 2 seconds. The average number of oscillations for each of these intervals has been included in the table, although the individual records were read for 2, 4, 6, and 8 seconds, as was done in Dodge and Benedict's study. The total average number of movements occurring in the first 2 seconds of all normal days is 9.9 (see column of averages at the right in section I). For the first 4 seconds the average value is 19.5; the difference between this average and that for the first 2 seconds is $9.6, i . e$., the average number of oscillations occurring in the second 2second interval. The average number in the third 2-second interval is 9.3 , and in the fourth, 9.1 oscillations. The comparable averages in the alcohol data are given in the same column as those just cited and are 9.7, 9.5, 9.2, and 9.0, respectively. The decrease from second to second is thus evident on both normal and alcohol days. On the normal days the falling off is at the rate of 0.3 oscillation every 2 seconds. On the alcohol days it is not quite so large, being more nearly 0.2 oscillation. While this is not a large difference, we may not assume that it is entirely without significance.

${ }^{1}$ In period 6 of July 4, the greatest number of finger oscillations were performed of any period in the six experimental days. This decided spurt of effort on the part of the subject confirms to some extent what has been previously pointed out in reference to the records for word reactions and memory in the latter part of this same day. The subject was glad to be finishing the experiments. 
TABLE 15.-Complete oscillations of the reciprocal innervation of the middle finger tabulated with reference to homologous periods of the experimental sessions.

\begin{tabular}{|c|c|c|c|c|c|c|c|c|c|c|c|c|c|}
\hline \multirow{2}{*}{$\begin{array}{l}\text { Length of } \\
\text { observation } \\
\text { and date } \\
\text { (1914). }\end{array}$} & \multicolumn{7}{|c|}{$\begin{array}{c}\text { Section I. Observations in experimental } \\
\text { periods. }\end{array}$} & \multicolumn{6}{|c|}{$\begin{array}{l}\text { Section II. Differences after dose } \\
(2-1,3-1,4-1 \text {, etc. })\end{array}$} \\
\hline & $\begin{array}{c}\text { Period } \\
1 .\end{array}$ & $\begin{array}{l}\text { Period } \\
2 .\end{array}$ & $\begin{array}{c}\text { Period } \\
3 .\end{array}$ & $\begin{array}{c}\text { Period } \\
4 .\end{array}$ & $\begin{array}{c}\text { Period } \\
5 .\end{array}$ & $\begin{array}{c}\text { Period } \\
6 .\end{array}$ & Av. & \begin{tabular}{c|c} 
Period \\
2.
\end{tabular} & $\begin{array}{l}\text { Period } \\
3 .\end{array}$ & $\begin{array}{c}\text { Period } \\
4 .\end{array}$ & & & Av. \\
\hline 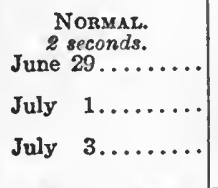 & $\begin{array}{r}10.2 \\
9.9 \\
10.0 \\
10.0 \\
10.0 \\
9.0\end{array}$ & $\begin{array}{r}9.6 \\
9.0 \\
10.7 \\
9.9 \\
10.5 \\
9.0\end{array}$ & $\begin{array}{r}10.1 \\
10.0 \\
10.5 \\
9.5 \\
9.9 \\
10.0\end{array}$ & $\begin{array}{r}10.5 \\
9.4 \\
10.5 \\
11.0 \\
10.0 \\
9.6\end{array}$ & $\begin{array}{r}\cdots \\
10.5 \\
9.7 \\
10.0 \\
9.1\end{array}$ & $\begin{array}{l}\cdots \\
\cdots \cdots \\
\cdots \\
9.7 \\
9.2\end{array}$ & $\begin{array}{r}10.1 \\
9.5 \\
10.6 \\
10.0 \\
10.0 \\
9.4\end{array}$ & $\begin{array}{l}-0.6 \\
-0.9 \\
+0.7 \\
+0.1 \\
+0.5 \\
0\end{array}$ & $\begin{array}{l}-0.1 \\
+0.1 \\
+0.5 \\
-0.5 \\
-0.1 \\
+1.0\end{array}$ & $\begin{array}{l}+0.3 \\
-0.5 \\
+0.5 \\
+1.0 \\
0 \\
+0.6\end{array}$ & $\begin{array}{r}\cdots . . \\
+0.5 \\
-0.3 \\
0 \\
+0.1\end{array}$ & $\begin{array}{c}\ldots \\
\cdots \\
\cdots \\
-0.3 \\
+0.2\end{array}$ & $\begin{array}{r}-0.13 \\
-.43 \\
+.55 \\
+.02 \\
+.02 \\
+.38\end{array}$ \\
\hline $\begin{array}{r}\text { Av. for first } 2 \\
\text { geconds....... } \\
\text { M. V. .......... }\end{array}$ & $\begin{array}{c}9.85 \\
.3 \\
\end{array}$ & $\begin{array}{l}9.78 \\
.6\end{array}$ & $\begin{array}{r}10.0 \\
.2\end{array}$ & $\begin{array}{r}10.17 \\
.5\end{array}$ & $\begin{array}{c}9.82 \\
.4\end{array}$ & $\begin{array}{c}9.45 \\
.3\end{array}$ & $\begin{array}{r}9.9 \\
\cdots \\
\end{array}$ & -.07 & $\begin{array}{l}+.15 \\
\ldots . . \\
\end{array}$ & $\begin{array}{c}+.32 \\
\cdots . . \\
\end{array}$ & $\begin{array}{l}+.07 \\
\ldots . \\
\end{array}$ & $\begin{array}{c}-.05 \\
\ldots . \\
\end{array}$ & $\begin{array}{l}+.07 \\
\ldots . \\
\end{array}$ \\
\hline 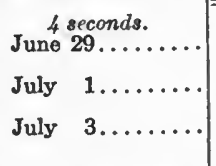 & $\begin{array}{l}20.0 \\
19.3 \\
19.9 \\
19.4 \\
19.0 \\
17.7\end{array}$ & $\begin{array}{l}19.0 \\
18.0 \\
20.5 \\
20.0 \\
20.0 \\
18.0\end{array}$ & $\begin{array}{l}20.5 \\
19.5 \\
20.9 \\
19.4 \\
19.6 \\
19.3\end{array}$ & $\begin{array}{l}19.9 \\
19.3 \\
19.5 \\
21.0 \\
19.3 \\
18.8\end{array}$ & $\begin{array}{l}\cdots \cdots \\
20.0 \\
19.4 \\
19.0 \\
18.3\end{array}$ & $\begin{array}{l}\cdots \cdots \\
\cdots \cdots \\
1 \ddot{9} \dot{0} \\
18.0\end{array}$ & $\begin{array}{l}19.9 \\
18.9 \\
20.2 \\
19.9 \\
19.4 \\
18.5\end{array}$ & $\begin{array}{l}-1.0 \\
-1.3 \\
+0.6 \\
+0.6 \\
+1.0 \\
+0.3\end{array}$ & $\begin{array}{r}+0.7 \\
+0.2 \\
+1.0 \\
0 \\
+0.6 \\
+1.6\end{array}$ & $\begin{array}{l}-0.1 \\
0 \\
-0.4 \\
+1.6 \\
+0.3 \\
+1.1\end{array}$ & $\begin{array}{c}\cdots \cdots \\
+\ddot{0} \cdot \dot{1} \\
0 \\
0 \\
+0.6\end{array}$ & $\begin{array}{c}\cdots \\
\cdots \\
\cdots \\
0 \\
+0.3\end{array}$ & $\begin{array}{l}-.13 \\
+.37 \\
+.32 \\
+.55 \\
+.38 \\
+.78\end{array}$ \\
\hline $\begin{array}{r}\text { Av. for } 4 \text { sec- } \\
\text { onds .......... } \\
\text { M. V. . . . . . . } \\
\text { Av. for second } \\
2 \text { seconds.... }\end{array}$ & $\begin{array}{c}19.21 \\
.6 \\
9.36\end{array}$ & $\begin{array}{c}19.25 \\
.9 \\
9.47\end{array}$ & $\begin{array}{c}19.90 \\
.6 \\
9.90\end{array}$ & $\begin{array}{c}19.63 \\
.5 \\
9.46 \\
\end{array}$ & $\begin{array}{c}19.17 \\
.5 \\
9.35 \\
\end{array}$ & $\begin{array}{c}18.50 \\
.5 \\
9.05\end{array}$ & $\begin{array}{c}19.5 \\
\cdots \\
9.6\end{array}$ & $\mid \begin{array}{c}+.03 \\
\cdots \\
\cdots \\
\end{array}$ & $\mid \begin{array}{c}+.68 \\
\cdots \\
\cdots\end{array}$ & $\begin{array}{c}+.42 \\
\cdots \\
\cdots \\
\end{array}$ & $\mid \begin{array}{c}+.17 \\
\cdots \\
\cdots\end{array}$ & $\begin{array}{c}+.15 \\
\cdots \\
\cdots \\
\end{array}$ & $\begin{array}{l}+.25 \\
\cdots \\
\cdots\end{array}$ \\
\hline 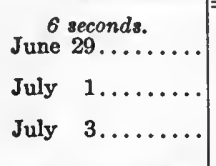 & $\begin{array}{l}29.5 \\
28.5 \\
29.0 \\
28.4 \\
27.9 \\
26.8\end{array}$ & $\begin{array}{l}27.7 \\
26.7 \\
30.0 \\
29.0 \\
29.6 \\
27.0\end{array}$ & $\begin{array}{l}30.0 \\
29.0 \\
30.4 \\
29.0 \\
28.6 \\
29.2\end{array}$ & & $\begin{array}{l}\cdots \cdots \\
30.0 \\
28.5 \\
28.5 \\
27.4\end{array}$ & $\begin{array}{l}\ldots \ldots \\
\ldots \\
28.0 \\
26.8\end{array}$ & $\begin{array}{l}29.2 \\
28.4 \\
29.8 \\
29.2 \\
28.5 \\
27.7\end{array}$ & $\begin{array}{l}-1.8 \\
-1.8 \\
+1.0 \\
+0.6 \\
+1.7 \\
+0.2\end{array}$ & $\begin{array}{l}+0.5 \\
+0.5 \\
+1.4 \\
+0.6 \\
+0.7 \\
+2.4\end{array}$ & $\begin{array}{l}+0.5 \\
+1.0 \\
0 \\
+2.0 \\
+0.1 \\
+1.2\end{array}$ & $\begin{array}{r}\cdots \\
+1.0 \\
+0.1 \\
+0.6 \\
+0.6\end{array}$ & $\begin{array}{c}\ldots \\
\cdots \\
\cdots \\
+0 . \\
0\end{array}$ & $\begin{array}{l}-.27 \\
+.10 \\
+.85 \\
+.82 \\
+.64 \\
+.88\end{array}$ \\
\hline $\begin{array}{r}\text { Av. for } 6 \text { sec- } \\
\text { onds. ....... } \\
\text { M. V. . . . } \\
\text { Av. for third } \\
2 \text { seconds.... }\end{array}$ & $\begin{array}{c}28.35 \\
.7 \\
9.14 \\
\end{array}$ & $\begin{array}{c}28.33 \\
1.2 \\
9.08\end{array}$ & $\begin{array}{c}29.37 \\
.5 \\
9.47 \\
\end{array}$ & $\begin{array}{c}29.15 \\
.8 \\
9.52 \\
\end{array}$ & $\begin{array}{c}28.60 \\
.7 \\
9.43 \\
\end{array}$ & $\begin{array}{c}27.40 \\
.6 \\
8.90\end{array}$ & $\begin{array}{c}28.8 \\
\cdots \\
9.3\end{array}$ & $\mid \begin{array}{c}-.02 \\
\cdots \\
\cdots\end{array}$ & $\left|\begin{array}{c}+1.02 \\
\cdots \\
\cdots\end{array}\right|$ & $\begin{array}{c}+.80 \\
\cdots \\
\cdots \\
\end{array}$ & $\mid \begin{array}{c}+.57 \\
\cdots\end{array}$ & $\begin{array}{c}+.05 \\
\cdots \\
\cdots \\
\end{array}$ & $\begin{array}{c}+.47 \\
\cdots \\
\cdots\end{array}$ \\
\hline 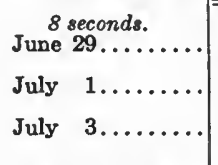 & $\begin{array}{l}38.5 \\
37.6 \\
37.8 \\
37.4 \\
37.0 \\
35.4\end{array}$ & $\begin{array}{l}36.6 \\
35.1 \\
39.3 \\
38.0 \\
38.6 \\
36.0\end{array}$ & $\begin{array}{l}39.6 \\
38.0 \\
40.0 \\
38.2 \\
37.8 \\
38.5\end{array}$ & $\begin{array}{l}39.0 \\
39.0 \\
38.0 \\
39.6 \\
37.0 \\
37.6\end{array}$ & $\begin{array}{l}\cdots \cdots \\
39.7 \\
37.4 \\
37.0 \\
36.2\end{array}$ & $\begin{array}{l}\cdots \\
\cdots \\
\cdots \cdots \\
36.8 \\
35.1\end{array}$ & $\begin{array}{l}38.4 \\
37.4 \\
39.2 \\
38.3 \\
37.4 \\
36.7\end{array}$ & $\begin{array}{l}-1.9 \\
-2.5 \\
+1.5 \\
+0.6 \\
+1.6 \\
+0.6\end{array}$ & $\begin{array}{l}+1.1 \\
+0.4 \\
+2.2 \\
+0.8 \\
+0.8 \\
+3.1\end{array}$ & $\begin{array}{r}+0.5 \\
+1.4 \\
+0.2 \\
+2.2 \\
0 \\
+2.2\end{array}$ & $\begin{array}{c}\cdots \\
+1.9 \\
0 \\
0 \\
+0.8\end{array}$ & $\begin{array}{l}\cdots \\
\cdots \\
\cdots \\
-0 . \\
-0.3\end{array}$ & $\begin{array}{l}-.10 \\
+.23 \\
+1.45 \\
+.90 \\
+1.44 \\
+1.28\end{array}$ \\
\hline $\begin{array}{r}\text { Av. for } 8 \text { sec- } \\
\text { onds. . . . . . } \\
\text { M. V. . . . . . . } \\
\text { Av. for fourth } \\
2 \text { seconds.... }\end{array}$ & $\begin{array}{c}37.28 \\
.8 \\
8.93\end{array}$ & $\begin{array}{c}37.27 \\
1.4 \\
8.94\end{array}$ & $\begin{array}{c}38.68 \\
.7 \\
9.31\end{array}$ & $\begin{array}{c}38.37 \\
.8 \\
9.22\end{array}$ & $\begin{array}{r}37.57 \\
.8 \\
8.97\end{array}$ & $\begin{array}{c}35.95 \\
.8 \\
8.55\end{array}$ & $\begin{array}{l}37.9 \\
\cdots \cdots \\
9.1\end{array}$ & -.02 & $\begin{array}{c}+1.40 \\
\cdots \\
\cdots\end{array}$ & $\left|\begin{array}{c}+1.08 \\
\cdots \\
\cdots\end{array}\right|$ & $\left|\begin{array}{c}+.67 \\
\cdots \\
\cdots\end{array}\right|$ & \begin{tabular}{c|}
-.25 \\
$\cdots$ \\
$\cdots$
\end{tabular} & $\begin{array}{l}+.62 \\
\cdots \\
\cdots \\
\end{array}$ \\
\hline $\begin{array}{l}\text { Av. of four 2- } \\
\text { second results }\end{array}$ & 9.32 & 9.32 & 9.67 & 9.59 & 9.39 & 8.99 & 9.5 & & & ... & ... & . & $\ldots$ \\
\hline 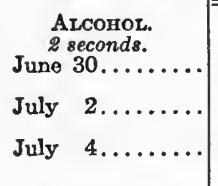 & $\begin{array}{r}10.6 \\
10.0 \\
10.4 \\
9.0 \\
9.9 \\
9.5\end{array}$ & $\begin{array}{l}9.5 \\
9.0 \\
9.0 \\
8.5 \\
9.9 \\
9.5\end{array}$ & $\begin{array}{r}10.0 \\
10.0 \\
9.0 \\
9.0 \\
10.2 \\
10.3\end{array}$ & $\begin{array}{r}10.5 \\
10.0 \\
9.8 \\
8.5 \\
10.0 \\
9.8\end{array}$ & $\begin{array}{r}10.5 \\
10.0 \\
9.5 \\
8.3 \\
10.5 \\
10.4\end{array}$ & $\begin{array}{r}\ldots \ldots \\
10.0 \\
9.3 \\
10.5 \\
10.6\end{array}$ & $\begin{array}{r}10.1 \\
9.7 \\
9.5 \\
8.7 \\
10.2 \\
10.1\end{array}$ & $\begin{array}{l}-1.1 \\
-1.0 \\
-1.4 \\
-0.5 \\
0 \\
0\end{array}$ & $\begin{array}{r}-0.6 \\
0 \\
-1.4 \\
0 \\
+0.3 \\
+0.3\end{array}$ & $\begin{array}{c}-0.1 \\
0 \\
-0.6 \\
-0.5 \\
+0.1 \\
+0.3\end{array}$ & $\begin{array}{c}-0.1 \\
0 \\
-0.9 \\
-0.7 \\
+0.6 \\
+0.9\end{array}$ & $\begin{array}{c}\ldots . \\
\because 0.4 \\
+0.3 \\
+0.6 \\
+1.1\end{array}$ & $\begin{array}{l}-.47 \\
=.25 \\
=.94 \\
\bar{t} .28 \\
+.32 \\
+.62\end{array}$ \\
\hline $\begin{array}{r}\text { Av. for first } 2 \\
\text { seconds...... } \\
\text { M. V. . . . . }\end{array}$ & $\begin{array}{c}9.90 \\
.4\end{array}$ & $\begin{array}{l}9.23 \\
.4\end{array}$ & $\begin{array}{c}9.75 \\
.5\end{array}$ & $\begin{array}{c}9.77 \\
.5\end{array}$ & $\begin{array}{l}9.85 \\
.7\end{array}$ & $\begin{array}{c}10.10 \\
.4\end{array}$ & $\begin{array}{r}9.7 \\
\cdots\end{array}$ & -.66 & $-\ldots$ & -.13 & $\begin{array}{c}-.03 \\
\ldots . .\end{array}$ & $\begin{array}{c}+.40 \\
\ldots .\end{array}$ & -.17 \\
\hline
\end{tabular}


TABLE 15-Complete oscillations of the reciprocal innervation of the middle finger tabulated with reference to homologous periods of the experimental sessions.-Continued.

\begin{tabular}{|c|c|c|c|c|c|c|c|c|c|c|c|c|c|}
\hline \multirow{2}{*}{$\begin{array}{l}\text { Length of } \\
\text { observation } \\
\text { and date } \\
\text { (1914). }\end{array}$} & \multicolumn{7}{|c|}{$\begin{array}{l}\text { Section I. Observations in experimental } \\
\text { periods. }\end{array}$} & \multicolumn{6}{|c|}{$\begin{array}{l}\text { Section II. Differences after dose } \\
(2-1,3-1,4-1 \text {, etc. })\end{array}$} \\
\hline & $\begin{array}{c}\text { Period } \\
1 .\end{array}$ & $\begin{array}{c}\text { Period } \\
2 .\end{array}$ & $\begin{array}{l}\text { Period } \\
3 .\end{array}$ & $\begin{array}{l}\text { Period } \\
4 .\end{array}$ & $\begin{array}{c}\text { Period } \\
5 .\end{array}$ & $\begin{array}{l}\text { Period } \\
6 .\end{array}$ & Av. & $\begin{array}{c}\text { Period } \\
2 .\end{array}$ & $\begin{array}{l}\text { Period } \\
3 .\end{array}$ & $\begin{array}{l}\text { Period } \\
4 .\end{array}$ & $\begin{array}{l}\text { Period } \\
5 .\end{array}$ & $\begin{array}{l}\text { Period } \\
6 .\end{array}$ & Av. \\
\hline $\begin{array}{l}\text { ALcоног con. } \\
4 \text { seconds. } \\
\text { June } 30 \ldots . . .\end{array}$ & \multirow{4}{*}{$\begin{array}{l}20.7 \\
19.5 \\
19.9 \\
18.2 \\
18.5 \\
18.8\end{array}$} & \multirow{4}{*}{$\begin{array}{l}19.0 \\
18.0 \\
17.8 \\
17.0 \\
19.2 \\
19.5\end{array}$} & \multirow{4}{*}{$\begin{array}{l}19.5 \\
19.0 \\
18.0 \\
17.6 \\
20.2 \\
20.2\end{array}$} & \multirow{4}{*}{$\begin{array}{l}20.1 \\
19.2 \\
19.0 \\
17.0 \\
20.0 \\
20.0\end{array}$} & \multirow{4}{*}{$\begin{array}{l}20.2 \\
19.9 \\
18.7 \\
16.6 \\
20.8 \\
19.5\end{array}$} & \multirow{4}{*}{$\begin{array}{l}\ldots . . \\
19.9 \\
18.8 \\
21.0 \\
21.5\end{array}$} & \multirow{4}{*}{$\begin{array}{l}19.7 \\
19.0 \\
18.7 \\
17.4 \\
20.2 \\
20.1\end{array}$} & \multirow{4}{*}{$\begin{array}{l}-1.7 \\
-1.5 \\
-2.1 \\
-1.2 \\
+0.7 \\
+0.7\end{array}$} & \multirow{4}{*}{$\begin{array}{l}-1.2 \\
-0.5 \\
-1.9 \\
-0.6 \\
+1.7 \\
+1.4\end{array}$} & \multirow{4}{*}{$\begin{array}{l}-0.6 \\
-0.3 \\
-0.9 \\
-1.2 \\
+1.5 \\
+1.2\end{array}$} & \multirow{4}{*}{$\begin{array}{l}-0.5 \\
+0.4 \\
-1.2 \\
-1.6 \\
+2.3 \\
+0.7\end{array}$} & \multirow{4}{*}{$\begin{array}{r}\ldots \\
0 \\
0 \\
+0.6 \\
+2.5 \\
+2.7\end{array}$} & \multirow{4}{*}{$\begin{array}{l}-1.00 \\
=.47 \\
-1.22 \\
+1.80 \\
+1.74 \\
+1.34\end{array}$} \\
\hline July $2 \ldots .$. & & & & & & & & & & & & & \\
\hline July 4 & & & & & & & & & & & & & \\
\hline July & & & & & & & & & & & & & \\
\hline \multirow{3}{*}{$\begin{array}{r}\text { Av. for } 4 \text { sec- } \\
\text { onds......... } \\
\text { M. V. . . . . . } \\
\text { Av. focond } \\
2 \text { seconds.... }\end{array}$} & & & & & & & & & & & & & \\
\hline & $\begin{array}{r}19.27 \\
.8\end{array}$ & $\begin{array}{c}18.42 \\
.6\end{array}$ & $\begin{array}{l}19.08 \\
.9\end{array}$ & $\begin{array}{l}19.22 \\
.6\end{array}$ & $\begin{array}{c}19.28 \\
1.1\end{array}$ & $\begin{array}{r}20.30 \\
.9\end{array}$ & \begin{tabular}{|l|l|}
19.2 \\
\end{tabular} & -.85 & $-\ldots 18$ & $\mid \begin{array}{l}-.05 \\
\ldots .\end{array}$ & +.02 & $\begin{array}{l}+1.45 \\
\ldots \ldots\end{array}$ & \\
\hline & 9.37 & 9.19 & 9.33 & 9.45 & 9.43 & 10.20 & 9.5 & $\ldots$ & $\ldots$ & $\ldots$ & & $\ldots$ & \\
\hline $\begin{array}{l}6 \text { seconds. } \\
\text { June } 30 \ldots . . .\end{array}$ & \multirow{4}{*}{$\begin{array}{l}30.2 \\
29.0 \\
29.3 \\
27.0 \\
28.0 \\
27.9\end{array}$} & \multirow{4}{*}{$\begin{array}{l}28.2 \\
26.6 \\
26.8 \\
25.0 \\
28.5 \\
29.4\end{array}$} & \multirow{4}{*}{$\begin{array}{l}28.3 \\
28.3 \\
26.9 \\
25.6 \\
29.5 \\
29.9\end{array}$} & \multirow{4}{*}{$\begin{array}{l}29.9 \\
28.4 \\
27.7 \\
25.4 \\
30.0 \\
30.0\end{array}$} & \multirow{4}{*}{$\begin{array}{l}29.5 \\
29.0 \\
27.8 \\
24.4 \\
30.6 \\
29.0\end{array}$} & \multirow{4}{*}{$\begin{array}{l}\ldots . . \\
29.5 \\
28.0 \\
30.9 \\
31.3\end{array}$} & \multirow{4}{*}{$\begin{array}{l}29.0 \\
28.1 \\
27.7 \\
25.7 \\
29.9 \\
29.9\end{array}$} & \multirow{4}{*}{$\begin{array}{l}-2.0 \\
-2.4 \\
-2.5 \\
-2.0 \\
+0.5 \\
+1.5\end{array}$} & \multirow{4}{*}{$\begin{array}{l}-1.9 \\
-0.7 \\
-2.4 \\
-1.4 \\
+1.5 \\
+2.0\end{array}$} & \multirow{4}{*}{$\begin{array}{l}-0.3 \\
-0.6 \\
-1.6 \\
-1.6 \\
+2.0 \\
+2.1\end{array}$} & \multirow{4}{*}{$\begin{array}{l}-0.7 \\
0.7 \\
-1.5 \\
-2.6 \\
+2.6 \\
+1.1\end{array}$} & & \\
\hline July 2 . & & & & & & & & & & & & $\dddot{+0} \ddot{2}$ & $z_{-1}$ \\
\hline July 4 . & & & & & & & & & & & & +1.0 & 1 \\
\hline & & & & & & & & & & & & & \\
\hline Av. for 6 sec- & & & & & & & & & & & & & \\
\hline M. v... & $\begin{array}{c}28.57 \\
.9\end{array}$ & $\begin{array}{c}27.42 \\
1.3\end{array}$ & $\begin{array}{l}28.08 \\
1.2\end{array}$ & $\begin{array}{r}28.57 \\
1.4\end{array}$ & $\begin{array}{c}28.38 \\
1.5\end{array}$ & $\begin{array}{r}29.92 \\
.8\end{array}$ & 28.4 & -1.15 &.- .48 & 0.0 & $-\ldots 18$ & $\mid+1.87$ & $\mid \begin{array}{l}-.18 \\
\ldots .\end{array}$ \\
\hline Av. for third & 9.30 & 9.00 & 9.00 & 9.35 & 9.10 & 9.62 & 9.2 & ... & $\ldots$ & ... & $\ldots$ & ... & \\
\hline $\begin{array}{r}8 \text { seconds. } \\
\text { June } 30 . . . . .\end{array}$ & 39.8 & 37.1 & & 40.0 & 38.3 & & 38.5 & -2.7 & & +0.2 & -1.5 & & -1 . \\
\hline July & $\begin{array}{l}38.3 \\
38.2\end{array}$ & $\begin{array}{l}35.0 \\
35.0\end{array}$ & $\begin{array}{l}37.5 \\
36.7\end{array}$ & $\begin{array}{l}37.4 \\
36.0\end{array}$ & $\begin{array}{l}38.0 \\
36.0\end{array}$ & $\dot{3} \dot{9} . \dot{0}$ & $\begin{array}{l}37.0 \\
36.5\end{array}$ & $\begin{array}{l}-3.3 \\
-3.2\end{array}$ & $\begin{array}{l}-0.8 \\
-1.5\end{array}$ & $\begin{array}{l}-0.9 \\
-2.2\end{array}$ & $\begin{array}{l}-0.3 \\
-2.2\end{array}$ & $\dddot{+0} \ddot{8}$ & $\mid \begin{array}{l}-1.32 \\
-1.66\end{array}$ \\
\hline July & & 33.0 & 33.7 & 33.5 & 32.3 & 36.6 & 33.8 & -2.5 & -1.8 & -2.0 & -3.2 & +1.1 & -1.6 \\
\hline & & $\begin{array}{l}38.2 \\
39.0\end{array}$ & $\begin{array}{l}39.2 \\
38.8\end{array}$ & $\begin{array}{l}39.5 \\
39.0\end{array}$ & $\begin{array}{l}39.5 \\
38.3\end{array}$ & $\begin{array}{l}40.1 \\
42.0\end{array}$ & $\begin{array}{l}39.3 \\
39.4\end{array}$ & +0.5 & $\begin{array}{l}+1.5 \\
+2.1\end{array}$ & $\begin{array}{l}+1.8 \\
+2.3\end{array}$ & $\begin{array}{l}+1.8 \\
+1.6\end{array}$ & $\begin{array}{l}+2.4 \\
+5.3\end{array}$ & $\begin{array}{l}+1.60 \\
+2.72\end{array}$ \\
\hline $\begin{array}{l}\text { Av. for } 8 \mathrm{sec}- \\
\text { onds }\end{array}$ & & & & & & & & & & & & & \\
\hline$M . v \ldots$ & 1.10 & $\begin{array}{r}36.22 \\
1.9\end{array}$ & $\begin{array}{l}37.18 \\
1.5\end{array}$ & $\begin{array}{c}37.57 \\
1.9\end{array}$ & $\begin{array}{r}37.07 \\
1.8\end{array}$ & $\begin{array}{c}39.42 \\
1.6\end{array}$ & & $\begin{array}{l}-1.48 \\
\cdots\end{array}$ &.- .10 &.- .13 & 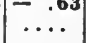 & +2.4 & $\therefore 28$ \\
\hline 2 seconds... & 9.13 & 8.80 & 9.10 & 9.00 & 8.69 & 9.50 & 9.0 & & .... & ... & $\ldots$ & .... & .... \\
\hline $\begin{array}{l}\text { Av. of four } 2- \\
\text { second results }\end{array}$ & 9.42 & 9.05 & 9.29 & 9.39 & 9.27 & 9.85 & 9.4 & & & & & & \\
\hline
\end{tabular}

This falling off in the performance from second to second in the different experimental periods can be better demonstrated in diagrammatic form (see fig. 9). In plotting these curves the data for the average performance in the six periods for each succeeding 2 -second interval has been used (see section I of table 15). The series of normal curves $(A)$ resemble each other very much in form and, for the most part, consistently maintain their different levels, each representing the number of oscillations performed in 2 seconds. The uppermost curve in $A$ of figure 9 is for the first 2 -second interval. The values represented are $9.85,9.78,10.0,10.17,9.82$, and 9.45 for periods 1 to 6 . The curves for the second and third 2-second intervals cross each other at periods 4 and 5 ; otherwise the points in all the curves are consistent in showing a rather regular falling off from second to second throughout the record and the experimental day. The curves for the alcohol days ( $B$ in fig. 9) also show a decrease in the number of oscillations performed from 


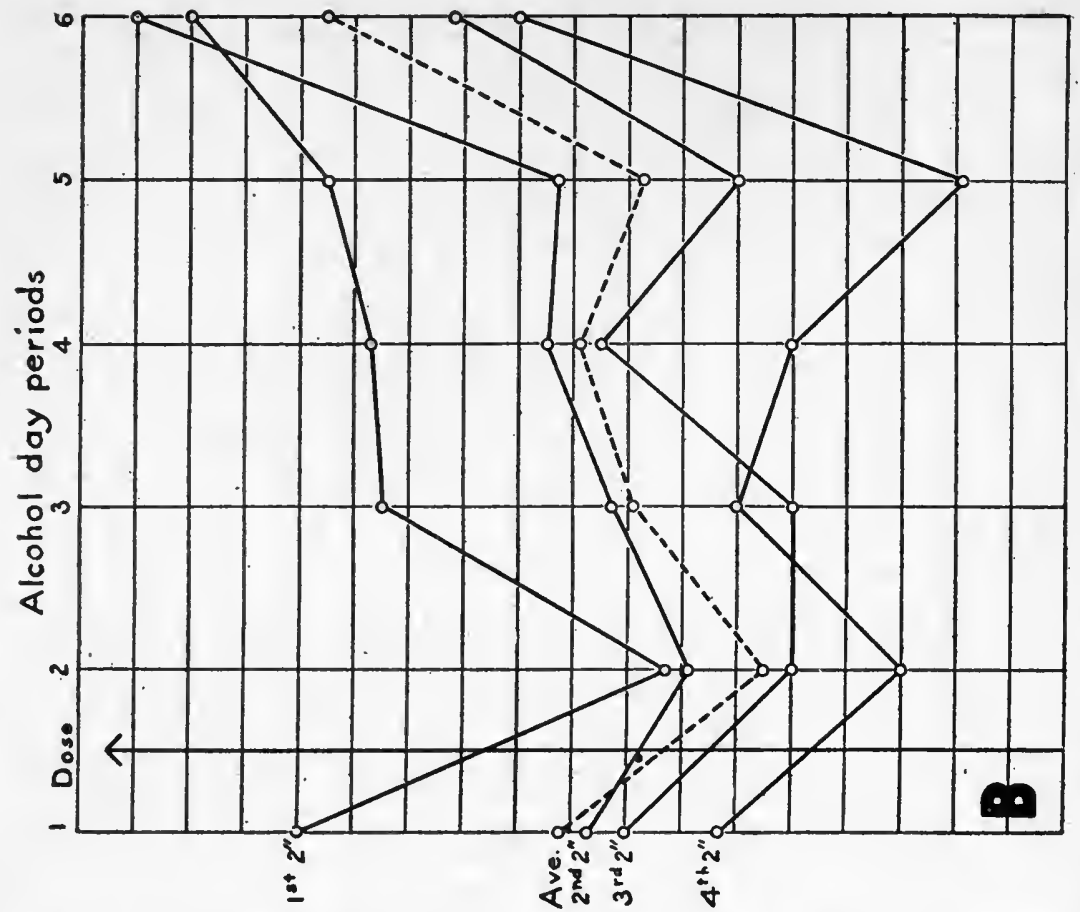

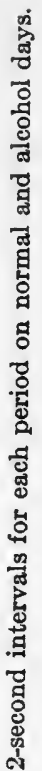

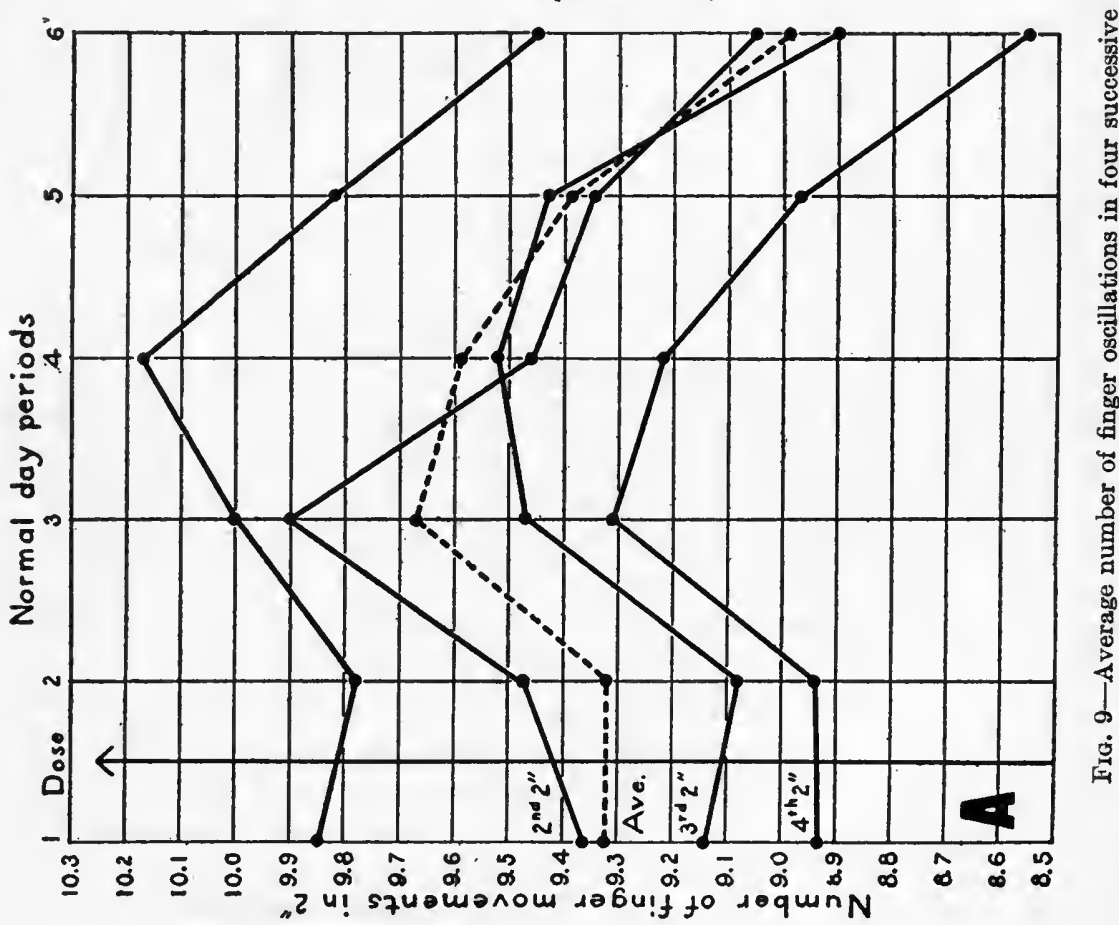


second to second, and the curve for each 2-second interval tends to maintain its relativelevel to the curves for the other 2-second intervals. Curves 1 and 2 cross at period 6 , and curves 3 and 4 at period 3 . After period 1 the general configuration of the two groups of curves are opposed in that the tendency is for one to rise where the other falls, and vice versa.

The broken-line curve shows the average for each group. For the non-alcohol days the average performance in period 2 was not inferior to that of period 1 . In periods 3 and 4 there was a definite increase, while period 5 is practically at the level of 1 and 2 ; period 6 is somewhat below the average number of oscillations in the other periods. In con-

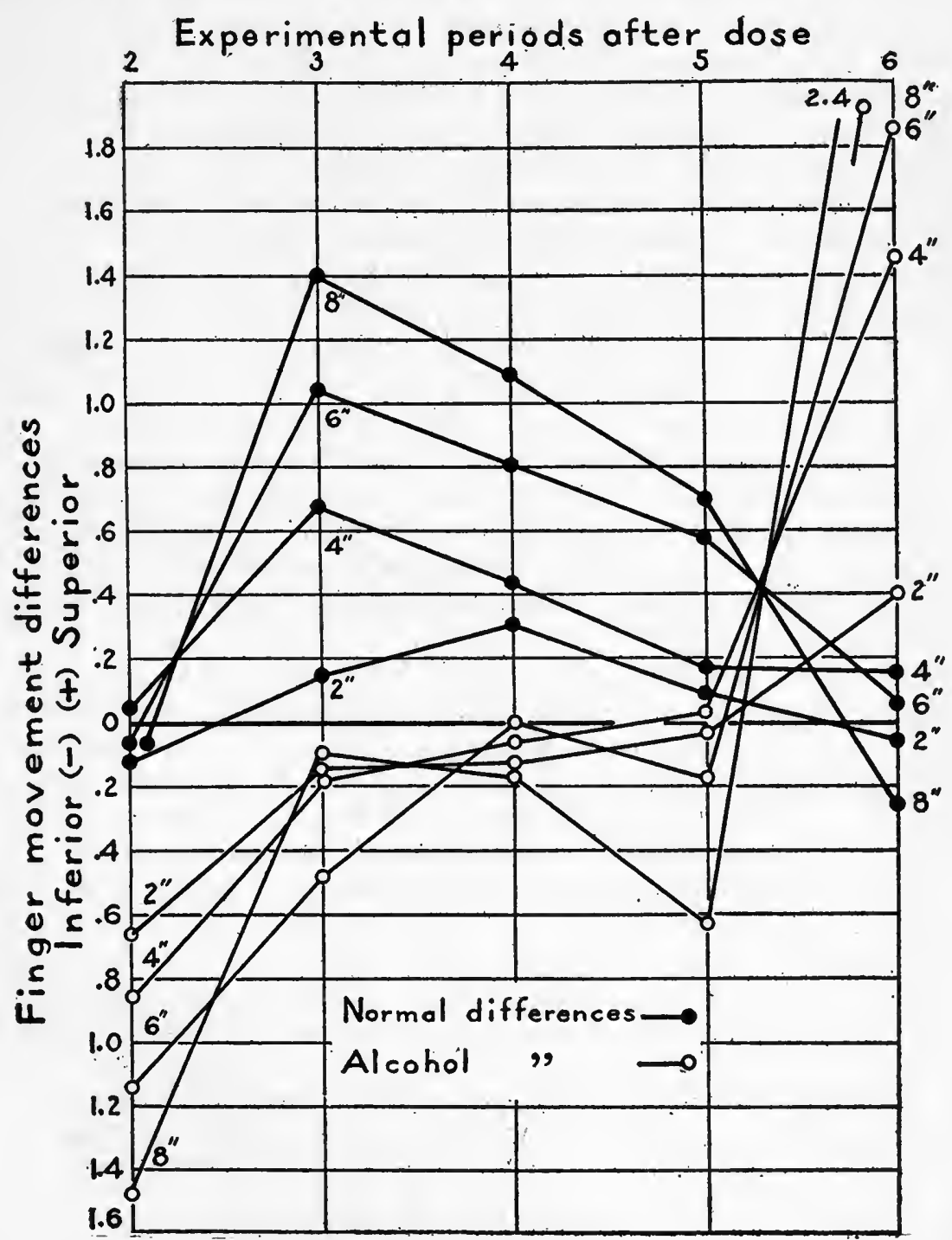

Fig. 10.-Differences for finger oscillations in $2,4,6$, and 8 second intervals for each period after the control and alcohol doses. 
trast, the average for the alcohol curves shows period 2 as clearly lower than period 1, while 3 and 4 tend to a progressive rise, but not quite to the level of period 1. The curve drops somewhat at period 5, particularly in the third and fourth 2-second intervals, but period 6 shows decidedly the best average performance for the alcohol days, and reaches a level which is not equaled by any period in the average for the non-alcohol days. All of the alcohol curves show a drop between periods 1 and 2 , but this is much more prominent in the first 2-second interval, indicating that the alcohol had a particularly depressant. effect upon the beginning of action.

The differences between the periods before and after the control mixture or the alcohol are given in section II of table 15. Computation has been made for records of $2,4,6$, and 8 seconds, as in the presentation of data by Dodge and Benedict. An examination of these values shows that following the control dose the differences are quite regularly positive, while after the alcohol dose they are more generally negative. The course of the normal differences is shown by figure $10^{1}$ (solid dots). As would be expected from $A$ in figure 9 , the differences are almost zero in period 2, as the performance in this period was almost identical with that in period 1 in the normal curves. In period 3 they are markedly plus, becoming continuously smaller but without change of sign in periods 4 and 5 and with a return to practically zero in period 6 . The course of the alcohol differences (fig. 10, open dots) are in sharp contrast with the normal series. Period 2 is far below the base line; periods 3 and 4 show a relatively large rise over period 2 , but still remain minus and are decidedly different from periods 3 and 4 on the non-alcohol days; period 5 is distinctly minus for the 6 and 8 second curves; period 6 rose far above the line.

While the effect of alcohol is evident in these curves to give it a concrete numerical statement requires an expression for the differences between the course of the two groups of curves, $i$. e., a statement of the true difference between the results obtained on the non-alcohol and alcohol days. This has been computed for the full 8-second performance and is presented in table 16. The differences between the values before and after the control dose or the alcohol dose are obtained in the usual manner from section II of table 15, these differences for the respective periods being $-1.46,-1.50,-1.15,-1.30$, and +2.65 complete oscillations. The percentile differences are obtained by dividing these differences by the average of the relevant normals, $i$. $e$., the average of the two average values for period 1 in the normal series (37.28) and in the alcohol group (37.70). Using the average (37.5), we find that the alcohol depression amounts to about 4 per cent in periods 2 and 3 and

1 Figure 10 has been drawn for $2,4,6$, and 8 second differences, $i$. $e$., the 8-second differences in a way include those for 6,4 , and 2 seconds, and the 6 seconds include the 4 seconds and 2 seconds, etc. In $A$ and $B$ of figure 9 , on the contrary, each curve is for the performance of a separate 2 second interval. 
changes to approximately 3.3 per cent in periods 4 and 5 . Apparently there was a facilitation in period 6 , amounting to 7.1 per cent. ${ }^{1}$

TABLE 16.-Effect of alcohol upon rapidity of finger movements during a performance of 8 seconds.

\begin{tabular}{|c|c|c|c|c|c|}
\hline & Period 2. & Period 3. & Period 4. & Period 5. & Period 6. \\
\hline Differences . & -1.46 & -1.50 & -1.15 & -1.30 & +2.65 \\
\hline Per cent differences........ & -3.9 & -4.0 & -3.1 & -3.5 & +7.1 \\
\hline Differences divided by P.E.D.... & 1.80 & 2.63 & 1.62 & 1.84 & 3.20 \\
\hline Probable correctness........... & 0.886 & 0.961 & 0.862 & 0.891 & 0.984 \\
\hline
\end{tabular}

Since the finger oscillations of a record were not measured individually, no mean variation was obtainable within the period. The M. V. placed in table 15 refers to the variations between the two records of the same day and period and between the records of the different days. Thus, for all the normal days taken together, there were six 8second records which came in period 1; the average of these is 37.28 and their M. V. is 0.8 . The mean variations are smaller on normal than on alcohol days. On the former they average 0.9 , which is 2.4 per cent of the average (37.9) of all the 8-second records following the control dose. For alcohol the mean variations average 1.7 or 4.5 per cent of the average 8-second score (37.4) following the 30 c.c. alcohol dose. The smallness of the mean variations between records of homologous periods is noteworthy, indicating a very even performance from day to day. The probable correctness figures for the differences have been computed from the above-described mean variations and necessarily are quite small, since the maximum number of cases could not be more than six.

Comparison of these data with those previously obtained with the same subject and on other normal subjects by Dodge and Benedict (see their report, p. 182, table 30, for 6 seconds) reveals that the average number of complete finger oscillations in 6 seconds previously scored (27.8) is about the same as in these later results, to wit, 28.8 and 28.4. According to the data obtained by Dodge and Benedict, this subject was very slow, as he performed in 6 seconds on the average about 8 complete oscillations less than the average performance for their normal group. As a result of alcohol (dose A), he shows a depression for 6 seconds amounting to 15.2 per cent. (See Dodge and

\footnotetext{
1 From the course of the curves for alcohol days it would be interpreted offhand that the alcohol depression was decidedly most prominent in period 2. It should be remembered, however, that the effect of alcohol is a statement of the contrast between what occurred on alcohol days and what occurred on non-alcohol days, rather than simply what occurred on successive periods of alcohol days. For example, in the data under discussion, while it is apparent that the depression of alcohol was prominent in period 2, yet it is as evident that the difference in the level between the average for alcohol, period 3, and that for normal days, period 3, is as great as the difference for period 2 , and hence the effect of alcohol in the final statement appears as large.
} 
Benedict's report, table 33, p. 185.) This was the largest depression but one (that for Subject IX) found with the normal group, which had an average depression with dose $A$ of 8.9 per cent. Both of these figures are larger than the percentile effects given in our table 15 for 8 seconds. They contain no contradiction, however, as to the nature of the alcohol effect.

Briefly, the results of this test of motor ability are as follows:

(1) The dose of 30 c.c. of alcohol with this subject reduced the number of free finger oscillations which the subject could perform in a period of 8 seconds by 3 or 4 per cent, roughly according to the time that had elapsed since the ingestion of the dose.

(2) The alcohol effect was more pronounced in the first record of a period than in the second record; it was more pronounced in the performance during the first 2-second interval than in any later similar interval (except in period 5); both of these results tend to reduce somewhat the falling off by fatigue after alcohol, and show the effect of alcohol to be stronger on the initial performance.

(3) The variability in the performance after alcohol is larger than after the control dose, this being shown by an increase in the mean variation after alcohol.

\section{PULSE AND RESPIRATION.}

\section{TETANUS PULSE.}

It was mentioned in a previous paragraph (see p. 24) that 11 pulse records were taken in each period. Of this number, 9 were under experimental conditions which favored more or less relaxation of the subject as he reclined in a steamer chair, or under conditions of moderate mental and physical activity, as, for example, during the word reactions. It seemed desirable, also, to measure the effect of alcohol upon the pulse before, during, and immediately following general muscular tension. To this end, and with the purpose of providing conditions which would test the promptness of changes in heart rate, continuous pulse records were taken in which the subject was (1) relaxed in the steamer chair, (2) holding the muscles of the limbs and trunk rigid for a period of 5 seconds, and (3) relaxed following the period of exertion. Dodge and Benedict (see p. 15 of their report, series 3) took pulse records of the subject immediately after standing and after 60 seconds of standing, after two double genuflections, and after 60 seconds of quiet. In comparison with this it will be seen that our pulse records are absolutely continuous.

Studies on the effect of vigorous muscular exercise on the heart rate of man have usually been limited to the pulse rate before and after the activity. The most notable exception previous to the last decade is the excellent contribution of Bowen, ${ }^{1}$ who, with a specially designed tambour

${ }^{1}$ Bowen, Contributions to Medical Research dedicated to Victor Clarence Vaughn, June 1903, p. 462, Ann Arbor, Mich. 
arrangement, was able to secure graphic records of the pulse from the carotid of subjects working vigorously on a bicycle ergometer. The curves could be read for the duration of individual pulse cycles. To minimize the disturbances from movements of the head and neck it was usually necessary for the subject to rest the forehead and shoulders against padded supports. The periods of work varied from one minute to one hour and a quarter.

Among later researches which have employed sphygmographic technique, those of Aulo may be mentioned. Radial pulse was taken from the right arm with an arrangement similar to that described by Tigerstedt $t^{2}$ and used later by Dodge and Benedict ${ }^{3}$ for their "association pulse." The subject reclined in an easy chair or on a bed and, when told, actively produced tension in all the bodily muscles, excepting that the right arm was kept as relaxed and quiet as possible, as this was essential for legible records. No periods of activity of less than a minute are reported.

Fortunately, with much less limitation of the subject, electro-cardiograms giving a photographic record for accurate determination of heart rate can be taken under conditions of physical activity, and there are no great complications caused by the vibration of the apparatus or the movements of the subject. Miss Buchanan ${ }^{4}$ took continuous electro-cardiograms showing the pulse rate during moments of change from rest to muscular tension. The subject sat with one hand and one foot in vessels of salt solution connected with the terminals of a capillary electrometer. Upon hearing a given signal he clenched the fist that was free or gripped a hand dynamometer. The pulse-cycles were measured individually in hundredths of a second and an account was taken of the relation of the signal to the systole. Later the same author (Buchanan) ${ }^{5}$ took electro-cardiograms from a subject who was riding on a stationary tricycle. No details of the application of the leading-off electrodes are given. Benedict and Murschhauser ${ }^{6}$ report: "By using body-leads and the Bock-Thoma oscillograph or the Einthoven string galvanometer, we were able to secure graphic records of the pulse rate of the subject while he was walking upon the treadmill." The treadmill was operated by a built-in 220 v., d. c. motor. As would naturally be expected with so sensitive an instrument as the string galvanometer, much difficulty was experienced from leakage currents and static charges which found their way into the galvanometer circuit. After a special metallic brush, which was earthed, was arranged

\footnotetext{
1 Aulo, Skand. Archiv f. Physiol., 1909, 21, p. 146; 1911, 25, p. 347.

2 Tigerstedt, Hygiea, Festband, 1908.

'Dodge and Benedict's report, p. 192.

4 Buchanan, Trans. Oxford Univ. Junior Scientific Club, n.s., No. 34, 1909, p.351, reprinted in The Smithsonian Report for 1910, pp. 487-505; Science Progress No. 17, July 1910, p. 60.

${ }^{6}$ Reported by Krogh and Lindhard, Journ. Physiol., 1913, 47 (see p. 117).

- Benedict and Murschhauser, Energy Transformations during Horizontal Walking, Carnegie Inst. Wash. Pub. No. 231, 1915, p. 31.
} 
to drag over the surface of the revolving belt, satisfactory photographic records were obtained, although but few such records are reported in their data. Professor H. Monmouth Smith, of the Nutrition Laboratory, has made extensive use of this method and has accumulated a large amount of data on the pulse rate during walking. Dodge and Benedict ${ }^{1}$ called attention to the unique advantage of the body-leads for leading-off electrodes in taking electro-cardiograms during muscular activity. Since these are "situated directly over relatively small trunk-muscles, even violent activity need not interfere with the records." Recently Krogh and Lindhard, ${ }^{2}$ assisted by Fridericia and Westerlund, made some determinations of the pulse rate while the subject was working on an ergometer, recording the pulse by means of a string galvanometer. For electrodes wet bandages and thin copper wire were wrapped about the wrists.

Our own experimental conditions may be more clearly understood in connection with a description of the illustrated records (see fig. 11). After the finger movements the subject leaned back in the steamer chair and was told to relax as much as possible. No adjustments were necessary, as he was already connected to the string galvanometer for pulse observations and also with the apparatus for recording the respiration rate. After approximately 60 seconds, or longer if the operator saw by the deflections of the string that the subject's pulse had not become regular, the record was begun. (See left-hand end of record, $A$ in figure 11.) $)^{3}$ After 8 or 10 seconds the signal "go" was given forcefully by the operator. At this signal the subject voluntarily contracted the muscles of arms, legs, and trunk, and retained this condition of tension until the signal "stop," at which he fell back in the chair and remained quiet. The beginning of voluntary contraction (see the vertical line drawn near the left end of the record) and the interval of its duration are clearly shown. The action currents associated with the general muscle contraction produced in the pulse tracing a prominent deflection of the galvanometer record. Furthermore, the setting of abdominal muscles caused a marked disturbance in the respiration curve. The pulse curve was continuously disturbed during the interval of tetanus by the action current from contracted muscles. However, the sharp spike of the $R$ wave ${ }^{4}$ of the electrocardiogram complex is clearly visible. The cessation of contraction is

\footnotetext{
1 See Dodge and Benedict's report, p. 193.

2 Krogh and Lindhard, Journ. Physiol., 1917, 51, p. 182, see p. 186.

3 The camera had been in operation for some seconds previous to the beginning of the photographic record in order that the actual commencement of the record should not attract the attention of the subject, who was within a few feet of the apparatus. (See Dodge and Benedict's report, fig. 1, position 1, p. 31.)

4 Standard electro-cardiograms are always read from left to right. The deflections which are above the base line (positive variations) have by Einthoven been termed $P, R, T$, and $U$. The sharp $R$ wave very slightly precedes active ventricular contraction. For fuller explanation of terminology, time relations, and interpretation of the electro-cardiogram waves, see Wiggers, Circulation in health and disease, Philadelphia, 1915.
} 
not so clearly marked as is the beginning, partly because the contraction gradually decreased in vigor from second to second and the fall due to the final relaxation was not so pronounced as was the rise at the start. The period of muscular tension (tetanus) was approximately 5 seconds in duration. A clock beating seconds was in front of the operator, and by it the signals were given. Following the tetanus, the pulse tracings became regular, all waves of the electro-cardiogram being discernible, and the record was continued for 20 to 25 seconds. We thus have a continuous record approximately 35 to 40 seconds in length, which makes possible the careful measurement of individual pulse cycles during the following conditions: (1) subject comfortably resting; (2) transition to severe muscular tension; (3) a section during which muscular tension is continued; (4) transition to rest; and (5) a period of recuperation. ${ }^{1}$

It is of course recognized that with condensers in series with the subject there is an alteration in the form of the waves of the electrocardiogram. The $R$ wave is more prominent, while $P$ and $T$ are relatively reduced. The condensers are necessary, however, to minimize fluctuations of the base line, and these curves have been used solely for determination of heart rate. With the technique as outlined, the $P$ wave is not always visible in the record; it was therefore not practicable to determine the length of pulse cycles by measuring from $P$ to $P$. As the peak of the $R$ wave is always clearly marked in all the records, it seems most practical to measure from one $R$ peak to the next. Technically speaking, we are thus not measuring isolated individual pulse cycles, but the duration obtained would represent the $R-P$ of one pulse cycle and the $P-R$ of the next. Probably for our simple measurements of rate this method does no great violence to the data, especially in consideration of the fact that the duration between $R$ and $R$ can be determined much more exactly than that from $P$ to $P$.

Pulse records such as those under discussion and illustrated in figure $11, A$ and $B$, are naturally considered in three divisions, which we have termed for convenience (from left to right) pre-tetanus, tetanus, and post-tetanus. As previously stated, it was not difficult in practice to set the limit for the different parts, because of the disturbance in the pulse and respiration tracings occasioned by the voluntary muscle contraction, although it was more difficult to mark the end of the tetanus than its beginning. Each pulse cycle (from $R$ to $R$, as previously explained) was measured in tenths of millimeters. This distance, divided by that which represents the corresponding second or seconds of time on the time line made by a Jaquet clock below the pulse curve, gives the length of the individual pulse cycle expressed in hundredths of

\footnotetext{
1 In figure 31, p. 201 of Dodge and Benedict's report, it will be observed that frequently the pulse at the end of post-stimulation had not reached the same level as that at the beginning of pre-stimulation. For comments explaining this, see Appendix IV, p. 143, of this monograph.
} 
a second. For example, if the distance from $R$ to $R$ is found to be 12.8 $\mathrm{mm}$. and the distance on the time line for the corresponding second; that is, the second directly below the pulse cycle under measurement, is $15 \mathrm{~mm}$., then the duration of the pulse cycle is 12.8 divided by 15 , or 0.85 second; in terms of pulse rate this would be 70 beats per minute. ${ }^{1}$ Obviously the longer the duration of the individual pulse cycle, the slower the rate per minute will be. A duration of 1.00 second equals a rate of 60 per minute. A duration of 1.1 seconds equals 55 per minute, and so on. For the convenience of the reader the curves which follow will be accompanied by a column at the right which will translate the pulse duration into terms of rate per minute.

A pulse cycle which fell partly in two divisions of the record was counted as belonging to that one of the divisions-pre-tetanus, tetanus; or post-tetanus-which contained the greater part of its duration. A comparison of the pulse cycles in the pre-tetanus and post-tetanus divisions which are indicated in $A$ and $B$, figure 11, shows clearly that

1 While it is more common to present pulse data in terms of rate per minute, when considering individual pulse cycles as in these experiments such terminology seems misleading.

\section{Fig. 11.-Pulse and Finger-movement Records.}

$A$ and $B$. July 2 , period 1, No. 11 , and June 29 , period 2, No. 10, tetanus pulse records to be read from left to right. In $A$ the white vertical lines have been drawn in to make clear the divisions of the record and the different sections have been marked. From the left to the first line is the pre-tetanus section, during which the subject was resting; between the vertical lines occurs the tetanus section, when the muscles were voluntarily tensed; from the second line outward to the right-hand end the subject was recuperating after the activity; this section is designated posttetanus. From the point in the record where activity began (left vertical line) six of the pretetanus pulse cycles were numbered and measured. Also, from here proceeding to the right the tetanus cycles are numbered and read until reaching the point where the muscles relax. The posttetanus cycles are numbered in order and measured from left to right. The $P, R$, and $T$ waves of the electro-cardiogram have been designated for one pulse cycle in $A$. It can be observed that the $R$ wave is definitely visible during the period of tetanus. The respiration-recording apparatus was so arranged that the curves rise at inspiration. The time is in seconds.

C. Section of post-tetanus record July 2, period 3, No. 11. Not infrequently with Subject VI there were periods of several seconds without any appreciable respiration, as is shown in the left portion of $C$. When a record 15 seconds in length has no rise and fall in the respiration tracing save that the pulse is shown, it might be argued that the tambour which was placed on the subject was not properly located. This criticism can not apply to figure $C$.

$D$. June 30 , period 2, No. 1, after taking the first alcohol dose and before the patellar-reflex measurement. Two short vertical lines have been drawn through the respiration curve to indicate the two points between which the pulse cycles were counted.

$E$ and $F$. June 29 , period 3 , Nos. 8 and 9 . The pulse tracings in these two fingcr-movement records illustrate the phenomenon described in the text, p. 117. A change in the electrical axis of the heart seems the most plausible explanation for this reduction in the size and occasional disappearance of the usual electrical waves. In $E$ the finger-movement record has been divided into four 2-second sections and these have been marked for the number of finger movements occurring in $2,4,6$, and 8 seconds, respectively.

$G$. July 4, period 6, No. 6, pulse record taken during the last word reactions on the last day. The extra oscillations of the string were caused by induction effects from the electrically driven kymograph and the action of the word-exposure apparatus. The kymograph drum made a complete revolution in 5 seconds (see text, p. 25), and at each revolution broke the circuit of the exposure apparatus. The moments when this event occurred are marked by $b$ in the picture. The swift downward movement of the respiration curve shortly following every second break indicates the reaction (marked $r$ in the picture) which consisted in speaking the word exposed.

$H$. July 4 , period 1 , No. 7 , pulse following the word reactions. Occasionally the body electrodes or the subject came into a position such that the respiration is seen to change the base line of the pulse curve. Observe also the right-hand portion of $C$ in this figure. 
in the post-tetanus division the shortening of the pulse cycle is due almost entirely, so far as preliminary measurements reveal, to a shortened duration of the diastole (distance from end of $T$ to beginning of $P$ ), as the distance from the beginning of $P$ to the end of $T$ (systole) remains quite constant. It is a well-recognized fact that the diastole is the portion of the pulse cycle that shows the greatest percentage of change in length with the transition from rest to exertion and from exertion to rest under conditions of such short periods of activity. In our measurements, however, it was not practicable to begin or end the muscular tension with a fixed relation to diastole. Since the vagus mechanism has a latency in its action, it occasionally happened that tetanus began at such a point during systole or immediately following it that a particular pulse cycle, although counted as belonging to the tetanus division, shows no conspicuous change in the length of its diastole; $i . e$. , the action of the vagus does not appear until the next cycle, which is the second for that section of the record. Illustrations of this are found in table 17 , June 29 , period 3, record 2, and June 30 , period 2, both records. Usually the first cycle in the tetanus division is shorter by several hundredths of a second than that immediately preceding, $i . e$., the last cycle in the pre-tetanus division. The fact that the $P-R$ time is the latter part of the distance which we are measuring for each pulse cycle must be remembered when considering the data at the transition point in relation to vagus action.

In tabulating these data it is not expedient to use the form employed for other measurements, for even the most condensed form of table is necessarily large and unwieldy. Table 17 follows the same general arrangement as the individual record. The left section of the table shows the duration of individual pulse cycles preceding tetanus, the central section the duration of those during tetanus, and the large section at the right the post-tetanus pulse cycles. The beginning of tetanus is made the starting-point for the measurement of the record. Six pre-tetanus cycles were measured; these from the start of tetanus are numbered in order from right to left. The cycles which came in the tetanus period are numbered from left to right and likewise for the posttetanus period from the end of tetanus. For the sake of clearness the cycles have been numbered in $A$ of figure 11, the same numbers being given in the headings of the columns in table 17 . The pre-tetanus section of the record contained more than 6 cycles, but the cycles measured immediately preceding the beginning of tetanus were limited to this number. The tetanus occupied approximately 5 seconds; the number of pulse cycles which fell within these limits varied from 6 to 9 . Of the 60 records which enter into table 17,7 contained only 6 pulse cycles in the tetanus section, 10 records contained 9 cycles, and 16 others contained 8 cycles. On July 4 , the last alcohol day, the pulse rate tended to be faster, hence during the 5 seconds of tetanus more 
TABLE 17.-Duration of individual pulse cycles preceding, during, and following tetanus.

[Length of pulse cycles given in hundredths of a sccond.]

\begin{tabular}{|c|c|c|c|c|c|c|c|c|c|c|c|c|c|c|c|c|c|}
\hline \multirow{2}{*}{$\begin{array}{c}\text { Kind of } \\
\text { experiment, } \\
\text { date, and period. }\end{array}$} & \multicolumn{8}{|c|}{ Pre-tetanus pulse cycles. } & \multicolumn{9}{|c|}{ Tetanus pulse cycles. } \\
\hline & 6 & 5 & 4 & 3 & 2 & 1 & Av. & M. V. & 1 & 2 & 3 & 4 & 5 & 6 & 7 & Av. ${ }^{2}$ & M. V. \\
\hline Normal: & & & & & & & & & & & & & & & & & \\
\hline $\begin{array}{l}2 \ldots \\
3 \ldots\end{array}$ & $\begin{array}{r}103 \\
98 \\
111 \\
120 \\
109 \\
103 \\
106 \\
105 \\
109\end{array}$ & $\begin{array}{r}99 \\
101 \\
110 \\
112 \\
103 \\
108 \\
111 \\
104 \\
108\end{array}$ & $\begin{array}{l}100 \\
105 \\
116 \\
119 \\
114 \\
107 \\
111 \\
100 \\
111\end{array}$ & $\begin{array}{r}100 \\
97 \\
103 \\
119 \\
106 \\
109 \\
117 \\
104 \\
110\end{array}$ & $\begin{array}{r}93 \\
100 \\
103 \\
115 \\
112 \\
112 \\
110 \\
108 \\
110\end{array}$ & $\begin{array}{r}95 . \\
103 \\
107 \\
116 \\
111 \\
107 \\
112 \\
112 \\
111\end{array}$ & $\begin{array}{r}98 \\
101 \\
108 \\
117 \\
109 \\
108 \\
111 \\
105 \\
110\end{array}$ & $\begin{array}{l}3 \\
2 \\
4 \\
2 \\
3 \\
2 \\
2 \\
3 \\
3\end{array}$ & \begin{tabular}{|r}
94 \\
80 \\
87 \\
100 \\
85 \\
106 \\
105 \\
89 \\
95
\end{tabular} & $\begin{array}{l}77 \\
77 \\
79 \\
84 \\
81 \\
78 \\
70 \\
83 \\
79\end{array}$ & $\begin{array}{l}76 \\
73 \\
77 \\
56 \\
75 \\
87 \\
89 \\
77 \\
77\end{array}$ & $\begin{array}{r}73 \\
72 \\
74 \\
101 \\
75 \\
75 \\
74 \\
73 \\
79\end{array}$ & $\begin{array}{l}73 \\
69 \\
73 \\
56 \\
74 \\
77 \\
75 \\
76 \\
72\end{array}$ & $\begin{array}{l}73 \\
67 \\
73 \\
88 \\
72 \\
75 \\
71 \\
77 \\
76\end{array}$ & $\begin{array}{l}71 \\
67 \\
73 \\
7 \dot{75} \\
75 \\
68 \\
85 \\
75\end{array}$ & $\begin{array}{l}77 \\
72 \\
77 \\
81 \\
77 \\
82 \\
79 \\
80 \\
79\end{array}$ & $\begin{array}{r}5 \\
4 \\
4 \\
15 \\
4 \\
8 \\
10 \\
5 \\
8\end{array}$ \\
\hline July $1-$ & 108 & 100 & 111 & 100 & 100 & 111 & 100 & & & & $\pi$ & 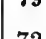 & & 10 & & & \\
\hline & $\begin{array}{l}111 \\
103\end{array}$ & $\begin{array}{l}111 \\
108\end{array}$ & $\begin{array}{r}107 \\
95\end{array}$ & $\begin{array}{r}110 \\
97\end{array}$ & $\begin{array}{l}101 \\
103\end{array}$ & $\begin{array}{l}107 \\
100\end{array}$ & $\begin{array}{l}108 \\
101\end{array}$ & $\begin{array}{l}3 \\
4\end{array}$ & $\begin{array}{l}80 \\
97\end{array}$ & $\begin{array}{l}79 \\
81\end{array}$ & $\begin{array}{l}76 \\
80\end{array}$ & $\begin{array}{l}72 \\
73\end{array}$ & $\begin{array}{l}72 \\
77\end{array}$ & $\begin{array}{l}77 \\
73\end{array}$ & $\ddot{7} \ddot{7}$ & $\begin{array}{l}76 \\
80\end{array}$ & $\begin{array}{l}3 \\
5\end{array}$ \\
\hline & 104 & 114 & 113 & 117 & 115 & 113 & 113 & 3 & 82 & 79 & 75 & 73 & 73 & 70 & 72 & 75 & 3 \\
\hline & 113 & 92 & 110 & 110 & $\begin{array}{l}117 \\
103\end{array}$ & 113 & 109 & 6 & 111 & 87 & 80 & 79 & 73 & 73 & . & 84 & 10 \\
\hline 3 & $\begin{array}{r}89 \\
111\end{array}$ & $\begin{array}{r}88 \\
100\end{array}$ & $\begin{array}{r}94 \\
111\end{array}$ & $\begin{array}{r}96 \\
107\end{array}$ & $\begin{array}{l}103 \\
113\end{array}$ & $\begin{array}{l}100 \\
111\end{array}$ & $\begin{array}{r}95 \\
109\end{array}$ & $\begin{array}{l}\mathbf{5} \\
\mathbf{3}\end{array}$ & $\begin{array}{l}82 \\
90\end{array}$ & $\begin{array}{l}78 \\
85\end{array}$ & $\begin{array}{l}74 \\
78\end{array}$ & $\begin{array}{l}77 \\
78\end{array}$ & $\begin{array}{l}71 \\
75\end{array}$ & $\begin{array}{l}71 \\
75\end{array}$ & $\ddot{8} \dot{5}$ & $\begin{array}{l}75 \\
81\end{array}$ & $\begin{array}{l}3 \\
5\end{array}$ \\
\hline & 120 & 125 & 128 & 125 & 122 & 121 & 123 & $\ddot{2}$ & 96 & 84 & 80 & 74 & 74 & 76 & 79 & 80 & 5 \\
\hline & 121 & 118 & 121 & 123 & 122 & 127 & 122 & $\overline{2}$ & 109 & 87 & 81 & 77 & 75 & 73 & 79 & 83 & 9 \\
\hline & 93 & 93 & 93 & 99 & 105 & 105 & 98 & $\overline{\mathbf{5}}$ & 99 & 78 & 79 & 77 & 74 & 71 & 71 & 78 & 6 \\
\hline Average ${ }^{2}$. & $\begin{array}{l}104 \\
107\end{array}$ & $\begin{array}{l}113 \\
105\end{array}$ & $\begin{array}{l}110 \\
110\end{array}$ & $\begin{array}{l}113 \\
111\end{array}$ & $\begin{array}{l}109 \\
113\end{array}$ & $\begin{array}{l}110 \\
112\end{array}$ & 110 & 2 & $\begin{array}{l}87 \\
94\end{array}$ & 81 & $\begin{array}{l}75 \\
78\end{array}$ & $\begin{array}{l}75 \\
76\end{array}$ & 73 & 72 & 78 & 77 & 4 \\
\hline July $3-$ & & 100 & & 111 & & & 110 & & 94 & 82 & 78 & 10 & 13 & 13 & $\gamma$ & 79 & 6 \\
\hline & 103 & 108 & 108 & 104 & 111 & 103 & 106 & 3 & 90 & 80 & 74 & 71 & 69 & 70 & 71 & 75 & 6 \\
\hline & 93 & $\begin{array}{r}114 \\
97\end{array}$ & $\begin{array}{l}112 \\
105\end{array}$ & $\begin{array}{l}109 \\
111\end{array}$ & $\begin{array}{l}114 \\
106\end{array}$ & $\begin{array}{r}101 \\
96\end{array}$ & $\begin{array}{l}109 \\
101\end{array}$ & $\begin{array}{l}4 \\
6\end{array}$ & $\begin{array}{l}83 \\
80\end{array}$ & $\begin{array}{l}78 \\
77\end{array}$ & $\begin{array}{l}75 \\
73\end{array}$ & $\begin{array}{l}74 \\
73\end{array}$ & $\begin{array}{l}71 \\
69\end{array}$ & $\begin{array}{l}69 \\
67\end{array}$ & $\begin{array}{l}69 \\
73\end{array}$ & $\begin{array}{l}74 \\
73\end{array}$ & 4 \\
\hline & 110 & 112 & 112 & 107 & 118 & 110 & 111 & 2 & 84 & 79 & 75 & 77 & & 78 & & 78 & $\begin{array}{l}3 \\
2\end{array}$ \\
\hline & 104 & 100 & 106 & 113 & 114 & 110 & 108 & 4 & 84 & 82 & 74 & 75 & 73 & 73 & 77 & 77 & 4 \\
\hline & 103 & 109 & 106 & 110 & 110 & 104 & 107 & 3 & 82 & 77 & 73 & 73 & 73 & 73 & 70 & 74 & 3 \\
\hline & 109 & 112 & 95 & 115 & 115 & 110 & 109 & $=$ & 86 & 79 & & 73 & 71 & 72 & 71 & & \\
\hline & 105 & 106 & 112 & $\begin{array}{r}115 \\
90\end{array}$ & $\begin{array}{r}119 \\
99\end{array}$ & 120 & 113 & 5 & $\begin{array}{l}87 \\
99\end{array}$ & 82 & 78 & 76 & 78 & 83 & 55 & 77 & 7 \\
\hline Average $^{2}$. . & 105 & 106 & 106 & 109 & 112 & $\begin{array}{l}117 \\
110\end{array}$ & $\begin{array}{l}105 \\
108\end{array}$ & $\begin{array}{l}7 \\
5\end{array}$ & $\begin{array}{l}92 \\
85\end{array}$ & $\begin{array}{l}81 \\
80\end{array}$ & $\begin{array}{l}78 \\
76\end{array}$ & $\begin{array}{l}74 \\
\mathbf{7 4}\end{array}$ & $\begin{array}{l}74 \\
74\end{array}$ & $\begin{array}{l}74 \\
74\end{array}$ & 70 & $\begin{array}{l}78 \\
76\end{array}$ & 4 \\
\hline$v^{2}$. & 107 & 106 & 109 & 110 & 112 & 111 & 109 & 4 & 91 & 80 & 77 & 76 & 73 & 74 & 74 & 78 & 6 \\
\hline $\begin{array}{l}\text { Alcohol: } \\
\text { June } 30-\end{array}$ & & & & & & & & & & & & & & & & & \\
\hline $1 \ldots \ldots$ & 103 & 104 & 99 & 98 & 103 & 94 & 100 & 3 & 90 & 72 & 81 & 74 & 73 & 73 & 69 & 76 & 5 \\
\hline & 96 & 111 & 107 & 106 & 110 & 107 & 106 & 3 & 81 & & 80 & 77 & 73 & 75 & 74 & 78 & 4 \\
\hline & $\begin{array}{l}101 \\
100\end{array}$ & $\begin{array}{l}103 \\
107\end{array}$ & $\begin{array}{r}97 \\
103\end{array}$ & $\begin{array}{r}90 \\
100\end{array}$ & $\begin{array}{l}103 \\
106\end{array}$ & $\begin{array}{l}100 \\
100\end{array}$ & $\begin{array}{r}99 \\
103\end{array}$ & $\begin{array}{l}\mathbf{4} \\
\mathbf{3}\end{array}$ & $\begin{array}{l}101 \\
102\end{array}$ & $\begin{array}{l}8 \\
8\end{array}$ & $\begin{array}{l}77 \\
79\end{array}$ & $\begin{array}{l}76 \\
79\end{array}$ & $\begin{array}{l}72 \\
79\end{array}$ & $\begin{array}{l}72 \\
79\end{array}$ & 81 & $\begin{array}{l}79 \\
83\end{array}$ & $\begin{array}{l}8 \\
5\end{array}$ \\
\hline & 101 & 107 & 107 & 101 & 103 & 93 & 102 & 4 & 92 & 7 & 8 & 71 & 70 & 68 & 67 & 74 & 6 \\
\hline & 107 & 110 & 116 & 104 & 119 & 103 & 110 & 5 & 93 & 8 & 7 & 76 & 71 & 78 & & 79 & 5 \\
\hline & 94 & 85 & 79 & 87 & 111 & 8 & 9 & 8 & 8 & 7 & & 7 & & & 71 & 74 & 3 \\
\hline & 111 & 108 & 111 & 101 & 104 & 10 & 10 & & 8 & 7 & 7 & & 74 & 78 & $7 \overline{7}$ & 77 & 3 \\
\hline & 95 & 93 & 101 & 101 & $\begin{array}{r}102 \\
95\end{array}$ & 95 & 98 & 3 & 88 & 77 & 78 & 69 & 70 & 71 & 71 & 74 & 5 \\
\hline rage ${ }^{2}$. & $\begin{array}{l}103 \\
101\end{array}$ & $\begin{array}{l}106 \\
102\end{array}$ & $\begin{array}{r}97 \\
101\end{array}$ & $\begin{array}{l}99 \\
98\end{array}$ & $\begin{array}{r}95 \\
105\end{array}$ & $\begin{array}{r}100 \\
98\end{array}$ & $\begin{array}{l}100 \\
101\end{array}$ & $\begin{array}{l}3 \\
4\end{array}$ & $\begin{array}{l}83 \\
91\end{array}$ & $\begin{array}{l}77 \\
78\end{array}$ & $\begin{array}{l}72 \\
76\end{array}$ & $\begin{array}{l}74 \\
74\end{array}$ & $\begin{array}{l}70 \\
\mathbf{7 2}\end{array}$ & 74 & $\begin{array}{l}73 \\
73\end{array}$ & $\begin{array}{l}74 \\
77\end{array}$ & $\begin{array}{l}3 \\
5\end{array}$ \\
\hline July & & & & & & & & & & & & & & & & & \\
\hline & 107 & 100 & 107 & 104 & 99 & 100 & 103 & 3 & 86 & 79 & 75 & 74 & 71 & 70 & 74 & 76 & 4 \\
\hline & $\begin{array}{r}108 \\
94\end{array}$ & $\begin{array}{r}115 \\
91\end{array}$ & $\begin{array}{r}113 \\
93\end{array}$ & $\begin{array}{r}113 \\
94\end{array}$ & $\begin{array}{r}115 \\
95\end{array}$ & $\begin{array}{r}106 \\
96\end{array}$ & $\begin{array}{r}112 \\
94\end{array}$ & $\begin{array}{l}3 \\
1\end{array}$ & $\begin{array}{l}85 \\
81\end{array}$ & $\begin{array}{l}82 \\
76\end{array}$ & $\begin{array}{l}76 \\
76\end{array}$ & $\begin{array}{l}7 \\
7\end{array}$ & 7 & 7 & 73 & 78 & $\begin{array}{l}4 \\
1\end{array}$ \\
\hline & 98 & 102 & 100 & 99 & 101 & 100 & 100 & 1 & 87 & 83 & 79 & 77 & 80 & 79 & 77 & 80 & 3 \\
\hline $3 \ldots$ & 93 & 91 & 100 & 113 & 107 & 99 & 10 & 6 & 87 & 7 & & & & & & 75 & 4 \\
\hline & 96 & 100 & 103 & 107 & 106 & 103 & 10 & 3 & 87 & 8 & & & & & & & 5 \\
\hline & 81 & 81 & 87 & 88 & 87 & 80 & 8 & 3 & 73 & 7 & 7 & & & & & 75 & 3 \\
\hline & 107 & 106 & 108 & 99 & 100 & 100 & 103 & 4 & 9 & 8 & 7 & 7 & & & & 78 & 4 \\
\hline & 97 & 97 & 94 & 100 & 10 & 97 & 9 & 2 & 8 & 7 & & 7 & & & & & 3 \\
\hline & 99 & 100 & 97 & 100 & 103 & 101 & 100 & 1 & 9 & & & 7 & & & & 77 & 4 \\
\hline & 98 & 97 & 100 & 100 & 112 & 101 & 101 & 3 & 88 & 78 & 7 & 74 & 71 & & 70 & 75 & 4 \\
\hline Average $^{2}$. & 96 & 96 & 98 & 100 & 102 & 97 & 98 & 3 & 86 & 78 & 76 & 75 & 74 & 73 & 73 & 76 & 3 \\
\hline July 4... & 103 & 99 & 104 & 97 & 103 & 105 & 102 & 0 & 86 & 77 & 75 & 74 & & & 70 & 75 & 4 \\
\hline & 97 & 106 & 103 & 100 & 102 & 94 & 100 & 3 & 79 & 7 & 7 & & & & & & 3 \\
\hline $2 \ldots \ldots$ & 98 & 94 & 96 & 91 & 95 & 94 & 95 & 2 & 9 & 8 & 7 & 7 & & & & 76 & 7 \\
\hline & 91 & 97 & 97 & 96 & 101 & 97 & 96 & & 87 & 8 & 7 & & & & & 75 & 6 \\
\hline & 97 & 99 & 100 & 94 & 97 & 97 & 98 & $\overline{2}$ & 94 & 7 & 7 & 7 & & & & & 6 \\
\hline & 94 & 100 & 10 & 9 & 10 & 9 & 9 & 2 & 9 & 7 & 7 & 6 & & & & & 6 \\
\hline & 94 & 97 & 102 & 93 & 99 & 96 & 9 & 2 & 8 & 7 & & 7 & & & & 73 & 3 \\
\hline & 104 & 99 & 99 & 106 & 110 & 106 & 104 & $\overline{3}$ & 81 & 8 & 7 & 7 & & & & & 2 \\
\hline & 100 & 107 & 104 & 103 & 105 & 100 & 103 & 2 & 9 & 8 & 7 & 7 & & & & & 6 \\
\hline & 100 & 103 & 94 & 9 & 9 & 91 & 97 & $\overline{3}$ & 79 & 7 & 7 & 7 & 7 & & & 75 & 5 \\
\hline & 100 & 93 & 87 & 89 & 93 & 91 & 92 & 3 & 81 & 7 & 7 & 69 & 6 & 6 & 6 & 72 & 5 \\
\hline & 109 & 106 & 107 & 102 & 102 & 104 & 105 & 2 & 87 & 77 & 73 & 70 & 67 & 67 & 6 & 73 & 6 \\
\hline & 99 & 99 & 99 & 97 & 100 & 97 & 98 & 2 & 87 & 78 & 74 & 72 & 71 & 70 & 71 & 75 & 5 \\
\hline & 99 & 99 & 99 & 98 & 102 & 97 & 99 & 3 & 88 & 78 & 75 & 74 & 72 & 72 & 72 & 76 & 4 \\
\hline
\end{tabular}

1 Occasionally there were one or two more pulse-cycles in the tetanus period than are recorded in the table (see text). 2 These averages do not include the pulse cycles in the first period, $i$, e., previous to the control or alcohol dose.

- First record in period 6 omitted as a portion of it was illegible. The data given are for the second record. 
Pulse and Respiration.

TABLE 17-Duration of individual pulse cycles preceding, during, and following telanus.-Continued.

\begin{tabular}{|c|c|c|c|c|c|c|c|c|c|c|c|c|c|c|c|c|c|c|c|c|}
\hline & & & & & & & & & t-tet & nus & pulse & cycle & & & & & & & & \\
\hline 1 & 2 & 3 & 4 & 5 & 6 & 7 & 8 & 9 & 10 & 11 & 12 & 13 & 14 & 15 & 16 & 17 & 18 & 19 & 20 & 21 \\
\hline & & & & & & & & & & & & & & & & & & & & \\
\hline $\begin{array}{l}74 \\
87\end{array}$ & $\begin{array}{l}83 \\
86\end{array}$ & $\begin{array}{l}83 \\
86\end{array}$ & $\begin{array}{l}76 \\
91\end{array}$ & $\begin{array}{l}74 \\
85\end{array}$ & $\begin{array}{l}75 \\
84\end{array}$ & $\begin{array}{l}75 \\
81\end{array}$ & $\begin{array}{l}75 \\
78\end{array}$ & & & & $\begin{array}{l}74 \\
81\end{array}$ & $\begin{array}{l}77 \\
82\end{array}$ & $\begin{array}{l}80 \\
82\end{array}$ & $\begin{array}{l}83 \\
89\end{array}$ & $\begin{array}{l}87 \\
90\end{array}$ & $\begin{array}{l}88 \\
81\end{array}$ & $\begin{array}{l}100 \\
100\end{array}$ & 106 & 105 & 103 \\
\hline $\begin{array}{l}86 \\
101\end{array}$ & $\begin{array}{l}86 \\
86\end{array}$ & $\begin{array}{l}86 \\
83\end{array}$ & $\begin{array}{l}91 \\
87\end{array}$ & $\begin{array}{l}85 \\
86\end{array}$ & $\begin{array}{l}84 \\
85\end{array}$ & $\begin{array}{l}81 \\
82\end{array}$ & 77 & 74 & $\begin{array}{l}77 \\
74\end{array}$ & $\begin{array}{l}78 \\
76\end{array}$ & $\begin{array}{l}81 \\
80\end{array}$ & $\begin{array}{l}82 \\
80\end{array}$ & $\begin{array}{l}82 \\
79\end{array}$ & $\begin{array}{l}89 \\
86\end{array}$ & $\begin{array}{r}90 \\
104\end{array}$ & $\begin{array}{r}81 \\
106\end{array}$ & $\begin{array}{l}103 \\
107\end{array}$ & $\begin{array}{r}97 \\
105\end{array}$ & $\begin{array}{l}106 \\
108\end{array}$ & 117 \\
\hline 76 & 79 & 86 & $\begin{array}{l}93 \\
81\end{array}$ & $\begin{array}{l}89 \\
76\end{array}$ & 82 & 84 & 82 & 79 & 79 & 77 & 77 & 73 & 75 & 73 & 75 & 73 & 78 & 89 & 97 & 100 \\
\hline 79 & 78 & 76 & 81 & 81 & 78 & $\begin{array}{l}74 \\
75\end{array}$ & $\begin{array}{l}75 \\
75\end{array}$ & $\begin{array}{l}75 \\
75\end{array}$ & 72 & $\begin{array}{l}71 \\
69\end{array}$ & $\begin{array}{l}1 \\
72\end{array}$ & $\dot{7} \dot{5}$ & $\ddot{79}$ & $\ddot{7} \ddot{9}$ & $\dddot{86}$ & iöo & $\dddot{9} \dot{9}$ & $i \ddot{0} \dot{5}$ & $i i \dot{9}$ & $\mathrm{ii2}$ \\
\hline 73 & 76 & 76 & 76 & 72 & 71 & 70 & 70 & 68 & 68 & 71 & 68 & 70 & 72 & 83 & 89 & 86 & 94 & 112 & 111 & 109 \\
\hline $\begin{array}{r}100 \\
85\end{array}$ & $\begin{array}{l}90 \\
81\end{array}$ & $\begin{array}{l}90 \\
82\end{array}$ & $\begin{array}{l}84 \\
84\end{array}$ & $\begin{array}{l}79 \\
80\end{array}$ & $\begin{array}{l}79 \\
78\end{array}$ & 79 & $\begin{array}{l}73 \\
75\end{array}$ & 71 & 73 & 77 & $\begin{array}{l}76 \\
74\end{array}$ & 74 & $\begin{array}{r}106 \\
82\end{array}$ & 94 & $\begin{array}{r}115 \\
94\end{array}$ & $\begin{array}{r}112 \\
95\end{array}$ & $\begin{array}{r}112 \\
98\end{array}$ & 114 & $\begin{array}{l}105 \\
108\end{array}$ & 109 \\
\hline 86 & 79 & 80 & 80 & 79 & 76 & 76 & 76 & 76 & 74 & 72 & 73 & 76 & 77 & 83 & 85 & 100 & 111 & 108 & 110 & 114 \\
\hline 81 & 77 & 80 & 80 & 79 & 77 & 79 & 77 & 73 & 73 & 73 & 73 & 73 & 75 & 73 & 80 & 97 & $\begin{array}{l}108 \\
\end{array}$ & 99 & 95 & 113 \\
\hline 74 & 75 & 72 & 76 & 75 & 74 & 70 & 71 & 70 & 70 & 67 & 67 & 68 & 70 & 73 & 73 & 73 & 77 & 85 & 91 & 96 \\
\hline $\begin{array}{l}79 \\
78\end{array}$ & $\begin{array}{l}96 \\
78\end{array}$ & $\begin{array}{l}87 \\
81\end{array}$ & $\begin{array}{l}87 \\
78\end{array}$ & $\begin{array}{l}85 \\
78\end{array}$ & $\begin{array}{l}78 \\
79\end{array}$ & $\begin{array}{l}80 \\
75\end{array}$ & $\begin{array}{l}82 \\
74\end{array}$ & $\begin{array}{l}82 \\
75\end{array}$ & $\begin{array}{l}83 \\
74\end{array}$ & $\begin{array}{l}86 \\
72\end{array}$ & $\begin{array}{l}87 \\
72\end{array}$ & $\begin{array}{l}81 \\
72\end{array}$ & $\begin{array}{l}86 \\
76\end{array}$ & $\begin{array}{l}93 \\
76\end{array}$ & $\begin{array}{l}87 \\
93\end{array}$ & $\begin{array}{l}107 \\
101\end{array}$ & $\begin{array}{l}111 \\
108\end{array}$ & $\begin{array}{l}113 \\
114\end{array}$ & $\begin{array}{l}114 \\
114\end{array}$ & $\begin{array}{l}108 \\
116\end{array}$ \\
\hline 86 & & 100 & 89 & 81 & 81 & 85 & 86 & 86 & 93 & 93 & 88 & 98 & 104 & 101 & 110 & 121 & 118 & 121 & 113 & \\
\hline 80 & 86 & 83 & 81 & 87 & 84 & 80 & 80 & 78 & 77 & 75 & 75 & 79 & 80 & 78 & 87 & 96 & 93 & 101 & 100 & 101 \\
\hline $\begin{array}{l}88 \\
84\end{array}$ & 84 & 78 & $\begin{array}{l}87 \\
81\end{array}$ & $\begin{array}{l}86 \\
82\end{array}$ & $\begin{array}{l}84 \\
81\end{array}$ & $\begin{array}{l}85 \\
75\end{array}$ & $\begin{array}{l}83 \\
73\end{array}$ & $\begin{array}{l}76 \\
74\end{array}$ & $\begin{array}{l}77 \\
75\end{array}$ & $\begin{array}{l}78 \\
76\end{array}$ & $\begin{array}{l}76 \\
73\end{array}$ & $\begin{array}{l}76 \\
76\end{array}$ & $\begin{array}{l}80 \\
77\end{array}$ & $\begin{array}{l}87 \\
75\end{array}$ & $\begin{array}{l}87 \\
81\end{array}$ & & $\begin{array}{l}100 \\
102\end{array}$ & $\begin{array}{l}110 \\
107\end{array}$ & $\begin{array}{l}107 \\
114\end{array}$ & 114 \\
\hline $\begin{array}{l}82 \\
81\end{array}$ & $\begin{array}{l}78 \\
85\end{array}$ & $\begin{array}{l}79 \\
83\end{array}$ & $\begin{array}{l}78 \\
82\end{array}$ & $\begin{array}{l}75 \\
81\end{array}$ & $\begin{array}{l}74 \\
79\end{array}$ & $\ddot{\mathbf{7 9}}$ & $\ddot{7} \dot{8}$ & $\ddot{7} \dot{7}$ & $\dot{7} \dot{8}$ & $\ddot{7} \dot{8}$ & $\ddot{\mathbf{7}}$ & $\ddot{79}$ & $\ddot{8} \dot{2}$ & $\ddot{8}$ & $\ddot{8} \dot{8}$ & 98 & $\mathrm{ioi}$ & 107 & 108 & 107 \\
\hline 88 & 86 & 75 & 81 & 81 & 81 & & & & 75 & 74 & 74 & 71 & 71 & & & & & & & 100 \\
\hline & 75 & 72 & 76 & 78 & 75 & 74 & 74 & 76 & 75 & & & 81 & 84 & 85 & 100 & 106 & 112 & 110 & 104 & 109 \\
\hline & 79 & 79 & 75 & 73 & 73 & 73 & 69 & 69 & 72 & 76 & 79 & 81 & 77 & 84 & 90 & 91 & 87 & 97 & 108 & 95 \\
\hline $\begin{array}{l}100 \\
116\end{array}$ & $\begin{array}{l}90 \\
90\end{array}$ & $\begin{array}{l}84 \\
84\end{array}$ & $\begin{array}{l}84 \\
83\end{array}$ & $\begin{array}{l}87 \\
80\end{array}$ & $\begin{array}{l}79 \\
83\end{array}$ & $\begin{array}{l}79 \\
84\end{array}$ & $\begin{array}{l}78 \\
77\end{array}$ & $\begin{array}{l}77 \\
79\end{array}$ & $\begin{array}{l}77 \\
83\end{array}$ & $\begin{array}{l}80 \\
82\end{array}$ & 8 & $\begin{array}{l}84 \\
79\end{array}$ & $\begin{array}{l}95 \\
80\end{array}$ & $\begin{array}{l}88 \\
90\end{array}$ & $\begin{array}{r}100 \\
94\end{array}$ & $\begin{array}{l}97 \\
92\end{array}$ & $\begin{array}{l}94 \\
85\end{array}$ & $\begin{array}{r}88 \\
103\end{array}$ & 115 & 104 \\
\hline 73 & 73 & $\begin{array}{l}84 \\
76\end{array}$ & 73 & 72 & 71 & 72 & 74 & 71 & 73 & 72 & 72 & 71 & 70 & 72 & 73 & $7 \overline{3}$ & 73 & 88 & 94 & $\ddot{9} \mathrm{i}$ \\
\hline & 82 & 74 & 77 & 77 & 79 & 73 & 73 & 72 & 72 & 68 & 7 & 70 & 71 & 70 & 77 & 84 & 89 & 95 & 101 & 98 \\
\hline 79 & $\begin{array}{l}99 \\
73\end{array}$ & $\begin{array}{l}90 \\
73\end{array}$ & $\begin{array}{l}87 \\
75\end{array}$ & $\begin{array}{l}88 \\
75\end{array}$ & $\begin{array}{l}87 \\
73\end{array}$ & $\begin{array}{l}81 \\
71\end{array}$ & $\begin{array}{l}76 \\
71\end{array}$ & $\begin{array}{l}75 \\
70\end{array}$ & $\begin{array}{r}75 \\
67\end{array}$ & $\begin{array}{l}77 \\
69\end{array}$ & 81 & $\begin{array}{l}80 \\
74\end{array}$ & $\begin{array}{l}87 \\
76\end{array}$ & 9 & $\begin{array}{l}99 \\
82\end{array}$ & $\begin{array}{l}99 \\
91\end{array}$ & $\begin{array}{r}100 \\
97\end{array}$ & $\begin{array}{l}97 \\
94\end{array}$ & $\begin{array}{r}96 \\
108\end{array}$ & $\begin{array}{r}96 \\
110\end{array}$ \\
\hline & 84 & 80 & 79 & 79 & 78 & 76 & 74 & 73 & 74 & & 7 & 7 & 79 & & 88 & 90 & 89 & 95 & 104 & 99 \\
\hline & 85 & 82 & 82 & 80 & 78 & 77 & 76 & 75 & 75 & 75 & 76 & 7 & 8 & & 9 & 94 & 96 & 102 & 107 & 105 \\
\hline 74 & 72 & 69 & 69 & 69 & 69 & 67 & 69 & 69 & 70 & 68 & 67 & 67 & 67 & 67 & 67 & 67 & 67 & 73 & 80 & $7 \theta$ \\
\hline $\begin{array}{l}80 \\
70\end{array}$ & $\begin{array}{l}77 \\
71\end{array}$ & $\begin{array}{l}80 \\
67\end{array}$ & $\begin{array}{l}80 \\
70\end{array}$ & $\begin{array}{l}75 \\
70\end{array}$ & $\begin{array}{l}77 \\
69\end{array}$ & $\begin{array}{l}77 \\
67\end{array}$ & 75 & $\begin{array}{l}73 \\
67\end{array}$ & $\begin{array}{l}71 \\
68\end{array}$ & $\begin{array}{l}73 \\
67\end{array}$ & $\begin{array}{l}72 \\
70\end{array}$ & $\begin{array}{l}72 \\
70\end{array}$ & $\begin{array}{l}72 \\
73\end{array}$ & $\begin{array}{l}79 \\
70\end{array}$ & $\begin{array}{l}84 \\
69\end{array}$ & $\begin{array}{l}81 \\
72\end{array}$ & $\begin{array}{c}96 \\
71\end{array}$ & $\begin{array}{r}104 \\
89\end{array}$ & $\begin{array}{l}99 \\
81\end{array}$ & 112 \\
\hline & 80 & 77 & 72 & 73 & 73 & 74 & $\begin{array}{l}69 \\
69\end{array}$ & 68 & $\begin{array}{l}68 \\
69\end{array}$ & 66 & 64 & 64 & 64 & 64 & 68 & 79 & 93 & 87 & $\begin{array}{l}81 \\
106\end{array}$ & 107 \\
\hline 68 & 68 & 69 & $\begin{array}{l}68 \\
81\end{array}$ & 67 & $\begin{array}{l}67 \\
77\end{array}$ & $\begin{array}{l}67 \\
77\end{array}$ & $\begin{array}{l}67 \\
74\end{array}$ & $\begin{array}{l}67 \\
72\end{array}$ & 67 & 67 & $\begin{array}{r}67 \\
68\end{array}$ & $\begin{array}{l}64 \\
66\end{array}$ & $\begin{array}{l}66 \\
68\end{array}$ & $\begin{array}{l}67 \\
70\end{array}$ & $\begin{array}{l}70 \\
69\end{array}$ & $\begin{array}{l}72 \\
69\end{array}$ & 81 & $\begin{array}{l}93 \\
79\end{array}$ & $\begin{array}{l}87 \\
87\end{array}$ & $\begin{array}{r}94 \\
114\end{array}$ \\
\hline 73 & 72 & 73 & $\begin{array}{l}11 \\
73\end{array}$ & 71 & 71 & 71 & $\begin{array}{l}64 \\
68\end{array}$ & 68 & 68 & 67 & $\begin{array}{l}68 \\
65\end{array}$ & $\begin{array}{l}66 \\
65\end{array}$ & $\begin{array}{l}68 \\
68\end{array}$ & 74 & $\begin{array}{l}69 \\
77\end{array}$ & $\begin{array}{l}69 \\
90\end{array}$ & $\begin{array}{l}75 \\
99\end{array}$ & $\begin{array}{l}79 \\
98\end{array}$ & $\begin{array}{r}106 \\
106\end{array}$ & $\begin{array}{r}114 \\
96\end{array}$ \\
\hline $\begin{array}{l}83 \\
77\end{array}$ & $\begin{array}{l}81 \\
79\end{array}$ & $\begin{array}{l}75 \\
74\end{array}$ & 75 & $\begin{array}{l}72 \\
76\end{array}$ & 71 & $\begin{array}{r}69 \\
71\end{array}$ & 68 & $\begin{array}{l}68 \\
71\end{array}$ & 68 & $\begin{array}{l}65 \\
71\end{array}$ & 66 & 66 & 68 & 68 & 68 & $\begin{array}{l}74 \\
84\end{array}$ & 87 & 87 & & \\
\hline & 79 & 67 & 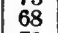 & 67 & 71 & 71 & 68 & 67 & & 0 & & & & & & & 98 & & 1009 & $\ddot{9} \dot{6}$ \\
\hline 18 & 77 & 73 & 73 & 72 & 72 & 71 & 70 & 68 & 68 & 68 & 67 & 66 & 68 & 71 & 74 & 77 & 88 & 92 & 96 & 99 \\
\hline 78 & 78 & 78 & 78 & 74 & 75 & 74 & 74 & 71 & 70 & 70 & 68 & 66 & 66 & 67 & 68 & 71 & 69 & 83 & 99 & 97 \\
\hline 83 & 83 & 84 & 79 & 79 & 78 & 77 & 72 & 74 & 72 & 72 & 77 & 83 & 9 & & & & 103 & 113 & 110 & 1.10 \\
\hline & 71 & 70 & 70 & 68 & 70 & 68 & $\begin{array}{l}68 \\
70\end{array}$ & $\begin{array}{l}65 \\
70\end{array}$ & 68 & 6 & 65 & 68 & & 6 & & & $\begin{array}{r}74 \\
110\end{array}$ & $\begin{array}{r}75 \\
\end{array}$ & 83 & 87 \\
\hline $\begin{array}{l}81 \\
74\end{array}$ & $\begin{array}{l}86 \\
74\end{array}$ & $\begin{array}{l}79 \\
72\end{array}$ & $\begin{array}{l}86 \\
80\end{array}$ & $\begin{array}{l}87 \\
73\end{array}$ & $\begin{array}{l}79 \\
71\end{array}$ & $\begin{array}{l}80 \\
71\end{array}$ & $\begin{array}{l}79 \\
71\end{array}$ & $\begin{array}{l}79 \\
72\end{array}$ & $\begin{array}{l}74 \\
69\end{array}$ & $\begin{array}{l}73 \\
71\end{array}$ & $\begin{array}{l}77 \\
73\end{array}$ & $\begin{array}{l}83 \\
72\end{array}$ & $\begin{array}{l}83 \\
72\end{array}$ & $\begin{array}{l}90 \\
74\end{array}$ & $\begin{array}{r}103 \\
79\end{array}$ & 104 & $\begin{array}{r}110 \\
93\end{array}$ & $\begin{array}{r}113 \\
97\end{array}$ & $\begin{array}{l}104 \\
104\end{array}$ & 109 \\
\hline & 74 & 74 & 74 & 73 & 71 & 71 & 71 & 71 & 71 & 7 & 7 & 70 & 70 & 7 & 74 & & 82 & 87 & 78 & 86 \\
\hline . & 81 & 79 & 80 & 79 & 75 & 72 & 72 & 72 & 74 & 73 & 73 & 75 & 80 & 84 & 87 & 93 & 100 & 97 & 87 & 100 \\
\hline 81 & 78 & 75 & $\begin{array}{l}81 \\
73\end{array}$ & 71 & 71 & 69 & 68 & 67 & 68 & 70 & 68 & 68 & 70 & 71 & 77 & 73 & 79 & 82 & 95 & $\begin{array}{r}03 \\
90\end{array}$ \\
\hline & 97 & 85 & $\begin{array}{l}79 \\
79\end{array}$ & 77 & $\begin{array}{l}76 \\
78\end{array}$ & 74 & 72 & 70 & 78 & 68 & 6 & & 6 & 7 & 84 & & & 90 & 92 & 107 \\
\hline 81 & 80 & 77 & 78 & 76 & 75 & 73 & 73 & 72 & 71 & 70 & $\mathbf{7 1}$ & 72 & 74 & 77 & 84 & $\ddot{87}$ & 93 & $\begin{array}{r}102 \\
95\end{array}$ & $\begin{array}{r}100 \\
95\end{array}$ & 98 \\
\hline 74 & & 70 & 70 & 70 & 70 & & 68 & 70 & 70 & 70 & 68 & 67 & 70 & 72 & 71 & 74 & 81 & 94 & 94 & 107 \\
\hline & 74 & 72 & 72 & 69 & 69 & 70 & 69 & 69 & 66 & 66 & 6 & 6 & 6 & & & & & 2 & 87 & 99 \\
\hline 7 & $\begin{array}{l}71 \\
78\end{array}$ & $\begin{array}{l}67 \\
775\end{array}$ & 69 & 69 & 68 & 68 & 68 & 68 & 65 & 68 & 6 & 6 & & & & & & & & 81 \\
\hline 69 & 68 & 69 & $\begin{array}{l}74 \\
69\end{array}$ & $\begin{array}{l}74 \\
69\end{array}$ & $\begin{array}{l}84 \\
69\end{array}$ & 68 & 68 & 64 & $\begin{array}{l}67 \\
64\end{array}$ & 62 & 6 & $\begin{array}{l}6 \\
62\end{array}$ & 6 & $\begin{array}{l}6 \\
6 \\
6\end{array}$ & $\begin{array}{l}7 \\
6 \\
\end{array}$ & 7 & $\begin{array}{l}8 \\
6\end{array}$ & $\begin{array}{l}93 \\
68\end{array}$ & $\begin{array}{l}99 \\
81\end{array}$ & $\begin{array}{l}92 \\
79\end{array}$ \\
\hline 75 & 78 & 73 & 73 & 73 & 73 & 73 & 70 & 67 & 68 & 68 & 6 & & & & & & 9 & 97 & 103 & 108 \\
\hline $\begin{array}{l}69 \\
81\end{array}$ & $\begin{array}{l}68 \\
76\end{array}$ & $\begin{array}{l}69 \\
78\end{array}$ & $\begin{array}{l}70 \\
75\end{array}$ & $\begin{array}{l}69 \\
73\end{array}$ & $\begin{array}{l}68 \\
72\end{array}$ & $\begin{array}{l}69 \\
67\end{array}$ & $\begin{array}{l}69 \\
67\end{array}$ & $\begin{array}{l}69 \\
67\end{array}$ & $\begin{array}{l}68 \\
64\end{array}$ & $\begin{array}{l}69 \\
64\end{array}$ & $\begin{array}{l}66 \\
65\end{array}$ & $\begin{array}{l}65 \\
65\end{array}$ & $\begin{array}{l}6 \\
6\end{array}$ & 6 & 6 & 7 & $\begin{array}{l}6 \\
8 \\
\end{array}$ & $\begin{array}{l}73 \\
88\end{array}$ & $\begin{array}{l}80 \\
96\end{array}$ & $\begin{array}{r}80 \\
108\end{array}$ \\
\hline 68 & 68 & 67 & 68 & 68 & 68 & 68 & 68 & 67 & 67 & 67 & 66 & 64 & 6 & 6 & 6 & 6 & 6 & 73 & 79 & 91 \\
\hline $\begin{array}{l}82 \\
72\end{array}$ & 82 & $\begin{array}{l}77 \\
71\end{array}$ & $\begin{array}{l}78 \\
70\end{array}$ & $\begin{array}{l}75 \\
68\end{array}$ & $\begin{array}{l}71 \\
68\end{array}$ & $\begin{array}{l}71 \\
68\end{array}$ & $\begin{array}{l}70 \\
68\end{array}$ & $\begin{array}{l}65 \\
67\end{array}$ & $\begin{array}{l}65 \\
67\end{array}$ & $\begin{array}{l}65 \\
67\end{array}$ & $\begin{array}{l}67 \\
67\end{array}$ & $\begin{array}{l}64 \\
67\end{array}$ & 6 & 6 & 6 & 6 & $\begin{array}{l}71 \\
70\end{array}$ & $\begin{array}{l}91 \\
79\end{array}$ & $\begin{array}{l}85 \\
84\end{array}$ & $\begin{array}{r}96 \\
100\end{array}$ \\
\hline & 73 & 73 & 73 & 71 & 67 & 65 & 66 & 63 & 67 & 66 & 62 & & & & 7 & 9 & 101 & & 98 & 101 \\
\hline & 73 & 72 & 72 & 71 & 70 & 69 & & & & & & & & & & & & & & 84 \\
\hline & & & & & & & & & & & & & & & & & & & & \\
\hline
\end{tabular}


pulse cycles occurred; usually 9 cycles were obtained on this day. In general the tetanus data beyond 7 cycles are very scattering for the other days; and averages beyond this number would be of little value. In the post-tetanus period, 21 cycles were usually counted, since at about this point the pulse seemed to have returned to near the pretetanus level. Two records were accidentally not completed at the time of taking, $i$ e., those of June 29, period 3, record 1, and for July 1, period 5 , record 2 . The first record on July 2 , period 6 , was partially illegible and not included; the second record for period 3 , July 3 , was missing.

Each record is represented by a line of values running horizontally through the table. The averages and mean variations are given for both the pre-tetanus and tetanus pulse cycles. For illustration, June 29 , period 1 , record 1 , shows values for the pre-tetanus pulse cycles beginning just before tetanus of $95,93,100,100,99$, and 103 , with an average of 98 and a mean variation of 3 . The values for the tetanus period for the same record are $94,77,76,73,73,73$, and 71 , with an average of 77 and a mean variation of 5 . There were just 7 cycles, hence all are given. Immediately after tetanus, $i$. e., in the posttetanus period, we have cycle durations of $74,83,83,76,74$, etc., until we reach 106, 105, and 103. The fluctuations in the pulse-length in the post-tetanus section are so large that averaging is of doubtful value. In this table, as in previous tables, the data for the alcohol and normal days are grouped separately. The line of averages under the records for the individual days include only those periods following the taking of the control or alcohol dose, i.e., all but the values for the first period. The general averages given for the normal and the alcohol days are drawn from the averages of the three normal days and the three alcohol days, respectively.

Attention may first be directed to the normal change of the heart rate occasioned by the muscular effort of tetanus. The general averages for homologous pulse cycles on the non-alcohol days have been plotted in the form of a curve and are shown in figure 12. The figure is so drawn that a rise in the curve denotes a change to a shorter pulse cycle (faster rate). In the column at the left durations in hundredths of a second are given, and at the right their approximate equivalent in terms of pulse rate per minute. The curve is divided by vertical lines showing the pre-tetanus, tetanus, and post-tetanus sections.

In examining the normal curve, we find that apparently relaxation was not complete previous to the tetanus, as the pulse cycles were continuously lengthening before the point where the signal "go" was given. The average duration for this section is 110 , or 55 beats per minute. From a pulse which is relatively relaxed, the transition is rapid after the beginning of muscular work. The first cycle at the beginning of tetanus shows a change from the average level of 110 to a level of 91 , or 
from 55 to 66 beats per minute. The second cycle reaches 80 , the third 77; the rise is then more gradual, being $76,73,74$, and 74 , or a pulse rate of 81 beats per minute. Immediately upon the relaxation of the muscles the cycle lengthens, dropping to 86 . From this point during next 8 pulse cycles the duration gradually decreases (shortens)

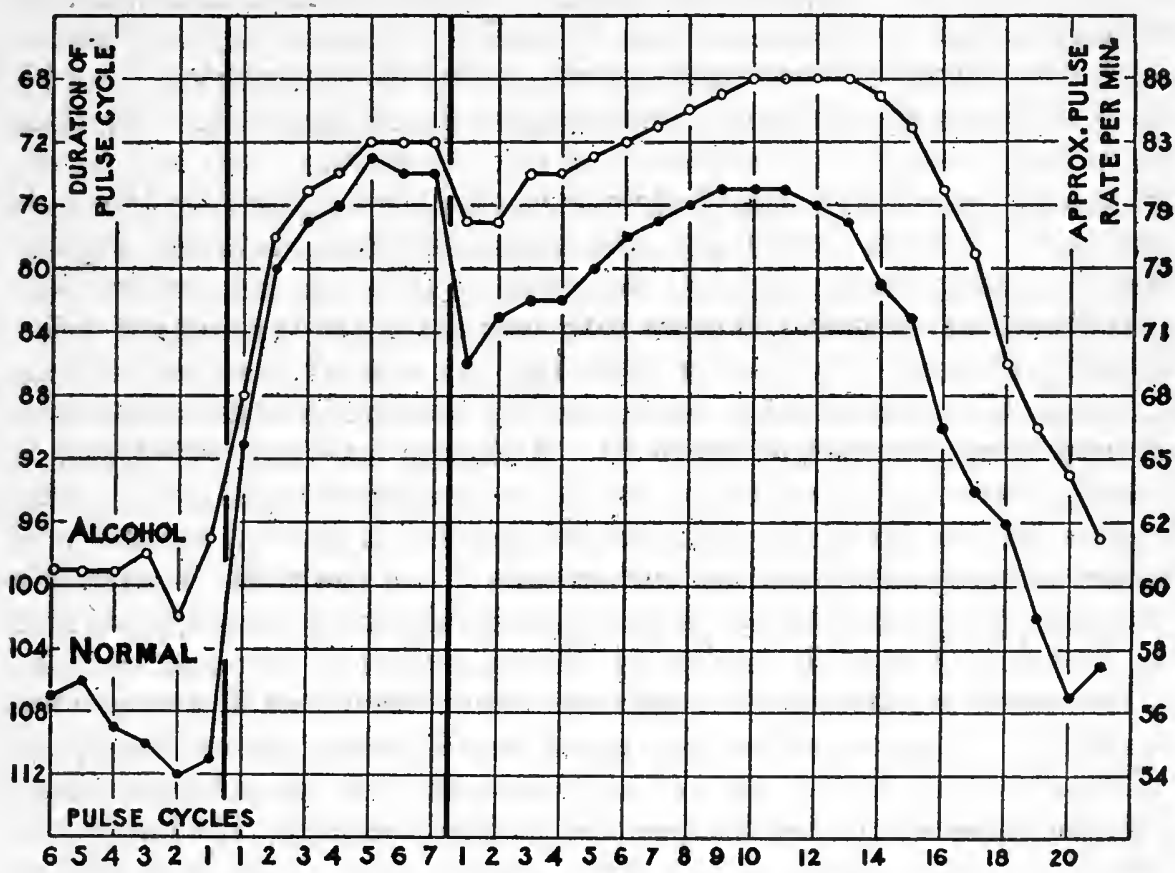

FIG. 12.-Average duration of pulse cycles given in hundredths of a second for pre-tetanus, tetanus, and post-tetanus periods on three normal and three alcohol days, after the control or normal dose.

until it reaches 75 , very nearly the duration in the latter part of the tetanus section (73). It remains at 75 (80 beats per minute) for 3 pulse cycles, then in 9 cycles it decreases to the level of 107 (56 beats per minute) or very nearly the level immediately before tetanus.

The curve under discussion is of course based upon the records taken on one subject only, and in the absence of similar data on other subjects no exact comparison can be drawn or proof given concerning the accuracy of its representation of the changes in pulse rate occasioned by the type and duration of exercise employed. However, that portion of the curve which shows the transition from rest to exertion is believed to be representative, since it is in perfect agreement with the data of Bowen ${ }^{1}$, Buchanan, ${ }^{2}$ and Krogh and Lindhard ${ }^{3}$ in demonstra-

\footnotetext{
1 Bowen, Contributions to Medical Rescarch dedicated to Victor Clarence Vaughn, June 1903, p. 462, Ann Arbor, Mich.

2 Buchanan, Trans. Oxford Univ. Junior Scientific Club, n. s., No. 34, 1909, p. 351 ; reprinted in the Smithsonian Report for 1910, pp. 487-505; Science Progress No. 17, July 1910, p. 60.

${ }^{3}$ Reported by Krogh and Lindhard, Journ. Physiol., 1913, 47, p. 117.
} 
ting that the first full pulse cycle after the beginning of "muscular work" is shortened in duration and that this decrease in pulse-length continues progressively for several cycles following. ${ }^{1}$ The dip in the curve immediately after tetanus and the secondary rise which follows have not been observed in any other published data. In the curves of Bowen ${ }^{2}$ and Aulo, ${ }^{3}$ to quote the former: "Upon the cessation of work the pulse rate falls in a manner precisely similar to its primary rise (at the beginning of work); very rapid at first, gradually diminishing in rapidity as it continues, and finally returning to the normal rate." In their researches, however, longer periods of work or exertion were employed, the shortest reported being 60 seconds as compared to the 5 or 6 seconds used here. This is not the place to present the data, but some unpublished records on other subjects clearly show that after such short periods of muscular tension the pulse rate does not fall in the manner designated by Bowen. The rate remains high for several beats, sometimes exceeding that during the tetanus, and the fall is more gradual than the primary rise, as shown in figure 12. Although no sinus arrhythmia is sensibly present in this subject, doubtless a respiration phase influences to some extent the pulse duration, as there is a natural tendency to exhale immediately following the tetanus. ${ }^{4}$ As the pulse is normally retarded during expiration, this would account perhaps in slight part for the drop in the curve immediately following tetanus, but occasionally, at this point, a particularly long cycle would occur (as illustration see $A$, fig. 11). Extra systoles were never found present with this subject.

The curve for the average of all homologous pulse cycles measured after the ingestion of alcohol (see the broken line in fig. 12) follows, in general, the same form as that for normal days. It is, however, at every point on a higher level than the normal curve, conspicuously so in the periods for pre-tetanus and post-tetanus, the latter period showing a pulse rate which is well above that during the tetanus section, 88 beats as compared to 83 beats per minute. Although both curves are from data which do not include the first-period values and are therefore wholly comparable as alcohol and non-alcohol averages, the difference in level of the two curves must not be uncritically accepted as entirely due to the alcohol ingested. Averages, although seemingly comparable, are sometimes misleading; the data should be considered by days and by periods, the difference being noted between the normal of the day and the succeeding experimental hours.

In the first place, we need to know if the difference in level between the normal and alcohol curves shown in figure 12 is due to the influence

\footnotetext{
${ }^{1}$ Bowen records that in one case the pulse rate steadily continued to increase for a period of 4 . minutes after starting vigorous work on a bicycle.

${ }^{2}$ Bowen, Contributions to Medical Research dedicated to Victor Clarence Vaughn, June 1903, p. 462, Ann Arbor, Mich.

Aulo, Skand. Archiv f. Physiol., 1911, 25, p. 347.

See figure 11, p. 96; a rise in the respiration curve denotes expiration. See also Appendix IV, p. 143.
} 
of any one experimental day. In figure 13 a curve is shown for each of the six days, the average for the day not including period 1. Light lines and heavy lines have been used to differentiate between the alcohol and non-alcohol days. It is apparent at once, in the pre-tetanus sections of the curve, that the light-line curves for the alcohol days are grouped at a higher level than the three heavy-line or normal curves. In the tetanus section this grouping does not persist and there is great

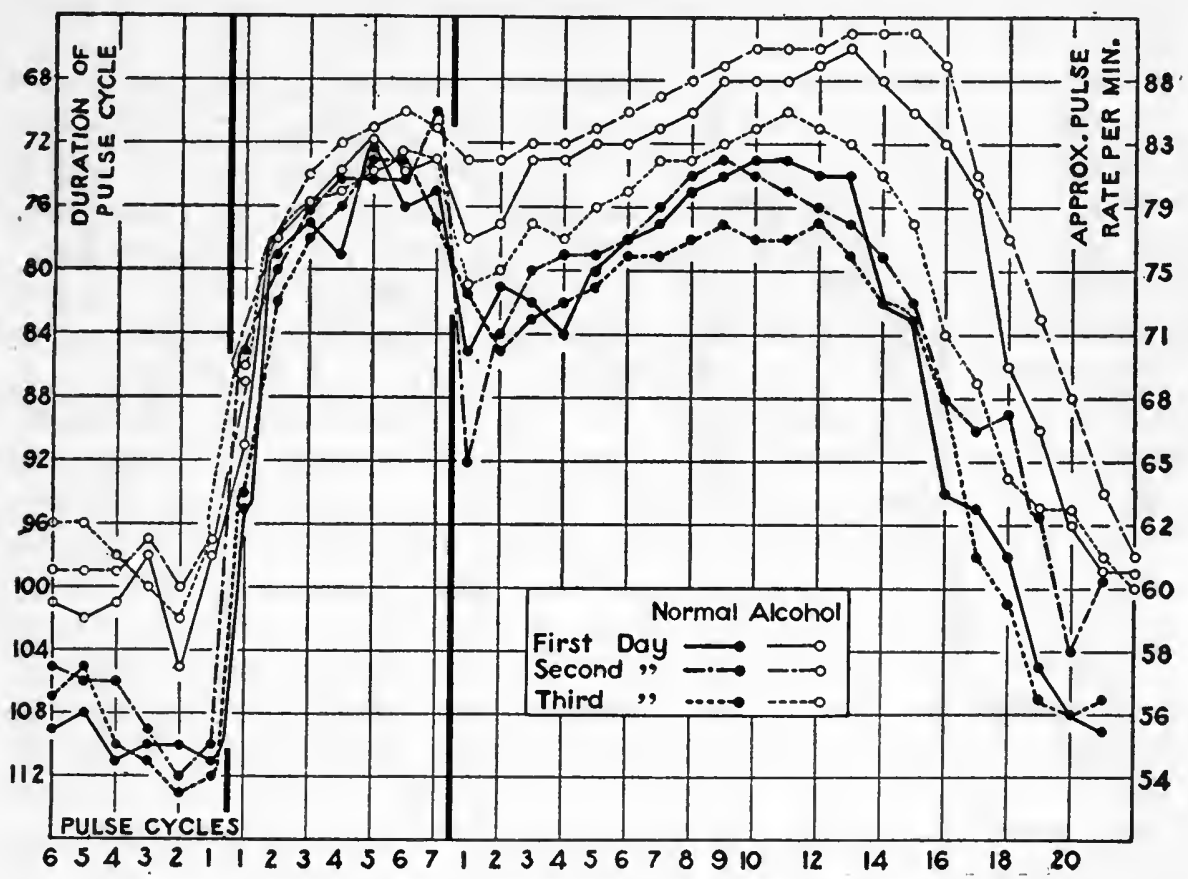

FIG. 13.-Average duration of pulse cycles given in hundredths of a second for three normal and three alcohol days during pre-tetanus, tetanus, and post-tetanus periods, after the control or alcohol dose.

confusion in the crossing and recrossing of the different curves, although the alcohol curves tend to remain above the normal curves. In the post-tetanus section there is more scattering, the alcohol curves particularly being less closely grouped, but always at a higher level than the normal or heavy curves throughout nearly the entire period represented. In one instance the curve for the second alcohol day crosses the curve for the third normal day near the latter portion of the posttetanus division. The curve for the last alcohol day, July 4, reaches the highest level in the post-tetanus division and is also, on the average, the highest in the tetanus section; furthermore, it shows the smallest drop immediately after the tetanus. From this diagram it is certain that the relations shown in figure 12 are not due to the fact that any one day exercises a predominating influence upon the shape of the curves. If we selected any one of the alcohol days and any one of the normal days 
and plotted the two curves, the form and relationship of the curves would be substantially like those of the curves in figure 12 .

The question which must be answered next concerns the first period for the alcohol days. As the results are obtained before the alcohol is taken, the data are normal, i.e., uninfluenced by alcohol. The natural query would be: Are the changes in pulse rate during the first period of alcohol days different from the changes during the first period of normal days? The answer to this question will be found in figure 14. Here, as

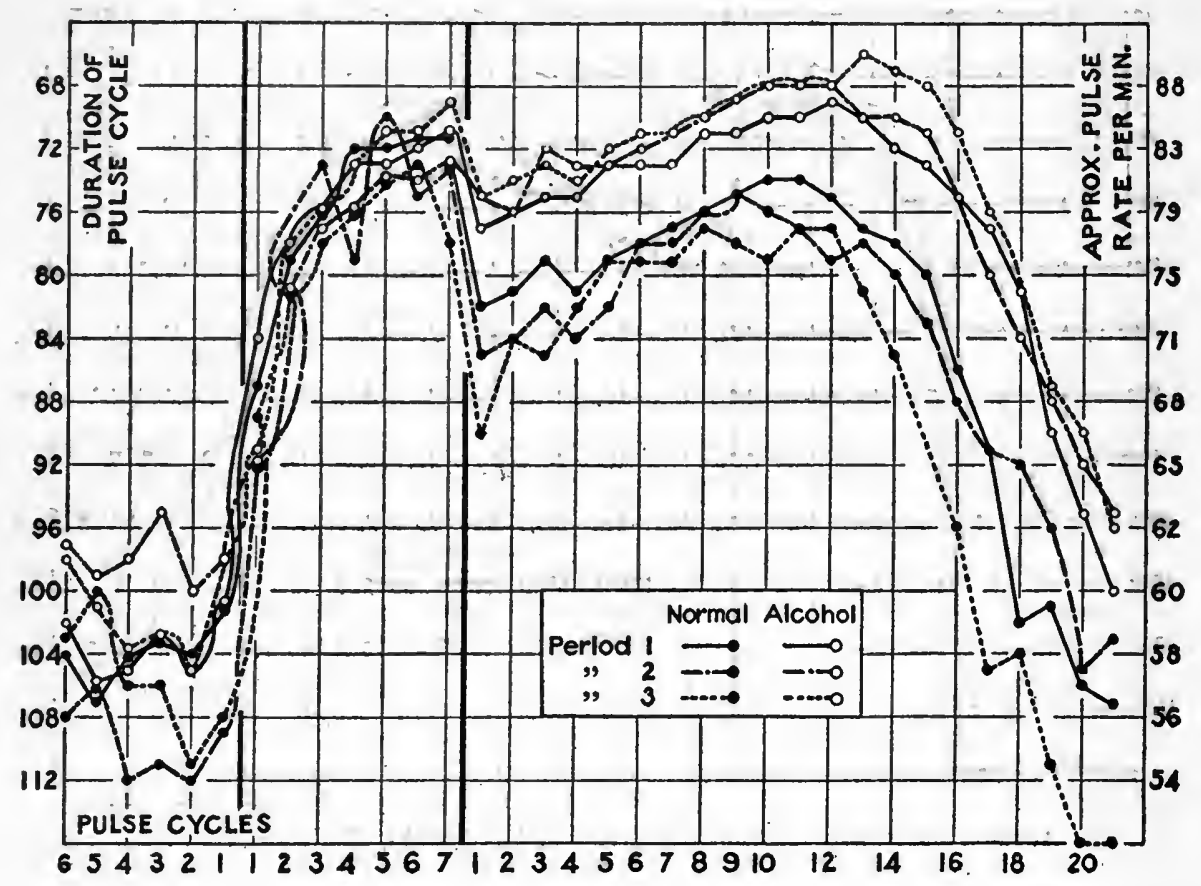

Fig. 14.-Duration of pulse cycles given in hundredths of a second in first, second, and third periods on normal and alcohol days in pre-tetanus, tetanus, and post-tetanus divisions.

in the preceding figure, light and heavy lines have been used to represent the data for alcohol and non-alcohol days, respectively. To simplify the figure only 6 curves are incorporated, these representing the averages for periods 1,2 , and 3 of the alcohol days and the same periods for the non-alcohol days. The two continuous-line curves, one light and the other heavy, for the first periods of the alcohol and normal days, respectively, both represent normal data, since in each case the records were taken preceding control or alcohol doses; these normal curves must be given the first attention. In the pre-tetanus section these curves lie very close together-closer in fact than any other two curves of the six. The tendency for the same two curves to fall on identical points is also prominent in the tetanus division of figure 14 
Immediately after the tetanus they separate and maintain their respective levels throughout the period of recuperation. In examining these two curves for period 1 it should be remembered that the terms alcohol and normal are purely arbitrary and used simply for convenience in designating the two groups of days. In reality each curve represents values as normal as the other, as both represent data obtained during the first experimental hour before either the control or the alcohol dose had been given.

No complete explanation is at hand for the fact that the two curves followed a nearly identical course during pre-tetanus and tetanus and then changed to such definitely different levels in the process of recuperation. Before such phenomena can be properly discussed, doubtless much more normal data must be obtained. The physical exercise which was chosen in this measurement to act as the stimulation to heart rate is not one that is susceptible of careful standardization. The chief thing which recommended it was the rapidity with which rest, muscular tension, and relaxation could follow each other. The transitional interval from rest to tension would naturally be much longer if the subject were required to rise, stand, and then perform genuflections or other vigorous movements; the transition to relaxation would also be lengthened. While voluntary stiffening of the muscles of limbs and trunk at a given signal is ideal from the standpoint of a quick transition from rest to activity, and then to rest, the intensity of activity or muscle tension is largely dependent upon the subject. The instruction to "be vigorous" avails, of course, only in a general way and does not produce uniformity. The experimenter did not observe with certainty that the tetanus was more vigorous on certain days than on others, but noted that it tended to decrease somewhat from second to second during the short interval which was used. There were times when the subject seemed to make a fresh effort during the last one or two seconds of the interval as if he himself recognized that he had relaxed his muscles. Some slight indication of the vigor of tetanus is provided in the actioncurrent curves which are shown along with the electro-cardiograms. These can be clearly seen in figure 11, $A$ and $B$, and are usually fairly prominent. Later trials with this same measurement on another subject, however, have shown that the pulse-rate in the post-tetanus part of a record is largely influenced by the vigor of the muscle tension during the 5-second interval. If the tension is very vigorous the rate in the recuperation period will reach a point equaling or surpassing that during the tetanus; that is, the condition will be just the same as was found for Subject VI in the pre-alcohol periods of the alcohol days. It thus appears probable that the subject, guessing that alcohol was to be given, was incited by the fact to more severe effort. That he should be more vigorous on July 4 is only to be expected from the general spurt which obtained on that day. 
Notwithstanding the fact that the considerable difference in level of the two curves in figure 12 and of the two groups in figure 13, particularly for the post-tetanus section, can not be considered as entirely due to alcohol, since the first period for normal and alcohol days also shows a difference in level, the alcohol did produce an effect upon the tetanus pulse. In figure 14, while the course of the curves is somewhat irregular, it is clear that the curves for periods 2 and 3 of the normal days in the pre-tetanus, tetanus, and post-tetanus sections are, in general, below the curve for the first period of normal days. This means that the course of the pulse on normal days tended towards a retardation following the first period, like that found by Dodge and Benedict for the group of normal subjects, particularly on the pulse during the association experiments. The condition after alcohol, as represented in figure 14 , is in direct contrast to this. In the pre-tetanus division the firstperiod curve, normal, for the alcohol days occupies the lowest level; that is, the curves for periods 2 and 3 do not touch any lower point. The curve for period 2 is decidedly above, showing an average duration of 98 as compared with 104 for period 1 . In the tetanus division of the figure, the curve for period 2 is below 1 , showing a less rapid pulse during the activity. Following the muscle tension there is but a slight drop; the curve crosses that for period 1 and remains above it during the post-tetanus division. The curve for period 3 of the alcohol days tends to be above that for period 1 in every section, thus showing a more rapid pulse following the alcohol, a condition of definite contrast with the normal days, when the heart rate was slower after period 1, notwithstanding the fact that there was a preliminary difference in level between the two groups of days in the post-tetanus section.

A summary of the durations of the pulse cycles by periods for both the normal and alcohol days is given in table 18, each pulse-length representing the average of the corresponding pulse cycles shown in table 17 for the respective periods on the normal and alcohol days. The differences, calculated according to the usual method, are likewise included in the table and the effect of alcohol on all periods taken together is given in differences and per cent. It will be seen at a glance that the differences for normal days are predominatingly plus, while those for the alcohol days are, as a rule, minus. This is a restatement of what was indicated in the curves in figure 14, i. e., that the pulse-length increased after the first period on normal days and decreased after the first period on alcohol days. The average normal differences deducted from those for alcohol show the contrast or general alcohol effect. At every point (see bottom of table 18) in the pre-tetanus and tetanus divisions and with the single exception of the eighteenth pulse cycle in the post-tetanus division, the sign is minus, indicating a shorter pulse cycle (faster pulse rate) after the alcohol. The effect is most prominent in the pre-tetanus division. Here the average for all the measured 
pulse cycles preceding tetanus shows a decrease of 9 per cent in cycle length, while for the tetanus division the decrease is 2.9 per cent. The post-tetanus division, which includes 21 cycles for comparison, as the pre-tetanus contains 6 and the tetanus 7 cycles, may be averaged in blocks of 7 cycles. Beginning at the left, the decrease in length for 1 to 7 inclusive is $-2.4,8$ to $14,-3.5$, and 15 to $21,-1.4$ per cent.

To provide a convenient numerical statement for the effect of alcohol by periods on the tetanus pulse, table 19 has been compiled. Here the effect of alcohol is given not on the individual homologous pulse cycles, but the differences have been averaged together to obtain a statement for the pre-tetanus, tetanus, and post-tetanus divisions of the record. This has been done for each experimental hour following the ingestion of alcohol. The method of compiling table 19 may be illustrated as follows:

In table 18 the differences for the first period of normal days in the pre-tetanus division are $+4,-1,+8,+8,+8$, and +8 ; the average of these differences is +6 . The corresponding differences for the first period on alcohol days in the same division are shown as $-5,-7,-7$, $-8,-5$, and -3 ; their average is -6 . From this latter average we subtract +6 for the normal days and obtain the difference of -12 as given in table 19. It will be seen, therefore, that the effect of alcohol in period 2 was to reduce the pulse length in the pre-tetanus division by an average of $0.12^{\prime \prime}$. In the tetanus division there was a slight increase in the length of $0.01^{\prime \prime}$, and in the post-tetanus division a decrease which was also slight, $0.02^{\prime \prime}$. In periods 3,4 , and 5 a clear tendency is shown for the pulse-length to decrease, this of course meaning a faster pulse rate as a result of the taking of alcohol. These values are given in terms of percentages in the right-hand columns of table 19. The values for the relevant normal were obtained by averaging the pulselengths in period 1 of the pre-tetanus, tetanus, and post-tetanus sections of table 18. For example, it will be seen from table 18, period 1, normal, that the relevant normal for the pre-tetanus division may be obtained by adding 103.8 (the average of 104, 107, 104, 103, 104, and 101) to 103.7 (the average of the similar values for the first period on the alcohol days, that is, 102, 106, 105, 103, 105, and 101) and dividing the total by 2 , giving an average relevant normal for the pre-tetanus division of 103.7. Using this average as a basal value, we may compute the percentile effect of alcohol from the values for differences given in table 19, the percentages for the pre-tetanus division being -11.6, $-3.9,-14.5$, and -5.8 for periods $2,3,4$, and 5 , respectively.

By way of summary, therefore, it may be said that in this measurement, under the conditions employed, a dose of 30 c.c. of absolute alcohol produces not only relatively but absolutely a positive rise in pulse rate per minute. The increase in rate is particularly prominent previous to muscular tension. During the period of tension the pulse fails 
Effect of Alcohol on Psycho-Physiological Functions.

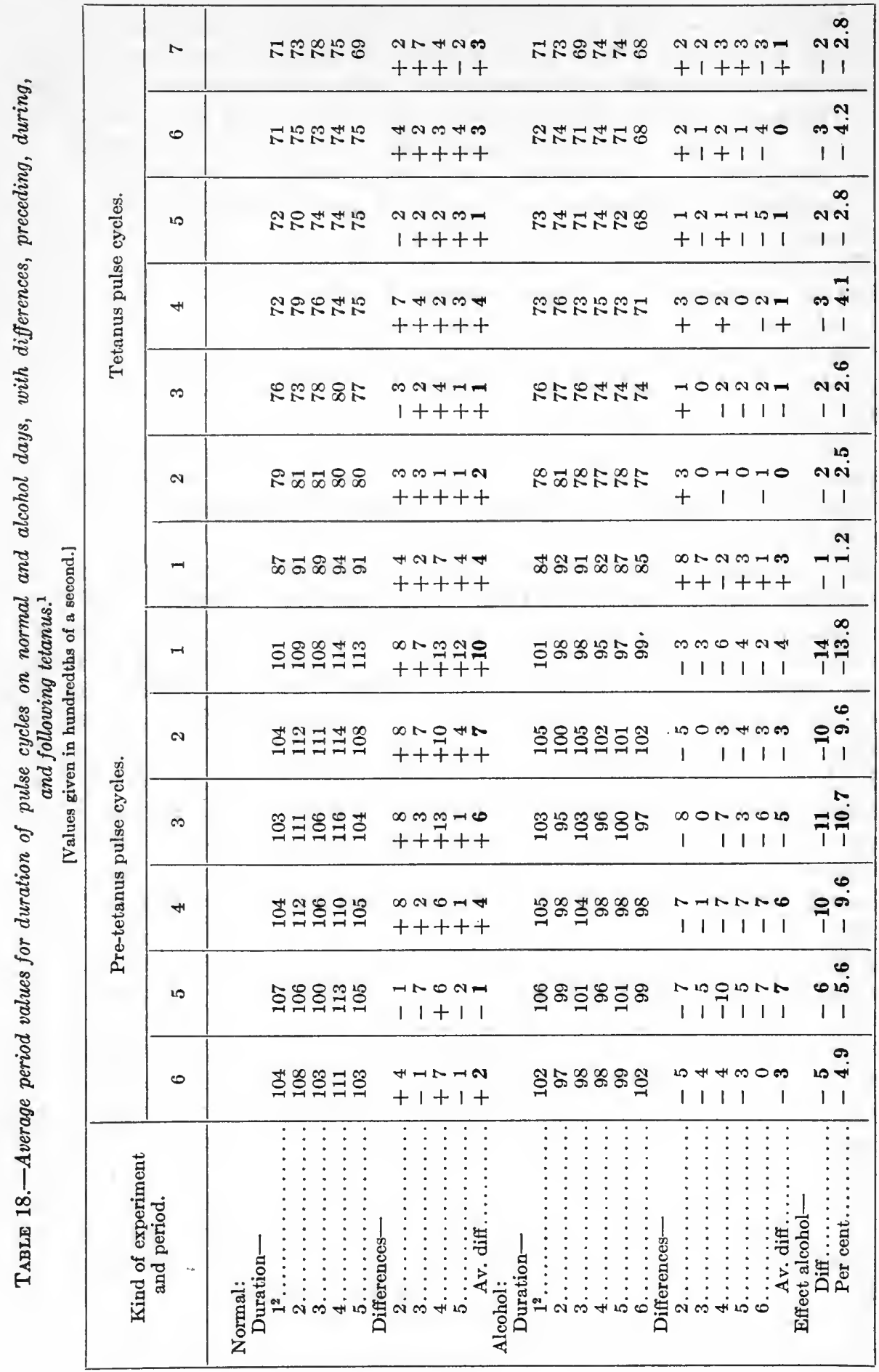


Pulse and Respiration.

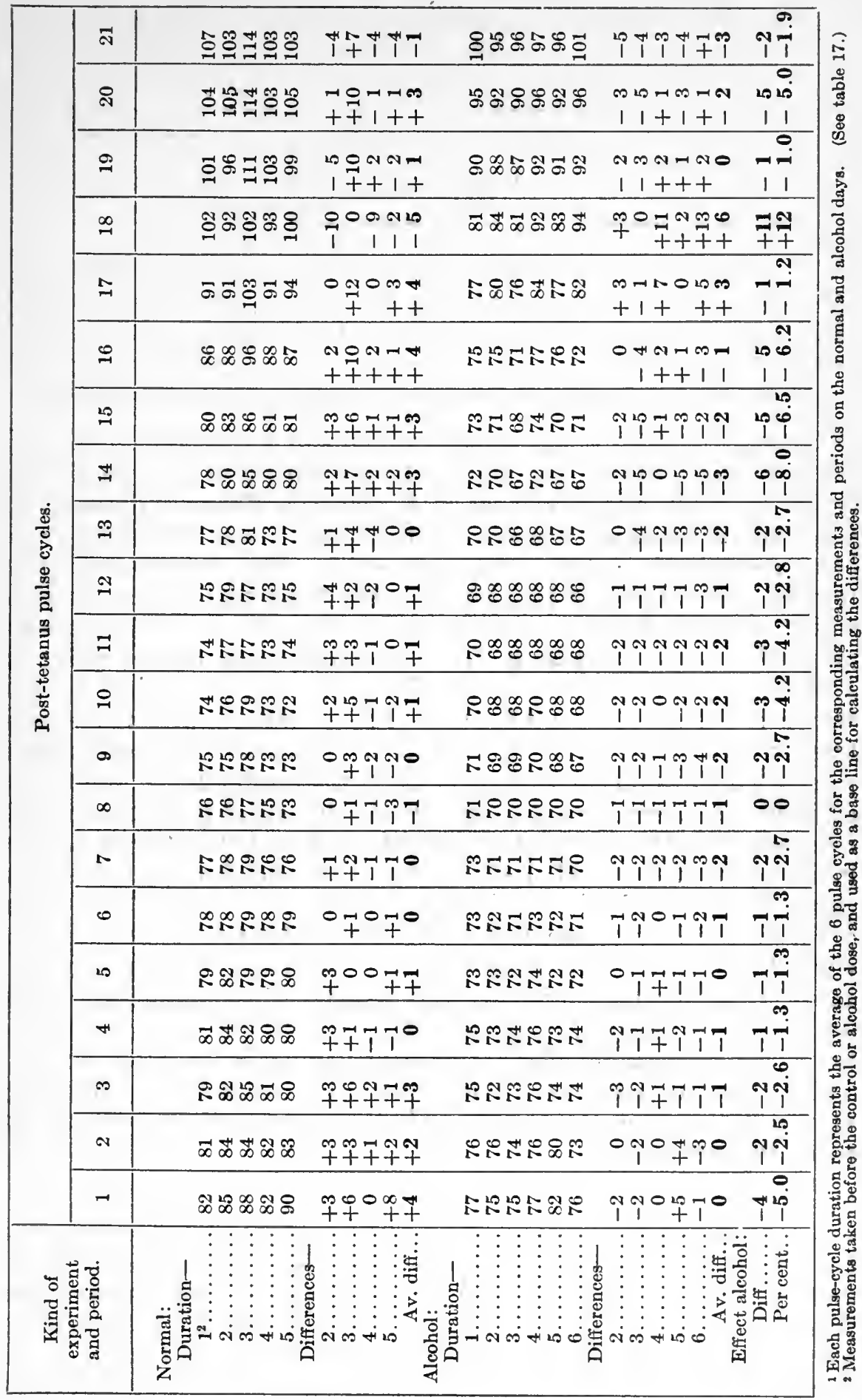


TABLE 19.-Effect of alcohol, as shown by differences, for pulse cycles preceding, during, and following tetanus.

[Differences given in hundredths of a second.]

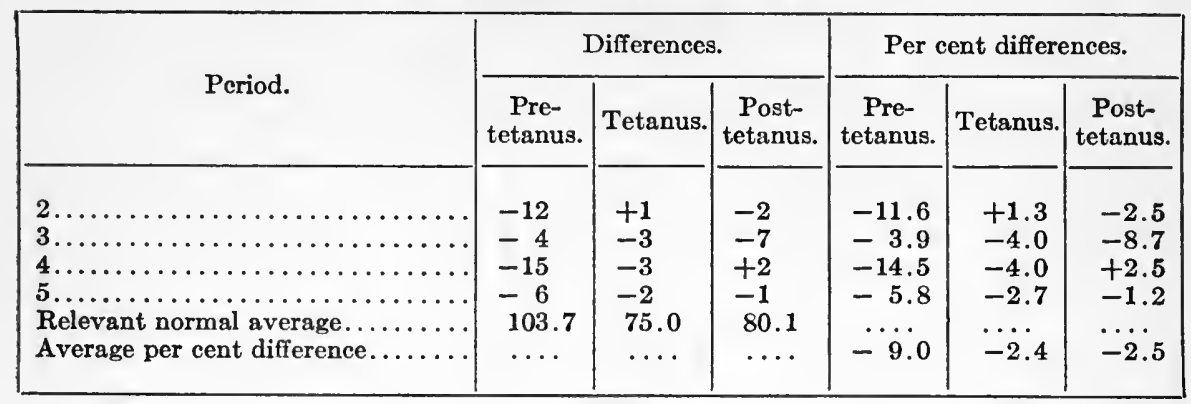

to respond in rate to the degree that would be expected; the percentage effects during the tetanus division as given in table 19 is for period $2,+1.3$, but in periods 3,4 , and 5 of the same division, the pulse rate is faster after alcohol than normally, the percentage values being respectively $-4.0,-4.0$, and -2.7 . The percentages for the tetanus division clearly indicate that the heart rate during muscular activity, of the duration used in this experiment, is not increased in proportion to the increase in the pre-tetanus pulse, during which the subject was more or less relaxed. The same may be said of the percentages $-2.5,-8.7,+2.5$, and -1.2 , average, -2.5 , in the posttetanus division of table 19; that is, they do not show relatively so great an increase in the pulse rate as do the results in the pre-tetanus division. It seems probable that the alcohol effect is proportionately reduced when the pulse rate is already fast and that this is another indication that the alcohol affects the vagus and through it the heart rate. Doubtless the lessened effect in this case is partly due to the conditions in the first period of alcohol days in the post-tetanus division when the rate was so surprisingly high. The alcohol effect is, in general, about equally prominent in periods 2,3 , and 4 , while period 5 shows it in less degree. Dodge and Benedict (see p. 239 of their report) observed that "the accelerating effect of muscular action is less after alcohol," and the tetanus pulse-data substantiate this conclusion, since the change in rate from pre-tetanus to tetanus is always less after the subject has taken the alcohol dose.

\section{ADDITIONAL PULSE DATA.}

As was explained on page 24 in the outline of the experimental cycle, the electro-cardiograms from body-leads were taken at the following points in the experimental hour: (1) preceding the patellar-reflex measurements with the subject resting; (2) following the patellar-reflex measurements with the subject resting; (3) following the taking of the faradic threshold with the subject resting; (4) before the word reaction 
with the subject seated in the upright chair, holding the voice key; (5) and (6) during the last third of the word-reaction measurement (taken by the assistant without in any way interrupting the word reactions); (7) following the word reactions with the subject sitting in upright chair, holding the voice key; (8) and (9) at the time of recording the finger movements. The last two records were separated from each other by 1 minute.

The body electrodes and the respiration tambour were continuously in place and caused the subject no discomfort. Usually connections to the string galvanometer and to the respiration recorder were maintained so that no adjustment would be necessary immediately before the taking of the record. The high-speed worm-gear motor used to drive the paper camera was in the same room with the subject; as this made a humming sound during action the subject could note approximately when the pulse record was being taken. It seems unlikely, however, that the subject paid any attention to this sound, as he was used to it in other groups of experiments in which the apparatus was essentially the same.

The usual length of a single pulse record for conditions 1 to $7,{ }^{1}$ of the experimental hour was 15 seconds. In these records the individual pulse cycles were not measured as in the case of the tetanus pulse. Homologous points were chosen in the respiration curve near each end of the record, and the number of pulse cycles between these two points were counted. In this way any effect of respiration upon the pulse rate tended to be compensated, since the same number of inspirations and expirations were taken in this interval during which the pulse was counted. The time distance represented in the same interval, divided by the number of pulse beats, equals the average pulse-length in terms of thousandths of a second for this record. Illustrative records are shown in figure 11, $C, D, G$, and $H$. (See p. 96.) Here the points in the respiration curves are marked so that the method of determining the pulse duration can be quickly understood. The records illustrated in $G$ and $H$ have been reduced in length for purposes of reproduction.

The pulse data for records 1 to 7 , inclusive, are given in table 20, which is really made up of 7 small tables arranged substantially in the usual form employed, and is accompanied by a summary of daily averages and of total averages. Since as a rule the individual pulse cycles were not measured, no mean variation is available. This has made it possible to condense the table somewhat by putting the differences in parallel columns with the pulse duration rather than in a separate section. The pulse durations and differences are given by periods. The averages (at the extreme right), as usual, do not include the first-period

\footnotetext{
1 For convenience in referring to the pulse records taken under the varying experimental conditions, the numbers 1 to 7 , inclusive, as defined in the first paragraph of this section, will be employed.
} 
TABLE 20.-Pulse measurements at various points in the experimental cycle.

[Values given in thousandths of a second.]

\begin{tabular}{|c|c|c|c|c|c|c|c|c|c|c|c|c|c|}
\hline \multirow{2}{*}{$\begin{array}{l}\text { Experimcntal condition } \\
\text { and date. }\end{array}$} & \multirow{2}{*}{$\begin{array}{c}\begin{array}{c}\text { Period } \\
1 .\end{array} \\
\begin{array}{c}\text { Dura } \\
\text { tion. }\end{array}\end{array}$} & \multicolumn{2}{|c|}{$\begin{array}{l}\text { Period } \\
2 .\end{array}$} & \multicolumn{2}{|c|}{$\begin{array}{l}\text { Period } \\
3 .\end{array}$} & \multicolumn{2}{|c|}{$\begin{array}{l}\text { Period } \\
\quad 4 .\end{array}$} & \multicolumn{2}{|c|}{$\begin{array}{l}\text { Period } \\
5 .\end{array}$} & \multicolumn{2}{|c|}{$\begin{array}{l}\text { Period } \\
6 .\end{array}$} & \multicolumn{2}{|c|}{ Average. } \\
\hline & & $\begin{array}{l}\text { Dura- } \\
\text { tion. }\end{array}$ & Diff. & $\begin{array}{l}\text { Dura- } \\
\text { tion. }\end{array}$ & Diff. & $\begin{array}{l}\text { Dura- } \\
\text { tion. }\end{array}$ & Diff. & $\begin{array}{l}\text { Dura- } \\
\text { tion. }\end{array}$ & Diff. & $\begin{array}{l}\text { Dura- } \\
\text { tion. }\end{array}$ & Diff. & $\begin{array}{c}\text { Dura- } \\
\text { tion. }\end{array}$ & Diff. \\
\hline \multicolumn{14}{|l|}{$\begin{array}{l}\text { 1. Resting before pa- } \\
\text { tellar reflex: } \\
\text { Normal- }\end{array}$} \\
\hline $\begin{array}{c}\text { Normal } \\
\text { June } 29\end{array} \ldots \ldots \ldots$ & 1035 & 1005 & -30 & 997 & -38 & 1099 & +64 & & & & & 1030 & \\
\hline July $\quad 1 \ldots$ & $\begin{array}{l}1079 \\
1061\end{array}$ & $\begin{array}{r}892 \\
1079\end{array}$ & $\begin{array}{l}-187 \\
+18\end{array}$ & $\begin{array}{l}1154 \\
1204\end{array}$ & $\begin{array}{l}+75 \\
+143\end{array}$ & $\begin{array}{l}10066 \\
1000\end{array}$ & $\begin{array}{l}=13 \\
=61\end{array}$ & $\begin{array}{l}1104 \\
1100\end{array}$ & $\begin{array}{l}+25 \\
+39\end{array}$ & $\mathrm{izi2}$ & +151 & $\begin{array}{l}1079 \\
1119\end{array}$ & $\begin{array}{r}\mp_{58}^{25} \\
\mp\end{array}$ \\
\hline $\begin{array}{l}\text { Average. } \\
\text { Alcohol- }\end{array}$ & 1058 & 992 & -66 & 1118 & +60 & 1055 & -3 & 1102 & +32 & 1212 & +151 & 1076 & +11 \\
\hline June $30 \ldots$ & 912 & 946 & $\begin{array}{l}+34 \\
\pm 14\end{array}$ & 1020 & $\begin{array}{l}+108 \\
+35\end{array}$ & 910 & $\begin{array}{l}-2 \\
-20\end{array}$ & 1058 & $\begin{array}{l}+146 \\
-83\end{array}$ & 1075 & & 984 & +72 \\
\hline July $4 \ldots$ & 1055 & & -167 & 1014 & -41 & 830 & -225 & 790 & -265 & $\begin{array}{r}1075 \\
840\end{array}$ & \pm-215 & 872 & -183 \\
\hline $\begin{array}{l}\text { Average..... } \\
\text { Effect of alcohol- }\end{array}$ & 987 & 938 & -49 & 1021 & +34 & 905 & -82 & 920 & -68 & 957 & -67 & 950 & -37 \\
\hline Differences..... & .... & $\ldots$ & +17 & 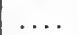 & -28 & $\ldots$ & -79 & 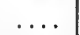 & -100 & $\ldots$ & -218 & & \\
\hline \multirow{2}{*}{\multicolumn{14}{|c|}{$\begin{array}{l}\text { 2. Resting after patel- } \\
\text { lar reflex: } \\
\text { Normal- }\end{array}$}} \\
\hline & & & & & & & & & & & & & \\
\hline June $29 \ldots \ldots \ldots$ & 971 & 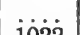 & $\cdots$ & 1051 & +80 & 1040 & +69 & & 15 & & & 1045 & +75 \\
\hline July & $\begin{array}{l}1045 \\
1005\end{array}$ & $\begin{array}{l}1022 \\
1119\end{array}$ & +114 & $\begin{array}{l}1020 \\
1082\end{array}$ & $\mp 77$ & $\begin{array}{l}1001 \\
1104\end{array}$ & $\begin{array}{l}+16 \\
+99\end{array}$ & 1072 & $\begin{array}{l}+10 \\
+67\end{array}$ & iioo & +95 & $\begin{array}{l}1042 \\
1095\end{array}$ & $\mp 90^{3}$ \\
\hline Averag & 1007 & 1070 & +45 & 1053 & +46 & 1068 & +61 & 1066 & +41 & 1100 & +95 & 1061 & +64 \\
\hline $\begin{array}{l}\text { Acono } \\
\text { June. }\end{array}$ & 971 & 949 & -22 & 1009 & +38 & 962 & 9 & 912 & -59 & & & 958 & -13 \\
\hline & 1040 & 929 & $\begin{array}{l}-111 \\
-205\end{array}$ & 980 & -60 & 874 & -166 & 914 & -126 & 938 & -102 & 927 & -113 \\
\hline July 4 .. & $\begin{array}{l}1070 \\
1027\end{array}$ & $\begin{array}{l}865 \\
914\end{array}$ & $\begin{array}{l}-205 \\
-113\end{array}$ & $\begin{array}{l}914 \\
968\end{array}$ & $\begin{array}{l}-156 \\
-59\end{array}$ & $\begin{array}{l}813 \\
883\end{array}$ & $\begin{array}{l}-257 \\
-144\end{array}$ & $\begin{array}{l}815 \\
880\end{array}$ & $\begin{array}{l}-255 \\
-147\end{array}$ & $\begin{array}{l}966 \\
\mathbf{9 5 2}\end{array}$ & $\begin{array}{l}-104 \\
-103\end{array}$ & $\begin{array}{l}875 \\
920\end{array}$ & $\begin{array}{l}-195 \\
-107\end{array}$ \\
\hline $\begin{array}{c}\text { Effec } \\
\text { Dif }\end{array}$ & & & -158 & & -105 & $\ldots$ & -205 & $\ldots$ & -188 & $\ldots$ & -198 & 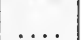 & \\
\hline Per cent differences & $\cdots$ & $\cdots$ & -15.6 & $\ldots$ & -10.3 & $\cdots$ & -20.1 & $\cdots$ & $-18.5 \mid$ & $\ldots$ & $\begin{array}{r}-19.5 \\
\end{array}$ & $\cdots$ & . \\
\hline \multicolumn{14}{|l|}{$\begin{array}{l}\text { 3. Resting after faradic } \\
\text { threshold: }\end{array}$} \\
\hline$\underset{\text { June } 29}{\text { Normal- }} \ldots \ldots \ldots$ & & 1023 & +135 & & +199 & & & & & & & 1073 & +185 \\
\hline Jul & 1069 & 1081 & $\begin{array}{l}+12 \\
+12\end{array}$ & 1054 & $\begin{array}{l}159 \\
-15\end{array}$ & 1078 & +9 & $\ddot{9} \dot{q} \mathrm{i}$ & $\because 98$ & $\ldots$ & & 1046 & $\begin{array}{l}+180 \\
-23\end{array}$ \\
\hline July & 1090 & 1137 & $\begin{array}{l}+47 \\
+45\end{array}$ & 1181 & $\begin{array}{l}+91 \\
+92\end{array}$ & 1129 & +39 & 1170 & +80 & 1189 & +99 & 1161 & +71 \\
\hline Alcohol- & 1016 & 1080 & +65 & 1107 & +92 & 1106 & +91 & 1070 & -9 & 1189 & +99 & 1093 & +78 \\
\hline Jun & 1036 & 919 & -117 & 1023 & -13 & 1041 & +5 & 1005 & -31 & $i \ddot{0} \ddot{0}$ & 61 & 997 & -39 \\
\hline & $\begin{array}{l}1090 \\
1041\end{array}$ & $\begin{array}{l}950 \\
965\end{array}$ & $\begin{array}{l}-140 \\
-76\end{array}$ & $\begin{array}{l}986 \\
963\end{array}$ & $\begin{array}{l}-104 \\
-76\end{array}$ & $\begin{array}{l}899 \\
915\end{array}$ & $\begin{array}{l}-191 \\
-126\end{array}$ & 950 & $=91$ & $\begin{array}{l}1029 \\
1045\end{array}$ & $7 \begin{array}{l}01 \\
+\quad 4\end{array}$ & 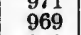 & $\begin{array}{l}-119 \\
-73\end{array}$ \\
\hline Av & 1056 & 945 & -111 & 991 & -65 & 952 & -104 & 982 & -74 & 1037 & -28 & 979 & -77 \\
\hline & & $\ldots$ & -176 & $\ldots$ & -157 & $\ldots$ & -195 & $\ldots$ & -65 & $\ldots$ & -127 & & \\
\hline \multirow{2}{*}{\multicolumn{14}{|c|}{$\begin{array}{l}\text { 4. Holding voice key } \\
\text { before word reac- } \\
\text { tions: }\end{array}$}} \\
\hline & & & & & & & & & & & & & \\
\hline$\stackrel{\text { Normal- }}{\text { June } 29 \ldots . . . . .}$ & & & & & & & & & & & & 040 & \\
\hline & $\begin{array}{r}960 \\
1050\end{array}$ & $\begin{array}{l}1033 \\
1100\end{array}$ & $\begin{array}{l}+73 \\
+50\end{array}$ & $\begin{array}{l}1061 \\
1061\end{array}$ & & $\begin{array}{l}1021 \\
1035\end{array}$ & $\begin{array}{l}+01 \\
\pm 15\end{array}$ & iiзo & $+80^{\circ}$ & & & 1081 & $\begin{array}{r}+89 \\
+32 \\
\end{array}$ \\
\hline July 3 . & 1071 & 1189 & +118 & & +1 & & + & & & 1265 & +194 & 1181 & +110 \\
\hline Average & 1027 & 1107 & +80 & 1130 & +103 & 1047 & +20 & 1129 & +68 & 1265 & +194 & 1104 & +77 \\
\hline$\underset{\mathrm{J}}{\text { Ale }}$ & 1036 & 980 & -56 & 963 & -73 & 1034 & -2 & 962 & -74 & & & 985 & -51 \\
\hline & & 1054 & & 102 & -8 & & -61 & & -3 & 981 & -125 & 1039 & -67 \\
\hline & 1100 & 914 & $\begin{array}{r}-186 \\
-98\end{array}$ & $\begin{array}{l}1019 \\
1002\end{array}$ & $=81$ & $\begin{array}{r}991 \\
1023\end{array}$ & $\begin{array}{l}-109 \\
-57\end{array}$ & $\begin{array}{r}992 \\
1015\end{array}$ & $=-66$ & 953 & $\begin{array}{l}-175 \\
-150\end{array}$ & $\begin{array}{l}968 \\
997\end{array}$ & $\begin{array}{l}-132 \\
-83\end{array}$ \\
\hline Effect & & & & & & & & & & 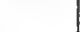 & & & \\
\hline f........ & ... & $\cdots$ & $\begin{array}{l}-178 \\
-16.9\end{array}$ & $\ldots$ & $\left|\begin{array}{l}-181 \\
-17.2\end{array}\right|$ & $\cdots$ & $=77.3$ & $\ldots$ & $\mid \begin{array}{l}-134 \\
-12.7\end{array}$ & $\cdots$ & $\left|\begin{array}{l}-344 \\
-32.6\end{array}\right|$ & $\ldots$ & $\ldots$ \\
\hline 5. During word reac- & & & & & & & & & & & & & \\
\hline $\begin{array}{l}\text { norm } \\
\text { nor }\end{array}$ & & & & & & & & & & & & & \\
\hline Jun & 960 & 1108 & +148 & 1018 & $\begin{array}{l}+58 \\
+65\end{array}$ & 1090 & +130 & i0̈25 & $\because \dot{5}$ & $\cdots$ & & $\begin{array}{l}1072 \\
1047\end{array}$ & $\begin{array}{l}+112 \\
-28\end{array}$ \\
\hline & 1075 & 1039 & $\begin{array}{l}=30 \\
-33\end{array}$ & $\begin{array}{l}1140 \\
1155\end{array}$ & $\begin{array}{r}+00 \\
+11\end{array}$ & $\begin{array}{l}984 \\
1150\end{array}$ & $\mp 91$ & 1091 & $=5$ & iizi & $\ddot{+} \ddot{27}$ & 1136 & $=8$ \\
\hline & 1060 & 1086 & +26 & 1104 & +45 & 1075 & +15 & 1058 & -51 & 1171 & +27 & 1085 & +25 \\
\hline $\begin{array}{l}\text { Alcoh } \\
\text { Jun }\end{array}$ & 978 & 962 & -1 & 1042 & +64 & 935 & -43 & 932 & -46 & $\ldots$ & $\ldots$ & 968 & -10 \\
\hline & & 96 & -7 & 955 & - & 940 & & 953 & -8 & & in & 952 & -86 \\
\hline & & 970 & -6 & 1059 & +28 & 950 & -81 & 960 & -71 & 900 & -131 & 968 & $\begin{array}{l}-63 \\
-6\end{array}$ \\
\hline & 1016 & 964 & -52 & 1019 & +3 & 942 & -74 & 948 & -67 & 900 & $\mid-131$ & 963 & -53 \\
\hline $\begin{array}{l}\text { Effect of alc } \\
\text { Difference }\end{array}$ & $\cdots$ & $\ldots$ & -78 & & -42 & $\ldots$ & -89 & $\ldots$ & -16 & $\ldots$ & -158 & $\ldots$ & $\ldots$ \\
\hline & & & & & & & & & & & & & \\
\hline
\end{tabular}


TABLE 20-Pulse measurements at various points in the experimental cycle.-Continued.

[Values given in thousandths of a second.]

\begin{tabular}{|c|c|c|c|c|c|c|c|c|c|c|c|c|c|}
\hline \multirow{2}{*}{$\begin{array}{l}\text { Experimental condition } \\
\text { and date. }\end{array}$} & \multirow{2}{*}{$\begin{array}{c}\begin{array}{c}\text { Period } \\
1 .\end{array} \\
\begin{array}{c}\text { Dura- } \\
\text { tion. }\end{array}\end{array}$} & \multicolumn{2}{|c|}{$\begin{array}{l}\text { Period } \\
2 .\end{array}$} & \multicolumn{2}{|c|}{$\begin{array}{l}\text { Period } \\
3 .\end{array}$} & \multicolumn{2}{|c|}{$\begin{array}{l}\text { Period } \\
4 .\end{array}$} & \multicolumn{2}{|c|}{$\begin{array}{l}\text { Period } \\
5 .\end{array}$} & \multicolumn{2}{|c|}{$\begin{array}{l}\text { Period } \\
6 .\end{array}$} & \multicolumn{2}{|c|}{ Average. } \\
\hline & & $\begin{array}{l}\text { Dura- } \\
\text { tion. }\end{array}$ & Diff. & $\begin{array}{l}\text { Dura- } \\
\text { tion. }\end{array}$ & Diff. & $\begin{array}{l}\text { Dura- } \\
\text { tion. }\end{array}$ & Diff. & $\begin{array}{c}\text { Dura- } \\
\text { tion. }\end{array}$ & Diff. & $\begin{array}{c}\text { Dura- } \\
\text { tion. }\end{array}$ & Diff. & $\begin{array}{l}\text { Dura- } \\
\text { tion. }\end{array}$ & Diff. \\
\hline \multicolumn{14}{|l|}{$\begin{array}{l}\text { 6. During word reac- } \\
\text { tions: }\end{array}$} \\
\hline$\stackrel{\text { Normal }}{\text { June } 29} \ldots \ldots \ldots \ldots$ & 946 & 1000 & +54 & 1056 & +110 & 1061 & +115 & & & 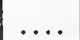 & & 1039 & +93 \\
\hline $\begin{array}{l}\text { July } \\
\text { July }\end{array}$ & $\begin{array}{l}1070 \\
1095\end{array}$ & $\begin{array}{l}1081 \\
1073\end{array}$ & \pm 11 & $\begin{array}{l}1110 \\
1209\end{array}$ & $\begin{array}{r}+40 \\
+114 \\
+14\end{array}$ & $\begin{array}{l}1069 \\
1154\end{array}$ & $\begin{array}{l}1 \\
+59\end{array}$ & 987 & -83 & $\mathbf{i} 200$ & +105 & $\begin{array}{l}1062 \\
1159\end{array}$ & $\mp \begin{array}{r}8 \\
+64\end{array}$ \\
\hline Average. & 1037 & 1051 & +14 & 1125 & +88 & 1095 & +58 & 987 & $-83^{\circ}$ & 1200 & +105 & 1087 & +60 \\
\hline June 30 . & 997 & 911 & -86 & 1000 & +3 & 985 & -12 & 902 & -95 & & & 950 & -48 \\
\hline $\begin{array}{l}\text { July } \\
\text { July } \\
4 \ldots\end{array}$ & $\begin{array}{r}992 \\
1031\end{array}$ & $\begin{array}{l}927 \\
924\end{array}$ & $\begin{array}{l}-65 \\
-107\end{array}$ & $\begin{array}{l}997 \\
981\end{array}$ & $\pm \quad 5$ & $\begin{array}{l}920 \\
914\end{array}$ & $\begin{array}{l}-72 \\
-117\end{array}$ & 963 & -29 & $\begin{array}{r}1000 \\
093\end{array}$ & $\begin{array}{l} \pm 8 \\
-38\end{array}$ & 961 & $=\begin{array}{l}31 \\
=78\end{array}$ \\
\hline Averso & 1007 & 921 & -86 & 993 & -14 & 940 & -67 & 932 & -62 & 996 & -15 & 955 & $=62$ \\
\hline $\begin{array}{l}\text { Eitrect or alc } \\
\text { Difference }\end{array}$ & $\cdots$ & $\cdots$ & -100 & $\cdots$ & -102 & ... & -125 & $\cdots$ & +21 & $\ldots$ & -120 & ... & $\cdots$ \\
\hline $\begin{array}{l}\text { 7. Holding voice kcy } \\
\text { after word reac- } \\
\text { tions: }\end{array}$ & $\cdots$ & & & & -10.0 & ... & -12.2 & $\cdots$ & +2.1 & $\cdots$ & -11.7 & $\cdots$ & \\
\hline$\underset{\text { June } 29 . .}{\text { Normal- }}$ & & & & 1057 & & 1087 & & & & & & 1070 & +125 \\
\hline & 1120 & & -107 & & -2 & & -48 & 1081 & -39 & $\mathrm{iiiii}$ & $\ldots \ldots$ & 1064 & -56 \\
\hline $\begin{array}{r}\text { July } \\
\text { Average.................. }\end{array}$ & 1052 & $\begin{array}{l}1120 \\
1066\end{array}$ & $\begin{array}{l}+29 \\
+14\end{array}$ & 1102 & $\begin{array}{l}+68 \\
+50\end{array}$ & 1182 & +91 & 1123 & +17 & 1144 & +53 & $\begin{array}{l}1094 \\
1096\end{array}$ & +44 \\
\hline$\underset{\text { June }}{\text { Alcohol- }} 30 \ldots \ldots \ldots$ & 1022 & 961 & -61 & 1004 & & 929 & -93 & 866 & -156 & & & 940 & -82 \\
\hline & & & -93 & & - & & -1 & 954 & -117 & 1050 & -21 & 972 & -80 \\
\hline & $\begin{array}{l}1081 \\
1058\end{array}$ & $\begin{array}{l}996 \\
978\end{array}$ & $\begin{array}{l}=85 \\
-80\end{array}$ & $\begin{array}{r}996 \\
1000\end{array}$ & $\begin{array}{l}-85 \\
-58\end{array}$ & $\begin{array}{r}1014 \\
958\end{array}$ & $\begin{array}{l}-67 \\
-100\end{array}$ & $\begin{array}{l}994 \\
938\end{array}$ & $\begin{array}{l}-88 \\
-120\end{array}$ & $\begin{array}{r}954 \\
1002\end{array}$ & $\begin{array}{l}-128 \\
-74\end{array}$ & 辇11 & $\begin{array}{l}=80 \\
-87\end{array}$ \\
\hline $\begin{array}{l}\text { Effect } \\
\text { Dif }\end{array}$ & & & -94 & & -108 & 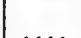 & -162 & . & -137 & 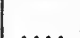 & -127 & & 0.0 \\
\hline Per & .... & .... & -8.9 & $\ldots$ & $\mid \begin{array}{r}-10.2 \\
-10.2\end{array}$ & $\ldots$ & {$\left[\begin{array}{l}-162 \\
-15.4\end{array}\right]$} & ..... & -13.0 & $\ldots$ & -12.0 & $\ldots$ & $\ldots$. \\
\hline $\begin{array}{l}\text { Daily a } \\
\text { Norm }\end{array}$ & & & & & & & & & & & & & \\
\hline Jun & 958 & 1039 & +83 & 105 & +93 & 1073 & +112 & & & . & & 1054 & +97 \\
\hline July $1 \ldots \ldots$ & $\begin{array}{l}1073 \\
1079\end{array}$ & 1033 & $\begin{array}{l}+40 \\
+39\end{array}$ & $\begin{array}{l}1091 \\
1175\end{array}$ & $\begin{array}{l}+18 \\
+96\end{array}$ & $\begin{array}{l}1052 \\
1115\end{array}$ & $\mp \begin{array}{l}20 \\
+35\end{array}$ & $\begin{array}{l}1051 \\
1121\end{array}$ & $\mp \begin{array}{l}21 \\
+44\end{array}$ & iiisi & $\ddot{+i 03}$ & $\begin{array}{l}1060 \\
1144\end{array}$ & +64 \\
\hline $\begin{array}{l}\text { Alcohol }- \\
\text { June } 30 . . . .\end{array}$ & 993 & & & 1009 & & 971 & & 948 & & & & 969 & \\
\hline July & $\begin{array}{l}1047 \\
1058\end{array}$ & $\begin{array}{l}968 \\
932\end{array}$ & $\begin{array}{l}-79 \\
-127\end{array}$ & $\begin{array}{r}996 \\
992\end{array}$ & $\begin{array}{l}-51 \\
-\quad 66\end{array}$ & $\begin{array}{l}940 \\
918\end{array}$ & $\begin{array}{l}-107 \\
-140\end{array}$ & 968 & $\begin{array}{l}-79 \\
-146\end{array}$ & $\begin{array}{r}i 0 i \dot{2} \\
946\end{array}$ & $\begin{array}{l}-37 \\
-112\end{array}$ & $\begin{array}{l}975 \\
942\end{array}$ & $\begin{array}{l}=72 \\
-116\end{array}$ \\
\hline $\begin{array}{l}\text { Total av } \\
\text { Norm }\end{array}$ & & & & & & & & & & & & & \\
\hline Alcohol.:. & $\begin{array}{l}1033 \\
1036\end{array}$ & $\begin{array}{r}949 \\
949\end{array}$ & & 999 & & $\begin{array}{r}1080 \\
943\end{array}$ & $\begin{array}{l}90 \\
-90\end{array}$ & 945 & \pm 86 & 971 & & 962 & -7 \\
\hline
\end{tabular}

values. The pulse data are given and averaged separately for each of the experimental conditions 1 to 7 .

The tolal averages reveal that the pulse level for the initial period is, on the average, practically identical for the two groups of days, being 1037 and $1033 \sigma$, as shown at the bottom of the table in the column headed Period 1. This average may be relied upon, as a comparison of the individual averages in this column shows that the average pulse duration for the first period of June 29, July 1; and July 3 is almost always approximately the same as the average for the same period on the corresponding alcohol dates, June 30, July 2, and July 4.

Inspection of the general averages for duration given in the next to the last column of the table ${ }^{1}$ will immediately show that in every case the averages for the normal days are larger than the averages for duration in the first period of these days. Thus, for the pulse preceding the 
patellar reflex (No. 1) we have the general average of 1076 for the duration of the pulse cycle during periods $2,3,4,5$, and 6 on June 29, July 1 , and July 3, and a value of 1058 for the average duration in the first period on these three days. For the other experimental conditions we have for pulse 2 the general average of 1061 as compared to 1007 for the first period; pulse 3, 1093 and 1016; pulse 4, 1104 and 1027; pulse 5, 1085 and 1060; pulse 6, 1087 and 1037; and finally pulse 7, 1096 and $1052 \sigma$, the value for period 1 being the smaller in each case. This must be interpreted as indicating that normally the pulse gradually lengthens after the first period; that is, its rate per minute becomes less, but the change is comparatively slight.

The comparable values for pulse duration on the alcohol days show an exactly reverse condition; that is, in every case the average for the first period on the three days, June 30 , July 2 , and July 4 , is larger than the average for periods $2,3,4,5$, and 6 of these three days. Since the pulse duration started at the same level for both groups of days, it is perfectly clear that the pulse on alcohol days following period 1 is more rapid. At the bottom of the table general averages are given for the normal and alcohol values. Each average, both normal and alcohol, is computed from the averages in the vertical column above it; they thus represent by periods the general tendency for all the pulse records taken under experimental conditions 1 to 7 , inclusive. The total average duration for the pulse cycle on alcohol days is 962 as compared with the average for normal days of $1086 \sigma$. The shorter pulse length after alcohol shown by these general averages is also revealed in each section of table 20 and in almost every period of each section. This tendency is so definite as to make it unnecessary to point out the individual comparisons.

The averages at the bottom of table 20 are also given in diagrammatic form in figure 15 (see solid-dot curves). The average durations of the cycles are given at the left and the corresponding pulse rate at the right. In this figure the heavy line represents the averages for the normal days. The curve starts with a duration of $1037 \sigma$, which corresponds to a rate of 58 beats per minute, and drops in periods 2 and 3 , reaching 55 beats per minute. In the fourth period there is a slight rise to 56 beats, which is continued in period 5 ; finally there is a decided drop to 51 beats in period 6 . Inasmuch as the fall in period 6 is in large part due to the more fragmentary data for this period (see table 20), the course of the normal curve shows a very slight decrease in pulse-rate throughout the experimental days. The alcohol curve starts at practically the same level as the normal curve, that is, 58 beats per minute. From this point there is a rise in period 2 to 63 beats per minute, a decrease in period 3 to 60 , then a return in period 4 to $63+$, with constancy in period 5 and a drop to 61 beats in period 6 . The two curves are sharply distinguished and show that the pulse of Subject VI was faster by about 6 beats per minute after the taking of alcohol. 
The effect of alcohol upon the pulse rate of Subject VI is also indicated in table 20 by the statistical method of differences. The average differences given in the last column of the table show that on the normal days the average difference is always a plus value. These average differences for the seven experimental conditions are, for the normal days, $+11,+54,+78,+77,+25,+50$, and +44 . The comparison values for the alcohol days are always minus, being $-37,-107,-77$, $-83,-53,-52$, and -87 . The general average differences for these two series are, respectively, +48 and -71 . What is thus indicated by the average differences will likewise be found to be true for the individual periods $2,3,4,5$, and 6 for the pulse taken under the different conditions from 1 to 7 ; that is, the differences for normal days have usually the plus sign, while those for alcohol days are usually minus.

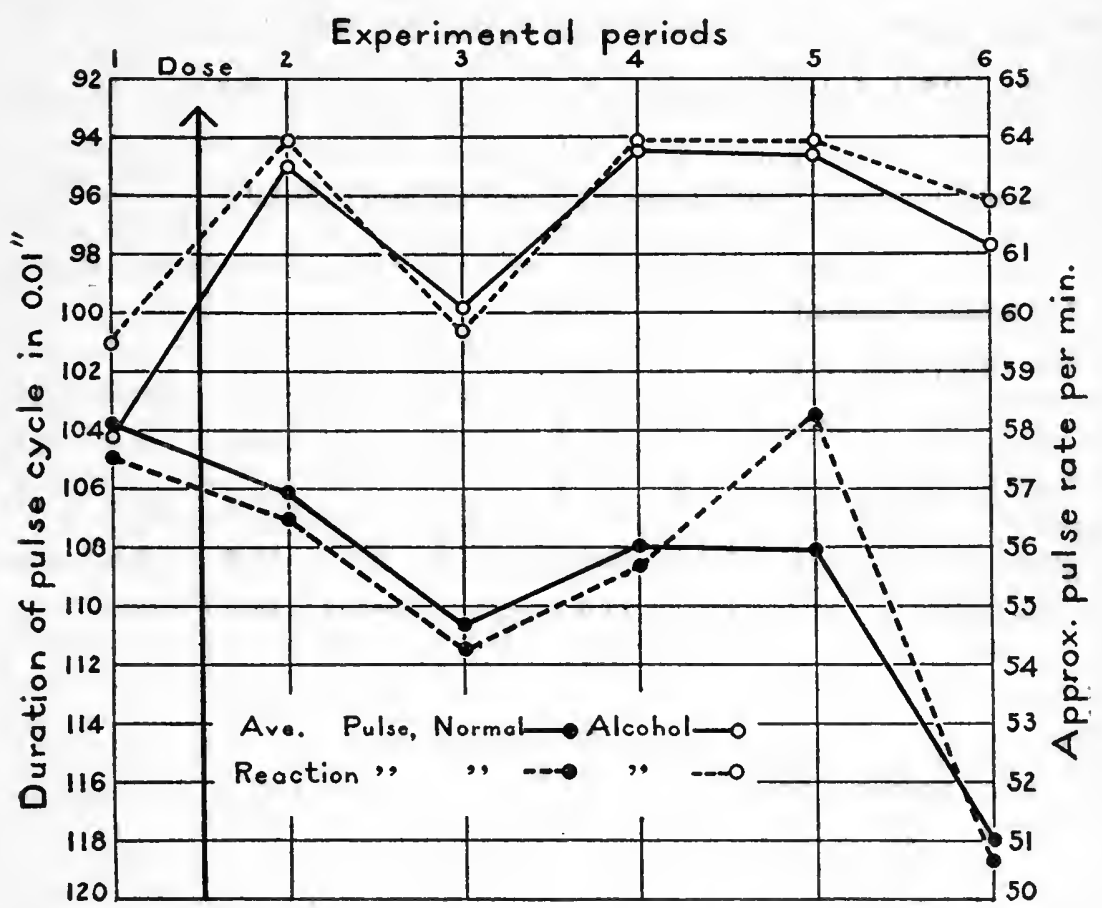

Fig. 15.-Average duration of pulse cycle under experimental conditions 1 to 7 on normal and alcohol days, as compared with pulse duration during word reactions (5 and 6).

The effect of alcohol is found by deducting the normal difference from the alcohol difference. These results are given for each of the seven experimental conditions in table 20 , and are also stated in terms of per cent. They are likewise summarized in table 21, which shows by periods the average effect of alcohol for each of the conditions. There are only two values in the latter table which are preceded by the plus 
sign, i. e., +1.7 and +2.1 . It is clear from table 21 that the pulse was quickened most under the experimental conditions 2,3 , and 4 , that is, in rest after the patellar reflex, in rest after the faradic-threshold measurement, and with the subject holding the voice key before the word-reaction test. In the latter case the high average of -17.3 is due partly to the value of -32.6 in the sixth period, which unfortunately is the period where the data are fragmentary. With the subject holding the voice key after the word-reaction test the average effect of the alcohol was -11.9. Here the subject was undoubtedly not so relaxed as under experimental conditions 2, 3, and 4. During the word reactions (5 and 6) the average effect was -7.4 , and -8.3 . In this measurement the subject was of course mildly active, or at least he was supposed to be. The pulse durations in table 20 do not show, however, that he was very active, as the word-reaction pulse was on normal days not faster during 5 and 6 than under the other conditions.

TABLE 21.-Effect of alcohol upon the pulse, expressed in per cent differences by periods.

\begin{tabular}{|c|c|c|c|c|c|c|c|}
\hline Experimental condition. & Period 2. & Period 3. & Period 4 & Period 5. & Period 6 & $\begin{array}{l}\text { Average } \\
\text { periods } \\
2 \text { to } 6 .\end{array}$ & $\begin{array}{c}\text { Last } \\
\text { period. }\end{array}$ \\
\hline 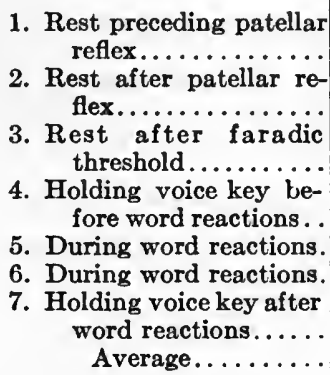 & $\begin{array}{l}+1.7 \\
-15.6 \\
-17.0 \\
-16.9 \\
-7.5 \\
-9.8 \\
-8.9 \\
-10.6\end{array}$ & $\begin{array}{l}-2.8 \\
-10.3 \\
-15.2 \\
-17.2 \\
-4.0 \\
-10.0 \\
-10.2 \\
-10.0\end{array}$ & $\begin{array}{l}-7.7 \\
-20.1 \\
-18.8 \\
-7.3 \\
-8.6 \\
-12.2 \\
-15.4 \\
-12.9\end{array}$ & $\begin{array}{l}-9.8 \\
-18.5 \\
-6.3 \\
-12.7 \\
-1.5 \\
+2.1 \\
-13.0 \\
-8.5\end{array}$ & $\begin{array}{r}-21.0 \\
-19.5 \\
-12.3 \\
-32.6 \\
-15.2 \\
-11.7 \\
-12.0 \\
-17.8\end{array}$ & $\begin{array}{l}-7.9 \\
-16.8 \\
-13.9 \\
-17.3 \\
-7.4 \\
-8.3 \\
-11.9 \\
-11.9\end{array}$ & $\begin{array}{l}-8.2 \\
-14.5 \\
-10.0 \\
-22.3 \\
-11.9 \\
-8.6 \\
-14.5 \\
-12.9\end{array}$ \\
\hline
\end{tabular}

The relation of the pulse duration during word reaction (averages by periods for pulses 5 and 6 of table 20) to the averages for all pulse data 1 to 7 are given in figure 15, page 115, in which the broken-line curves represent the averages for the word-reaction pulse measurements. Apparently there was more relaxation during word reactions on normal days than existed under any of the other conditions, for we find the broken-line curve (fig. 15, normal) is slightly below the average of all pulse measurements 1 to 7 in periods 1 to 4 , indicating slower pulse rate. On alcohol days the pulse rate during word reactions is faster than the average for all conditions. These facts are pertinent to the discussion of the word-reaction data on page 66 , where it was found that the reactions were considerably faster on alcohol days, including the preliminary period 1 , and where it was stated that usually on normal days the subject did not try hard to react quickly. It is unlikely that alert 
attention and quick response in reaction experiments would be associated with a pulse rate slower than the average resting pulse recorded. It will be seen that the faster pulse in period 1 (pre-alcohol) is in conformity with the results found for the same period with finger-movement pulse, and post-tetanus pulse, $i$. e., in all three cases the pre-alcohol pulse is faster than that before the control dose. It is probably not an accident that all these represent conditions where the subject was more active than in Nos. 1, 2, 3, 4, and 7 and the pre-tetanus period. The resting pulse preceding patellar reflex gives an average alcohol effect of -7.9 , which is relatively small, and particularly so if compared with the average of -16.8 for resting after the patellar reflex. Pulse record No. 1 was of course the very first record taken in each period. Previous to it the subject had been moving about more or less; in period 2 the dose for the day immediately preceded this record.

The average percentile effects of alcohol upon the pulse in the several experimental conditions for periods 2 to 6 , inclusive, are given in table 21 as $-10.6,-10.0,-12.9,-8.5$, and -17.8 , with a total average for all conditions and all periods of -11.9 per cent (decrease in duration of cycle length and increase in rate). The pulse-duration averages previously discussed and the differences summarized in table 21 therefore agree in showing a faster pulse after alcohol.

There still remain for consideration the pulse records 8 and 9, which were taken at the time of the finger movements. These were not usually 15 seconds long, but were regulated by the finger-movement records, which were about 10 seconds in length.

A peculiarity exists in the pulse during the finger movements which may be seen in the illustrative records shown in figure $11, E$ and $F$, page 96. The electrical waves are decidedly reduced in amplitude and in some instances seem to be dropped out, particularly the $P$ and $T$ waves. Approximately one-third, that is 20 , of the finger-movement pulse records show this phenomena in more or less marked degree. These records are well distributed throughout the various days, as there were three or four on each day except on June 30 . In considering this difficulty it may be called to mind that the subject in performing the fingermovement measurements tended to lean forward somewhat during the exercise. Since the pulse line shows no great irregularities, as would be expected were the electrodes out of contact with the body a part of the time, it seems that the only explanation of this phenomenon which is at all satisfactory is that a change in the position of the body produced a change in the electrical axis of the heart, so that at times there was no voltage across the string galvanometer. Curves $E$ and $F$ in figure 11, as well as others that might be shown, indicate that the condition was also dependent in part upon the phase of respiration, as the electrical waves disappear in the pulse cycles during the moments at the height of inspiration. 
This condition with the pulse during finger movements was not found with any other subject used by Dodge and Benedict, and a careful search did not reveal that it was certain with Subject VI in the former series of experiments. It must be observed, however, that Dodge and Benedict employed their pulse-recording technique No. 2, that is, the telephone pulse-recorder of Dodge with Subject VI. (See their report, p. 189.) In fact, all of their records for him were obtained with the telephone-recorder technique, except that of the normal electro-cardiogram taken at the beginning of the series of experiments. With the Dodge telephone recorder, the pulse during finger movements usually shows much disturbance and irregularity, and this irregularity is more marked than when using body electrodes. It was a surprise to find this to be the case, as one would think that the position of the body electrodes, because of movements of the arms and fingers, would cause other body currents to complicate the heart picture. On the other hand, one would not expect very much jarring and shaking of the head during the finger movements, but exactly this seems to have taken place and the pulse curve is complicated by many other deflections, large and small. This condition makes it impossible to compare the two groups of records taken by the different techniques. The change in the electrical axis of the heart which probably produced the condition under discussion seems to bear no relation to the dose of alcohol and must be regarded as without significance, aside from the fact that it made the elaboration of the records somewhat more difficult.

Since the pulse records taken during the finger movements showed the peculiarity that at times even the $R$ waves were absent, the records could not be dealt with as with pulse records 1 to 7 inclusive, but individual pulse cycles were measured as in the tetanus pulse and an average was taken for the measurable pulse cycles of each record.

All of the available data for the pulse during the finger movements are presented in table 22. This table is of the usual form, the results being presented by periods, with three sections showing (I) duration, (II) differences, and (III) the effect of alcohol by differences and percentiles. The average duration of $925 \sigma$ for the normal days shown in the next to the last column indicates that the pulse with the finger movements is considerably faster than in conditions 1 to 7 previously discussed. The same is shown by the averages 906 and $861 \sigma$ for period 1 . The latter value is for pre-alcohol and is noticeably shorter (faster rate) than that for the normal group of days, a condition quite parallel to that which existed for period 1 in the pulse during word reactions and in the post-tetanus pulse. The change in the level of preliminary pulse for the two groups of days does not favor the comparison by averages; nevertheless the averages in the different periods show the following: (1) a slight lengthening of the pulse from period to period throughout the normal days; the durations from period 1 to period 6 are 906, 898, 
$909,952,992$, and $986 \sigma$; the average for all the periods, excluding period 1 , is $925 \sigma$; (2) the pulse cycle after alcohol is shorter, $770,810,816$, 826 , and $869 \sigma$, the average for periods 2 to 6 being $813 \sigma$ as contrasted with $861 \sigma$ for period 1 ; the smallest average is that for period 2 of $770 \sigma$.

In section II of table 22, the average difference for all of the normal periods is $+21 \sigma$, and for the alcohol periods, $-49 \sigma$. Inspection of the individual differences shows that those for alcohol are quite regularly minus. On non-alcohol days the signs are more evenly distributed, but the larger number are plus. As seen from section III of table 22, alcohol produces a faster pulse with this subject during the condition of the finger movements by the percentile values of $-9.4,-5.6,-9.3$, -12.9 , and -7.0 for periods 2 to 6 , respectively, the average for these periods being -7.9 per cent. The alcohol effect, $i$ e., faster pulse, is therefore the same as that found in the tetanus pulse and under experimental conditions 1 to 7 , but is not so large as the average in table 21 .

In considering the probable cause of the relative acceleration of the pulse after alcohol, Dodge and Benedict pointed out that the mean vari-

TABLE 22.-Pulse during finger movements.

[Values given in thousandths of a second.]

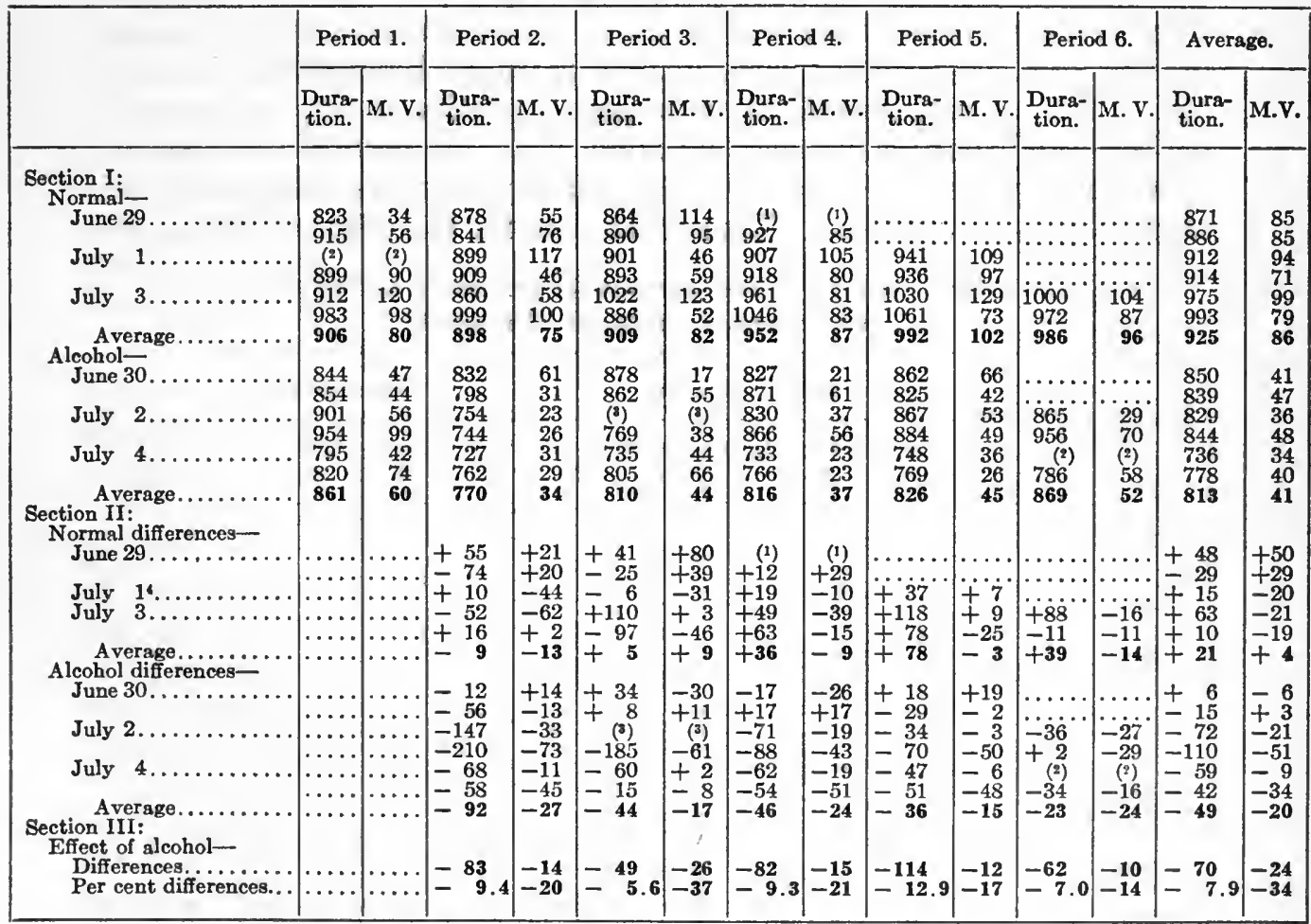

I Subject broke connection to galvanometer.

2 Electrical phenomenon of heart caused no deflection of galvanometer in first period.

Illegible because of faulty illumination.

- Second record for this date; see note 2 for information regarding first record. 
ation of the pulse-length after alcohol was considerably smaller than on normal days. It was this consistent change in the mean variation, together with other supporting evidence, which led to the belief that the effect produced by alcohol was probably a partial paralysis of the cardio-inhibitory mechanism. As a rule, the individual pulse cycles were not measured in the data for the repetition experiments on Subject VI, but in the case of the tetanus-pulse records and of those records taken with the finger movements, the individual cycles were by necessity measured; a mean variation is thus available for these.

The mean variations for the pulse taken during finger movements have been entered in table 22. Here it will be found that the normal values ranged about $80 \sigma$, approximately 10 per cent of the pulse duration. After alcohol there was a marked decrease, the average for all periods after the dose on the alcohol days being $41 \sigma$, with an average pulse duration of $813 \sigma$. In terms of per cent differences, the effect of alcohol upon the mean variation of the pulse duration is (section III), beginning with period $2,-20,-37,-21,-17$, and -14 per cent, the average for periods 2 to 6 being -34 per cent.

The mean variations in the pulse-length during pre-tetanus and tetanus are given in table 23 by periods and by days. The average pretetanus mean variation for periods 2 to 5 of the normal days is 3.7 hundredths of a second and for the alcohol days, 3.0 hundredths of a second. The average normal tetanus mean variation is 5.7, exclusive of period 1, and that for the alcohol periods is 4.4 hundredths of a second. The decrease in mean variation is particularly prominent in period 2 of alcohol pre-tetanus pulse. Thus these data for the effect of alcohol on

TABLE 23.-Mean variation of pulse duration for pre-tetanus and tetanus periods.

[Values given in hundredths of a second.]

\begin{tabular}{|c|c|c|c|c|c|c|c|c|c|c|}
\hline \multirow{2}{*}{$\begin{array}{l}\text { Kind of experiment } \\
\text { and date. }\end{array}$} & \multicolumn{5}{|c|}{ Pre-tetanus period. } & \multicolumn{5}{|c|}{ Tetanus period. } \\
\hline & $\begin{array}{c}\text { Period } \\
1\end{array}$ & $\begin{array}{c}\text { Period } \\
2\end{array}$ & $\begin{array}{c}\text { Period } \\
3\end{array}$ & $\begin{array}{c}\text { Period } \\
4\end{array} \mid$ & $\left|\begin{array}{c}\text { Period } \\
5\end{array}\right|$ & $\begin{array}{c}\text { Period } \\
1\end{array}$ & $\begin{array}{l}\text { Period } \\
\quad 2\end{array}$ & $\begin{array}{c}\text { Period } \\
3\end{array}$ & $\begin{array}{c}\text { Period } \\
4\end{array}$ & $\begin{array}{c}\text { Period } \\
5\end{array}$ \\
\hline \multirow{2}{*}{$\begin{array}{l}\text { Normal: } \\
\quad \text { June } 29 \ldots \ldots \ldots\end{array}$} & 3 & 4 & 3 & 2 & .. & 5 & 4 & 4 & 10 & . \\
\hline & 2 & 2 & 2 & 3 & & 4 & 15 & 8 & 5 & \\
\hline July & 3 & 3 & 5 & 2 & 5 & 3 & 3 & 3 & 5 & $\begin{array}{l}6 \\
4\end{array}$ \\
\hline \multirow[t]{2}{*}{ July } & $\begin{array}{l}4 \\
3\end{array}$ & $\begin{array}{l}6 \\
6\end{array}$ & $\begin{array}{l}3 \\
4\end{array}$ & $\begin{array}{l}2 \\
3\end{array}$ & $\begin{array}{l}2 \\
5\end{array}$ & $\begin{array}{l}5 \\
6\end{array}$ & $\begin{array}{r}10 \\
3\end{array}$ & $\begin{array}{l}5 \\
4\end{array}$ & $\begin{array}{l}9 \\
3\end{array}$ & $\begin{array}{l}4 \\
7\end{array}$ \\
\hline & 4 & 2 & & 5 & 7 & 4 & 2 & . & 5 & 5 \\
\hline Av. M. V.... & 3.2 & 3.8 & 3.4 & 2.8 & 4.7 & 4.5 & 6.2 & 4.8 & 6.2 & 5.5 \\
\hline \multirow[t]{2}{*}{$\begin{array}{l}\text { Alcohol: } \\
\quad \text { June } 30 \ldots \ldots\end{array}$} & 3 & 4 & 4 & 8 & 3 & 5 & 8 & 6 & 3 & 5 \\
\hline & 3 & 3 & 5 & 3 & 3 & 4 & 5 & 5 & 3 & 3 \\
\hline \multirow[t]{2}{*}{ July } & 3 & 1 & 6 & 3 & 2 & 4 & 1 & 4 & 3 & 3 \\
\hline & 3 & 1 & 3 & 4 & 1 & 4 & 3 & 5 & 4 & 4 \\
\hline \multirow[t]{2}{*}{ July } & 2 & 2 & 2 & 2 & 2 & 4 & 7 & 6 & 3 & 6 \\
\hline & 3 & 2 & 2 & 3 & 3 & 3 & 6 & 6 & 2 & 5 \\
\hline Av. M. V.... & 2.8 & 2.2 & 3.7 & 3.8 & 2.3 & 4.0 & 5.0 & 5.3 & 3.0 & 3.4 \\
\hline
\end{tabular}


mean variation of the pulse rate, meager as they are in comparison with those collected by Dodge and Benedict, are directly in accord with the findings ${ }^{1}$ of those investigators in showing a decreased mean variation following alcohol.

Taken as a whole, the pulse data where comparable in the two series of experiments on Subject VI are in accord in every important detail.

(1) There is normally, under such experimental conditions as those employed, a gradual retardation of the pulse rate from period to period throughout the experimental day, this retardation being less prominent after alcohol; the alcohol pulse is therefore relatively faster. Aside from the association pulse data of the first series, this subject varied from the normal group in that he did not show so prominent a retardation as the others.

(2) The pulse rate after alcohol is absolutely faster, as the cycle duration is actually shortened after the dose in comparison to that for the pre-alcohol period of the same day. This is found in all of the records taken in this series, with the exception of those during the actual moments of tetanus. In Dodge and Benedict's table 42, page 230 , where a summary of the average pulse differences is presented and where a plus value means an absolute rise in pulse rate per minute, Subject VI has an unduly large proportion of the plus signs. This table gives data for 7 subjects; of the 43 plus signs occurring, Subject VI has 16 , or 37 per cent.

(3) The effect of alcohol on the pulse rate is apparent in periods 2 , $3,4,5$, and 6 , but in general is not conspicuously more prominent in any one of these than in the others. There is no indication that the effect had reached its limit at the end of the experimental day, which extended 4 hours after the ingestion of the alcohol.

(4) The alcohol effect is greatest upon the pulse rate when the subject is resting quietly, there being an average increase of about 11 per cent at such a time, as compared to an increase of about 7 per cent when the subject is mildly active, as in sitting upright and reacting by speech.

In interpreting the increased pulse rate, either relative or absolute, after a dose of alcohol a question must be raised which Dodge and Benedict did not consider and which can not be answered here, as it involves further experimentation. With the possible exception of periods of very severe muscular activity, an individual's pulse rate is generally considered to be approximately a linear function of his metabolism, high pulse rate being associated with a high total heat production and vice versa. $^{2}$ The metabolism does not keep a dead level throughout the

\footnotetext{
${ }^{1} \mathrm{~A}$ correction should be made in Dodge and Benedict's table 44, p. 237, as follows: The data for two genuflections, normal and alcohol, and 60 seconds after two genuflections, normal and alcohol, are recorded under Subject IV, but should be placed one column to the right, that is, under Subject VI. (See table 40, p. 217 , in which the mean variation averages are first presented.)

2 See Benedict and Carpenter, Carnegie Inst. Wash. Pub. No. 126, 1910, p. 248; Dodge and Benedict's report, p. 253 ff., and other publications and articles from the Nutrition Laboratory; also see Henderson and Prince, Am. Journ. Physiol., 1914, 35, p. 106; Murlin and Greer, Am. Journ. Physiol., 1914, 33, p. 251, and Krogh and Lindhard, Journ. Physiol., 1917, 51, p. 182.
} 
24 hours of a day. It of course varies with excitement, exercise, and relaxation and also with ingestion of food. Other things being equal, it is highest after meals and presumably the pulse follows these fluctuations with fair approximation. In a laboratory session, which comes between meals and lasts 3 to 5 hours with the subject under uniform conditions that demand but slight activity, the metabolism theoretically should decline; pulse records taken frequently and at homologous points in the periods should therefore naturally show some progressive decrease in rate aside from any change due to psychic factors, such as a growing familiarity with the experimental environment. Both series of experiments, particularly the former, have thoroughly demonstrated this normal decline in pulse rate which probably has its basis in a change in metabolism. After the first period on alcohol days there was an energy intake of dose A, 30 c.c. approximately 260 calories, or of dose B, 45 c.c., about 390 calories, and the pulse following was found to be relatively faster than on normal days, when occasionally a control dose of cereal "coffee" was employed. The specific effect of alcohol on the total metabolism has not been conclusively established, but there appears to be slightly more evidence for a small rise than for a fall after alcohol. ${ }^{1}$ Hence, in the absence of definite proof to the contrary, the pulse changes with it are such as to raise the question whether they are not due to normal metabolism phenomena rather than to so-called drug action.

\section{RESPIRATION DATA.}

As respiration records were also incorporated with the pulse records, some attention should be given these from the standpoint of a possible effect of alcohol upon the respiration rate. In the Tentative Plan ${ }^{2}$ the effect of alcohol upon respiration-rate was but a small part of the proposed respiration section, and our data can be regarded as only supplementary. In the first place, it must be said that Subject VI was naturally very irregular in his breathing. Dr. Carpenter ${ }^{3}$ for this cause found him quite unsatisfactory as a subject in some respiration experiments. In our pulse and respiration records there are frequently intervals of apnea; a record of this type is shown in $C$, figure 11 (see p. 96). That the apparatus for recording the respiration was not insensitive is proved by the fact that the pulse shows very clearly in the curve.

The average length of the respiration in seconds for the different days and the different periods of pre-tetanus and post-tetanus pulse is shown in table 24. Naturally the respiration curve could not be interpreted during the moments of tetanus. From the normal data in the upper

\footnotetext{
${ }^{1}$ Carpenter, Am. Journ. Physiol., 1917, 42, p. 605; Higgins, Journ. Pharm. and Exp. Ther., 1917, 9, p. 441.

${ }^{2}$ Tentative plan for a proposed investigation into the physiological action of ethyl alcohol in man, Boston, 1913; reprinted in Dodge and Benedict's report as Appendix I (see p. 269).

${ }^{3}$ Carpenter, Carnegie Inst. Wash. Pub. No. 216, 1915.
} 
part of the table, it can be seen that the respiration was longer in the post-tetanus division of the record, the average for period 1 being 3.7 seconds as compared with 2.8 seconds for pre-tetanus; the total average for periods 2 to 6 during post-tetanus was 3.2 seconds as compared with 2.8 seconds for the pre-tetanus division. The curves were not such as could be measured for depth of respiration. In the alcohol section of the table (periods 2 to 6 and average), it is again shown that the respiration is longer in the post-tetanus division, but the difference is not so large as with the normal values. As with the word-reaction, finger-movement, and post-tetanus pulse, there is a difference in the -initial level of the respiration on the two groups of days, showing a shorter normal respiration on the alcohol days (see period 1); this limits our direct comparison of averages in other periods. The signs for the differences are about equally divided between plus and minus. The effect of alcohol in terms of per cent differences seems to be, in general,

TABIE 24.-Length of respiration in pre-tetanus and post-tetanus periods.

[Values given in seconds.]

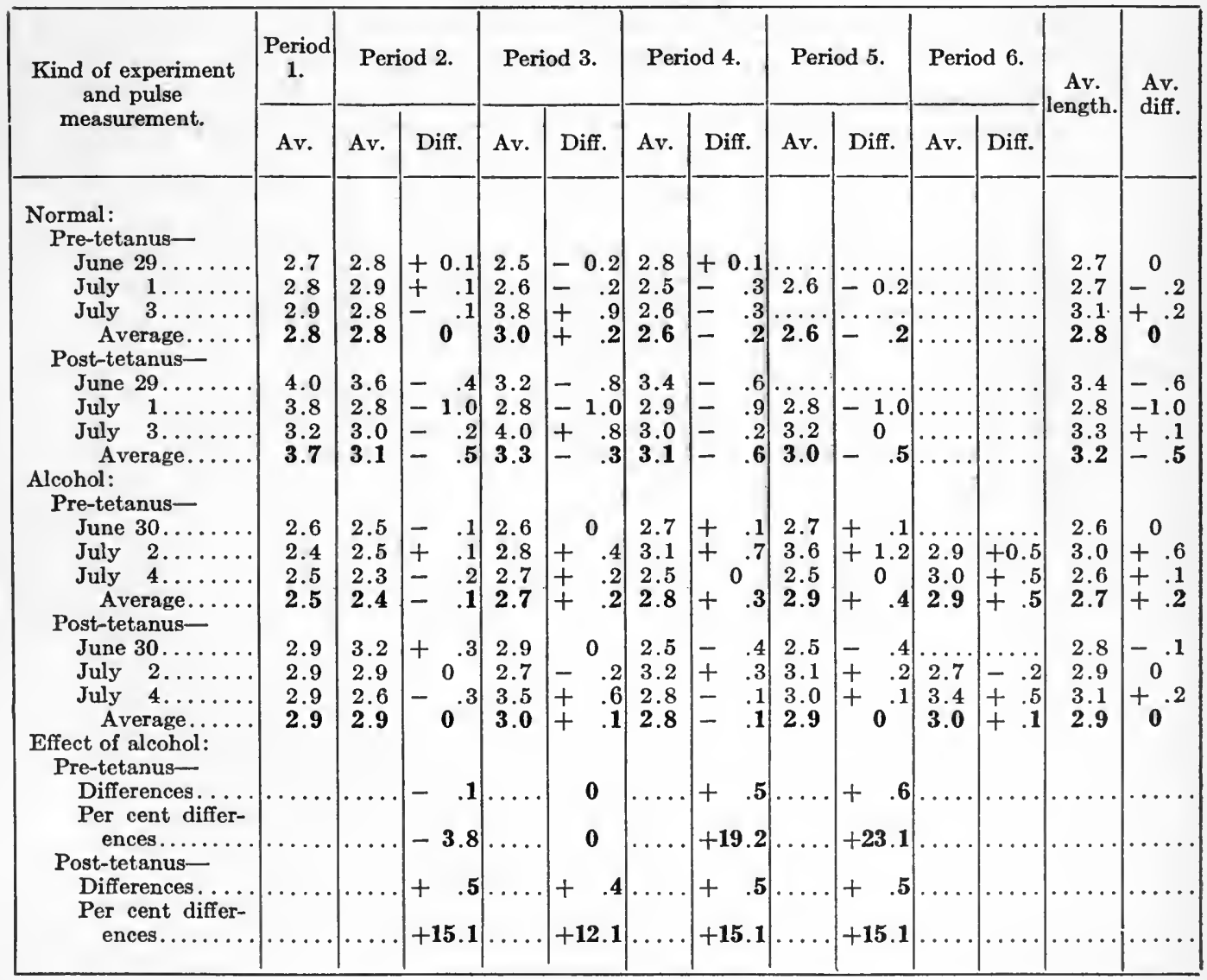


a lengthened respiration. This is not true in the second and third periods for the pre-tetanus condition, in which we have -3.8 and 0 per cent, but applies to the third and fourth periods of pre-tetanus $(+19.2$ and +23.1 per cent) and for all periods of post-tetanus $(+15.1,+12.1$, +15.1 , and +15.1 per cent).

The respiration data taken with pulse records 1 to 7 , inclusive, of the experimental cycle are recorded in table 25. Here the averages for the first period are the same for alcohol and non-alcohol days, i.e., 3.0 seconds. The average for all of the normal periods, exclusive of the first, is 2.9 seconds, while the comparison average for alcohol days is 2.8 seconds. The average respiration on the alcohol days in periods 2 and 3 is a little longer than for the same periods on the normal days, but the difference is insignificant. The effect of alcohol as shown by per cent differences is $+3.3,0,-13.3,-16.7$, and 0 per cent for periods 2 to 6 , respectively. On the whole our supplementary data for respirationrate, like those collected by Higgins, ${ }^{1}$ show no definite alcohol effect.

TABLE 25.-Length of respiration during pulse measurements Nos. 1 to 7 of experimental cycle.

[Values given in seconds.]

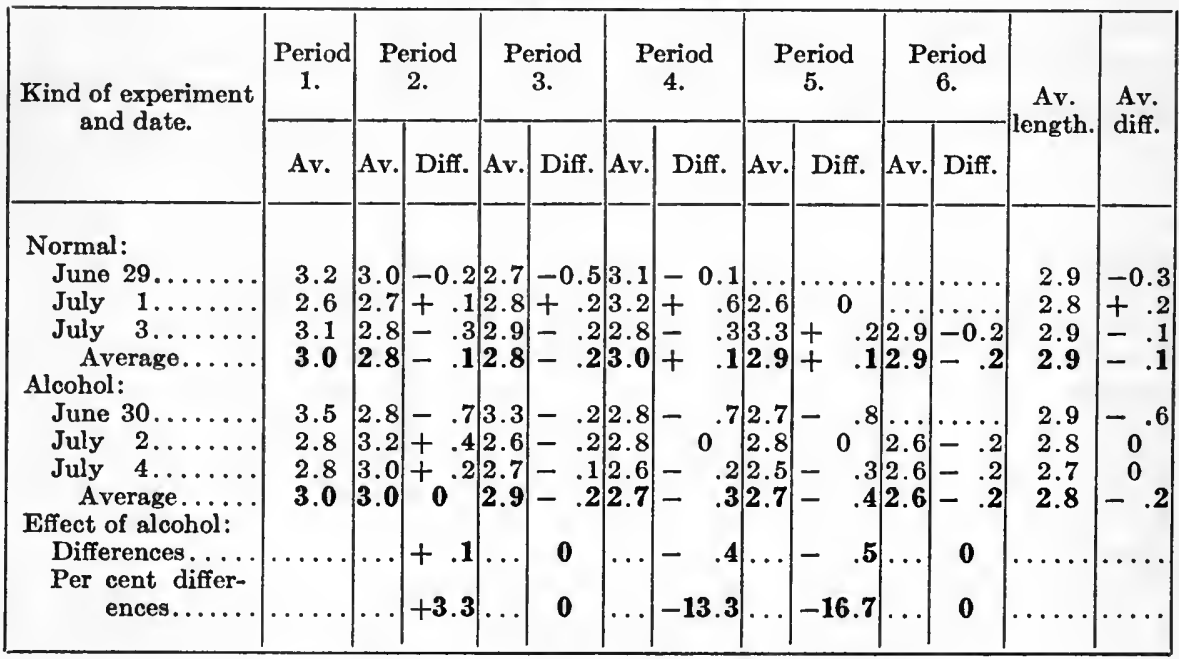

${ }^{1}$ Higgins, Journ. Pharm. and Exp. Ther., 1917, 9, p. 441. 


\section{CONCLUSIONS.}

This independent repetition series of experiments, employing equivalent dosage, the same apparatus and general conditions, and essentially the same technique as those used by Dodge and Benedict, was undertaken on one of their normal subjects (No. VI) for the purpose, among other things, of verifying the somewhat irregular results obtained on him in the first series. A summary of the findings in this repetition series for the different experimental periods following the ingestion of alcohol, together with the comparable averages found by Dodge and Benedict for their normal group, ${ }^{1}$ and also for Subject VI individually, is presented in table 26 . The values for the repetition series given in this table appear in section III of the foregoing tables and are the effects of alcohol stated in percentile differences for the various processes in question. ${ }^{2}$ A plus sign denotes an increase and a minus sign a decrease (see p. 35), and these signs must be interpreted according to the nature of the measurement.

For simplicity the summary table has been divided into two parts. In part I are grouped those measurements for which a plus sign supposedly means inferior or less efficient performance, $e . g$., longer reflex latency, slower movements or reactions, larger mean variation in reactions, and the like. To state this still more concretely, it will be observed that the first value in period 2 is +4.1 . This is a numerical expression of the contrast between the results of two groups of days, taking into account the preliminary periods of the same. It shows that the patellar-reflex latency with 30-gram stimuli was longer by 4.1 per cent in the first measurements made after the taking of 30 c.c. of alcohol as compared with the results found in the period immediately after the control dose was taken. This lengthening of the reflex latency was also present in the third and fourth periods, but the percentages +0.9 and +2.9 show that the effect was not so great. In the fifth and sixth periods the sign changes to minus $(-7.3$ and -1.5$)$, indicating a shortened reflex time.

Part II of table 26 includes those processes for which a plus sign supposedly signifies superior or more efficient performance. In the cases of pulse and respiration, minus denotes a decrease in length, that is to say, a faster pulse rate or respiration rate per minute. It will be seen that under period 2 and opposite "Number of finger movements in 8 seconds" -3.9 will be found, which means that the total number of free finger movements performed in 8 seconds was 3.9 per cent less after alcohol in contrast with the record after control doses. Similar decrements were present, also, in periods 3,4 , and 5 , in which the percentage

\footnotetext{
${ }^{1}$ For some measurements the normal group was composed of 7 and for others of 6 men. In every case it included Subject VI.

${ }^{2}$ The method of computation has been fully discussed in connection with illustrative table 2 , p. 31 .
} 
reductions were $4.0,3.1$, and 3.5, respectively, while in period 6 there was an increase of 7.1 per cent. The foregoing illustrations should make it perfectly clear that a plus sign in part I and a minus sign in part II have fundamentally the same meaning - that is, an inferior or less satisfactory functioning of a process.

The general picture for the effect of alcohol on Subject VI, as shown by the repetition series, is definitely one of neuro-muscular depression, demonstrated by the fact that in part I of table 26 the signs for the percentile differences are predominantly plus, while in part in they are as prominently minus. At the bottom of each column in the table the signs of the column have been classified under the three heads-inferior, superior, and neutral-and the entries are the percentages found for the several categories.

TABLE 26.-Percentile effects of ingestion of 30 c.c. of absolute alcohol on a related group of processes. ${ }^{1}$

\begin{tabular}{|c|c|c|c|c|c|c|c|c|c|}
\hline \multirow{3}{*}{ Processes measured. } & \multicolumn{7}{|c|}{ Repetition series. } & \multirow{2}{*}{\multicolumn{2}{|c|}{$\begin{array}{l}\text { First series. }{ }^{2} \text { Results } \\
\text { found by Dodge and } \\
\text { Benedict with } \\
\text { equivalent dose. }\end{array}$}} \\
\hline & \multicolumn{6}{|c|}{$\begin{array}{l}\text { Experimental periods following the taking } \\
\text { of alcohol. }\end{array}$} & \multirow{2}{*}{$\begin{array}{l}\text { Av. } \\
\text { periods 2, } \\
\text { 3, and 4. }\end{array}$} & & \\
\hline & $\left|\begin{array}{c}\text { Period } \\
2 .\end{array}\right|$ & $\begin{array}{c}\text { Period } \\
3 .\end{array}$ & $\begin{array}{c}\text { Period } \\
4 .\end{array}$ & $\begin{array}{c}\text { Period } \\
\mathbf{5} .\end{array}$ & $\begin{array}{c}\text { Period } \\
6 .\end{array}$ & $\begin{array}{c}\text { Last } \\
\text { period. }\end{array}$ & & $\begin{array}{l}\text { Av. for } \\
\text { normal } \\
\text { group. }\end{array}$ & $\begin{array}{l}\text { Av. for } \\
\text { Subject } \\
\text { VI. }\end{array}$ \\
\hline 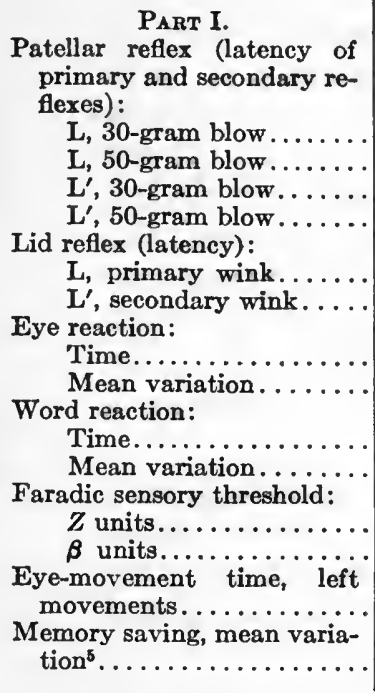 & $\begin{array}{l}+4.1 \\
+2.1 \\
0 \\
+1.3 \\
+13.3 \\
+15.0 \\
+12.0 \\
+34 \\
+3.1 \\
-2.0 \\
+17 \\
+32 \\
+14 \\
+10\end{array}$ & $\begin{array}{l}+0.9 \\
+0.9 \\
+2.6 \\
+2.7 \\
+5.7 \\
+0.7 \\
+13 \\
+41 \\
-9.0 \\
+7.0 \\
+0.9 \\
+10 \\
+6.4 \\
-10\end{array}$ & $\begin{array}{c}+2.9 \\
0 \\
+11 \\
+1.1 \\
-2.9 \\
-7.5 \\
+9.5 \\
+6.3 \\
-7.4 \\
0\end{array}$ & $\begin{array}{l}+6.4 \\
-3.7 \\
+6.2 \\
-25 \\
-11 \\
+21 \\
+6.2 \\
+25 \\
+5.0 \\
-15\end{array}$ & $\begin{array}{l}-\quad 1.5 \\
-\quad 4.5 \\
-\quad 5.3 \\
-16.0 \\
+\quad 4.3 \\
+\quad 3.7 \\
-\quad 1.9 \\
+\quad 47 \\
-21 \\
+\quad 25 \\
-11 \\
-\quad 7.9 \\
-\quad 2.1 \\
-\quad 5.0\end{array}$ & $\begin{array}{rr}-\quad 9.8 \\
-12.0 \\
-\quad 5.3 \\
-15.0 \\
-\quad 5.8 \\
-\quad 6.7 \\
+\quad 8.1 \\
+22 \\
-\quad 9.6 \\
+35.0 \\
+\quad 0.9 \\
+24 \\
+\quad 3.0 \\
-10.0\end{array}$ & $\begin{array}{l}+2.6 \\
+1.0 \\
+4.5 \\
+1.7 \\
+5.4 \\
+2.7 \\
+11.5 \\
+27.1 \\
-4.4 \\
+1.7 \\
+7.7 \\
+16.4 \\
+9.2 \\
+4.3\end{array}$ & $\begin{array}{c}+11.1 \\
+\quad 4.0 \\
+\quad 5.9 \\
+\quad 6.8 \\
-\quad 5.4 \\
\ldots \ldots \ldots \\
\ldots \ldots \ldots \\
\ldots \\
+21 \\
\ldots \ldots \ldots \\
+\quad 3.4\end{array}$ & $\begin{array}{c}+0.3 \\
\left.{ }^{3}\right) \\
-\quad 4.5 \\
-10.7 \\
-\quad 9.3 \\
\ldots \ldots \ldots \\
-5 \\
\ldots \ldots \ldots \\
+48 \\
\cdots \ldots \ldots \\
4 \\
+25.8\end{array}$ \\
\hline
\end{tabular}

1 The values given in this table differ in certain instances from those published in the preliminary abstract (Miles, Proc. Nat. Acad. Sci., 1916, 2, p. 703), e. g., the patellar reflexes from 30 and 50 gram stimuli have been treated separately; there were also one or two errors discovered in the original computations.

2 The signs used in presenting Dodge and Benedict's data have been changed to make them conform with the usage in this monograph, where a plus means increase and a minus decrease in the quantities measured.

3 The records were illegible.

4 No left eye movements are given for Subject VI in Dodge and Benedict's table 28, p. 166; therefore the percentile difference for right movements is entered here.

"From computations based on the "saving" between the first and second reactions; see table 11, p. 71 . 
TABLE 26-Percentile effects of ingestion of 30 c.c. of absolute alcohol on a related group of processes. ${ }^{1}-$ Cont'd.

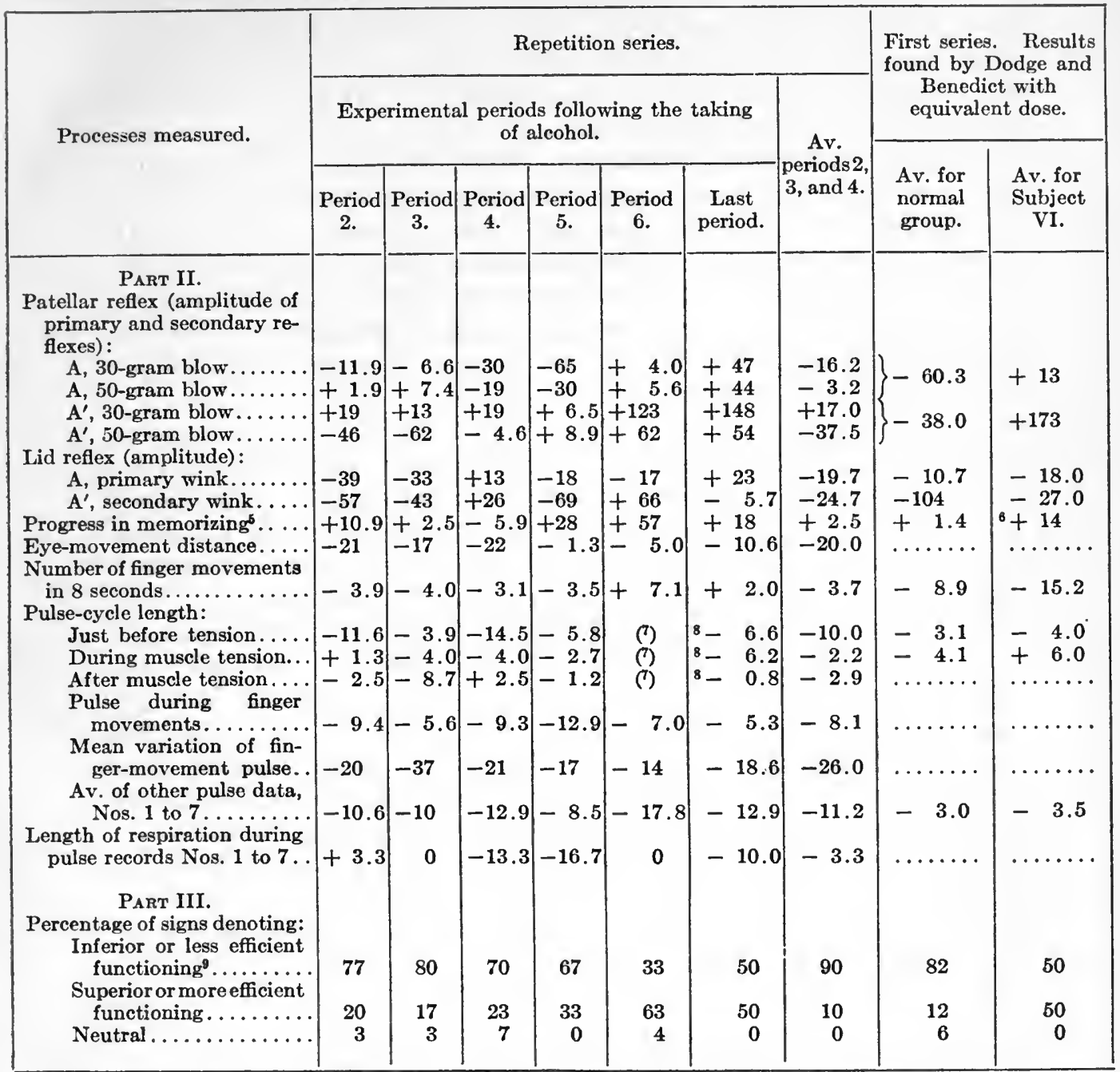

${ }^{6}$ Corrected value according to the method of not including the first-period score on normal days; see Appendix III, p. 140.

7 There was no period 6 in the normal data of tetanus pulse.

8 The computation was not carried out for each pulse cycle, but averages were found for cycles 1 to 7,8 to 14 , and 15 to 21 , from the averages in the pre-tetanus and tetanus divisions, and in the post-tetanus division, and computations were made finally, taking the average percentile difference for the three groups of 7 pulse cycles of the post-tetanus divison.

9 The assumption that a faster respiration rate may be rightly classified as less efficient functioning is admittedly somewhat arbitrary.

In but one instance, period 6 , are there more signs indicating a superior functioning of processes than were found for inferior performances. The usual effect of alcohol would seem to be reversed in the sixth period, so that the subject actually did better in the majority of processes measured at the end of the alcohol-day experiments than he did 
on non-alcohol days. Some indication of this reversal appeared to be present in the former experiments ${ }^{1}$ and one of the reasons for using 5 -hour sessions in the repetition series in place of 3 hours as formerly was to obtain data for a longer time following the ingestion of alcohol which might illuminate this problem of possible facilitation succeeding depression. For reasons which have been previously explained (see p. 29 ), it was practically impossible in the later experiments to have an equal number of periods on each day. Hence it transpires that for the sixth period the data are confined to one normal and two alcohol days. The normal day was July 3, on which the subject tried less to carry out the instructions in performing his part of the experiments. The general relaxation and drowsiness of the subject are confirmed by the fact that the pulse rate was decidedly the slowest on this day. This can be seen in the "daily averages" at the bottom of table 20, p. 113 , where the general average pulse-cycle length for the day in question is 1.14 seconds, equaling a rate of 52.6 per minute. On the other hand, the results obtained on July 4, the last alcohol day, were considerably influenced by a spurt of effort made by the subject. These conditions seriously complicate the interpretation of the results for period 6 which might otherwise appear as a post-alcohol facilitation. Obviously, however, it would not be unfair, as the days were all 5 hours in length, to compute percentile differences, using as a basis the last period of each day, regardless of whether the periods were numbered 4,5 , or 6 . The differences are already in the tables for the various measurements. It is necessary to find the "last-period" average difference for normal and alcohol days separately, to subtract the former from the latter, and to divide the result by the average of all first-period scores. For illustration, the percentile difference effect of alcohol in the last period of eye reactions would be found as follows (see p. 60, table 9, section II): The normal differences for the last period are $-23,+26$, and +12 , average +5 ; the alcohol differences are $+51,-16$, and +32 , average +22 ; the alcohol average minus the normal average equals +17 , which, divided by the average of relevant first-period normals $(211+208 \div 2$ $=209.5$ ), equals 8.1 per cent; this is entered in the column headed "Last period" in table 26. This percentile difference, +8.1 , for the last period of eye reactions shows continued depression to the end of the experimental day. It would seem that the value -1.9 in period 6 was largely due to the fragmentary data for this period and not to a real facilitation of the process. When the signs for all the 30 percentage values of the last period are classified, it is found that half of them represent inferior and half superior performance, while in period 6 the pro-

\footnotetext{
${ }^{1}$ Dodge and Benedict's report, p. $258 \mathrm{ff}$.

2 This comparison is not strictly accurate, as there was no tetanus pulse for period 6 . Since there is a strong probability, judging by the other tetanus pulse data, that these three signs would have been minus if present, the proportion might have stood 40,57 , and 3 , which would be a little less favorable to facilitation in period 6.
} 
portion was 1 to 2 , i. e., 33, 63, and $4 .^{2} \quad$ (See table 26 , columns headed "Period 6" and "Last period" and note signs for different measurements.) Specifically, the changes in sign (superior to inferior) from period 6 to the last period have been with eye-reaction time, faradicsensory threshold for both $\mathrm{Z}$ units and $\beta$ units, eye-movement time, and lid reflex $\mathrm{A}^{\prime}$. There are also some changes from inferior in period 6 to superior in the last period, the reverse of those just given; these are lid reflex $\mathrm{L}$ and $\mathrm{L}^{\prime}$ and lid reflex $\mathrm{A}$.

From the percentile differences in the last period (in contrast with period 6) certain quite definite conclusions can be drawn regarding the effect of alcohol on this subject 4 hours after the dose of 30 c.c. had been taken:

(1) The reflexes are more active, their latency is shorter, and the amplitude is increased. There are 12 percentile differences for the effect of alcohol on the reflexes. It will be observed that in the last period every difference except that for lid reflex $\mathrm{A}^{\prime}$ shows relative facilitation, and the percentages are so large as to establish the observation.

(2) The faster pulse and respiration rates continue, $i . e$., the direction of the alcohol effect is here unchanged. The 7 values are in agreement and there is no certain decrease in the alcohol effect found by comparing the last period with the average of periods 2,3 , and 4 .

(3) The measured processes, word-reaction time, and progress in memorizing, which were found to be superior in periods 2 to 4 , are the same in the last period. Eye-reaction time and mean variation, wordreaction mean variation, faradic threshold $Z$ and $\beta$, eye-movement time and distance, and number of finger movements in 8 seconds, all of which showed depression in the earlier periods, are found to do likewise in the last period.

Facilitation in these experiments therefore seems limited to the reflexes, and pending the accumulation of data with other subjects it is best to forego further discussion of the matter here.

Considering again periods 2,3 , and 4 , we find that the results for all of these are from 3 normal and 3 alcohol days, and that together the three periods make a time interval following the dose which corresponds fairly well to the sessions of the first series. An average of the results of these periods is given in table 26 . Of these 30 percentile differences for the effect of alcohol, 27 (a ratio of 9 to 1 ) show inferior functioning of processes after the dose. The exceptions are those which the preceding consideration of the results would lead us to expect, i.e., word-reaction time, progress in memorizing, and patellar reflex, $\mathrm{A}^{\prime}, 30$ grams. ${ }^{1}$ Before accepting this predominance at its face value, it is desirable to know if the 9 to 1 ratio can in any way be due to the pecu-

\footnotetext{
${ }^{1}$ It was pointed out on page 43 that as the primary reflex decreases in amplitude, the secondary one, which falls in the relative refractory phase, tends to increase. This inverse ratio between the amplitude of such successive reflexes appears to be a normal phenomenon as well as an alcohol result.
} 
liar results of one or two days which have exercised undue weight on the average differences. When from section II of the preceding tables all the signs for the differences in periods 2,3 , and 4 for the 30 measurements were counted separately for each day and classified under the three heads inferior, superior, and neutral functioning, the results in terms of per cent were as shown in table 27.

TABLE 27.-Comparison of results for the six experimental days.

\begin{tabular}{|c|c|c|c|c|c|c|}
\hline & $\begin{array}{l}\text { June 29, } \\
\text { normal. }\end{array}$ & $\begin{array}{l}\text { June 30, } \\
\text { alcohol. }\end{array}$ & $\begin{array}{l}\text { July 1, } \\
\text { normal. }\end{array}$ & $\begin{array}{l}\text { July 2, } \\
\text { alcohol. }\end{array}$ & $\begin{array}{l}\text { July 3, } \\
\text { normal. }\end{array}$ & $\begin{array}{l}\text { July 4, } \\
\text { alcohol. }\end{array}$ \\
\hline Infe & 43 & 59 & 49 & 78 & 48 & 64 \\
\hline Superior functioning. . & 52 & 35 & 48 & 17 & 44 & 29 \\
\hline Neutral functioning. . & $\mathbf{5}$ & 6 & 3 & 5 & 8 & $\begin{array}{llll}7 & & \end{array}$ \\
\hline
\end{tabular}

For normal days the condition is about 50 to 50, implying that observations made following the preliminary period and the control dose stand even chances of showing superior or inferior functioning. On the other hand, it can be definitely stated that the differences on each alcohol day show that inferiority is predominant in these periods. This condition or change to inferiority denoted by the difference between preliminary measurements and those made after the ingestion of 30 c.c. of alcohol should be designated as absolute, since it is not relative to the normal or control results. There is some indication that the alcohol effect increased from day to day. July 2 shows a higher percentage of inferior signs than is evident for June 30; this is also true for July 4, notwithstanding a decided spurt on the part of the subject in certain voluntary processes on that day. In general it appears that although there is variation from day to day with specific measurements, no one day can be said to have exercised a predominating influence in producing the ratio of 9 to 1 for inferior functioning of processes in the repetition series.

For comparison the results found in the Dodge and Benedict series have been entered at the right in table 26 . In the column which gives the average for the normal group the proportion of signs indicating the alcohol effect as being inferior, superior, and neutral is 82,12 , and 6 , these percentages comparing very favorably with the 90,10 , and 0 for the average of periods 2,3 , and 4 of the repetition series. The signs for the two series disagree at three points. Dodge and Benedict's subjects were nearly all new to the eye-reaction test, and as there was a practice effect and as the first day was normal, this condition largely accounts for the percentile difference being minus. ${ }^{1} \quad$ Subject VI did not have a practice change in the repetition series, hence the alcohol effect had a better opportunity to show itself. The disagreement on eye reactions can therefore be discounted. On word reactions the average for the

${ }^{1}$ Dodge and Benedict's report, pp. 89 and 250. 
normal group is zero, but there were two, one of them Subject VI, who showed minus differences and 4 men plus differences. This is a real disagreement between the series, as is also that with the patellar reflex $A^{\prime}, 30$ grams, where Subject VI was the one man in 6 who had a plus percentile difference. These disagreements in the direction of the alcohol

TABLE 28.-Percentile effects of alcohol arranged in order of magnitude.

\begin{tabular}{|c|c|c|}
\hline Measurements. & $\begin{array}{l}\text { Second series. } \\
\text { Av. of periods } \\
2,3 \text {, and } 4 .\end{array}$ & $\begin{array}{l}\text { Dodge and } \\
\text { Benedict series } \\
\text { (normal group). }\end{array}$ \\
\hline 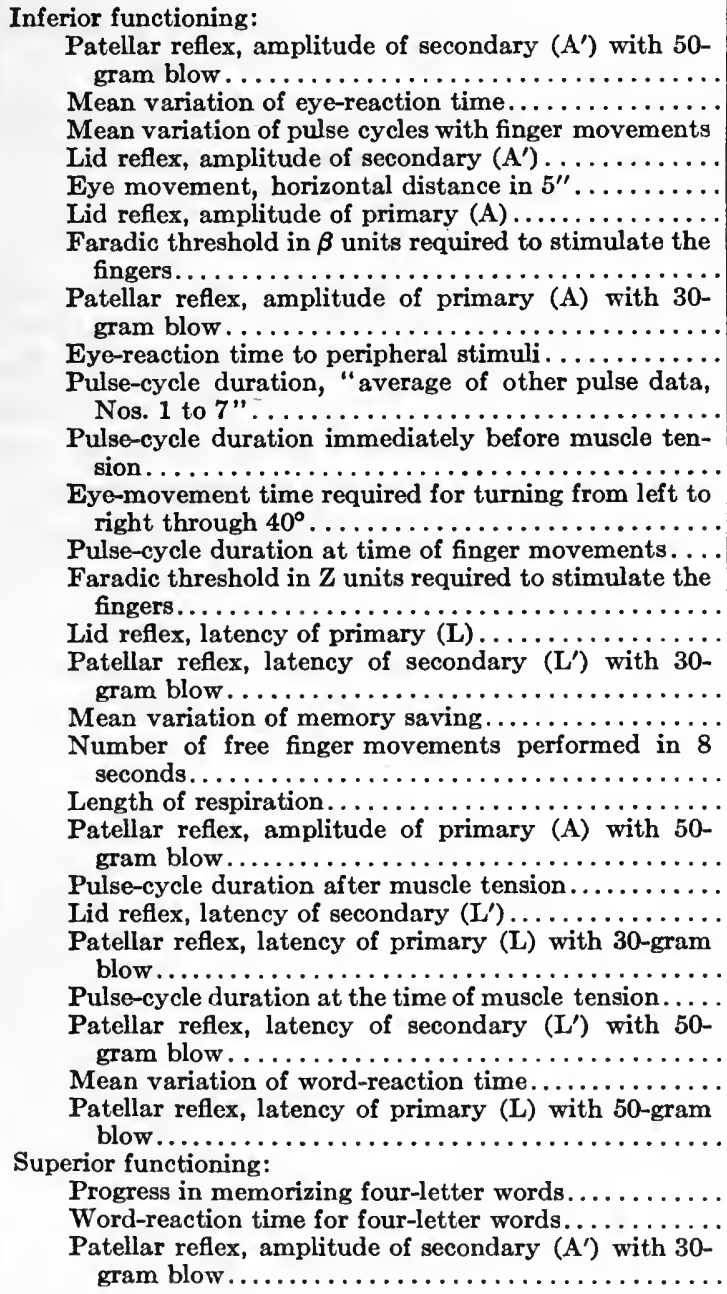 & $\begin{array}{r}37.5 \\
27.1 \\
26.0 \\
24.7 \\
20.0 \\
19.7 \\
16.4 \\
16.2 \\
11.5 \\
11.2 \\
10.0 \\
9.2 \\
8.1 \\
7.7 \\
5.4 \\
4.5 \\
4.3 \\
3.7 \\
3.3 \\
3.2 \\
2.9 \\
2.7 \\
2.6 \\
2.2 \\
1.7 \\
1.7 \\
1.0 \\
2.5 \\
4.4 \\
17.0\end{array}$ & 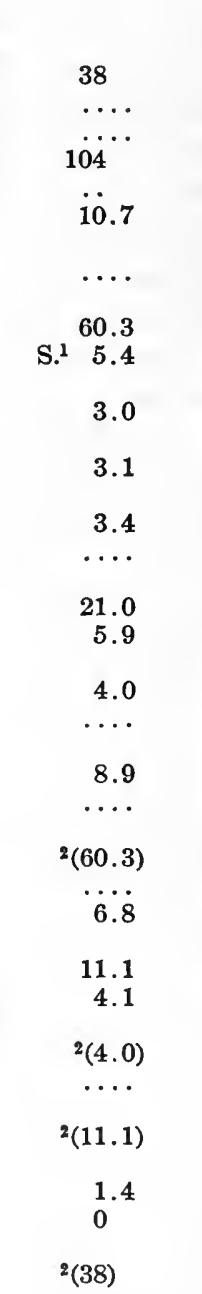 \\
\hline
\end{tabular}

1 Superior with Dodge and Benedict.

${ }^{2}$ Dodge and Benedict made no distinction between intensities of stimulation for the patellar reflex in their final summaries. 
effect are not more striking than some that could be pointed out between others of the so-called normal subjects and the average for the normal group.

The amount of the alcohol effect is variable. The different processes arranged in order of magnitude of the average percentile difference for periods 2,3 , and 4 are shown in table 28 .

There are 7 instances in which the inferiority is less than 3 per cent and 16 cases in which it is less than 10 per cent. With any one of these relatively small effects, since the number of observations is also statistically small, the probable error would be large and a single value by itself could not be regarded as of much significance. The probability that the results indicate the true nature of the alcohol effect is greatly multiplied when many such results fall in the same direction. If the experiment had been limited to the 16 end results which showed an inferiority of less than 10 per cent and to the 3 instances of superiority, the case would still be quite definite for the alcohol effect.

Of the 27 results showing inferior functioning, 11 range from 10.0 to 37.5 per cent. Prominent among these are 4 for reflex amplitude, with an average of 24.5 per cent, and 3 for pulse, which average 15.7 per cent. Other than this the repetition series does not indicate clearly that the more simple processes are affected most and the higher processes least by alcohol. ${ }^{1}$ Grouping the 30 end results under convenient heads for averaging in comparison with Dodge and Benedict's average results for their normal group with dose A, the summary in table 29 is obtained.

TABLE 29.-Comparison of alcohol effects found in two series of measurements.

\begin{tabular}{|c|c|c|}
\hline Percentage effect on measurements. & $\begin{array}{l}\text { Second series. } \\
\text { Av. of periods } \\
2,3 \text {, and } 4 \text {. }\end{array}$ & $\begin{array}{l}\text { Dodge and } \\
\text { Benedict's } \\
\text { normal group. }\end{array}$ \\
\hline $\begin{array}{l}\text { Lengthening of reflex latency } \ldots \ldots \ldots \ldots \ldots \ldots \ldots \ldots \ldots \ldots \\
\text { Decrease in reflex amplitude. } \ldots \ldots \ldots \ldots \ldots \ldots \ldots \\
\text { Increase in pulse rate } \ldots \ldots \ldots \ldots \ldots \ldots \\
\text { Average inferior functioning of all other processes } \ldots \ldots \ldots \ldots\end{array}$ & $\begin{array}{l}3 \\
14 \\
17 \\
28.6\end{array}$ & $\begin{array}{r}\mathbf{7} \\
\mathbf{5 3} \\
\mathbf{3} .4 \\
\mathbf{4} .4\end{array}$ \\
\hline
\end{tabular}

${ }^{1}$ Average of pulse before, during, and after muscle tension, pulse during finger movements, and "Av. of other pulse data."

2 This includes memory, word reactions, and mean variations.

The most conspicuous effect found by Dodge and Benedict was the decrease in reflex amplitude, which is confirmed by the second series, but is not relatively so large a decrement. ${ }^{2}$

Two indications exist for the time relation of the maximum effect to the alcohol dose, viz, the predominance of sign and the average amount of the effect in the different periods. By the former it would seem, ac- 
cording to table 26, part III, that the maximum effect came in period 3 , as here the proportion of signs stands 80,17 , and 3 for inferior, superior, and neutral functioning, respectively. In no other period is there so large a percentage for inferior functioning. The average effect for each individual period, expressed in percentages and including all the 30 measurements, is: period 2, 11.7 per cent; period 3, 9.5 per cent; period 4, 4.8 per cent; period 5, 7.6 per cent; period 6 (s), 8.3 per cent. All are inferior except 8.3 per cent for period 6 , which is superior, as previously noted. The maximum average amount of change is at period 2, but period 3 is not far short. The two indications for maximum effect do not absolutely agree as to period, but in general it evidently occurs within 90 to 120 minutes after the dose. As the experimental periods in the repetition series were 50 to 60 minutes long and a larger variety of measurements (see p. 23) was given within the period, the data do not lend themselves readily to the problem of temporal incidence of effect.

There are 16 percentile differences from the first series of observations on Subject VI to compare with the results of the later experiments. Classified under the heads "inferior" and "superior," these stand exactly 50 to 50 . In 11 of the 16 cases the differences have signs which the repetition series of observations verify regarding the nature of the alcohol effect on this individual. For example, the superior progress in memorizing after alcohol is verified for this subject under the specified conditions employed. In the former series, however, he did better than here, and was, in fact, the best of the three subjects who showed superior performance. Shorter word-reaction time after alcohol is another of these agreements. This one may more properly be looked upon as an individual peculiarity, as it was found with only one other subject (IX). The other agreements call for no special comment.

There are 5 cases in which the comparable differences of the two series show conflicts as follows: patellar reflex A, 30-gram, lid reflex L and $L^{\prime}$, eye-reaction time, and pulse during muscle tension. The more or less detailed discussion of these conflicts given in connection with the presentation of data for the individual measurements may be summarized in part as follows:

(1) The different results for patellar reflex A, 30-gram, are likely referable to the condition that the former data were quite limited, as there was only one normal and one alcohol day (dose A). The former result of slightly lengthened latency with increased amplitude in the primary reflex is abnormal according to the present basis of judgment, but this subject is unique in demonstrating a relatively small and in certain respects peculiar alcohol effect with the reflexes. It is furthermore noteworthy that the reflexes alone show facilitation at the end of the day. 
(2) It was shown (p.54 ff.) that anticipatory voluntary lid movement. -another characteristic peculiar to Subject VI and one which was also very troublesome in the eye-movement measurements-changed the latency of the lid reflex, and that this factor happened to be so distributed as to markedly influence the earlier results and make this conflict probably accidental, although it must be noted that the average differences for inferiority in the second series are small, +5.4 and +2.7 per cent, and an occasional change of sign under such circumstances may be expected.

(3) This subject, like the majority of others in the normal group, showed a practice change in eye reactions. He had but one normal day, which was the first for this test. The alcohol effect was therefore hidden in the former reactions and quite overbalanced by the practice change.

(4) The differences opposite the heading "Pulse during muscular tension" are not strictly comparable, as is explained on page 92 . The conflict is, however, not to be ignored. It is important to observe that in the repetition experiments, in which the records were continuous through rest, tension, and post-relaxation, the alcohol effect is on the average very small during muscle tension, and, in fact, is +1.3 (a slower pulse rate, the same as reported by Dodge and Benedict) in period 2, where for most other measurements the maximum alcohol effect occurs. A shorter pulse cycle during rest and a longer pulse cycle (relative to preliminary periods or to normal days) during brief periods of muscle tension are two phases of the same condition, viz, a depressed vagus control of the heart. It is not possible at present to state the time relations or the conditions which govern the appearance and predominance of one or the other of these results.

The resulting data from the repetition experiments with Subject VI are the most complete thus far secured for any of the alcohol subjects used at the Nutrition Laboratory. These data show that concerning the nature of the alcohol effect this subject is not a physiological exception according to present normal standards, since in 27 out of 30 measurements inferior functioning of processes was discovered after the ingestion of doses containing 30 c.c. of absolute alcohol. He does show some individual peculiarities. Conspicuous among these is the relatively ${ }^{1}$ small effect on the reflexes. It is believed to have been primarily this, with the added conditions that insufficient data were obtained and that the differences from the reflexes made up a large proportion (6) of the experimental results, which raised the question about Subject VI in the minds of the former authors. ${ }^{2}$ The two series of observations on this subject are in agreement with 11 out of 16 measurements which the former series contained. Analysis has proved that

\footnotetext{
1 Relative to the normal group of subjects used by Dodge and Benedict.

2 It is in connection with the patellar-reflex data that they give their long footnote concerning VI (see Dodge and Benedict's report, p. 55).
} 
the disagreements are not without apparently reasonable explanations. It may naturally be expected that variation will exist in the amounts of the effects found in the two series. From the trend of the investigation it is clear that had the first series been as extensive as the later series, a greater degree of correlation would have been found.

A repetition series by an independent experimenter has proved, therefore, that this subject was affected by alcohol in substantially the same way as five or six other men previously studied. Furthermore, it has verified, in large part at least, the direction of the former results. These contributions are considered of far more significance than alcohol data equivalent in amount on some new and untried individual. The measurement of the alcohol effect from many standpoints on this one man is believed to have accomplished more in establishing results than would have been possible by following the characteristic statistical method and distributing the equivalent data in observations on a group of subjects.

\section{APPENDIX I.}

\section{DATA CONCERNING THE USE OF ALCOHOLIC BEVERAGES OUTSIDE OF THE PSYCHO- LOGICAL LABORATORY BY THE SUBJECTS OF DODGE AND BENEDICT.}

In the personal history ${ }^{1}$ of the Dodge and Benedict subjects, statements were made concerning the last use of alcohol. These statements refer only to the days immediately preceding the first experiment and not to the period of months during which the experiments were interspersed. They are therefore supplemented by excerpts from the original protocols. These data regarding the extra-laboratory use of alcoholic beverages are of significance in the interpretation of the alcohol results of the individual subjects.

Subject II.-October 8, 1913 (normal), no alcohol in preceding week. November 14, 1913 (normal), no alcohol during preceding week. November 20, 1913 (alcohol, dose A), no alcohol since the experiment on November 14 (a normal day). December 5, 1913 (normal), " 3 glasses of cider during previous week." December 19, 1913 (alcohol, dose A), no alcohol during the week and no coffee. January 6, 1914 (normal) and January 13, 1914 (alcohol, dose A), no data given. February 3, 1914 (alcohol, dose B), no alcohol during preceding week. February 17, 1914 (normal), no alcohol during preceding week. March 10, 1914 (alcohol, dose B), no alcohol during preceding week. March 17, 1914 (normal), no alcohol since March 10 (when a 45 c.c. dose was taken). These notes confirm the statement in the personal history that Subject II was a "very moderate user." They are of importance when it is remembered that of all the subjects compared for susceptibility to the influence of alcohol, ${ }^{2}$ Subject II shows the most marked effects of the alcohol, his average percentage being +5.1 .

Subject III.-October 1, 1913 (normal), no alcohol during previous week. January 5, 1914 (normal), seidel of beer and 2 highballs taken during previous week; "nothing yesterday." January 12, 1914 (alcohol, dose A), no data given. January 19, 1914, Monday (normal), " 3 or 4 bottles of beer taken in previous week; last Saturday night, also 1 bottle of Burgundy." January 26,

\footnotetext{
${ }^{1}$ Dodge and Benedict's report, Appendix II, p. 276.

${ }^{2}$ See Dodge and Benedict's report, p. 263, table 50, in which Subjects II, III, IV, VI, VII, IX, and $\mathrm{X}$ are discussed and compared.
} 
1914 (alcohol, dose A), no data given. February 2, 1914, Monday (alcohol, dose B), " 1 cocktail and 1 bottle of beer taken last Saturday night." February 9,1914 , Monday (alcohol, dose B), Wednesday, 1 cocktail, 1 pint sauterne; Monday, 1 glass beer." It is not clear which Monday is meant. February 16, 1914 (normal), no alcohol during preceding week. March 9, 1914, Monday (normal), " 1 bottle of beer Wednesday night." According to table 50, previously referred to, Subject III showed an alcohol effect less than the average; in fact he was below the average in 5 of 6 recorded measurements in that table.

Subject IV.-September 27, 1913 (alcohol, dose A), last alcohol taken on September 24, 1 liter of beer at dinner. October 2, 1913 (normal), no alcohol taken during succeeding week. January 8, 1914 (normal), no data given. January 15, 1914 (alcohol, dose A), no data given. January 30, 1914 (normal), "one-half pint whisky and 2 glasses of sherry taken for grippe on January 21-23." February 6, 1914, Friday (alcohol, dose B), "2 glasses of sherry; last evening 1 small glass of wine and 1 glass of beer." February 13, 1914, Friday (alcohol, dose B), "last Sunday night, 1 cocktail and beef cordial, 3 glasses of sherry; no alcohol yesterday." February 19, 1914 (normal), "2 glasses of sherry on the 17th, 1 glass yesterday." March 19, 1914 (normal), 1 glass of sherry and 2 cocktails taken during previous week; no statement made concerning their relation to experimental day. Subject IV ranked third in regard to the average effects of the alcohol.

Subject VI.-See statements made on page 18 of this monograph.

Subject VII.-October 6, 1913 (experimental data not published), 400 c.c. of beer on the afternoon of October 4. October 8, 1913 (normal), no data given. October 15, 1913 (alcohol, dose A), " 1 glass of ale last night; during the week had "ptomaine poisoning," and used 5 ounces of brandy, jamaica ginger, and 4 ounces of wine; 3 pints of beer also taken since last experiment." The subject said on this day that he had a cold in the head and felt "dopey." October 17, 1913 (alcohol, dose A), no alcohol since last experiment. October 21,1913 (normal), 60 ounces of beer during previous week; no statement of its relation to the experimental day. October 28, 1913 (alcohol, dose A), 60 ounces of beer during the week, 1 bottle taken preceding night. November 4, 1913 (normal), no statements recorded. November 11, 1913, Tuesday (alcohol, dose A), " 1 glass of ale and one-half bottle of wine taken last Saturday p. m." November 18, 1913 (normal), "during the week 3 glasses of beer, 3 glasses of port wine; "ptomaine poisoning" from steak Friday night, some cramps to-day." December 3, 1913, Wednesday (alcohol, dose A), "during the week 1 pint of claret, Saturday 24 ounces of beer, Monday 1 glass of ale, and Tuesday 2 glasses of ale." December 10, 1913 (normal), " 2 glasses of beer," but no statement as to date. December 17, 1913 (alcohol, dose A), "1 quart of light wine and 3 ounces of claret, the latter taken last night." February 27, 1914 (alcohol, dose B), 7 glasses of wine, one of them taken last night. March 6, 1914 (normal), 2 glasses of wine and 5 glasses of beer taken during the week; 1 glass of beer taken previous night. March 13, 1914 (alcohol, dose B), 7 glasses of beer during the week, one taken each night. March 20,1914, Friday (normal), "last Saturday, small bottle of wine; Monday, 1 glass of beer; Tuesday, 3 gin-rickeys." Subject VII ranked next to the last in regard to the average effect of alcohol.

Subject VIII.-(Total abstainer.) He served on only four days, October 9, 1913 (normal), October 16 (alcohol, dose A), October 23 (normal), and October 30 (alcohol, dose A). The series of experiments was thus incomplete and data were published for patellar reflex, faradic threshold, and finger movements only. No mention is made of him in Dodge and Benedict's summary chapter, and thus we have no detailed information as to the relative effect of alcohol 
upon him. Concerning the patellar-reflex data, the authors state (p. 54 of their report, table 3, note 4), "his results are in the same direction (lengthened latency and decreased amplitude of the reflex) as the average of the group, but greater in degree." The effect of alcohol on the faradic threshold was in the same direction and practically equal to the average for the group.

Subject IX.-October 11, 1913, the statement is made in the history by Dodge and Benedict as follows: Subject "drinks one-half to 1 bottle of wine or beer a day now, but previously 3 bottles a day, in the evening; no general effects. Largest amount taken, 4 bottles beer in the evening; did not feel intoxicated, but vomited. Last use, previous evening 1 bottle of beer; no effects. Never intoxicated. 2 or 3 liters of beer could be taken in the evening without noticeable effects. Sometimes produced vomiting next day. In excess of 2 or 3 liters it acted as a diuretic." October 20, 1913 (alcohol, dose A), no statements given. October 27, 1913 (normal), 3 bottles of beer 1 day before. November 3, 1913, Monday (alcohol, dose A), "during last week used 4 bottles of beer; Friday last, 3 bottles"; not discoverable whether the 3 was in addition to the 4, thus meaning a total of 7 . November 10, 1913, Monday (normal), 2 bottles of beer previous Friday. November 17, 1913, Monday (alcohol, dose A), 2 bottles of beer on the 15th, 1 bottle of beer on the 16th. November 24, 1913, Monday (normal), "4 bottles of beer last Saturday night." According to the personal history in Dodge and Benedict's report, this amount was as much as the largest amount ever taken previous to the beginning of the observation. December 1, 1913, Monday (alcohol, dose A), 2 bottles of beer on the preceding Friday, and 2 on the preceding Wednesday. December 15, 1913 (alcohol, dose A), 1 bottle of beer taken 3 days before. December 22, 1913, Monday (normal, 12-hour experiment), " 4 bottles of beer taken Saturday." December 23, 1913 (alcohol, dose C, 12-hour experiment), no statements made. January 21, 1914 (alcohol, dose B), 6 bottles of beer during the preceding week. January 29, 1914, Thursday (alcohol, dose B), 2 bottles of beer on Sunday and 1 on previous Friday. February 20, 1914 (alcohol, dose B), 1 glass of beer two days before. March 3, 1914, Tuesday (normal), 1 glass of beer preceding Saturday. Subject IX, according to Dodge and Benedict's table 50 (page 263 of their report) ranked second in prominent alcohol effect, i. e., +2.0 .

Subject $X$.-February 11, 1913, largest amount and last time taken was on December 15, 1912, 2 glasses of champagne at dinner. No statements are made concerning the use of alcohol in the succeeding experiments, except for that on March 11, 1913, at which time it was stated that no alcohol had been used preceding the experiment. It is assumed that the same condition existed for the other days. This subject was fourth in the order of alcohol effect. It should be stated in this connection that he alone, of all the subjects, ate a full meal at the laboratory immediately before the experiment (see Appendix II, p. 139) and that only dose A was used on the 3 alcohol days of the 6 days on which he served as subject.

In estimating the susceptibility of an individual to the effects of a dose of alcohol, account must be taken of the individual's habits. It is uncertain to what extent the regular use of alcohol develops a tolerance for it and so reduces the effects incident to the ingestion of a dose, or whether prolonged effects have such an influence on the normal or control experiments as to reduce the contrast between these and the alcohol experiments. The Dodge and Benedict series indicates that those subjects who are practically abstainers show more than an average alcohol effect. It may be said that in a short series of experiments this will be due to psychical factors. These experiments were, however, carefully designed to avoid this difficulty. Subject IV, and more 
particularly Subject IX, although regular users, were still affected more than the average, according to data in Dodge and Benedict's table 50. Judged in the light of their regular habits, these subjects are probably the most susceptible to the alcohol effect. Subject III is the least susceptible. He used less alcohol than Subjects VI, VII, or IX and yet shows the smallest alcohol effect.

APPENDIX II.

THE GENERAL EFFECTS OF ALCOHOL, DOSES A AND B, EXPERIENCED BY THE SUBJECTS OF DODGE AND BENEDICT'S EXPERIMENTS.

Dodge and Benedict made no attempt to collect complete introspective data from their subjects. Their measurements were planned to present objective results, free from the personal bias of either subject or experimenter. The protocols, however, contain the following notes, which are relevant to the important question of what amount of alcohol may be considered a moderate dose. The general effects are furthermore of significance as sidelights on the susceptibility of the individual to the influence of alcohol as shown by experimental methods.

Subject II.-September 23,1913 , dose A $8^{\mathrm{h}} 32^{\mathrm{m}}$ p. m. $8^{\mathrm{h}} 50^{\mathrm{m}}$ p. m. dizzy when he moves; $9^{\mathrm{h}} 10^{\mathrm{m}}$ p. m., still feels dizzy, warm feeling in the stomach since he took alcohol; $9^{\mathrm{h}} 30^{\mathrm{m}}$ p. m., not dizzy when he moves. November 20, 1913 , dose A, $5^{\mathrm{h}} 15^{\mathrm{m}}$ p. m. At $5^{\mathrm{h}} 55^{\mathrm{m}}$ p. m., dizzy when he moves; feels unnatural sleepiness. December 19,1913 , dose A about $5^{\mathrm{h}} 30^{\mathrm{m}}$ p. m. $6^{\mathrm{h}} 12^{\mathrm{m}}$ p. m., slightly dizzy, warmth in stomach. January 13,1914 , dose $A, 5^{\mathrm{h}} 30^{\mathrm{m}} \mathrm{p} . \mathrm{m}$. $5^{\mathrm{h}} 55^{\mathrm{m}} \mathrm{p}$. m., dizzy and sleepy; no doubt of alcohol effect; feels himself whirling around. February 3,1914 , dose $B, 5^{\mathrm{h}} 27^{\mathrm{m}}$ p. m. $5^{\mathrm{h}} 47^{\mathrm{m}}$ p. m., subject tingling and numb all over, "on edge of a jag"; later, feels dizzy and slightly nauseated. March 10,1914 , dose B, $5^{\mathrm{h}} 55^{\mathrm{m}}$ p. m. $\quad 6^{\mathrm{h}} 05^{\mathrm{m}}$ p. m., dizzy and numb, especially in arms and legs; 7 p. m., a slight nausea, sleepy, but "chipper" (cheerful); $7^{\mathrm{h}} 30^{\mathrm{m}}$ p. m., very sleepy and still somewhat nauseated.

Subject III.-September 24,1913 , dose A, $7^{\mathrm{h}} 50^{\mathrm{m}}$ p. m. $8^{\mathrm{h}} 02^{\mathrm{m}}$ p. m., head feels full, face is flushed, feeling of well-being intensified; $8^{\mathrm{h}} 17^{\mathrm{m}} \mathrm{p}$. m., face still flushed, slightly drowsy when relaxed, not so elated as earlier; $8^{\mathrm{h}} 35^{\mathrm{m}}$ p. m., flush gone. January 26,1914 , dose $\mathrm{A}, 4^{\mathrm{h}} 50^{\mathrm{m}} \mathrm{p} . \mathrm{m}$. To the experimenter the subject seemed mildly elated directly after the dose. $5^{\mathrm{h}} 45^{\mathrm{m}}$ p. m., sleepy. February 2, 1914, dose B, $4^{\mathrm{h}} 57^{\mathrm{m}}$ p. m. $5^{\mathrm{h}} 50^{\mathrm{m}}$ p. m., "feels like counting" to be sure of himself. February 9,1914 , dose B, about $4^{\text {h }} 30^{\mathrm{m}} \mathrm{p} . \mathrm{m}$. No marked dizziness experienced.

Subject IV.-September 27,1913 , dose A, $4^{\mathrm{h}} 04^{\mathrm{m}} \mathrm{p} . \mathrm{m}$. No comments made. February 6,1914 , dose B, about $4^{\mathrm{h}} 30^{\mathrm{m}}$ p. m. $4^{\mathrm{h}} 57^{\mathrm{m}}$ p. m., dizzy, head throbbing, vision hazy; 6 p. m., urination; $6^{\mathrm{h}} 18^{\mathrm{m}}$ p. m., head somewhat clearer; doubts if he could have walked before. February 13,1914 , dose $\mathrm{B}, 5^{\mathrm{h}} 05^{\mathrm{m}}$ p. m. $5^{\mathrm{h}} 25^{\mathrm{m}}$ p. m., complained of headache; somewhat relieved by removal of telephone pulse-recorder from the head; dizzy; no elation, but depression and dullness.

Subject VI.-See this monograph, page $20 \mathrm{ff}$.

Subject VII.-October 15,1913 , dose A, $5^{\mathrm{h}} 05^{\mathrm{m}}$ p. m. $5^{\mathrm{h}} 30^{\mathrm{m}}$ p. m., sleepy; $6^{\mathrm{h}} 20^{\mathrm{m}}$ p. m., not so sleepy. October 17,1913 , dose A, $3^{\mathrm{h}} 47^{\mathrm{m}}$ p. m. $4^{\mathrm{h}} 15^{\mathrm{m}}$ p. m., during faradic threshold falls asleep. More extensive introspective notes are said to have been recorded on cards, but these are not available. October 28,1913 , dose A, 5 p. m. No comments made November 11, 1913, dose A, 5 p. m. $5^{\mathrm{h}} 40^{\mathrm{m}}$ p. m., notices narcotic, irresponsible feeling; $6^{\mathrm{h}} 02^{\mathrm{m}} \mathrm{p} . \mathrm{m}^{\mathrm{m}}$, less of the narcotic feeling. December 3,1913 , dose A, $4^{\mathrm{h}} 40^{\mathrm{m}}$ p. m., relatively little effect; sleepy at first; slight fermentation; hot feeling; gas after one-half hour. 
$5^{\mathrm{h}} 37^{\mathrm{m}}$ p. m., still some gas in stomach. December 17,1913 , dose $A, 4^{\mathrm{h}} 45^{\mathrm{m}}$ p. m. No effect noted. February 27,1914 , dose B, $4^{\mathrm{h}} 48^{\mathrm{m}}$ p. m. $5^{\mathrm{h}} 30^{\mathrm{m}}$ p. m., feels hypnotic; 6 p. m., urinated March 6, 1914, normal experiment, began $4^{\mathrm{h}} 25^{\mathrm{m}}$ p. m. $6^{\mathrm{h}} 20^{\mathrm{m}}$ p. m., subject comments: "alcohol makes it easier to keep still." March 13,1914 , dose $\mathrm{B}, 5^{\mathrm{h}} 11^{\mathrm{m}}$ p. m. $5^{\mathrm{h}} 25^{\mathrm{m}}$ p. m., says dose was soothing; "I would know that I had taken alcohol."

Subject VIII.-October 16,1913 , dose A, $5^{\mathrm{h}} 20^{\mathrm{m}}$ p. m. $5^{\mathrm{h}} 50^{\mathrm{m}}$ p. m., "sleepy since I took the alcohol "; $6^{\text {h }} 15^{\mathrm{m}}$ p. m., not so sleepy. October 30,1913 , dose A, $5^{\mathrm{h}} 43^{\mathrm{m}}$ p. m. Said "the dose tasted frightful"; $6^{\mathrm{h}} 04^{\mathrm{m}}$ p. m., body numb, no control of feet, words just come out, touch blunted, stomach sensations hot or cold; $6^{\mathrm{h}} 20^{\mathrm{m}}$ p. m., marked incoordination, "extremities don't seem to belong to me"; $6^{\text {h }} 30^{\mathrm{m}}$ p. m., "numb all over"; doesn't care what he does. It may seem strange that the subject makes all of these comments on this day when he made such slight comment upon taking dose $\mathrm{A}$ the first time. In this connection it is noted that on October 30 , in preliminary statements, he said: "After taking the alcohol on October 16, I couldn't study." Subject VIII was not able to complete the experimental series. (See Dodge and Benedict's report, p. 25.)

Subject IX.-October 20,1913 , dose A, $5^{\mathrm{h}} 07^{\mathrm{m}}$ p. m. No comments made on alcohol effect. November 3,1913 , dose A, about $6 \mathrm{p}$. m. No comments. November 17, 1913, dose A, about $5^{\mathrm{h}} 30^{\mathrm{m}} \mathrm{p}$. m. No comments. December 1 , 1913, dose A, about 5 p. m. No comments on alcohol effect. December 15, 1913 , dose A, about $5^{\mathrm{h}} 50^{\mathrm{m}}$ p. m. No comments. December 23, 1913, dose C, as explained in note 2 , table 1 , page 13 , of this monograph. No mention of alcohol effect. January 21, 1914, dose $\mathrm{B}, 5^{\mathrm{h}} 05^{\mathrm{m}}$ p. m. Only comment, "subject slept after alcohol." January 29, 1914, dose B, 5 p. m. Began to perspire at $5^{\mathrm{h}} 05^{\mathrm{m}}$ p. m. ; later talkative, felt fine and not so tired; spoke previously of being tired because of examinations taken; $6^{\mathrm{h}} 05^{\mathrm{m}} \mathrm{p}$. m., urinated. February 20, 1914, dose B, 5 p. m. No mention of alcohol effect.

Subject X.-February 18, 1914, dose A, $2^{\mathrm{h}} 40^{\mathrm{m}} \mathrm{p} . \mathrm{m}$. Felt hot in stomach for first few minutes; unable to notice any particular change during the whole afternoon, except that in perhaps the very last period of word reactions attention apt to waver; knew he was to take alcohol on this day. At end of first period after taking alcohol, distinct discomfort and passed a large quantity of urine. At end of experiment, no particular desire to urinate. March 4, 1914, dose A, 2 p. m. $2^{\mathrm{h}} 30^{\mathrm{m}}$ p. m., some gas, but not so much as on previous days and not so uncomfortable; slight headache; wouldn't have noticed it at usual work; no desire to urinate until 4 p. m. March 18, 1914, dose A, 2 p. m; $2^{\mathrm{h}} 20^{\mathrm{m}}$ p. m., gas, feeling of warmth in the stomach; none at $2^{\mathrm{h}} 30^{\mathrm{m}}$ p. m.; $2^{\mathrm{h}} 45^{\mathrm{m}}$ p. m., eyes feel heavy; tendency not to look up; in the eye movements, feels that the eyes move down instead of straight across; $3^{\mathrm{h}} 10^{\mathrm{m}} \mathrm{p} . \mathrm{m}$., slightly sleepy; $3^{\mathrm{h}} 20^{\mathrm{m}} \mathrm{p}$. m., wink stimulus felt to be 50 per cent louder than on previous days; $3^{\mathrm{h}} 22^{\mathrm{m}}$ p. m., very sleepy during word reactions; feels that the pause between the reactions was quite long; $4^{\mathrm{h}} 21^{\mathrm{m}} \mathrm{p}$. m., notices how automatic the wordreaction device is; surprised he can wake up and say the word so quickly; more sleepy than in previous experiment; poor attention. On each of the 6 experimental days on which Subject X served, he ate dinner at the laboratory immediately before the experimental session, $1 \mathrm{p}$. m. to $1^{\mathrm{h}} 25^{\mathrm{m}} \mathrm{p} . \mathrm{m}$. The dinner was on all days as follows: cooked beefsteak, 170 grams; boiled potatoes, 224 grams; butter, 12 grams; bread, 37 grams; water, 300 c.c. The experiments began at $1^{\mathrm{h}} 30^{\mathrm{m}} \mathrm{p} . \mathrm{m}$. on each day and continued until $4^{\mathrm{h}} 30^{\mathrm{m}} \mathrm{p} . \mathrm{m}$. In the case of all the other subjects used by Dodge and Benedict the previous food was taken from $12^{\mathrm{h}} 30^{\mathrm{m}} \mathrm{p}$. m. to $1 \mathrm{p} . \mathrm{m}$., and the experiments usually began from 4 to $6 \mathrm{p}$. m. Only dose A was taken by Subject X. 


\section{APPENDIX III.}

\section{OBSERVATIONS ON THE AVERAGES OF DATA FOR NORMAL AND ALCOHOL DAYS PRESENTED BY DODGE AND BENEDICT.}

The following discussion has absolutely no bearing or modifying effects upon any of the comparisons which Dodge and Benedict have made by what they term "the method of differences." It applies only to their discussion of average values, which they have used as supplementary values in expressing the effect of alcohol on the various processes and occasionally have limited their comparisons to them. A common footnote which accompanied their tables states that "the values for the first period of the alcohol experiment were obtained before the alcohol was given, and are therefore not included in the averages." No specific statement is made as to whether the values for the first period on normal days were included or omitted in the averages for these days, which were to be compared with the average values for the alcohol days, but as their footnote implies and a recomputation of any of the data in their tables will show, the first-period values were included in the averages for the normal days. The alcohol and normal days would have been more directly comparable had the averages in both cases been computed without including the first period, which is termed "normal of the day," and is really preliminary. The point is a minor one, and produces no qualitative change in the conclusions offered by Dodge and Benedict, but as it is one the careful critic may notice, the following recomputations of the Dodge and Benedict data are presented:

The pulse data obtained during mental and physical activity are given in Dodge and Benedict's table 40, pages 212 to 222 of their report. The mean variations between the lengths of individual pulse cycles for the respective periods are regarded as significant measures and are further presented in their tables 44 and 45 . They form the basis of discussion of these data, with the conclusion that the pulse after alcohol shows a smaller mean variation and hence a decreased responsiveness of the cardio-inhibitory mechanism (see pages 238 and 239 of their report). A recalculation of the averages and the mean variations in their table 40 will show that the mean variation for the first period of an experimental day is usually smaller than the average mean variation for the other periods, $i . e$. , the heart rate was usually faster. If, therefore, we omit the first period in the averages for the normal day, as was done in the averages for the alcohol days, the final computed decrease of the mean variations, as shown in their table 45, will be 22 per cent in place of 19 per cent. The method of presentation has to an appreciable extent masked the effect of the alcohol in this instance.

The summary of the association pulse data in table 38, page 209 of their report, is an apparent exception to the usual method of computing the averages; although no statement is made in the text, the averages for both normal and alcohol days apparently include the first-period values. This is the only observed instance in Dodge and Benedict's computations where the average for the alcohol experiment has included the normal of the day. These averages, as presented in their table 38, are therefore directly comparable, but since the first period has been included, the alcohol section of the experiment is not so well isolated. If we accept the data in table 36, pages 202 to 205 , as correct, then it is a simple matter to reconstruct table 38 , as the preliminary data for it are given in the extreme right-hand column of table 36 . In part I of table 30, Dodge and Benedict's table 38 is reprinted as published. Unfortunately this contained several errors. One of these errors is large, $i$. e., the average for Subject VI, Normal I and II, should be 806 instead of 876 . In part II the errors have been corrected, the method of computation employed being that used in the original table. In part III of table 30 the averages do 
not include the values for the first period. It will be seen that in part III the values given in the column of normal averages are in every instance larger than their comparison values in part II of the table, which is another way of saying that the pulse was most rapid in the first period in normal days. The average values for dose $A$ and dose $B$, part III, are in the majority of instances larger than the comparable ones in part II, but in general the leaving off of the first period on alcohol days has not increased the final averages, 879 and 886, as much as it did for the average of the normal days. Hence as a measure of the effect of alcohol in terms of the average we have -53 and -28 as compared to the previous -46 and -18 .

With the memory data the result of considering the averages in the way suggested is opposed to that just described. As the series of words used in these experiments varied, it seemed to the authors that the method of averaging the differences would be misleading, and that if they were to use the data at all, recourse must be made to the averages for a comparison. Reference to their table 20, page 131, will show that the "saving" in the first period is frequently much larger than in any other period during the day. It is clear that if the average for the normal day includes the "saving" of the first period and that for the alcohol day omits it, the comparison will give the normal day a

TABLE 30.-Association pulse data of Dodge and Benedict as affected by changes in method of computation.

[Values given in thousandths of a second.]

\begin{tabular}{|c|c|c|c|c|c|c|c|c|c|c|}
\hline \multirow{3}{*}{ Subject. } & \multirow{2}{*}{\multicolumn{2}{|c|}{$\begin{array}{l}\text { Normal } \\
\text { I and II. }\end{array}$}} & \multicolumn{4}{|c|}{ Alcohol. } & \multicolumn{4}{|c|}{$\begin{array}{l}\text { Effect of alcohol } \\
\text { (alcohol-normal). }\end{array}$} \\
\hline & & & \multicolumn{2}{|c|}{ Dose A. } & \multicolumn{2}{|c|}{ Dose B. } & \multicolumn{2}{|c|}{ Dose A. } & \multicolumn{2}{|c|}{ Dose B. } \\
\hline & Av. & $\begin{array}{l}\text { Av. } \\
\text { diff. }\end{array}$ & Av. & $\begin{array}{l}\text { Av. } \\
\text { diff. }\end{array}$ & Av. & $\begin{array}{l}\text { Av. } \\
\text { diff. }\end{array}$ & Av. & $\begin{array}{l}\text { Av. } \\
\text { diff. }\end{array}$ & Av. & $\begin{array}{l}\text { Av. } \\
\text { diff. }\end{array}$ \\
\hline PART I. & & & & & & & & & & \\
\hline II......... & 1050 & -69 & 1018 & +8 & 1040 & +26 & -32 & +77 & -10 & +95 \\
\hline III. & 797 & -106 & 769 & -79 & 872 & -59 & -28 & +27 & +75 & +47 \\
\hline IV. & 931 & -168 & 890 & -152 & 927 & -114 & -41 & +16 & & +54 \\
\hline VI. & 876 & -172 & & & 849 & -173 & $\ldots$ & & -27 & \\
\hline VII. & 816 & -91 & 799 & -56 & 728 & +1.4 & -17 & +35 & -88 & +92 \\
\hline IX... & 968 & -102 & 862 & -44 & 850 & +19 & -106 & +58 & -118 & +121 \\
\hline $\mathrm{x} . \ldots$ & 913 & -161 & 862 & -88 & & & -51 & +73 & & \\
\hline Averag & 907 & -124 & 867 & -68 & 878 & -50 & -46 & +48 & -29 & +68 \\
\hline PART II. & & & & & & & & & & \\
\hline II....... & 1050 & -69 & 1018 & +8 & 1047 & +10 & -32 & +77 & & +79 \\
\hline III. & 797 & -106 & 769 & -79 & 872 & -59 & -28 & +27 & +75 & +47 \\
\hline IV. & 93 & -144 & 890 & -155 & 927 & -135 & -41 & -11 & & \\
\hline VI. & 806 & -167 & & & 848 & -176 & $\ldots$ & $\ldots$ & +42 & - \\
\hline VII. & 87 & 91 & 799 & -52 & 718 & +13 & -17 & + & & +105 \\
\hline IX. & 968 & -102 & 862 & -46 & 850 & +19 & -106 & +56 & -118 & +121 \\
\hline & 913 & -161 & 862 & -88 & & & -51 & +73 & & \\
\hline Averag & 897 & -120 & 867 & -69 & 877 & -55 & -46 & +43 & -18 & +59 \\
\hline Part II & & & & & & & & & & \\
\hline II.... & 1062 & & 1017 & & 1045 & & -45 & $\ldots$ & -17 & $\ldots$ \\
\hline III. . & 81 & & 782 & & 882 & & -31 & & +69 & $\ldots$ \\
\hline IV. & 95 & . & 921 & & 950 & $\ldots$ & -37 & .. & & $\ldots$ \\
\hline & & & & & 87 & & & & +44 & $\ldots$ \\
\hline VII. & 832 & & 808 & & 71 & & -24 & & -116 & $\ldots$ \\
\hline IX. & 986 & $\ldots$ & 869 & $\ldots$ & 847 & $\ldots$ & -117 & .... & -139 & $\ldots$ \\
\hline $\mathrm{x}$. & 940 & & & & & & -64 & $\ldots$ & & $\ldots$ \\
\hline & 918 & $\ldots$ & 879 & & 886 & $\ldots$ & -53 & .... & -28 & $\cdots$ \\
\hline
\end{tabular}

${ }^{1}$ Part $\mathrm{I}$ is a reprint of the data published in table 38, page 209, of Dodge and Benedict's report, with signs as used by them. 
decided advantage. In the accompanying table, No. 31 , in which the averages computed by Dodge and Benedict are given in part I, it will be observed that the computation of the averages for the normal days without including the first-period values (see part II) has decreased the average saving for the effect of alcohol with all of the subjects except Subject VIII, who shows a saving of 1,027 as compared with 1,005. The only case in which the signs for the percentile effects have been changed from minus to plus is in the values for Subject IX, but all of the plus values have been increased in size and, except with Subject VIII, the minus values diminished. For purposes of comparison, average savings have been computed for the alcohol days, by including the firstperiod values for the respective sessions, the results being given in part III. The values in the normal column of part III correspond exactly to those in the normal column of part $\mathrm{x}$. With this method of computation, the alcohol values for memory are larger in every instance but one than those shown in the comparison column of part II. The final effect of alcohol, when thus more nearly isolated and given in per cent, is +1.4 as compared to +2.5 previously reported.

Computing the average normal in the way suggested has sometimes produced only minor changes, as in the case of eye reactions and finger movements, showing the effect of alcohol as a little larger than stated; at other times, as in the case of word reactions and eye movements, the effect of such recomputations has been to show a smaller effect for the alcohol. With the association experiments there is no apparent difference; the averages are not discussed for the faradic threshold. These points have been raised solely with a view to justifying the method of elaboration used in the second series of experiments and of emphasizing that when differences are available they should be given chief consideration. It must again be urged that changes in the averages of the normal days change in no way the comparisons which are based on average differences between the normal of the day and succeeding periods.

TABLE 31.-Memory data of Dodge and Benedict as affected by changes in method of computation.

\begin{tabular}{|c|c|c|c|c|c|c|c|}
\hline & $\begin{array}{l}\text { Subject } \\
\text { II. }\end{array}$ & $\begin{array}{l}\text { Subject } \\
\text { VI. }\end{array}$ & $\begin{array}{l}\text { Subject } \\
\text { VII. }\end{array}$ & $\begin{array}{l}\text { Subject } \\
\text { VIII. }\end{array}$ & $\begin{array}{l}\text { Subject } \\
\text { IX. }\end{array}$ & $\begin{array}{c}\text { Subject } \\
\mathrm{X} .\end{array}$ & Average \\
\hline \multicolumn{8}{|l|}{$\begin{array}{l}\text { PART I. } \\
\text { Average saving: }\end{array}$} \\
\hline Normal....... & 932 & 761 & 1,382 & 1,005 & 921 & 980 & \\
\hline Alcohol.......... & 939 & 856 & 1,189 & 974 & 881 & 1,071 & \\
\hline $\begin{array}{l}\text { Effect of alcohol (alcohol- } \\
\text { normal).................. }\end{array}$ & +7 & +95 & -193 & -31 & -40 & +91 & -12 \\
\hline Percentile effect........... & +0.6 & $\begin{array}{r}8.7 \\
+8.7\end{array}$ & -13.1 & -4.1 & -3.9 & +7.0 & -0.8 \\
\hline $\begin{array}{l}\text { PART II. } \\
\text { Average saving: }\end{array}$ & & & & & & & \\
\hline Normal...... & 858 & 711 & 1,298 & 1,027 & 862 & 978 & \\
\hline Alcohol....................... & 939 & 856 & 1,189 & 974 & 881 & 1,071 & $\cdots$ \\
\hline $\begin{array}{l}\text { Effect of alcohol (alcohol- } \\
\text { normal) ................. }\end{array}$ & +81 & +145 & -109 & -53 & $\begin{array}{l}+19 \\
+18\end{array}$ & +93 & +29 \\
\hline Percentile effect......... & +6.9 & +13.3 & -7.4 & -6.9 & +1.8 & +7.2 & +2.5 \\
\hline $\begin{array}{l}\text { PART III. } \\
\text { Average saving: }\end{array}$ & & & & & & & \\
\hline Normal....... & 932 & $\begin{array}{l}761 \\
914\end{array}$ & 1,382 & $\begin{array}{r}1,005 \\
009\end{array}$ & 921 & 980 & $\cdots \cdots$ \\
\hline Effect of alcohol (alcohol- & & 814 & 1,248 & 909 & 903 & 1,170 & \\
\hline normal) $\ldots \ldots \ldots \ldots \ldots$ & +31 & +153 & -135 & -96 & -18 & +196 & +22 \\
\hline & & & & & & & \\
\hline
\end{tabular}




\section{APPENDIX IV.}

\section{OBSERVATIONS ON THE ASSOCIATION PULSE DATA OF DODGE AND BENEDICT.}

The measurements of the association pulse by Dodge and Benedict were divided into three divisions-pre-stimulus, stimulus to reaction, and postreaction. The latter is sometimes mentioned as post-stimulation. (See their page 198.) In their figure 31 they have embodied diagrammatically the records of Subject VII. In these curves it may be clearly seen that an increase in pulse rate follows the stimulation of the association words. One point, however, deserved consideration in reference to these curves. It appears that the right end of the curve almost invariably fails to reach the level of the left end. The large fall which frequently occurred between the pre-stimulus and post-reaction ends of the curves in figure 31, taken in connection with the statement on page 198 of Dodge and Benedict's report that all the pulse waves were read and the data are capable of any other arrangement that statistical interest might demand, led us to reread the record which forms the basis for Dodge and Benedict's table 34, page 197.

It will be observed from their figure 30 , page 195, that there are unbroken horizontal lines which separate the reactions into groups of five. This was produced by breaking the circuit of the pulse-recorder so that the marker point gave a straight line. Sometimes this break in the circuit came quite soon after the fifth reaction, hence there are fewer post-stimulus cycles after the fifth reaction, and furthermore, the last figure in a fifth reaction was not joined directly to the first measured value of the next reaction. In Dodge and Benedict's table 34, page 197, it will be seen that the fifth reaction rarely has more than four pulse cycles in the post-reaction phase. In three cases, the fifth or last reaction in a set contained only three pulse cycles in its postreaction phase. The two readings of the record checked remarkably well. In the final tables 35 and 36 , from which figure 31 was drawn, many measurements are dropped out by limiting the number of columns. For example, the number of columns from stimulus to reaction is given in the average tables as 2 , while in table 34 there were many times when three or more pulse cycles came within that period. The same may be said for the pre-stimulation and the post-reaction divisions of the tables. The averages at the foot of table 34 show that in 26 cases pulse cycles were omitted from the final averages, and that in 21 cases pulse cycles were omitted from the pre-stimulus section. Four of these cycles were of longer duration than the last which was included in their table; 12 were shorter and 5 of the same length. It is therefore certain that if we plotted table 34 with the additional data, curve 2 for the first day in figure 31 (page 201) would connect at its ends on the same level. The discrepancies between the level of the ends of these curves and also in the data in table 36 are largely to be explained in this way.

One point in the technique of Dodge and Benedict intensified this tendency to drop out data at the extreme ends of the table. This was the fact that there was no experimental break between the post-reaction and the pre-stimulation pulse cycles, since the records were taken on a kymograph, although an apparent break was produced when the record was cut to be removed from the drum. Since this apparent break was not always the same in its time relation to the three phases of the record, the post-reaction phase was occasionally shortened and, in consequence, the pre-stimulation phase was lengthened, and vice versa. When the final tables were made up these extra long ends were not included in the averages, thus omitting the essential transitions between the two ends of the curves under discussion. 
In connection with the post-stimulation pulse acceleration reported by Dodge and Benedict in their association experiments, some account should be taken of the respiration phase. As stated by them (page 196 of their report) respiration records were incorporated with the association pulse curves. These are indicated in their illustrative figure 30 (page 195) by the long broken lines in the record. These must not be confused with the very regular short dotted lines which are the control time. In the discussion of the association pulse no account seems to be taken of the respiration records. Sample association pulse records were selected for each of the normal subjects, and these were prepared by scratching with a stylus a dot at the beginning of each inspiration. (The pointer of the respiration recorder was in contact with the drum during inspiration.). These dots were clearly marked and could easily be counted. The records, 8 in number, were then placed one above the other, so that their stimulus columns formed practically a straight line. A cord was stretched along the line so as to represent as nearly as possible the stimulus point of all the records. This cord was marked $S$. Other cords were placed parallel to $S$ on both sides at distances of 5 centimeters, which represents the duration of 1 second. The dots representing the beginnings of inspiration were then counted and recorded. The results are given in table 32.

TABLE 32.-Relation of respiration phase to association pulse.

\begin{tabular}{|c|c|c|c|c|c|c|c|c|c|c|c|}
\hline & \multicolumn{4}{|c|}{ Before stimulus. } & \multicolumn{7}{|c|}{ After stimulus. } \\
\hline & $\begin{array}{l}\text { 4th } \\
\text { sec- } \\
\text { ond. }\end{array}$ & $\begin{array}{l}3 d \\
\text { sec- } \\
\text { ond. }\end{array}$ & $\begin{array}{l}2 d \\
\text { sec- } \\
\text { ond. }\end{array}$ & $\begin{array}{l}1 \text { st } \\
\text { sec- } \\
\text { ond. }\end{array}$ & : & $\begin{array}{l}1 \text { st } \\
\text { sec- } \\
\text { ond. }\end{array}$ & $\begin{array}{l}2 \mathrm{~d} \\
\text { sec- } \\
\text { ond. }\end{array}$ & $\begin{array}{l}3 \mathrm{~d} \\
\text { sec- } \\
\text { ond. }\end{array}$ & $\begin{array}{l}4 \text { th } \\
\text { sec- } \\
\text { ond. }\end{array}$ & $\begin{array}{l}5 \text { th } \\
\text { sec- } \\
\text { ond. }\end{array}$ & $\begin{array}{l}6 \text { th } \\
\text { sec- } \\
\text { ond. }\end{array}$ \\
\hline $\begin{array}{l}\text { No. of inspirations begin- } \\
\text { ning in } 1^{\prime \prime} \text { intervals }{ }^{1} . \ldots \\
\text { Per cent per interval...... }\end{array}$ & $\begin{array}{c}62 \\
5.6\end{array}$ & $\begin{array}{l}139 \\
12.5\end{array}$ & $\begin{array}{c}108 \\
9.8\end{array}$ & $\begin{array}{c}81 \\
7.3\end{array}$ & & $\begin{array}{c}140 \\
12.6\end{array}$ & $\begin{array}{l}207 \\
18.6\end{array}$ & $\begin{array}{c}56 \\
5.0\end{array}$ & \begin{tabular}{|c|}
95 \\
8.6
\end{tabular} & $\begin{array}{l}155 \\
14.0\end{array}$ & $\begin{array}{c}68 \\
6.1\end{array}$ \\
\hline
\end{tabular}

1 Total number of inspirations counted 1,111. It required 10 seconds for the kymograph drum to complete one revolution.

According to the statement of Dodge and Benedict in table 13 (p. 114) the average reaction time in these experiments was 2.16 seconds. There was therefore a marked tendency for inspiration to occur or at least to begin after the stimulus word and previous to the reaction, since the percentages 12.6 and 18.6 are largest at this section of the table. The smallest percentage of inspiration occurs during the 1-second interval following the reaction. This same relationship of respiration to the association experiment is logical. Preparatory to reacting by vocalization the subject will naturally inspire and will tend to hold the breath until he reacts. The vocalization constitutes the first phase of the expiration. If the subject in this experiment tended to have in any degree sinus arrhythmia, there would be a more or less rapid pulse from this cause alone during and just after the reaction which would tend to be counted as pulse acceleration and due to the stimulation word of the association experiments. It therefore seems probable that the post-stimulation acceleration is due in part to the stimulation of the vagus by inspiration as well as the word stimulation of the experiment; this respiratory influence applies also to the post-tetanus phase of the tetanus pulse records of Subject VI. 


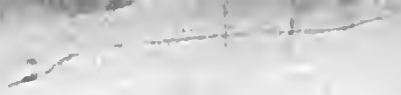




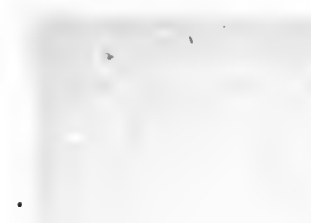

5
5
3
3

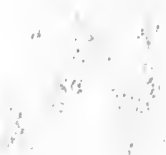




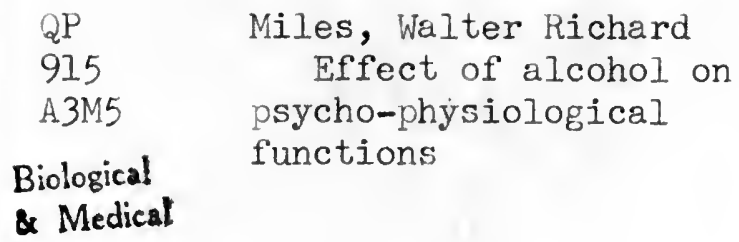

\& Medical

\author{
PLEASE DO NOT REMOVE \\ CARDS OR SLIPS FROM THIS POCKET
}

UNIVERSITY OF TORONTO LIBRARY 


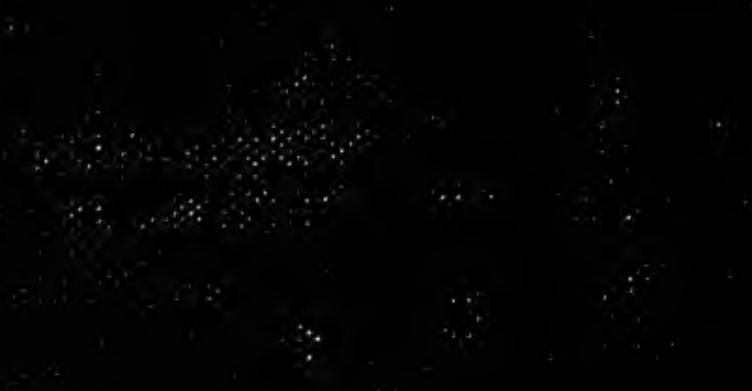

